\title{
Asimilación de mediciones GNSS y de altimetría satelital en el Modelo Ionosférico La Plata
}

Tesista: Isabel Bibbó

Director: Claudio Brunini

Facultad de Ciencias Astronómicas y Geofísicas

Universidad Nacional de La Plata 


\section{Prefacio}

Este trabajo fue realizado como parte de los requerimientos para acceder al título de Doctor en Astronomía en la Facultad de Ciencias Astronómicas y Geofísicas de la Universidad Nacional de La Plata.

La investigación fue solventada por la Facultad de Ciencias Astronómicas y Geofísicas y realizada en el Laboratorio de Geodesia Espacial y Aeronomía (GESA) perteneciente a la misma. 


\section{Resumen}

Desde su descubrimiento, hace algo más de un siglo, la ionosfera terrestre ha sido estudiada utilizando técnicas de observación que hoy son consideradas convencionales. En particular, a lo largo de los últimos años, las observaciones GNSS realizadas desde la superficie de la Tierra se han convertido en una herramienta de uso habitual en la investigación ionosférica. A escala global, las mediciones GNSS tienen una buena resolución espacial y temporal pero se hallan concentradas en la parte continental de planeta; además no brindan información directa del contenido electrónico total ionosférico, sino que deben ser reducidas mediante una función de mapeo y las mediciones se hallan sesgadas por biases instrumentales. Otras observaciones geodésicas, como las que proporcionan las misiones de altimetría satelital oceánica TOPEX/Poseidón y Jason (NASA / CNES) son menos utilizadas, si bien brindan determinaciones directas de contenido electrónico vertical a las que se les ha asignado gran precisión.

En este trabajo se presenta un modelo ionosférico global de asimilación de observaciones GNSS y altimétricas. El modelo tiene en cuenta los principales biases que afectan ambas determinaciones y permite complementar las ventajas de cada una: el sistema GNSS provee la información necesaria para alcanzar una resolución temporal de pocas horas en la descripción de la variabilidad del TEC, mientras que la altimetría satelital aporta datos confiables sobre la región oceánica de la Tierra. Se parte del Modelo Ionosférico La Plata y se ensayan dos estrategias diferentes de asimilación; la primera asimila bloques de información correspondientes a 24 horas mientras que la segunda es capaz de procesar grandes bloques de datos necesarios para sacar el mayor provecho posible a las observaciones altimétricas. Como resultado de la combinación se obtienen mapas ionosféricos globales basados en mediciones GNSS+altimétricas con una resolución de 2 horas y un conjunto de estaciones calibradas y, como subproducto, se generan mapas del contenido electrónico plasmasférico global con la misma resolución temporal y una estimación del bias que afecta las mediciones altimétricas. 


\section{Tabla de contenidos}

Prefacio 22

Resumen 3

Tabla de contenidos $\quad 4$

$\begin{array}{ll}\text { Introducción } & 7\end{array}$

Capítulo 1: La Tierra en el espacio. Origen y variabilidad de la lonosfera 12

$\begin{array}{ll}\text { 1.1. El Sol } & 13\end{array}$

1.2. El medio interplanetario 16

1.2.2. El campo magnético interplanetario 18

1.2.3. Partículas energéticas 20

1.3. La Tierra $\quad 21$

1.3.1. El campo magnético terrestre 21

1.3.2. La atmósfera 26

1.4. La ionosfera 28

1.4.1. Interacción de la radiación solar con atmósfera superior de la Tierra 29

1.4.2. Estratificación de la ionosfera 36

1.4.3. Interacción de partículas cargadas y campo magnético terrestre 39

1.4.4. Variabilidad espacial y temporal de la ionosfera 41

1.4.5. Modelos ionosféricos 43

Capítulo 2: GPS y altimetría satelital para estudios ionosféricos 45

2.1. Propagación de ondas electromagnéticas en la atmósferera 46

2.1.1. Índice de refracción 46

2.1.2. Camino óptico 49

2.1.3. Contenido electrónico total 50

2.2. Sistema de Posicionamiento Global 51

2.2.1. Arquitectura del sistema GPS 51

2.2.2. Las señales GPS

2.2.3. Observables GPS 54 
2.2.4. Fortalezas y limitaciones de los datos GPS 58

2.3. Altimetría satelital 59

2.3.1. Satélites TOPEX/Poseidón y Jason 60

2.3.2. Configuración orbital 61

2.3.3. Las señales altimétricas 63

2.3.4. Observable altimétrico 64

2.3.5. Fortalezas y limitaciones de los datos altimétricos 67

Capítulo 3: Asimilación de datos en LPIM 69

3.1. El Modelo Ionosférico de La Plata 70

3.1.1. La capa delgada 70

3.1.3. La función de mapeo 71

3.1.4. Sistema de coordenadas 72

3.1.5. Parametrización de VTEC 74

3.1.6. Ecuación de observación y restricciones 75

3.2. Asimilación de datos altimétricos 78

3.2.1. Ecuación de observación TOPEX/Poseidón 78

3.2.2. Estrategia de asimilación $\quad 79$

3.2.3. Datos observacionales 80

3.3. Resultados 83

3.3.1. Contenido electrónico total vertical 84

3.3.2. Retardos instrumentales 92

3.3.3. Bias de TOPEX/Poseidón 102

3.4. Conclusiones del capítulo 104

Capítulo 4: Nueva técnica de asimilación de datos en LPIM 107

4.1. Distribución espacial y temporal de los datos 108

4.2. Acumulando los sistemas normales diarios $\quad 110$

4.2.1. Validación de la técnica: DCBs de satélites y receptores GPS con datos GPS únicamente $\quad 113$

4.3. Resultados 114

4.3.1. Calibración de satélites y receptores con datos GPS + TOPEX/Poseidón 114

4.3.2. Mapas ionosféricos globales 
4.4. Validación de los resultados

4.4.1. Modelo NeQuick

4.4.2. Datos artificiales

4.4.3. La técnica de acumulación con datos sintéticos

4.5. Conclusiones del capítulo

Capítulo 5: Modelo ionosférico y plasmasférico

5.1. La plasmasfera

5.2. Modelo de Gallagher

5.3. Modelo ionsoférico y plasmasférico de La Plata LPIPM

5.4. Resultados

5.4.1. DCBs de satélites y receptores GPS

5.4.2. Bias TOPEX/Poseidón

5.4.3. Mapas ionosféricos globales

5.4.4. Mapas plasmasféricos globales

5.4.5. Contribución relativa al TEC

5.4.6. Contenido electrónico plasmasférico en el tiempo

5.4.7. Estructuras a gran escala en la plasmasfera

5.5. Conclusiones del capítulo

Capítulo 6: Conclusiones y próximos trabajos

6.1. Conclusiones

6.2. Próximos trabajos

Referencias

Anexo 1. Estaciones GNSS de monitorio utilizadas

Anexo 2. DCBs de los satélites GNSS

Anexo 3. DCBs de receptores GNSS utilizados en el Capítulo 3

Anexo 4. DCBs de receptores y VTEC medio medido en la estación.

Anexo 5. DCBs de receptores y satélites GPS calculados con datos GPS y altimétricos supuestos constantes en 100 días.

Anexo 6. DCBs de receptores y satélites GPS con datos artificiales 


\section{Introducción}

La ionosfera es un gas parcialmente ionizado, confinado dentro del campo magnético de la Tierra entre las alturas de aproximadamente 50 y $1000 \mathrm{~km}$. Por encima de los $1000 \mathrm{~km}$ se extiende una región denominada plasmasfera, donde el gas se halla completamente ionizado. Tales regiones constituyen un laboratorio natural para la experimentación científica relacionada con las interacciones entre el plasma, la radiación y el viento solar, el campo magnético de la Tierra y el interplanetario, la gravedad y otras fuerzas debidas a los vientos termosféricos, etc. (Schunk \& Nagy, 2000). Para los tecnólogos resulta cada vez más importante predecir el comportamiento del plasma ionizado por la influencia que ejerce sobre los sistemas de comunicaciones terrestres, con aeronaves y vía satélite (Davies, 1990), los sistemas satelitales de observación de la Tierra (Chapin et al., 2006), los radares de control del espacio aéreo (Bothmer, 2006) y los sistemas de radionavegación global apoyada en satélites artificiales (ICAO, 2006).

Las observaciones convencionales, principalmente los sondeos efectuados con instrumentos localizados sobre la superficie de la tierra y a bordo de globos, cohetes y satélites artificiales, han permitido estructurar modelos ionosféricos climatológicos con los cuales es posible predecir, con bastante exactitud, las condiciones medias de la densidad electrónica y sus variaciones casi periódicas (Hargreaves, 1995). Sin embargo, las variaciones de la actividad solar y de la emisión de plasma desde la corona solar provocan cambios dramáticos en el ambiente espacial que circunda la tierra difíciles de predecir. El estudio de estos cambios forma parte de una rama del conocimiento llamada meteorología del espacio (Sahai et al., 2008).

El Sistema Global de Navegación Satelital GNSS (Global Navigation Satellite System) es un servicio que agrupa diferentes sistemas dedicadas a la generación de datos precisos para distintos usos. En particular, el Sistema de Posicionamiento Global (NAVigation Satellite Timing and Ranging Global Positioning System, NAVSTAR GPS o simplemente GPS), formado por una constelación de 31 satélites que orbitan la Tierra a una altitud aproximada de $20200 \mathrm{~km}$ transmitiendo señales de forma continua, es intensamente utilizado para estudiar la climatología y la meteorología ionosférica (Davies \& Hartmann, 1997). La ionosfera es un medio dispersivo que afecta las señales provenientes de los satélites; la diferencia entre mediciones realizadas en dos frecuencias diferentes permite separar el contenido electrónico total de la ionosfera (TEC, Total Electron Content) de toda otra información independiente de la frecuencia. 
El modelo ionosférico La Plata LPIM (La Plata lonospheric Model, Brunini, 1998) es un modelo para estimar la distribución global del contenido electrónico total de la ionosfera basado hasta ahora en mediciones GPS. El modelo se fundamenta en una aproximación simple, que consiste en representar a la ionosfera a través de una capa de espesor despreciable, ubicada entre 350 y $450 \mathrm{~km}$ de altura, aproximadamente donde la concentración de electrones alcanza su valor máximo. Para representar la distribución espacial del TEC sobre la capa delgada se utiliza una combinación lineal de funciones bidimensionales dependientes de la latitud y la longitud (desarrollo en armónicos esféricos). La variabilidad temporal del TEC queda representada por los coeficientes de la combinación lineal, que son funciones dependientes del tiempo. En síntesis, el TEC queda expresado a través de una función dependiente de la latitud, la longitud y el tiempo, en la que aparece un gran número de coeficientes constantes, cuyos valores son ajustados con las observaciones GPS mediante el método de mínimos cuadrados. Utilizando observaciones de alrededor de 300 estaciones terrestres es posible calcular mapas diarios que describen la distribución global del TEC con una resolución espacial de unos quince grados y una resolución temporal de aproximadamente dos horas. Los biases instrumentales que se producen en el hardware de los satélites y de los receptores, denominados diferential code biases (DCB), son tratados como incógnitas adicionales y estimados, junto con los coeficientes del modelo inosférico, utilizando los mismos datos GPS.

Por otra parte, las determinaciones del contenido electrónico realizadas por las misiones altimétricas representan una medida directa del TEC vertical sobre la superficie de los océanos. La misión TOPEX/Poseidón y sus sucesoras Jason I y II (NASA / CNES) operan desde 1992 con el objetivo central de estudiar la topografía de la superficie del mar (Fu \& Cazenave, 2001; Menard \& Haines, 2001). Consiste básicamente en un altímetro montado sobre un satélite que órbita a aproximadamente $1300 \mathrm{~km}$ de altura, con una inclinacion de $66^{\circ}$ con respecto al ecuador. El altímetro emite verticalmente hacia abajo un pulso de radiofrecuencia que se refleja verticalmente hacia arriba desde la superficie del mar. Para corregir el retardo ionosférico, el altímetro emite sus señales en dos frecuencias distintas, gracias a lo cual es posible utilizar las observaciones TOPEX/P para obtener una estimación prácticamente directa del TEC vertical, hasta la altura del satélite, sobre las superficies oceánicas entre $\pm 66^{\circ}$ de latitud. Puesto que en este caso no se utiliza ningún modelo ionosférico a priori la estimación del TEC está, en principio, menos afectada por errores sistemáticos que la obtenida a partir de las observaciones GPS. La principal limitación de las mediciones altimétricas, desde el punto de vista de la investigación ionosférica, es su baja resolución temporal, ya que para cubrir todo el planeta el satélite necesita 10 días, y para muestrear dos veces un punto a la misma hora local requiere 
aproximadamente 96 días. Además, trabajos comparativos entre el TEC derivado de GPS y de TOPEX/P han puesto de manifiesto la existencia de sistematismos zonales y estacionales y de un bias positivo de entre 2 y $410^{16}$ electrones $/ \mathrm{m}^{2}$ entre ambas determinaciones (Ho et al., 1997, Brunini et al., 2005; Azpilicueta \& Brunini, 2008).

El objetivo de esta tesis es asimilar en un modelo consistente las estimaciones de contenido electrónico total vertical producidas por GPS y por las misiones de altimetría satelital oceánica TOPEX/Poseidón y sus sucesoras Jason. Desde el punto de vista de la distribución geográfica de los datos, la principal limitación del sistema GPS radica en que la distribución global de las estaciones de monitoreo no es uniforme, sino principalmente concentrada en el hemisferio norte sobre la parte continental del planeta. La asimilación del contenido electrónico medido por los satélites altimétricos sobre la superficie oceánica es complementaria y viene a subsanar esta carencia.

En la primera parte del trabajo se investiga el comportamiento de los biases instrumentales más importantes: DCB de los satélites GPS; DCB de los receptores GPS y bias electromagnético de TOPEX/Poseidón. Se parte de las siguientes hipótesis: los DCB de los satélites varían muy suavemente a lo largo del tiempo, los DCB de los receptores exhiben una variación más irregular y de mayor amplitud (Coco et al., 1991; Sardon \& Zarraoa, 1997; Ciraolo et al., 2007; Brunini \& Azpilicueta, 2009 y 2010) y los retardos instrumentales de los radares altimétricos se mantienen constantes tanto en el espacio como en el tiempo (Azpilicueta \& Brunini, 2008 y 2009). Se proponen los modelos correspondientes y se estiman sus parámetros por mínimos cuadrados utilizando observaciones GPS y TOPEX/Poseidón. Sobre la base de los resultados que se obtienen, se ensaya una nueva estrategia de asimilación que permite procesar grandes bloques de datos. Esta consiste en acumular las ecuaciones normales diarias para asimilar de forma simultánea observaciones GNSS y altimétricas de varios días; específicamente se procesan bloques de 100 días, sabiendo que es aproximadamente el tiempo que los satélites altimétricos necesitan para cubrir el planeta observando en diferentes momentos del día.

Finalmente, el método de acumulación de sistemas normales es utilizado para separar la contribución del gas completamente ionizado que compone la plasmasfera, suponiendo que esta contribución está dominada por variaciones latitudinal y diurna simples (Gallagher et al., 1988; Carrano et al., 2009; Mazzella, 2009). 
La validación de los resultados se realiza mediante simulaciones numéricas empleando datos sintéticos generados con el modelo NeQuick (Nava et al., 2008).

El contenido del trabajo ha sido estructurado en 6 capítulos.

Capítulo 1: La Tierra en el espacio. Origen y variabilidad de la lonosfera.

Este capítulo presenta las características generales de la ionosfera. Comienza haciendo una caracterización de los elementos que componen el medio en el cual la Tierra se halla inmersa y continúa con una descripción de los procesos de producción, pérdida y transporte de electrones en la atmósfera. Estos elementos combinados permiten una discusión sobre la variablilidad espacial y temporal del contenido electrónico observado en la ionosfera de la Tierra.

Capítulo 2: GPS y altimetría satelital para estudios ionosféricos .

El capítulo comienza con una descripción de la forma en que las ondas electromagnéticas interactúan con la ionosfera. Contiene una presentación general de la arquitectura del sistema GPS y de las misiones de altimetría satelital TOPEX/Poseidón y Jason. El capítulo se centra en el estudio de los procedimientos para obtener información sobre el contenido electrónico en la ionosfera a partir de las señales que transmiten los satélites. Se discuten las ventajas y debilidades de cada misión como fuente de información ionosférica.

Capítulo 3: Asimilación de datos en LPIM

El capítulo presenta una descripción del modelo ionosférico de La Plata y de los procesos para generar mapas globales de distribución del contenido electrónico a partir de mediciones GPS y altimétricas. Se desarrolla una primera estrategia de asimilación y se muestran los resultados que se obtienen a partir de ella. Se comparan los mapas ionosféricos globales generados a partir de la incorporación de datos altimétricos con los mapas basados en determinaciones GPS y se discute la calibración de los biases instrumentales, especialmente de los receptores GPS y del satélite TOPEX/Poseidón. 
Capítulo 4: Nueva estrategia de asimilación de datos en LPIM

Sobre la base de los resultados obtenidos en el capítulo 3, en este se presenta un nuevo método para la asimilación de los datos altimétricos. Se discute una estrategia de acumulación de sistemas normales diarios para procesar de forma simultánea bloques de datos correspondientes a varios días de observación. Se muestran los resultados que se obtienen luego de la implementación del nuevo código y su validación.

Capítulo 5: Modelo ionsoférico y plasmasférico de La Plata

La diferencia en las alturas de las órbitas de los satélites GPS y altimétricos abre la posibilidad de separar el contenido el contiendo electrónico total en dos componentes: una, netamente ionosférica, hasta una altura de $1300 \mathrm{~km}$, y por encima de ella otra atribuible a la plasmasfera. En este capítulo se propone un procedimiento para separar ambas contribuciones, se estima la componente plasmasférica y se muestran los resultados.

Capítulo 6: Conclusiones y futuros trabajos

Como cierre, se ofrecen los principales aportes del trabajo y las iniciativas que han surgido a partir de él. 


\section{Capítulo 1: La Tierra en el espacio. Origen y variabilidad de la}

Ionosfera

Todos los cuerpos del sistema solar que tienen envolturas gaseosas, además de gas neutro poseen también electrones libres e iones. La radiación solar $y$, en menor media, las partículas energéticas que en forma de viento solar penetran las envolturas de planetas, lunas y cometas, interactúan con los átomos y moléculas neutras provocando su ionización. Una vez formadas, las partículas cargadas intervienen en diferentes procesos dinámicos asociados a los campos electromagnéticos en los cuales se encuentran inmersas. A su vez, en el Sol tienen lugar una serie de fenómenos intensos, localizados y de diversos períodos que alteran el flujo de energía y hacen sentir su efecto sobre las envolturas de los planetas.

Para comprender el origen de la ionización en la atmósfera de la Tierra y su variabilidad, es necesario conocer tanto las propiedades de la radiación solar, de las partículas y del campo magnético que conforman el medio interplanetario como las características de la atmósfera de la Tierra y de su campo magnético. Estos elementos componen el medio Sol-Tierra o geoespacio.

El conocimiento actual del geoespacio es el resultado de la observación directa, hecha con diversos y sofisticados dispositivos y técnicas, combinada con el desarrollo de complejas teorías y modelos. El objeto del presente capítulo es dar una idea general de los procesos físicos involucrados en el medio Sol-Tierra y de su importancia para la comprensión de la formación de la ionosfera, sin profundizar en las técnicas observacionales ni en el tratamiento detallado de los procesos. Un planteo riguroso puede encontrarse en Schunk \& Nagy (2000), Priest (1982), Hargreaves (1995), Prölss (2004) y Kelly (2009), trabajos que han sido tomados como principales fuentes para el desarrollo de este capítulo. Sí se profundiza en los fundamentos físicos de la formación de la ionosfera, específicamente en los procesos de ganancia y pérdida de iones en la atmósfera superior de la Tierra, los cuales proporcionan las bases para la comprensión de las variaciones espaciales y temporales observadas en la ionosfera (Memarzadeh, 2009). 


\subsection{El Sol}

El Sol es un cuerpo compuesto fundamentalmente de hidrógeno ( $90 \%)$ y helio $(\sim 10 \%)$, y pequeñas cantidades $(0,1 \%)$ de otros elementos como argón, calcio, carbono, hierro, magnesio, neón, nitrógeno, oxígeno, silicio y azufre, en proporciones similares a las halladas en la Tierra, lo que sugiere un origen común para ambos cuerpos como pudo ser el interior de estrellas viejas. En el Sol estos átomos se encuentran comprimidos por acción de su propia atracción gravitatoria y en su mayor parte en estado ionizado (estado de plasma) a causa de las altas temperaturas. La temperatura $\left(1.610^{7} \mathrm{~K}\right)$ y densidad $\left(1.610^{5} \mathrm{~kg} \mathrm{~m}^{-3}\right)$ alcanzadas en el núcleo son suficientes como para desatar reacciones termonucleares; la energía generada en la región central es transferida de forma lenta a través de una zona intermedia por difusión radiativa y luego es trasportada por convección. La zona donde la radiación es capaz de fluir directamente desde el Sol marca el límite entre la zona convectiva y la base de la fotósfera, que es la capa superficial visible.

El brillo de la fotósfera no es uniforme sino que aparece cubierta por millones de gránulos brillantes formados por material ionizado caliente en ascenso. A pesar de ello, la radiación solar por segundo en los rangos visible e infrarrojo y ultravioleta cercanos se mantiene prácticamente constante. En estas longitudes de onda, el espectro de emisión del Sol es comparable al de un cuerpo negro con una temperatura efectiva próxima a los $6000 \mathrm{~K}$.

La Figura 1.1 muestra el espectro de radiación solar en las proximidades de la órbita de la Tierra. En la parte superior de la figura se identifican con línea punteada las bandas visibles y de radio en las cuales la radiación puede atravesar la atmósfera de la Tierra. El resto de la radiación solar es absorbida en la atmósfera antes de llegar a la superficie terrestre. Interesa especialmente la energía correspondiente al extremo ultravioleta y rayos $X$ del espectro, ya que constituye la principal fuente de ionización de la atmósfera superior de la Tierra. El flujo de radiación en esta región del espectro exhibe importantes fluctuaciones dependiendo de la actividad solar.

Una mirada detallada sobre la atmósfera del Sol, revela una gran variedad de estructuras dinámicas superpuestas sobre ella. Es posible distinguir regiones activas brillantes, filamentos, regiones oscuras de intenso campo magnético llamadas manchas solares $y$, cerca de éstas, regiones de intensa emisión conocidas como flares. Estas estructuras involucran una variedad de escalas espaciales, temporales y de intensidad de radiación, pero simplemente 
representan las diferentes respuestas del plasma solar al desarrollo del campo magnético subyacente.

Figura 1.1: Espectro de radiación del Sol (Prölss, 2004).

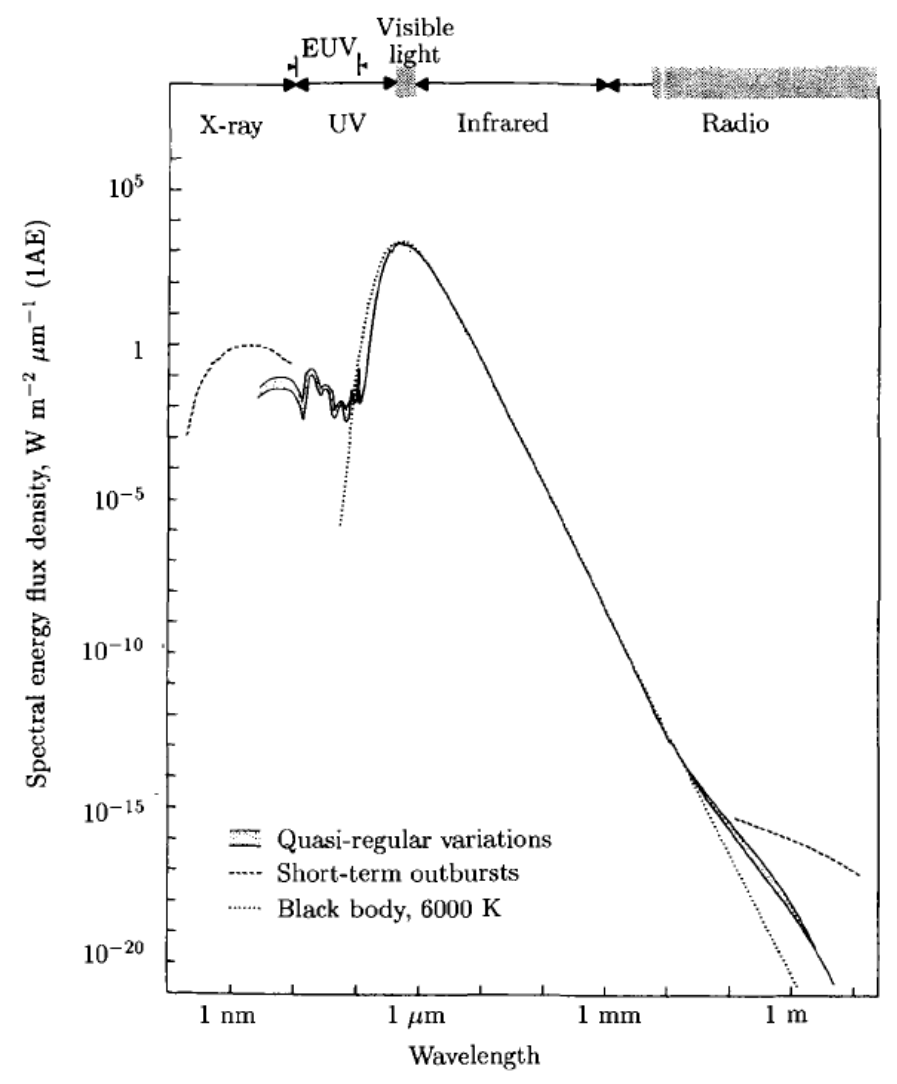

En particular, las manchas solares representan un rasgo distintivo de la fotósfera y son características de la fase más intensa de una región activa. Las manchas tienen diámetros típicos que oscilan entre los 1000 y 40000 km, aparecen más oscuras que su entorno debido a que son zonas más frías que el medio que las rodea y representan concentraciones excepcionales de flujo magnético. Típicamente, las manchas aparecen a pares y gradualmente se van separando. La mayoría de las manchas están confinadas en un cinturón ecuatorial $\pm 35^{\circ}$ de latitud) y exhiben un movimiento propio ordenado. En la Figura 1.2 está representado el número mensual de manchas solares.

El número de manchas solares f y de grupos de manchas solares g visibles sobre el disco solar combinadas dan origen al número de Wolf $\mathrm{R}$ :

$$
R=K(10 g+f)
$$

La constante $\mathrm{K}$ (típicamente 0.6) es un factor de corrección observacional. 
El número de Wolf es un indicador de la actividad solar, con un período de aproximadamente 11 años conocido como ciclo solar.

Otro indicador de la actividad solar, fuertemente correlacionado con $\mathrm{R}$ y más utilizado, es el índice $\mathrm{F}_{10.7}$. Este mide la intensidad de la radiación solar en la longitud de onda de $10.7 \mathrm{~cm}$ observada en la Tierra.

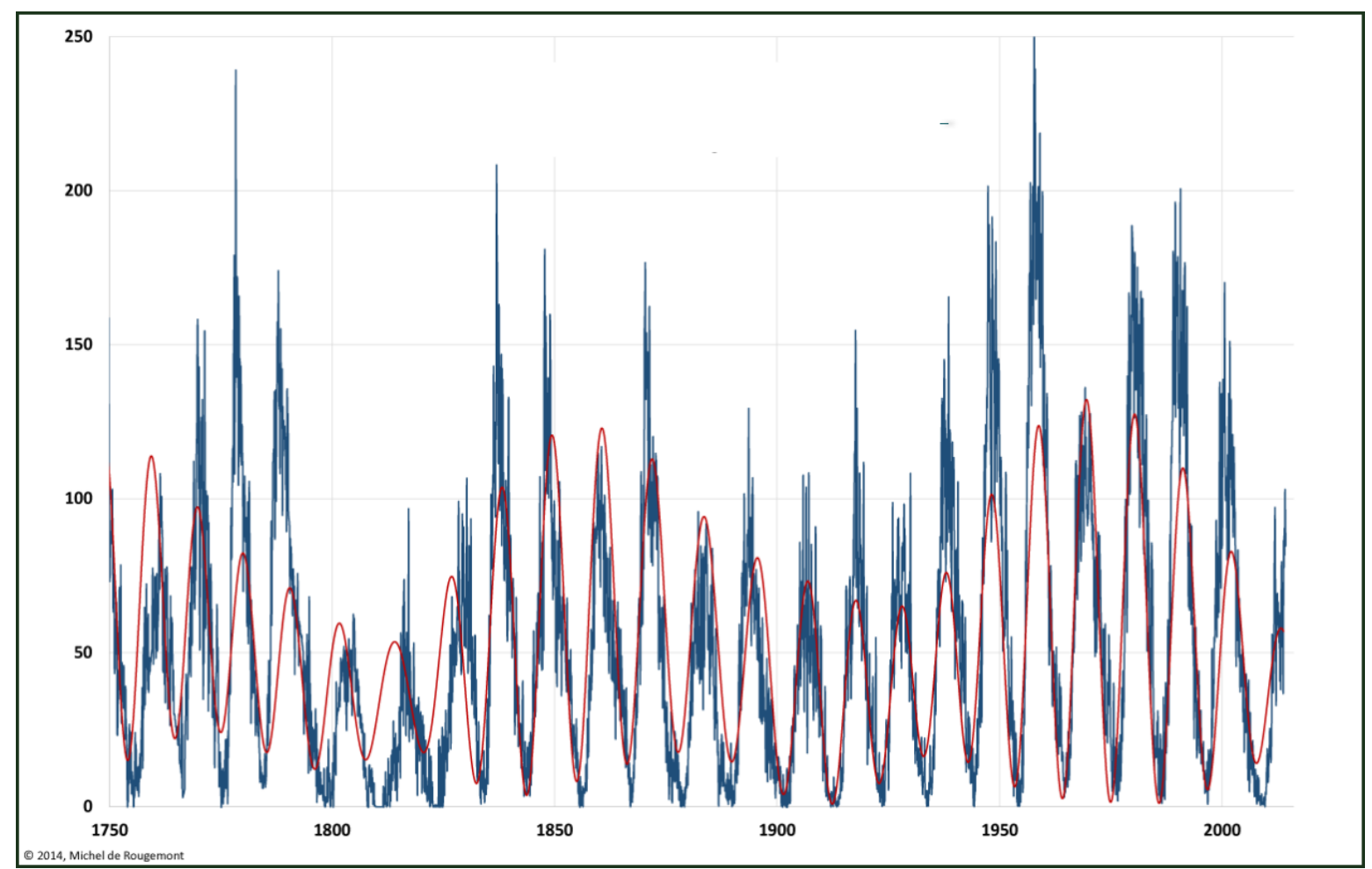

Figura 1.2: Manchas solares. En azul: número mensual de manchas observado; en rojo: análisis de regresión. (Fuente: Royal Observatory of Belgium, http://sidc.be/silso/home)

El ciclo solar está sujeto a variaciones irregulares tanto en el período como en la amplitud. Superpuesto al ciclo de 11 años se advierten otros, como el de 27 días, asociado al período de rotación del Sol y un intervalo de 80 años marcado por la falta de actividad entre los años 1645 y 1715 conocida como mínimo de Maunder. Sin embargo, el período fundamental del ciclo solar es de 22 años, asociado a la inversión de los polos magnéticos del Sol: la máxima actividad siempre ocurre en la etapa de inversión.

La persistencia del campo magnético del Sol, la inversión de los polos y las principales características de las manchas solares se explican a partir de un 
mecanismo de dínamo magnetohidrodinámico que opera en las profundidades de la zona convectiva del Sol.

A otra escala, los flares o fulguraciones constituyen uno de los fenómenos más violentos del sistema solar. Son eventos muy localizados y de corta duración (menos de una hora) mediante los cuales se libera una gran cantidad de energía $\left(310^{25} \mathrm{~J}\right)$. Se caracterizan por un aumento rápido en la emisión en diferentes regiones del espectro (micro-ondas, Ha, rayos X, y ultravioleta extremo), eyección de partículas de alta energía y burbujas de plasma. Estos cambios violentos alcanzan la atmósfera terrestre y por este motivo constituyen un elemento fundamental de la relación Sol-Tierra. Los flares se originan en la zona de contacto entre manchas solares de polaridad opuesta muy próximas. En estos casos, los gradientes magnéticos pueden resultar excepcionalmente altos y producirse el fenómeno de reconexión magnética, mediante el cual la energía magnética se convierte en calor y energía de las partículas.

\subsection{El medio interplanetario}

Los campos y partículas que llenan la región comprendida entre el Sol y los planetas constituyen el medio interplanetario. Las partículas provienen en su mayoría del viento solar, aunque también se hallan partículas energéticas de diferentes orígenes. El campo más relevante es el campo magnético interplanetario.

\subsubsection{El viento solar}

Hacia fines de la década de 1950 E. Parker predijo la existencia y delineó analíticamente las principales características de un flujo de material que abandona el Sol y fluye hacia el espacio, al cual denominó viento solar (Parker, 1958). El flujo fue observado directamente poco tiempo después por los satélites Lunik III y Venus I e investigado con gran precisión a partir de la misión Mariner II.

El viento solar se origina en la envoltura externa y tenue del sol conocida como corona. Está compuesto esencialmente de protones y electrones, con una pequeña fracción de partículas alfa (que se puede incrementar en condiciones perturbadas). Las propiedades del flujo en la órbita de la Tierra, es decir en el plano de la eclíptica y a una distancia heliocéntrica del UA, se resumen en la Tabla 1.1. Mientras que a la luz solar le lleva 8 minutos alcanzar la Tierra, el plasma 
recorre la misma distancia, en promedio, en 5 días. Fuera de la órbita terrestre, el viento solar se extiende hasta confundirse con el medio interestelar a 50 o 100 UA.

\begin{tabular}{|l|l|l|}
\hline Parámetro & Viento lento & Viento rápido \\
\hline Densidad del plasma & $11.9 \mathrm{~cm}^{-3}$ & $3.9 \mathrm{~cm}^{-3}$ \\
\hline Velocidad de deriva & $327 \mathrm{~km} \mathrm{~s}^{-1}$ & $702 \mathrm{~km} \mathrm{~s}^{-1}$ \\
\hline Temperatura protónica & $0.3410^{5} \mathrm{~K}$ & $2.310^{5} \mathrm{~K}$ \\
\hline Temperatura electrónica & $1.310^{5} \mathrm{~K}$ & $1.010^{5} \mathrm{~K}$ \\
\hline
\end{tabular}

Tabla 1.1. Características del viento solar (Shunk \& Nagy, 2000)

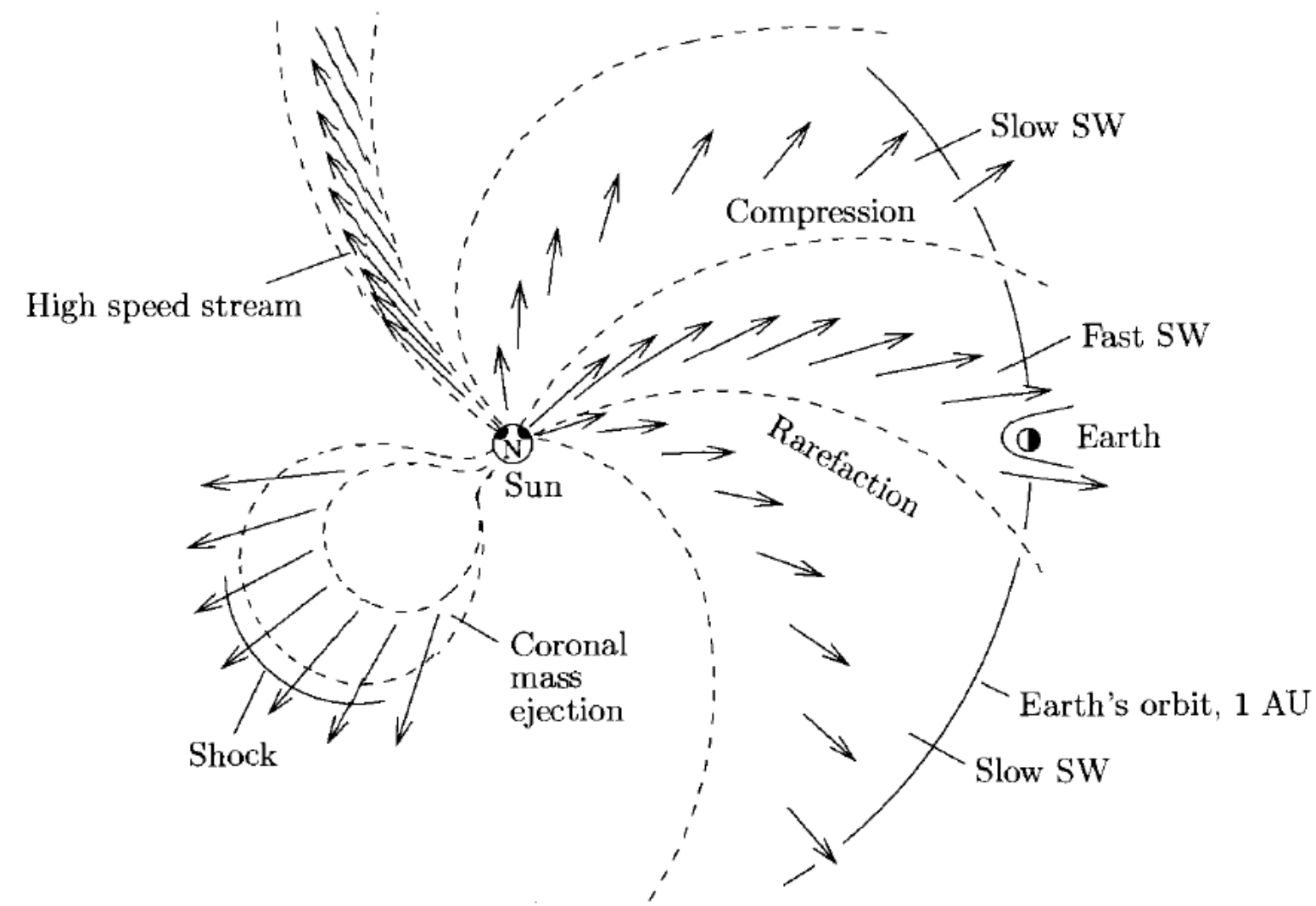

Figura 1.3. Estructura del viento solar en la eclíptica, vista desde el polo norte (Prölss, 2004)

El viento solar no es un flujo uniforme. Es posible distinguir un viento solar lento (velocidad $<400 \mathrm{~km} / \mathrm{s}$ ) y un viento solar rápido (velocidad $>600 \mathrm{~km} / \mathrm{s}$ ), asociados a dos orígenes diferentes del flujo. El flujo rápido proviene de los agujeros coronales

I. Bibbó | La Tierra en el espacio. Origen y variabilidad de la lonosfera 
y constituye la parte más uniforme del viento solar, mientras que el viento lento se origina en los campos abiertos sobre las regiones activas.

En el plano de la eclíptica, las partículas de cada región de la corona que componen el viento solar difieren en su velocidad, pero también en la densidad y temperatura. Cerca del Sol, el flujo es prácticamente radial, pero combinado con la velocidad acimutal provista por la rotación solar, origina un viento solar inhomogéneo con una estructura a gran escala con forma de espiral (Figura 1.3). La diferencia en las velocidades de ambos flujos en el espacio interplanetario provoca una compresión del plasma del viento solar en el frente del flujo rápido. Estas regiones de interacción co-rotantes son responsables de perturbaciones periódicas en la atmósfera de la Tierra conocidas como tormentas geosféricas (sección 1.4.4).

Otro evento solar capaz de perturbar el espacio interplanetario son las llamadas eyecciones de masa coronal.

\subsubsection{El campo magnético interplanetario}

El campo magnético interplanetario está íntimamente relacionado con el viento solar. La mayor parte del viento solar proviene de los agujeros coronales, especialmente de los pares de agujeros polares que normalmente se encuentran presentes. Los dos agujeros poseen, usualmente, campos magnéticos opuestos y a pequeñas distancias de la superficie solar, están separados por una configuración magnética cerrada; pero a una distancia de uno o dos radios solares entran en contacto en una hoja de corriente heliomagnética neutra. En una atmósfera solar idealizada, esta hoja de corriente debería coincidir con el ecuador magnético (Figural.4). Sin embargo, aún en los períodos de mínima actividad solar, la presencia de áreas unipolares deforma la hoja dándole una apariencia de ala de sombrero (Figura 1.5).

Así, a medida que el Sol rota, un observador sobre el ecuador solar atraviesa alternativamente regiones de polaridad opuesta (típicamente cuatro veces por período de rotación solar) según esté de un lado u otro de la hoja. Además, el Sol como un todo sufre una inversión de la polaridad cada aproximadamente 22 años. En el período de transición el campo magnético global es muy complejo, la hoja se aparta del ecuador y podría describirse como una composición de varias hojas topológicamente diferentes. 


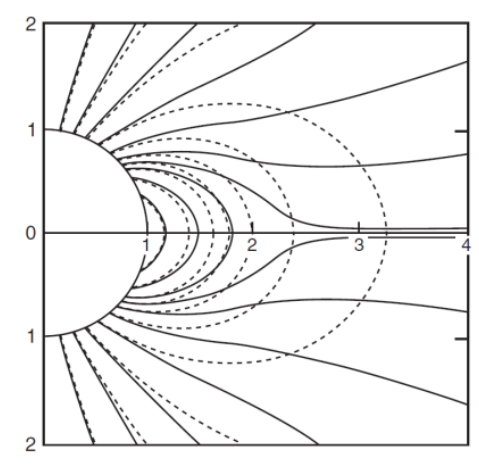

Figura 1.4. Líneas de campo magnético (según modelo de Pneuman-Kopp, Priest, 1982)

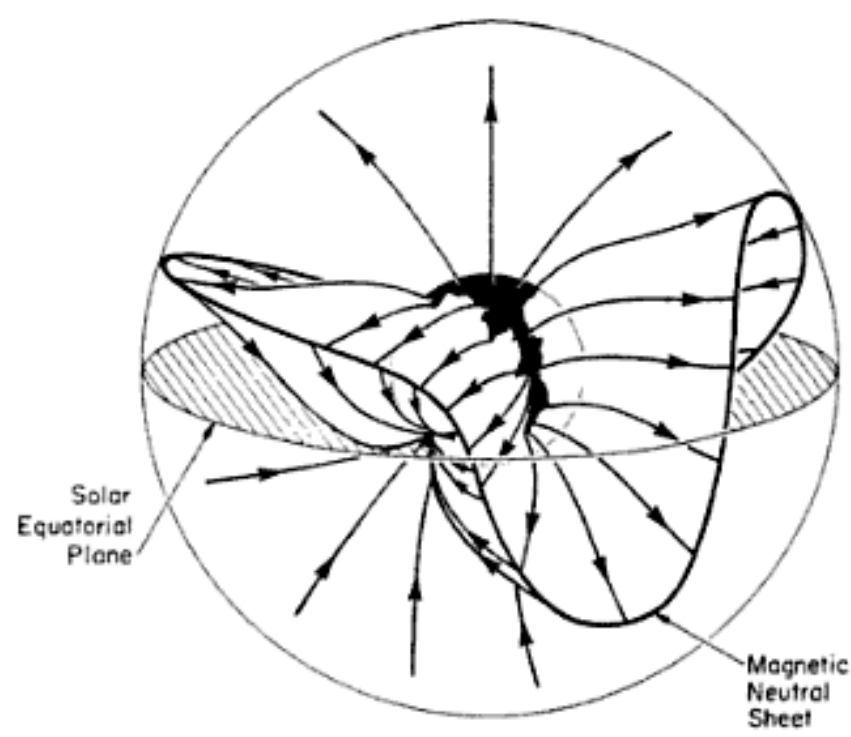

Figura 1.5. Esquema de la hoja de corriente neutra deformada por la presencia de un gran agujero coronal que se extiende hasta el ecuador (Priest, 1982).

La Tierra, entonces, por períodos, se encuentra embebida en un campo magnético dirigido hacia afuera del Sol (sector magnético positivo), o en un campo que apunta hacia el Sol (sector magnético negativo).

En las proximidades de la órbita terrestre, el campo magnético interplanetario ha sido explorado y por lo tanto sus principales características han sido determinadas. Éstas se sintetizan en la Tabla 1.2.

\begin{tabular}{|l|l|}
\hline Parámetro & \\
\hline Intensidad del Campo Magnético B & $3.5(0.2-50) \mathrm{nT}$ \\
\hline Ángulo de inclinación con la dirección radial & $43^{\circ}$ \\
\hline Parámetro $\beta^{*}$ & 450 \\
\hline
\end{tabular}

Tabla 1.2. Propiedades del campo magnético interplanetario en las proximidades de la órbita de la Tierra.

Un parámetro importante es el $\beta^{*}$, que mide la razón entre la presión cinética y la magnética. El valor elevado de $\beta^{*}$ da cuenta de que la configuración del campo magnético debe adaptarse a la estructura del viento solar (campo magnético congelado). 
El campo magnético surge del Sol principalmente en forma radial pero es arrastrado por el viento solar y adquiere la forma de espiral característica de la Figura 1.6, donde las líneas de campo magnético actúan como trazadores del viento.

Además de la configuración a nivel global descripta, el medio interplanetario exhibe fluctuaciones a menor escala en diferentes parámetros observacionales, muchas veces correlacionados, explicables a partir de la formación de ondas magnetohidrodinámicas.

Figura 1.6. Líneas de campo magnético interplanetario (Kelly, 2009)

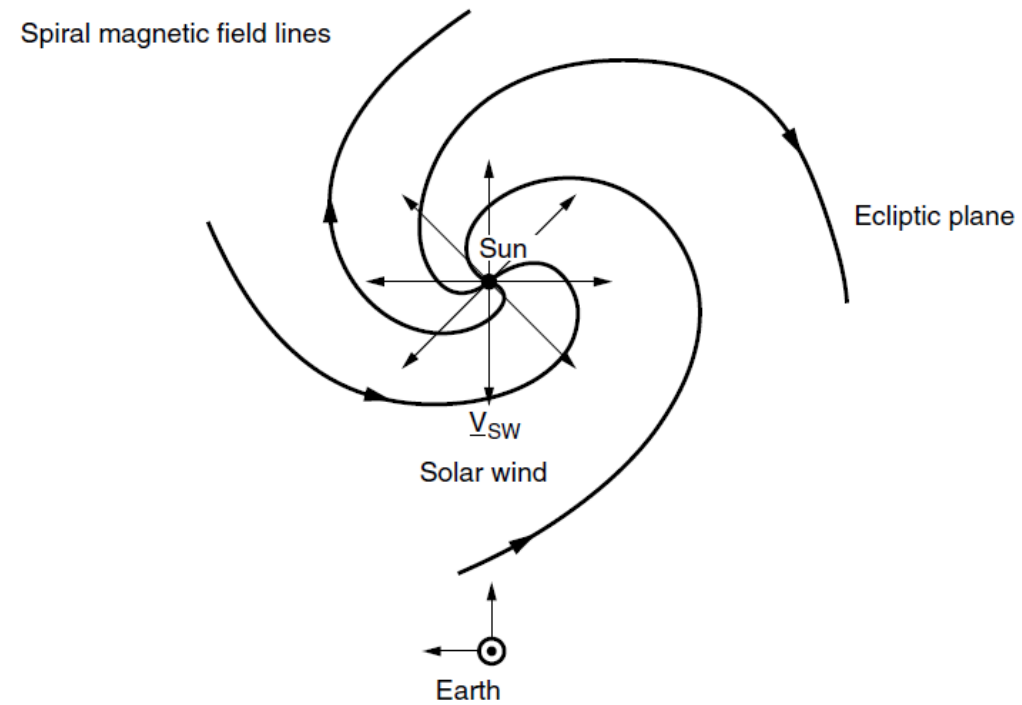

\subsubsection{Partículas energéticas}

Además del viento solar, el espacio interplanetario está poblado de un amplio espectro de partículas de altas energías. En este contexto, se trata de partículas cuyas energías son superiores a la energía característica de los protones del viento solar, es decir que exceden los keVs, y pueden llegar hasta los $10^{20} \mathrm{eV}$.

Las partículas de mayor energía, que penetran el espacio interplanetario uniformemente desde todas las direcciones, son de origen galáctico y se conocen como rayos cósmicos. Se trata principalmente de protones, en menor medida partículas a y electrones, y muy escasos núcleos de elementos más 
pesados. En la época de máxima actividad solar (fase de inversión del campo magnético solar) se registra la mínima incidencia de estas partículas sobre la Tierra.

Además de los rayos cósmicos existen otras poblaciones de partículas energéticas producidas en el espacio interplanetario. En este grupo se distinguen los llamados rayos cósmicos anómalos, con energías entre los 50 y $300 \mathrm{MeV}$ y abundancias explicables en términos de interacciones dentro de la heliosfera, y las partículas aceleradas por las ondas de choque asociadas a regiones de interacción corotantes. La principal característica de esta población de partículas es que son observadas repetidamente a intervalos de una rotación solar (27 días). Los protones pueden tener energías de varios $\mathrm{MeV}$.

La atmósfera del Sol es otra fuente de partículas energéticas. Se producen durante los impulsivos flares solares. Comparada con la población de partículas aceleradas por ondas de choque, estas partículas energéticas solares son sobreabundantes en electrones, isótopos de ${ }^{3} \mathrm{He}$ y elementos pesados en altos grados de ionización. Los electrones pueden alcanzar valores de $1 \mathrm{MeV}$ y los protones pueden superar varios $\mathrm{GeV}$, aunque valores altos no son muy frecuentes.

\subsection{La Tierra}

Las dos secciones anteriores han permitido caracterizar el medio físico en el cual la Tierra se mueve. Esta sección se centra en la atmósfera y el campo magnético que rodean a la Tierra, cuyas fisonomías no son independientes del medio descripto. En términos generales, la atmósfera terrestre es una envoltura gaseosa relativamente densa cerca de la superficie de la Tierra, mientras que el campo geomagnético puede aproximarse a un campo dipolar. Sin embargo, la energía proveniente del Sol penetra la atmósfera, provoca su calentamiento y altera la composición. Especialmente por encima de los 100 km, por acción de la radiación, el grado de ionización del material es importante. En esta región, el movimiento de las partículas cargadas está dominado por el campo magnético de la Tierra, cuyo comportamiento, a su vez, es modelado por el viento solar.

\subsubsection{El campo magnético terrestre}

El campo geomagnético de la Tierra es creado por las corrientes que se originan en la parte líquida y conductora del núcleo del planeta, impulsadas por la 
convección térmica. En una primera aproximación y cerca de la superficie de la Tierra, el campo magnético resultante es equivalente al campo de un dipolo cuyo eje está inclinado aproximadamente $11^{\circ}$ con respecto al eje terrestre de rotación y sujeto a variaciones seculares.

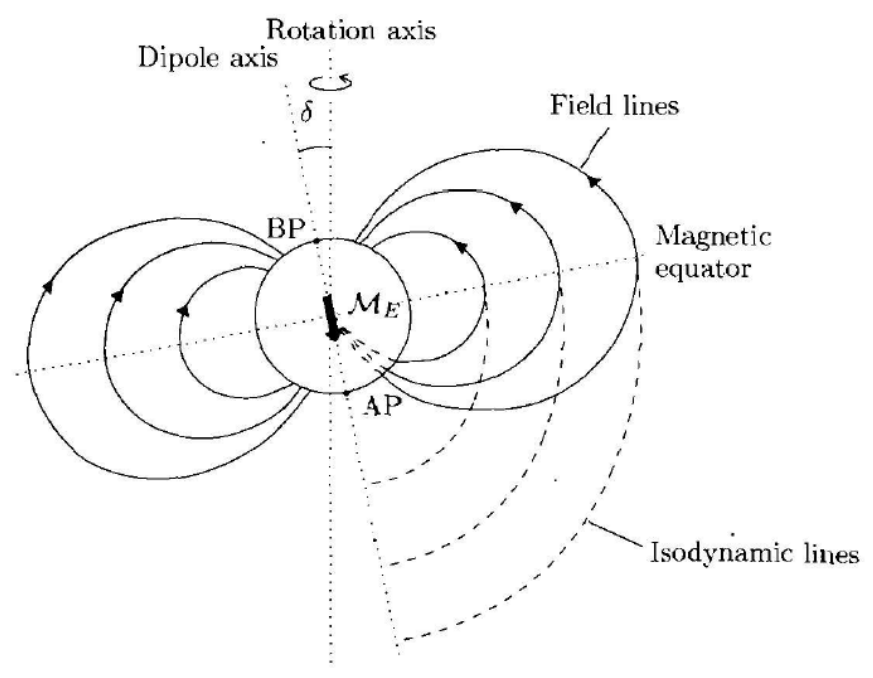

Figura 1.7. Esquema de
líneas de
magnético dipolar (Prölss,
2004)

En la actualidad, en campo magnético es tal que apunta hacia la superficie de la Tierra en el hemisferio norte y hacia afuera en el hemisferio sur (Figura 1.7). Estudios paleomagnéticos muestran que el campo se invierte en períodos irregulares de tiempo. El polo boreal del dipolo magnético se encuentra en latitudes y longitudes geográficas $\varphi_{0}=81.3^{\circ} \mathrm{N}$ y $\lambda_{0}=249.2^{\circ} \mathrm{E}$ respectivamente (determinadas en el año 2001), mientras que el polo austral tiene coordenadas geográficas $64.7^{\circ} \mathrm{S}$ y $138.1^{\circ} \mathrm{E}$ (determinadas en el año 2000). El plano perpendicular al eje del dipolo magnético determina el ecuador geomagnético, a partir del cual se mide la latitud magnética. La latitud geomagnética $\Phi$ está relacionada con las coordenadas geográficas $\varphi$ y $\lambda$ a través de la siguiente ecuación:

$$
\operatorname{sen} \Phi=\operatorname{sen} \varphi \operatorname{sen} \varphi_{0}+\cos \varphi \cos \varphi_{0} \cos \left(\lambda-\lambda_{0}\right)
$$

donde $\varphi_{0}$ y $\lambda_{0}$ son las coordenadas geográficas del polo boreal magnético dadas en el párrafo anterior. En esta aproximación, el campo magnético sobre la superficie de la Tierra permanece constante sobre los puntos de igual latitud geomagnética y varía entre aproximadamente 25000 nT y 75000 nT desde el ecuador hasta los polos.

En la aproximación dipolar, la densidad de flujo magnético está dada por 


$$
\mathbf{B}(\mathrm{r}, \lambda)=\frac{\mathbf{M}}{\mathrm{r}^{2}}\left(1+\operatorname{sen}^{2} \lambda\right)^{\frac{1}{2}}
$$

donde $\mathbf{M}$ es el momento dipolar, $\mathrm{r}$ es la distancia radial geocéntrica y $\lambda$ la latitud geográfica.

En la misma aproximación, la ecuación para las líneas de campo magnético puede escribirse como

$$
r=L R \cos ^{2} \lambda
$$

L es el parámetro de capa o parámetro de Mcllwain (Mcllain, 1961), definido como la distancia geocéntrica de una línea en el plano del ecuador geomagnético, medida en unidades de radios terrestres ( $R \cong 6371 \mathrm{~km}$ ).

En esta situación ideal, si la Tierra estuviera rodeada por vacío y en ausencia de fuentes de corrientes eléctricas, las líneas se extenderían según curvas de dimensión creciente como muestra la Figura 1.7. Pero, como hemos visto, la Tierra se halla inmersa en la atmósfera del Sol. Suponiendo que arriba un viento solar subsónico, ignorando el campo magnético interplanetario, una partícula de carga q que se aproxima a la Tierra con una velocidad v, en presencia del campo magnético terrestre $\mathrm{B}$, experimenta una fuerza magnética $\mathbf{F}$

$$
\mathbf{F}=\mathrm{q} \mathbf{v} \times \mathbf{B}
$$

Debido a la polaridad del campo magnético terrestre, los iones son forzados a moverse hacia el amanecer mientras que los electrones se mueven en dirección al atardecer. La situación se esquematiza en la Figura 1.8.

Una vez desviadas, las partículas describen espirales alrededor de las líneas de campo magnético y derivan alrededor de la Tierra, generando una corriente neta hacia el atardecer en una lámina delgada que atraviesa el plano de la figura 1.8. El campo magnético generado por esta corriente es paralelo al campo geomagnético y es tal que cancela el campo de la Tierra en dirección al Sol e incrementa su valor en la dirección opuesta. Entonces, la interacción del viento solar con el campo magnético terrestre genera un volumen alargado en la dirección contraria al Sol, gobernado por el campo magnético de la Tierra, conocido como la magnetosfera. El límite de la magnetosfera se conoce como la magnetopausa. 


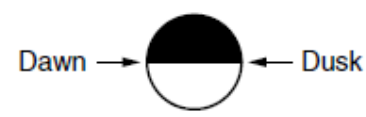

Ecliptic plane

Figura 1.8. Deflexión de las partículas del viento solar por acción del campo magnético terrestre (Kelly, 2009)

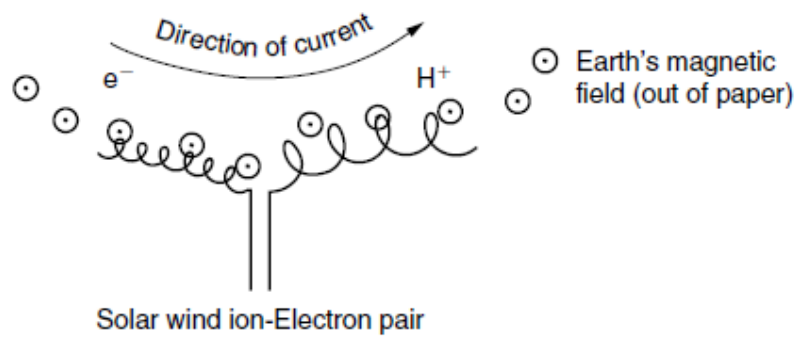

$\uparrow \uparrow \uparrow \uparrow \uparrow \uparrow$

En la aproximación descripta la magnetosfera es cerrada, ya que impide el ingreso de partículas del viento solar y todas las líneas de campo contienen principio y fin sobre la superficie de la Tierra. La naturaleza supersónica del viento solar complica la estructura de la magnetosfera, generado flujos dentro de la cavidad. Si además se contempla la interacción del sistema con el campo magnético interplanetario, la magnetosfera es escenario de otros fenómenos, representados en la Figura 1.9.

Cuando el campo magnético interplanetario se conecta con el terrestre se producen líneas de campo abiertas. Éstas se extienden alejándose de la Tierra en la magnetocola y atraviesan la magnetopausa para conectase con el campo magnético interplanetario en la envoltura magnética. Las líneas abiertas forman dos lóbulos separados por una hoja de corriente neutra $(B=0)$. Sobre ella, las líneas abiertas se reconectan en líneas cerradas que acarrean el plasma hacia a la Tierra. A medida que este flujo atraviesa el campo magnético creciente, el movimiento diferencial de los electrones y los iones produce un anillo de corriente (típicamente entre $\mathrm{L}=2$ y $\mathrm{L}=4$ ) similar al originado por el viento solar. Algunas de las partículas de la hoja se mueven a lo largo de líneas magnéticas y se precipitan en la atmósfera en un anillo alrededor de las regiones polares llamado aurora oval. El flujo de plasma sobre la hoja de corriente provee una fuente de precipitación estable que se corresponde visualmente con las emisiones extendidas llamadas auroras difusas. Esta precipitación también actúa como una fuente de ionización para la atmósfera superior de la Tierra. 


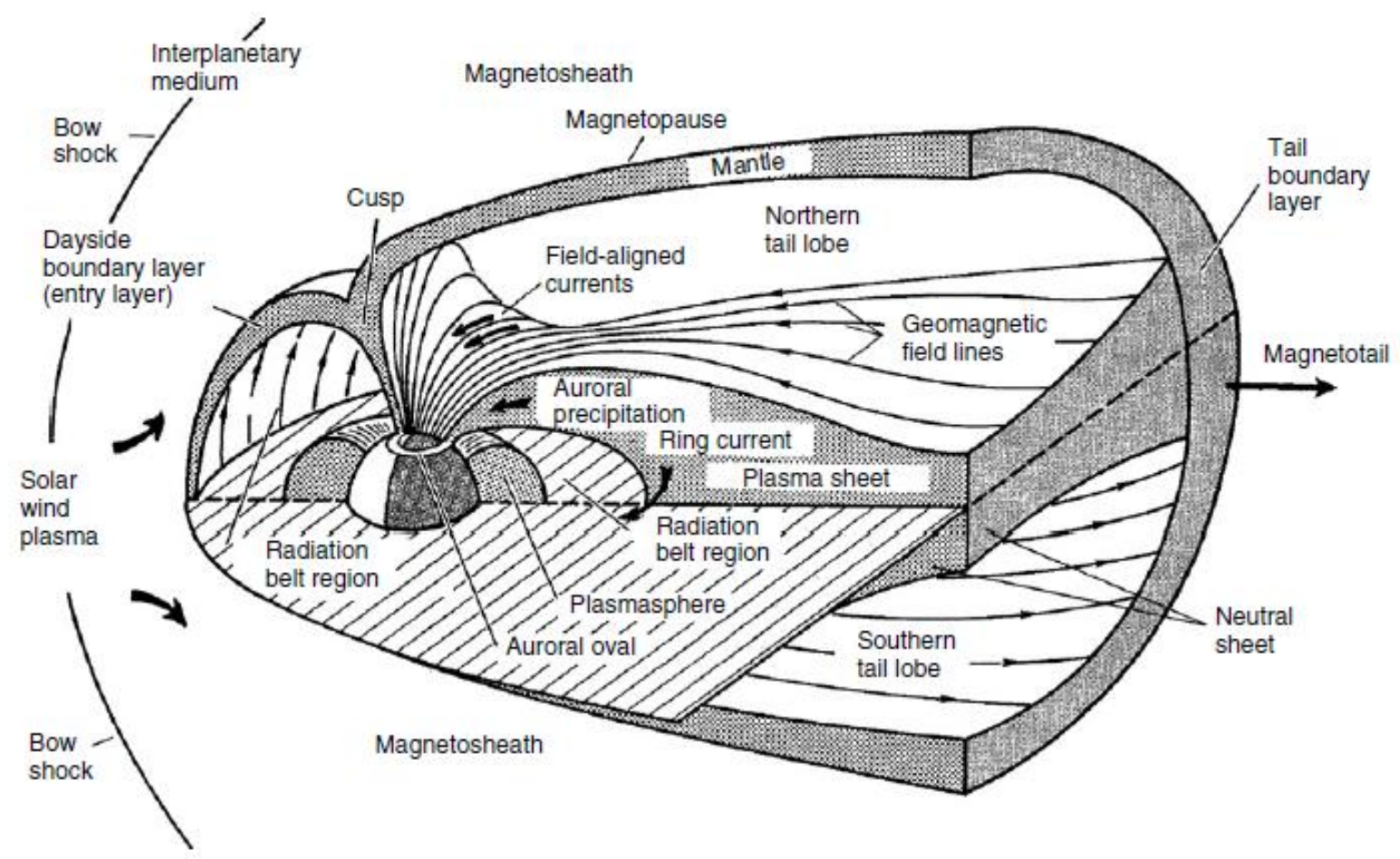

Figura 1.9. Representación esquemática de la magnetosfera (Kelly, 2009)

Las energías típicas de las partículas del viento solar oscilan entre los pocos eV (los electrones) y los kilovolts (los iones). En la hoja de corriente los electrones pueden alcanzar energías del orden de los kilovolts. Pero la magnetosfera alberga una región donde la energía característica de las partículas es muy elevada (del orden de los MeV para los protones y superior a los 50KeV para los electrones). Esta región se conoce como cinturón de radiación o cinturón de Van Allen (ver Figura 1.9). La fuente de energía de las partículas del cinturón está en las partículas de alta energía de origen cósmico que colisionan con núcleos del gas en la atmósfera densa de la Tierra. Los protones y electrones resultantes de la interacción quedan atrapados en las líneas cerradas del campo magnético terrestre, donde pueden permanecer por largo tiempo (años) girando, rebotando y derivando. La distribución de las partículas depende de su energía, pero es posible distinguir dos regiones bien definidas o cinturones. El primero se observa alrededor de $\mathrm{L}=1.8$ y está asociado al flujo máximo de protones, mientras que el segundo se ubica entre $\mathrm{L}=3$ y $\mathrm{L}=4$, donde se distribuyen mayoritariamente los electrones energéticos. Cuando estas partículas se precipitan fuera de la región de confinamiento contribuyen a la ionización de la atmósfera.

Finalmente, la magnetosfera encierra en su parte inferior una región compuesta por electrones, protones y algunos iones pesados con energías en el rango térmico (del orden de leV) conocida como plasmasfera. El límite exterior de la

I. Bibbó | La Tierra en el espacio. Origen y variabilidad de la lonosfera 
plasmasfera es la plasmapausa y separa el plasma que co-rota con la Tierra de aquél que permanece inafectado por la rotación.

Las perturbaciones que sufre el campo geomagnético por acción del flujo de partículas provenientes del Sol son caracterizadas por medio de un parámetro conocido como índice $K$ (de 0 a 9 en una escala logarítmica). Este índice es local y mide la variación en las componentes horizontales del campo magnético en intervalos de 3 horas. Un indicador global es el índice planetario Kp, que se obtiene a partir de las perturbaciones medidas en diferentes estaciones distribuidas en latitudes subaurorales (Bartels, 1957).

\subsubsection{La atmósfera}

La envoltura gaseosa que rodea de Tierra tiene su límite inferior a nivel del mar y se extiende hasta confundirse con el espacio interplanetario. Debido a la influencia de la gravedad, en una primera aproximación, la atmósfera terrestre se encuentra estratificada horizontalmente. De acuerdo con el parámetro físico que se elija, es posible establecer distintas clasificaciones para identificar las diferentes regiones de la atmósfera de la Tierra (Figura 1.10).

Figura 1.10. Clasificación y nomenclatura de la atmósfera terrestre.

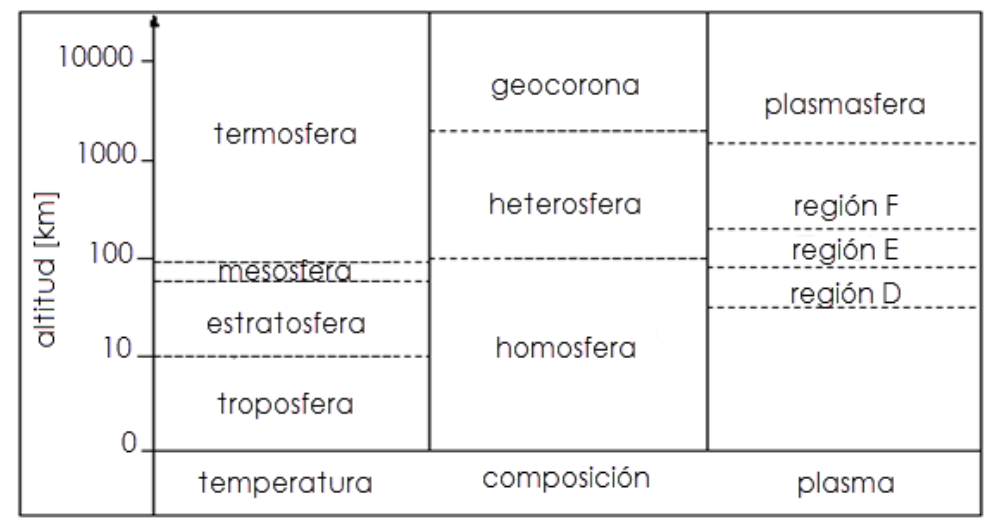

\subsection{2.a. Perfiles de temperatura, presión y densidad}

La clasificación más común de la atmósfera se basa en el perfil vertical de temperatura de la Figura 1.10. El calentamiento del gas que compone la envoltura gaseosa terrestre se debe a la absorción directa de la radiación solar o a la reabsorción de su propia radiación infrarroja reflejada por el vapor de agua 
(efecto invernadero). Como resultado, la temperatura media sobre la superficie de la Tierra alcanza los $288 \mathrm{~K}$. A partir de allí, la temperatura decrece con la distancia hasta una altura aproximada de $10 \mathrm{~km}$ debido al enfriamiento radiativo. Esta región se conoce como la troposfera y su límite superior es la tropopausa. Sobre ella, en la estratosfera, la temperatura comienza a ascender debido a la absorción de la radiación ultravioleta del Sol por parte del ozono presente en la región, hasta los $50 \mathrm{~km}$ donde alcanza nuevamente la temperatura propia de la superficie de la Tierra. Sobre la estratopausa la temperatura desciende nuevamente por efecto del enfriamiento radiativo, dentro de la zona llamada mesosfera, hasta alcanzar un mínimo de $160 \mathrm{~K}$ a los $80-90 \mathrm{~km}$ donde se ubica la mesopausa. A partir de esta altura, la temperatura se incrementa drásticamente debido a la absorción de fotones solares de mayor energía (ultravioletas y ultravioletas extremos) combinada con la ausencia de un proceso efectivo de enfriamiento. Esta región se conoce como la termosfera. Finalmente, por encima de los $200 \mathrm{~km}$ la temperatura tiende a un valor asintótico que puede variar entre los 600 y $2500 \mathrm{~K}$.

Figura 1.11. Perfil típico de temperatura $T$, presión $p y$ densidad $\rho$ en la atmósfera de la Tierra (Prölss, 2004 )

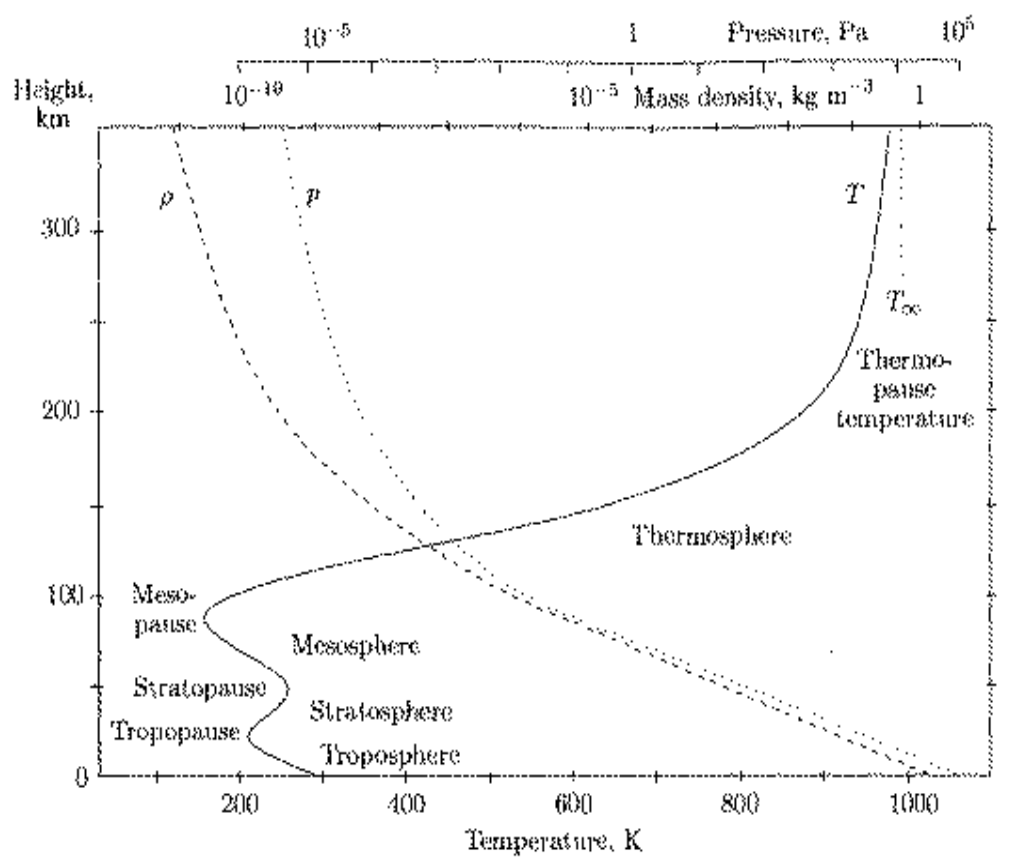

Es también común referirse a la troposfera como la atmósfera baja, a la estratosfera y mesosfera como la atmósfera media y a la termosfera como la atmósfera superior.

Por su parte, los perfiles verticales de presión y densidad decrecen monótonamente con la altura como se muestra en la Figura 1.11. 


\subsection{2.b. Composición química}

La composición química de la atmósfera terrestre (Figura 1.12) es el resultado de la acción de los procesos bio-físicos dentro de la envoltura primitiva del planeta. Por debajo de los $100 \mathrm{~km}$ la composición es relativamente uniforme debido a la presencia de una variedad de fenómenos turbulentos de mezcla. Esta característica establece otro criterio de clasificación que divide a la atmósfera de la Tierra en tres regiones: hasta los $100 \mathrm{~km}$, con una composición homogénea en la que predominan el nitrógeno y el oxígeno molecular, se extiende la homosfera;

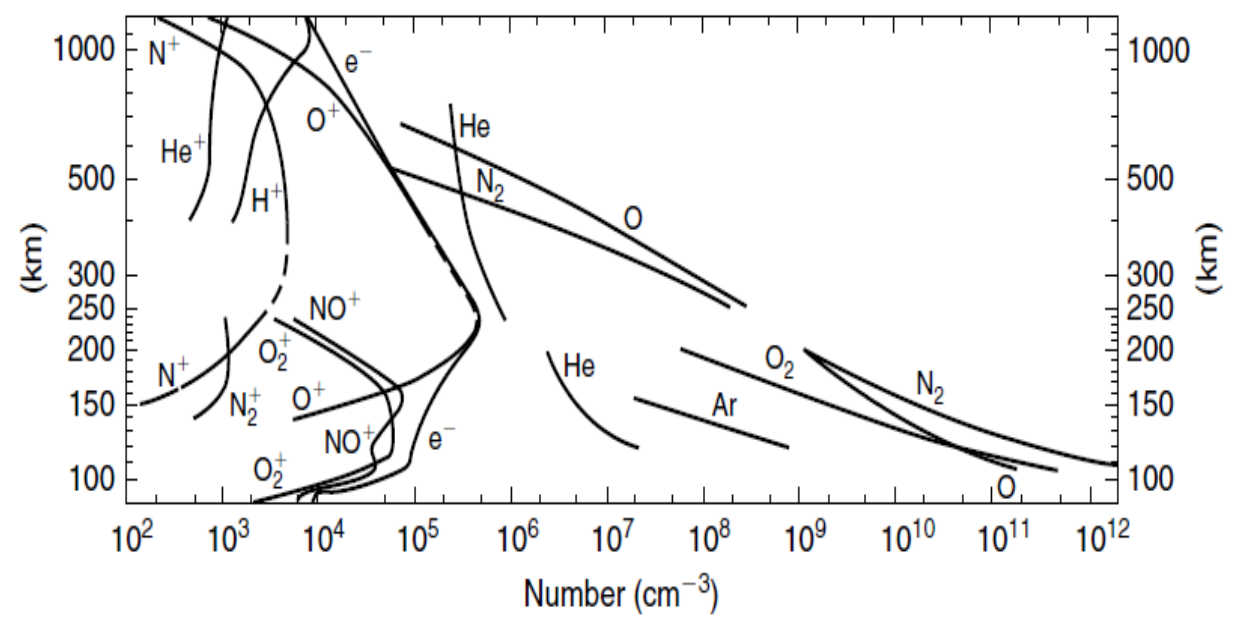

Figura 1.12. Composición química de la atmósfera terrestre (Kelly, 2009)

sobre ella, en la heterosfera, los elementos que componen el aire se separan por acción de la gravedad, y por encima de los 1700 km, donde el hidrógeno domina la composición, se encuentra la geocorona (Figura 1.10, segunda columna).

\subsection{La ionosfera}

Los átomos y moléculas neutros que constituyen la atmósfera de la Tierra son ionizados fundamentalmente por acción de la energía solar incidente. Debido a la baja presión, las especies ionizadas no necesariamente se recombinan rápidamente, resultando una población permanente de iones y electrones libres que da origen a la ionosfera.

La principal fuente de ionización es la radiación solar correspondiente a las regiones ultravioleta extrema y $\mathrm{X}$ del espectro, pero otros mecanismos descriptos 
en el presente capítulo, como la incidencia de partículas energéticas y la interacción del viento solar con el campo magnético terrestre, contribuyen a la formación de iones en la atmósfera superior de la Tierra.

En la ionosfera los iones y electrones constituyen un medio conocido como plasma. En este medio las partículas con cargas positiva y negativa se encuentran mezcladas en cantidades iguales, de forma tal que el material dentro de un dado volumen permanece eléctricamente neutro; las partículas con carga representan una fracción pequeña del gas que compone la atmósfera.

Si bien no es posible establecer límites definidos para la ionosfera debido a que la región se encuentra sujeta a fluctuaciones permanentes, se acepta que se extiende entre los $50 \mathrm{~km}$ y los $1000 \mathrm{~km}$ de altura. A alturas inferiores a los $50 \mathrm{~km}$ la radiación capaz de ionizar las moléculas neutras ha sido completamente absorbida en las capas externas de la atmósfera y sobre los $1000 \mathrm{~km}$ el gas es tenue y se halla completamente ionizado.

\subsubsection{Interacción de la radiación solar con atmósfera superior de la Tierra}

Dado que la radiación proveniente del Sol constituye la principal fuente para la formación de iones en la atmósfera, especialmente en las latitudes medias y bajas de la Tierra, esta sección está referida a los procesos de interacción entre la radiación y los átomos y moléculas que componen la atmósfera.

\subsection{1.a. Producción de iones. Función de Chapman}

La energía solar es absorbida en la atmósfera de la Tierra fundamentalmente a través de tres procesos: la fotodisociación, la fotoionización y la combinación de ellas o fotoionización disociativa. Entendiendo a las interacciones como colisiones entre los fotones solares y las partículas que componen la atmósfera terrestre, es posible escribir formalmente los procesos mencionados de la siguiente forma (Prölss, 2004):

- Fotodisociación $(\lambda \leq 242 \mathrm{~nm})$

$$
\mathrm{O}_{2}+v(\lambda \leq 242 \mathrm{~nm}) \rightarrow 0+0
$$


- Fotoionización $(\lambda \leq 103 \mathrm{~nm})$

$$
\begin{aligned}
& \mathrm{O}+\mathrm{v}(\lambda \leq 91 \mathrm{~nm}) \rightarrow \mathrm{O}^{+}+\mathrm{e} \\
& \mathrm{N}_{2}+\mathrm{v}(\lambda \leq 80 \mathrm{~nm}) \rightarrow \mathrm{N}_{2}^{+}+\mathrm{e} \\
& \mathrm{O}_{2}+\mathrm{v}(\lambda \leq 103 \mathrm{~nm}) \rightarrow \mathrm{O}_{2}^{+}+\mathrm{e}
\end{aligned}
$$

- Fotoionización disociativa $(\lambda \leq 72 \mathrm{~nm})$

$$
\mathrm{N}_{2}+\mathrm{v}(\lambda \leq 49 \mathrm{~nm}) \rightarrow \mathrm{N}^{+}+\mathrm{N}+\mathrm{e}
$$

A través de estos procesos, la radiación solar, especialmente correspondiente a las regiones ultravioleta, ultravioleta extremo y $X$ del espectro solar $(\lambda \leq 103 \mathrm{~nm})$, modifica sustancialmente las propiedades de la atmósfera superior. La fotoionización es el proceso clave que da como resultado la formación de iones positivos y electrones libres, transformado a la atmósfera en el medio conductor que llamamos ionosfera.

La producción de iones en la atmósfera depende de la intensidad de la radiación ionizante. Durante el día varía con el ángulo de elevación del Sol y decae durante la noche. Por otro lado, la intensidad de la radiación disminuye a medida que atraviesa la atmósfera, ya que es absorbida en el proceso de fotoionización. A su vez, las diferentes especies susceptibles de ser ionizadas se encuentran estratificadas por acción de la gravedad (Figura 1.12). Un modelo que, dentro de sus supuestos, explica las principales características de la ionosfera es la ley de producción de Chapman (Hargreaves, 1995).

La función de producción de electrones de Chapman es un modelo físico muy simple que relaciona la distribución de electrones en la atmósfera con la posición del Sol. En el contexto del presente trabajo, este modelo permitirá definir las variables que se utilizan en el tratamiento de la ionosfera y luego contribuirá a dar sustento al modelo ionosférico de La Plata.

En el modelo de Chapman se considera que:

a) la atmósfera está compuesta por una única especie, distribuida exponencialmente con altura de escala constante,

b) la atmósfera está estratificada horizontalmente,

c) la radiación solar es absorbida de forma proporcional a la densidad de partículas en el gas, y 
c) el coeficiente de absorción es constante; esto es equivalente a suponer que la radiación incidente es monocromática.

Figura 1.13: Geometría del modelo de Chapman

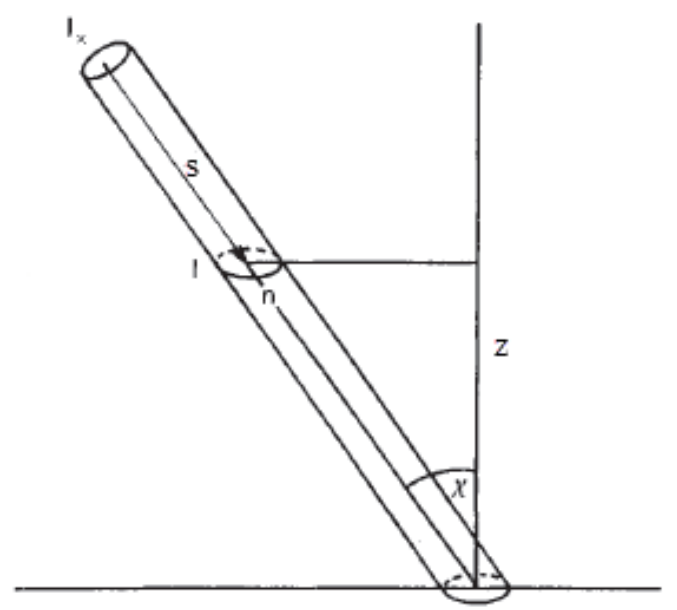

Sea I $(\mathrm{z})\left[\mathrm{J} / \mathrm{m}^{2} \mathrm{~s}\right]$ la intensidad de la radiación solar ionizante en algún punto $\mathrm{P}$ ubicado a una altura $\mathrm{z}$ en la atmósfera de la Tierra. Si n(z) [partículas $/ \mathrm{m}^{3}$ ] es la densidad de partículas ionizables, es decir la cantidad de átomos o moléculas neutras por unidad de volumen capaces de ser ionizadas por esa radiación, y $\sigma$ $\left[\mathrm{m}^{2}\right]$ es la sección eficaz de absorción de las partículas para la misma radiación, entonces la velocidad de producción de iones en el punto P ubicado a una altura $\mathrm{z}$ es:

$$
\mathrm{q}(\mathrm{z})=\eta \sigma \mathrm{n}(\mathrm{z}) \mathrm{I}(\mathrm{z})
$$

donde $\eta$ es la eficiencia de ionización que representa la fracción de la radiación absorbida utilizada para producir la ionización.

Cuando la radiación atraviesa un elemento ds, una fracción $\operatorname{dI}(\mathrm{z})=\mathrm{q}(\mathrm{z}) \mathrm{ds}$ es absorbida, de modo que el proceso de absorción de energía por ionización queda descripto por la siguiente ecuación diferencial:

$$
\frac{\mathrm{dI}(\mathrm{z})}{\mathrm{ds}}=-\eta \sigma \mathrm{n}(\mathrm{z}) \mathrm{I}(\mathrm{z})
$$

Teniendo en cuenta que ds $=-\sec (\chi) \mathrm{dz}$, donde $\chi$ representa el ángulo que forma la dirección del Sol con la vertical, es decir la distancia cenital solar, la ecuación anterior resulta

$$
\frac{\mathrm{dI}(\mathrm{z})}{\mathrm{I}(\mathrm{z})}=\eta \sigma \mathrm{n}(\mathrm{z}) \sec (\mathrm{X}) \mathrm{dz}
$$

E integrada da: 


$$
\mathrm{I}(\mathrm{z})=\mathrm{I}_{\infty} \mathrm{e}^{-\sec (\chi) \eta \sigma \int_{\mathrm{z}}^{\infty} \mathrm{n}(\mathrm{z}) \mathrm{dz}}
$$

donde $\mathrm{I}(\mathrm{z})$ representa la intensidad de radiación en el punto $\mathrm{P}$ teniendo en cuenta la cantidad de radiación que ha sido consumida en la ionización de las capas superiores. Sería posible determinar I(z) a partir de la variación de la densidad de moléculas con respecto a la altura. Suponiendo una atmósfera isoterma, la densidad $\mathrm{n}(\mathrm{z})$ responde a la ley barométrica

$$
n(z)=n_{0} e^{-\left(\frac{z}{H}\right)}
$$

donde $\mathrm{H}$ es una constante llamada altura de escala $\mathrm{y} \mathrm{n}_{0}$ es la densidad de partículas en la superficie de la Tierra $(z=0)$.

Reemplazando la ley barométrica en la ecuación para I(z) e integrando obtenemos

$$
\mathrm{I}(\mathrm{z})=\mathrm{I}_{\infty} \mathrm{e}^{-\sec (\chi) \eta \sigma \mathrm{n}_{0} \mathrm{H} \mathrm{e}^{-\left(\frac{\mathrm{z}}{\mathrm{H}}\right)} .}
$$

Finalmente, es posible obtener el ritmo de producción de iones en el punto $\mathrm{P}$ reemplazando I(z) en la ecuación 1.1:

$$
\mathrm{q}(\mathrm{z})=\eta \sigma \mathrm{n}_{0} \mathrm{I}_{\infty} \mathrm{e}^{-\left(\frac{\mathrm{z}}{\mathrm{H}}\right)} \mathrm{e}^{-\sec (\chi) \mathrm{n}_{0} \eta \sigma \mathrm{H} \mathrm{e}^{-\left(\frac{\mathrm{z}}{\mathrm{H}}\right)}}
$$

La ecuación anterior muestra que el ritmo de producción de electrones es el producto de dos funciones que varían con la altura: por un lado la densidad de partículas ionizables $\mathrm{n}(\mathrm{z})$ que decrece fuertemente cuando z aumenta, y por otro la intensidad de radiación I(z) que disminuye a medida que la radiación atraviesa la atmósfera. Del producto de ambas resulta una función con un marcado máximo ubicado a una altura $\mathrm{z}_{\mathrm{m}}$ que se obtiene igualando a cero la derivada de la función q(z) y es:

$$
\mathrm{z}_{\mathrm{m}}=\mathrm{H} \ln \left(\sec (\chi) \mathrm{n}_{0} \eta \sigma \mathrm{H}\right) .
$$

La altura a la cual está localizado el máximo depende del ángulo de incidencia de la radiación solar.

Sea $\mathrm{z}_{\mathrm{m} 0}$ la altura del máximo en la dirección del Sol, entonces

$$
\mathrm{z}_{\mathrm{m} 0}=\mathrm{H} \ln \left(\mathrm{n}_{0} \eta \sigma \mathrm{H}\right)
$$

Despejando $\mathrm{n}_{0} \eta \sigma \mathrm{H}=\mathrm{e}^{\left(\frac{\mathrm{z}_{\mathrm{m} 0}}{\mathrm{H}}\right)}$ y reemplazando en la última expresión para I(z) resulta

$$
\mathrm{I}(\mathrm{z})=\mathrm{I}_{\infty} \mathrm{e}^{-\sec \chi} \mathrm{e}^{-\left(\frac{\mathrm{z}-\mathrm{z}_{\mathrm{m} 0}}{\mathrm{H}}\right)} .
$$


Evaluando I(z) en $\mathrm{z}=\mathrm{z}_{\mathrm{m} 0}, \operatorname{con} \chi=0$, es posible calcular $\mathrm{I}_{\infty}$ :

$$
\mathrm{I}_{\infty}=\mathrm{I}\left(\mathrm{z}_{\mathrm{m} 0}\right) .
$$

De la misma forma, podemos calcular $\mathrm{n}_{0}$ evaluando $\mathrm{n}(\mathrm{z})$ en $\mathrm{z}_{\mathrm{m} 0}$ y resulta

$$
\mathrm{n}_{0}=\mathrm{n}\left(\mathrm{z}_{\mathrm{m} 0}\right) \mathrm{e}^{\left(\frac{\mathrm{z}_{\mathrm{mo}}}{\mathrm{H}}\right)}
$$

Finalmente, reemplazando $\mathrm{I}_{\infty}$ y $\mathrm{n}_{0}$ en la ecuación para $\mathrm{q}(\mathrm{z})$ obtenemos la expresión para el ritmo de producción de iones conocida como ley de producción de Chapman:

$$
\mathrm{q}(\mathrm{Z})=\mathrm{q}_{0} \mathrm{e}^{\left(1-\mathrm{Z}-\sec (x) \mathrm{e}^{-\mathrm{Z}}\right)},
$$

donde $\mathrm{Z}=\frac{\mathrm{z}-\mathrm{z}_{\mathrm{m} 0}}{\mathrm{H}}$ es la altura reducida $\mathrm{y} \mathrm{q}_{0}=\mathrm{q}\left(\mathrm{z}_{\mathrm{m} 0}\right)=\eta \sigma \mathrm{n}\left(\mathrm{z}_{\mathrm{m} 0}\right) \mathrm{q}\left(\mathrm{z}_{\mathrm{m} 0}\right)$.

La densidad de moléculas ionizables y la radiación ionizante a diferentes alturas de la atmósfera originan una capa a una altura $\mathrm{z}_{\mathrm{m}}$ donde la concentración de electrones alcanza su máximo.

\subsection{1.b. Pérdida de iones. Chapman a y Chapman $\beta$}

Una vez que los iones se producen, existen principalmente tres mecanismos a través de los cuales los electrones pueden desaparecer luego de cierto tiempo:

- Recombinación radiativa: un electrón se combina con un ion atómico

$$
\mathrm{O}^{+}+\mathrm{e} \rightarrow \mathrm{O}+\mathrm{v}(\lambda \leq 242 \mathrm{~nm})
$$

- Recombinación disociativa: un electrón se combina con un ion molecular

$$
\begin{aligned}
& \mathrm{O}_{2}^{+}+\mathrm{e} \rightarrow \mathrm{O}+\mathrm{O} \\
& \mathrm{N}_{2}^{+}+\mathrm{e} \rightarrow \mathrm{N}+\mathrm{N} \\
& \mathrm{NO}^{+}+\mathrm{e} \rightarrow \mathrm{N}+\mathrm{O}
\end{aligned}
$$

- Asociación: un electrón se asocia a una partícula neutra y produce un ion negativo 


$$
\mathrm{O}_{2}+\mathrm{e} \rightarrow \mathrm{O}_{2}^{-}
$$

El proceso de asociación ocurre únicamente en la región inferior de la ionosfera, donde las partículas neutras son abundantes. La recombinación es el proceso inverso de la fotoionización y juega el papel más importante en la desaparición de electrones. A su vez, la recombinación radiativa es un proceso más lento que la recombinación disociativa, de modo tal que la mayoría de los electrones se recombinan con iones positivos moleculares.

Para modelar la pérdida de electrones mediante el proceso de recombinación, suponemos que el ritmo de recombinación es proporcional a la densidad de electrones libres $n_{e}$ y de iones positivos $n^{+}$(Chapman alfa):

$$
\mathrm{L}(\mathrm{z})=\frac{\mathrm{dn}_{\mathrm{e}}(\mathrm{z})}{\mathrm{dt}}=-\alpha \mathrm{n}_{\mathrm{e}}(\mathrm{z}) \mathrm{n}^{+}(\mathrm{z})
$$

donde $\alpha\left[\mathrm{m}^{3} / \mathrm{s}\right]$ es el coeficiente de recombinación, el cual varía débilmente con la altura a través de su dependencia con la temperatura (Pröls, 2004). Despreciando el efecto de la asociación, la densidad de electrones libres es igual a la densidad de iones positivos, luego, la velocidad de desaparición de iones tiene una dependencia cuadrática con la densidad de electrones:

$$
\frac{\mathrm{dn}_{\mathrm{e}}(\mathrm{z})}{\mathrm{dt}}=-\alpha \mathrm{n}_{\mathrm{e}}^{2}(\mathrm{z})
$$

En ausencia de radiación solar, no se generan nuevos electrones. Integrando la ecuación anterior obtenemos la ley de decrecimiento de electrones con la altura:

$$
\mathrm{n}_{\mathrm{e}}(\mathrm{z})=\frac{\mathrm{n}_{\mathrm{e} 0}(\mathrm{z})}{1+\alpha \mathrm{n}_{\mathrm{e} 0}(\mathrm{z}) \mathrm{t}}
$$

donde $\mathrm{n}_{\mathrm{e} 0}(\mathrm{z})$ representa la densidad de electrones libres en $\mathrm{t}=0$.

El otro proceso que consume electrones libres es la asociación con un átomo neutro de oxígeno para formar un ion negativo. La velocidad de asociación, a una determinada altura, es proporcional a la densidad de átomos neutros de oxígeno $\mathrm{n}_{\mathrm{O}}(\mathrm{z})$ y a la densidad de electrones libres $\mathrm{n}_{\mathrm{e}}(\mathrm{z})$ (Chapman beta):

$$
\frac{\mathrm{dn}_{\mathrm{e}}(\mathrm{z})}{\mathrm{dt}}=-\beta \mathrm{n}_{\mathrm{e}}(\mathrm{z}) \mathrm{n}_{\mathrm{O}}(\mathrm{z})
$$

donde $\beta$ es el coeficiente de asociación. 


\subsection{1.c. Perfil vertical de densidad electrónica}

La variación en el tiempo de la cantidad de electrones en un volumen unitario de la ionosfera depende de la cantidad de electrones que se produzcan y desaparezcan dentro del volumen (por unidad de tiempo) por distintos procesos y de los que ingresen y/o salgan de él debido a diferentes mecanismos de transporte. La ecuación que describe el cambio es la ecuación de continuidad:

$$
\frac{\partial \mathrm{n}_{\mathrm{i}}}{\partial \mathrm{t}}=\mathrm{q}_{\mathrm{i}}-\mathrm{L}_{\mathrm{i}}-\nabla\left(\mathrm{n}_{\mathrm{i}} \mathbf{v}_{\mathrm{i}}\right)
$$

donde $\mathrm{n}_{\mathrm{i}}$ es la concentración de iones de determinada especie, $\mathrm{q}_{\mathrm{i}}$ y $\mathrm{L}_{\mathrm{i}}$ son los ritmos de creación y de desaparición de iones (por unidad de volumen y tiempo), $\mathbf{v}_{\mathbf{i}}$ es la velocidad de transporte de la i-sima especie y el término $\boldsymbol{\nabla}\left(\mathrm{n}_{\mathbf{i}} \mathbf{v}_{\mathbf{i}}\right)$ expresa la ganancia o pérdida en la concentración de iones por movimiento. La densidad de electrones es $n_{\mathrm{e}}=\sum \mathrm{n}_{\mathrm{i}}$.

Teniendo en cuenta como únicas fuentes de producción y pérdida de electrones a la fotoionización (ecuación 1.2) y recombinación disociativa (ecuación 1.3), bajo las hipótesis del modelo de Chapman y despreciando el término de transporte, la variación en el tiempo de la densidad de electrones puede escribirse como

$$
\frac{\partial \mathrm{n}_{\mathrm{e}}}{\partial \mathrm{t}}=\mathrm{q}-\mathrm{L}
$$

Si el ritmo de ionización es igual al de recombinación, o sea que se verifica la condición de equilibrio fotoquímico, $\mathrm{q}=\mathrm{L}$ y $\frac{\partial \mathrm{n}_{\mathrm{e}}}{\partial \mathrm{t}}=0$, entonces es posible obtener un perfil vertical idealizado de la densidad electrónica conocido como capa alfa de Chapman igualando las ecuaciones 1.2 y 1.3 :

$$
\mathrm{q}_{0} \mathrm{e}^{\left(1-\mathrm{z}-\sec (x) \mathrm{e}^{-\mathrm{z}}\right)}=-\alpha \mathrm{n}_{\mathrm{e}}^{2}
$$

Despejando $\mathrm{n}_{\mathrm{e}}(\mathrm{z})$ obtenemos

$$
\mathrm{n}_{\mathrm{e}}(\mathrm{Z})=\sqrt{\frac{\mathrm{q}_{0}}{\alpha}} \mathrm{e}^{\frac{1}{2}\left(1-\mathrm{Z}-\sec (\mathrm{X}) \mathrm{e}^{-\mathrm{z}}\right)}
$$

donde $\mathrm{Z}=\frac{\mathrm{z}-\mathrm{z}_{\mathrm{m} 0}}{\mathrm{H}}$ es la altura reducida $y \chi$ representa la distancia cenital solar. 


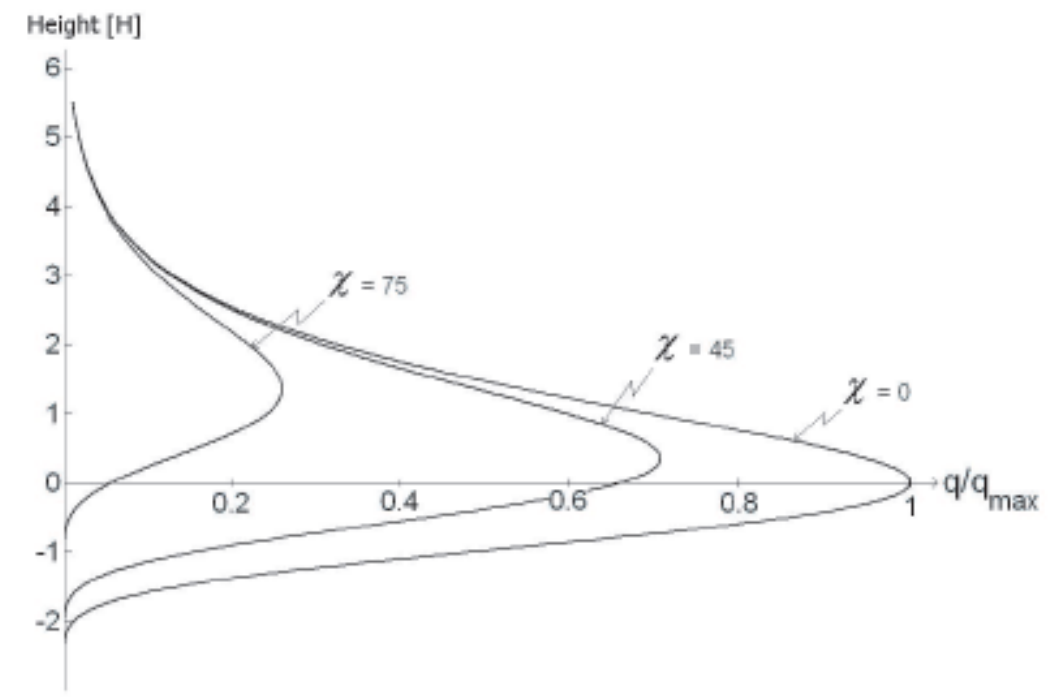

Figura 1.14. Modelo de Chapman. Perfil de densidad electrónica (Memarzadeh, 2009)

La forma típica del perfil de densidad electrónica resultante se ilustra en la Figura 1.14. Para un dado ángulo cenital, la densidad electrónica presenta un pico marcado ubicado a una altura superior a los $200 \mathrm{~km}$. Es decir que la mayor cantidad de electrones se encuentra concentrada en una capa delgada. El modelo ionosférico de La Plata tiene en cuenta esta característica y aproxima la ionosfera a una capa esférica de espesor infinitesimal situada entre 350 y $450 \mathrm{~km}$ por encima de la superficie de la Tierra.

El modelo de Chapman reproduce las principales características de la ionosfera, como son la dependencia de la densidad electrónica con el ángulo cenital solar y con la altura en la atmósfera, considerando a la radiación solar como única fuente de producción de iones y electrones. Una de las hipótesis del modelo es que a una altura z en la atmósfera hay una única especie ionizable. En realidad, varias especies contribuyen a la ionización en cada punto, pero en la mayoría de los casos el proceso está controlado por una de ellas. De esta forma, la teoría de Chapman, a partir de sus hipótesis simples, constituye un punto de partida invalorable para la interpretación de las características observadas en la ionosfera de la Tierra.

\subsubsection{Estratificación de la ionosfera}

Como se ha mencionado, por encima de los $100 \mathrm{~km}$ la composición de la atmósfera de la Tierra depende de la altura. Hasta los $170 \mathrm{~km}$ de altura, los 
componentes predominantes son el $\mathrm{N}_{2}$ y el O2. Más allá de los $170 \mathrm{~km}$, por efecto de la fotodisociación de $\mathrm{O}_{2}$, el elemento dominante es el $\mathrm{O}$ atómico. Los elementos más livianos como el He y el H son importantes a grandes alturas. Los ritmos de producción de iones y de recombinación están fuertemente relacionados con la composición del gas neutro y la densidad favorece las reacciones. En consecuencia, la distribución vertical de electrones en la atmósfera está caracterizada por una sucesión de picos asociados a la distribución vertical de elementos en la atmósfera neutra. Estos máximos en la densidad electrónica han dado origen a 3 regiones ionosféricas identificadas con las letras D, E y F (tercera columna de la Figura 1.10). La composición del aire a alturas superiores a los $1000 \mathrm{~km}$ está dominada por la presencia de protones, razón por la cual la capa externa de la atmósfera de la Tierra, completamente ionizada, se conoce como la protonosfera o plasmasfera.

Región D:

Se ubica entre los 60 y 95 km y no incluye un máximo definido en la distribución de electrones. Esta característica se explica si se tienen en cuenta dos factores: por un lado, debido a la alta presión, tanto las especies abundantes como minoritarias son importantes en las reacciones fotoquímicas; por otro, en esta región contribuyen significativamente a la producción de iones varias fuentes, como la línea Lyman-a del espectro solar, radiación UVE y X fuerte, rayos cósmicos de origen galáctico y, especialmente a altas latitudes, partículas energéticas solares (Hargreaves, 1995).

Región E:

La región está comprendida entre los 95 y $170 \mathrm{~km}$ de altitud, con un pico definido en la densidad electrónica ubicado entre los 105 y $110 \mathrm{~km}$. Los electrones se originan en la fotoionización del oxígeno molecular por la radiación UVE. El principal mecanismo de pérdida de electrones es la recombinación disociativa, de modo que es posible aproximar a la región E como una capa Chapman-alfa. Dos características que la apartan del modelo son el hecho de que la ionización no desaparece completamente durante la noche, lo que indica la existencia de alguna otra fuente de producción de iones, y la aparición de un pico ocasional en la densidad de electrones en la base de la región, en el hemisferio no iluminado por el Sol, conocido como capa esporádica Es. La capa Es es muy delgada, tiene un espesor de aproximadamente $1 \mathrm{~km}$. En latitudes medias es atribuida a la redistribución en la altura de la densidad de electrones por acción del viento que trasporta el material neutro y con él el plasma ionizado, dentro del campo geomagnético. A altas latitudes, la capa esporádica es el resultado de la ionización adicional que producen las partículas energéticas (electrones 
asociados con las auroras y protones más algunas partículas alfa, emitidas por el sol durante los flares).

Figura 1.15. Perfil típico de densidad electrónica durante el día en latitudes medias (Memarzadeh, 2009).

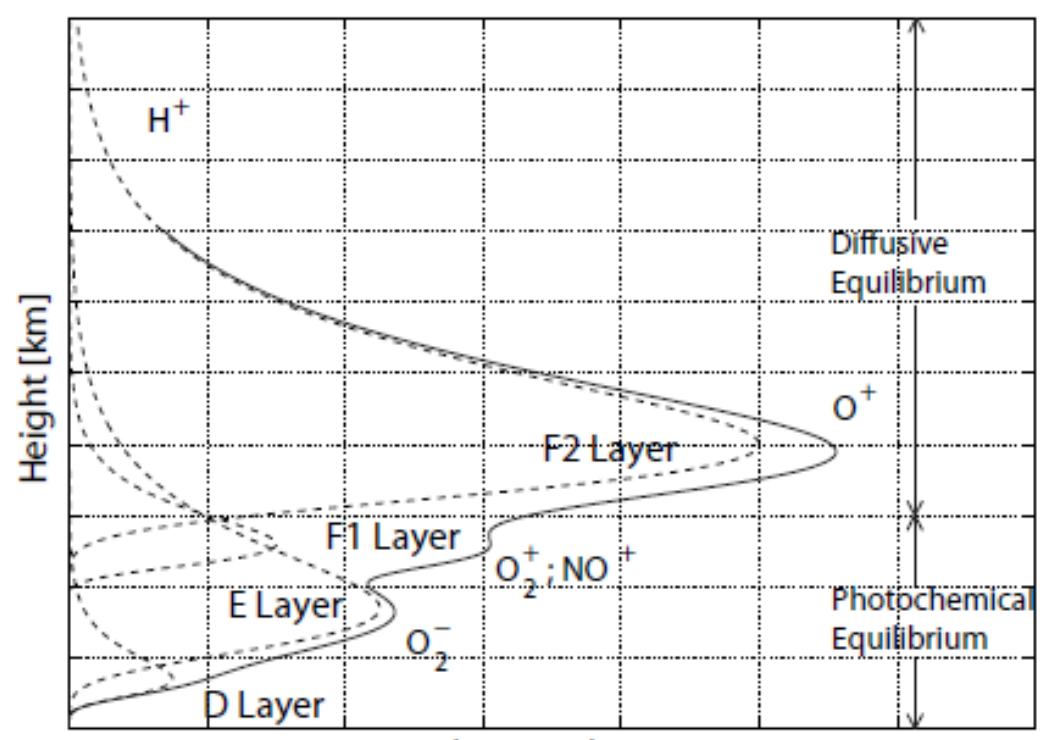

Electron density

\section{Región F:}

Comprendida entre los 170 y 1000 km de altura, proviene de la alta concentración de oxígeno atómico en esa altitud. Se halla dividida en dos capas: F1 y F2 (Figura 1.15).

En la región $\mathrm{Fl}$ los iones son originados por fotoionización. El ión más abundante es el $\mathrm{O}^{+}$, seguido de $\mathrm{N}_{2}^{+}$. En esta región tiene lugar un proceso de recombinación disociativa indirecta, ya que el ion de oxígeno atómico primero se convierte en ion molecular y éste pierde su carga por recombinación disociativa. Debido a la relativamente alta densidad de moléculas neutras de oxígeno y nitrógeno, el ritmo de recombinación es proporcional al cuadrado de la densidad electrónica, es decir que el perfil vertical de densidad electrónica de la capa Fl puede explicarse de forma razonable por medio del modelo de Chapman.

La región F2 se ubica entre los 200 y 600 km y está dominada por el ion oxígeno atómico $\mathrm{O}^{+}$. En esta región se encuentra la mayor concentración de electrones de la ionosfera, típicamente del orden de $10^{6}$ electrones por $\mathrm{cm}^{3}$. La densidad de partículas neutras continúa siendo dos órdenes de magnitud más grande que la de densidad de iones, pero debido a que la proporción es menor que en la capa Fl, la vida media de las partículas cargadas se incrementa. Por este motivo, en la capa F2 no se pueden despreciar los procesos de transporte. 


\subsubsection{Interacción de partículas cargadas y campo magnético terrestre}

El último término de la ecuación de continuidad (ecuación 1.4) tiene en cuenta el cambio en la densidad de iones y electrones en un determinado volumen debido al movimiento del plasma como un todo. En este transporte, el campo magnético terrestre juega un rol fundamental.

El movimiento de una partícula cargada en un campo electromagnético está descripto por la fuerza de Lorentz $\mathbf{F}=\mathrm{q}(\mathbf{v} \times \mathbf{B}+\mathbf{E})$.

Brevemente, en presencia de un campo magnético uniforme el movimiento de iones y electrones puede ser muy diferente. En ausencia de un campo eléctrico externo E, la componente de la velocidad de la partícula paralela al campo B se mantiene constante, mientras que sufre una aceleración que obliga a la partícula a describir un movimiento helicoidal alrededor de las líneas de $\mathbf{B}$; el movimiento para cargas positivas es opuesto al de las cargas negativas.

Si existe además un campo eléctrico externo, con una componente paralela a $\mathbf{B}$ no nula, tanto electrones como iones sufren una deriva (drift), independiente de la carga, en dirección perpendicular tanto a $\mathbf{B}$ como a E. La velocidad del difft es

$$
\mathbf{v}_{\mathbf{d}}=\frac{\mathbf{E}^{\perp} \times \mathbf{B}}{\mathrm{B}^{2}}
$$

Por otro lado, la fuerza gravitacional de la Tierra provoca un movimiento descendente de los iones y electrones en el plasma ionsoférico, a la vez que la fuerza debida al gradiente de presión induce un movimiento ascendente. Pero las partículas cargadas sólo pueden moverse a lo largo de las líneas de campo magnético. La velocidad que adquieren iones y electrones a lo largo de las líneas se conoce como velocidad de difusión y es proporcional al seno del ángulo de inclinación magnética I (ángulo que forma el vector campo magnético con el plano horizontal), o sea que será nula en el ecuador geomagnético donde $\mathrm{I}=0^{\circ}$ y máxima en los polos geomagnéticos (donde $\mathrm{I}=90^{\circ}$ ). Lo contrario sucede con el viento neutro o termosférico. Este se origina en la diferencia de temperatura que existe en la parte superior de la ionosfera entre la parte iluminada por el sol y la parte oscura. La diferencia de presión deriva en un viento horizontal desde la parte diurna hacia la parte nocturna. La velocidad $\mathrm{V}$ de este viento neutro se obtiene de la ecuación de movimiento, teniendo en cuenta además del gradiente de presión horizontal, la inercia y viscosidad del aire, la gravedad, las aceleraciones centrípetas y de Coriolis y el arrastre de los iones. La velocidad del plasma a lo largo de las líneas resulta proporcional a V cos I. Con frecuencia, en horas nocturnas en latitudes medias el viento horizontal tiene dirección hacia el ecuador; como consecuencia el plasma se eleva y tiende a incrementar la 
densidad de iones a mayores altitudes en la ionosfera; si el viento es hacia los polos, el plasma desciende y tiende a reducir la densidad en la parte alta de la ionosfera.

Figura 1.16. Sistema idealizado de corrientes en la ionosfera inducido por el calentamiento solar (Memarzdeh, 2009)

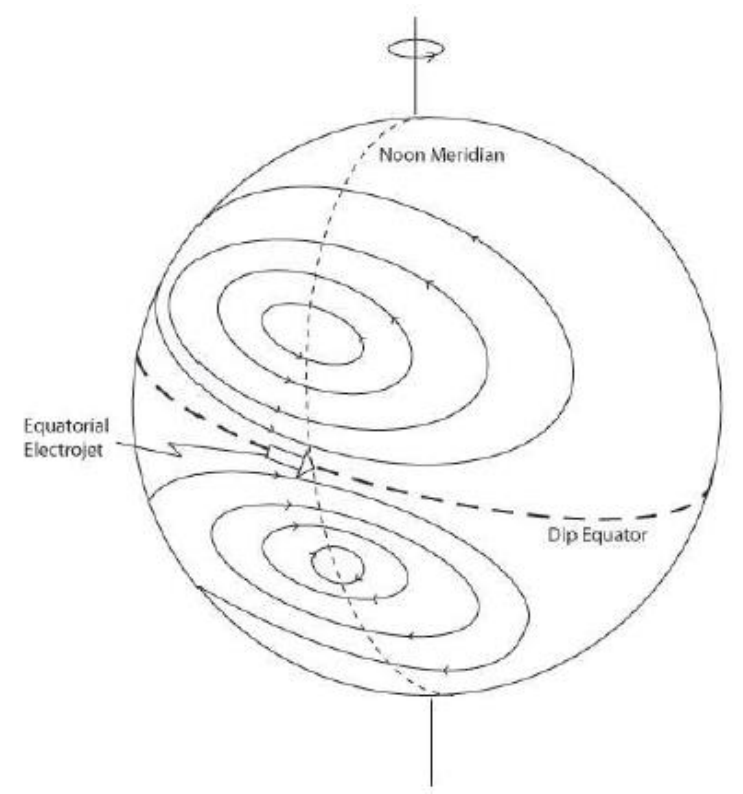

Tanto el viento termosférico como la atracción de la luna que genera una marea en la atmósfera provocan el movimiento del plasma a través de las líneas de campo magnético.

Este movimiento genera un campo eléctrico y en consecuencia un sistema de corrientes eléctricas, especialmente en la capa $\mathrm{E}$ donde la conductividad alcanza su valor máximo (Figura 1.16). En el ecuador geomagnético, donde las líneas de campo magnético son horizontales, se produce una intensa hoja de corriente conocida como electrojet ecuatorial que fluye a lo largo del ecuador magnético hacia el este durante el día y hacia el oeste por las noches (cuando la intensidad es menor debido a la menor concentración de electrones). La presencia de un campo eléctrico $\mathbf{E}$ dirigido hacia el este provoca un drift ascendente de las partículas cargadas a altitudes de la capa F. La velocidad del dirft es independiente de la carga; iones y electrones se mueven juntos en dirección perpendicular a $\mathbf{E}$ y a $\mathbf{B}$; se conoce como drift electromagnético $\mathbf{E} \times \mathbf{B}$ y su velocidad es $v_{d}=\frac{E}{B} \cos I$. 


\subsubsection{Variabilidad espacial y temporal de la ionosfera}

La dependencia de la densidad electrónica con la altura fue explicada en la sección 1.4.2.

La dependencia con la latitud geomagnética es fuerte, de forma que pueden distinguirse 3 regiones con características y propiedades diferentes:

Región ecuatorial: Se extiende hasta aproximadamente $20^{\circ}$ a cada lado del ecuador geomagnético; la densidad electrónica es variable y complicada de modelar como consecuencia del drift $\mathbf{E} \times \mathbf{B}$.

Región de latitudes medias: Comprendida entre los $20^{\circ}$ y $60^{\circ}$ de latitud geomagnética, es la región mejor entendida ya que los procesos de ionización están regidos solamente por la radiación solar. Los cambios diarios en las regiones E, F1 y F2 muestran variaciones regulares o levemente irregulares asociadas a cambios en la densidad de la atmósfera neutra y los vientos.

Región polar: A altas latitudes la ionosfera es considerablemente más compleja que en latitudes medias y bajas. El campo magnético es prácticamente vertical y las líneas de campo conectan con la parte exterior de la magnetosfera que está dominada por el viento solar.

Por otro lado, la configuración geométrica relativa entre el Sol y la Tierra es responsable de la variación de la radiación solar incidente y, en consecuencia, de las variaciones periódicas en el contenido electrónico más importantes: una diaria (Chapman, 1931) asociada a rotación de la Tierra y otra anual (Balan et al., 2000) asociada al ángulo de declinación del Sol.

Estas variaciones regulares son descriptas por el modelo de Chapman; los apartamientos de este comportamiento se consideran como anomalías. La región F2 por ser la más densa es la más variable; sus variaciones se conocen como anomalías clásicas de la región F2:

Anomía Ecuatorial o de Appleton: Es la característica más distintiva de la región F2 en latitudes bajas. Es la aparición de dos picos en la densidad electrónica, especialmente en horas del mediodía, localizados en la región ecuatorial a cada lado del ecuador dip entre las latitudes dip $\pm 16^{\circ}$ y $\pm 18^{\circ}$ (Appleton, 1946). Esta concentración de electrones es consecuencia de la aparición del campo eléctrico dirigido hacia el este descripta en la sección 1.4.2. El drif $\mathbf{E} \times \mathbf{B}$ ascendente, en combinación con la difusión a lo largo de las líneas de campo magnético debido a las fuerzas de gravedad y del gradiente de presión, origina una fuente de plasma desde la región ecuatorial hacia latitudes mayores. 
Anomalía diurna: De acuerdo con la teoría de Chapman la producción de iones debería ser máxima cuando el ángulo cenital del Sol alcanza su máximo valor, esto es al mediodía local. Sin embargo, en la atmósfera superior la temperatura alcanza su máximo alrededor de las 14:00 horas local y así el máximo en la producción de iones ocurre después del mediodía local.

Anomalías anuales y semi-anual: La teoría de Chapman predice que el valor del pico diario en la densidad electrónica debería ser mayor en verano que en invierno. Sin embargo, ocurre lo contrario (Appleton, 1938). Esto se conoce como anomalía de invierno. También es esperable que la densidad electrónica sea mayor durante el solsticio de diciembre que de enero considerando el cambio en la distancia Sol-Tierra; la diferencia se observa pero es mayor que la calculada, dando origen a la llamada asimetría anval (Mendillo, 2005). Además, se distingue una anomalía semi-anual que da mayores valores de la densidad electrónica en los equinoccios que en los solsticios (Li \& YU, 2003). El origen de estos fenómenos continúa siendo discutido en nuestros días (Azpilicueta et al., 2011, Azpilicueta \& Brunini, 2011).

Además de lo señalado, otra variación temporal medianamente regular en el contenido electrónico es la de aproximadamente 11 años asociada la actividad solar descripta en la sección 1.1 (Balan et al., 1994). En la Figura 1.17 es posible observar la fuerte correlación que existe entre el índice $\mathrm{F}_{10.7}$ (definido en la sección 1.1 e indicador de la actividad solar) y la frecuencia crítica foF2 (proporcional a la raíz cuadrada de la densidad electrónica de la capa F2, NmF2, medida por ionosondas, Galkin et al., 1999) para una latitud media en el período 1997-2009 (Park et al., 2010).

A las variaciones descriptas, que se producen con cierta regularidad, se suman otras completamente irregulares que involucran una variedad de escalas espaciales y temporales. Entre las más estudiadas figuran las perturbaciones solares, asociadas a los eventos conocidos como flares (sección 1.1). Como se mencinó, estas fulguraciones se caracterizan por un aumento repentino en la emisión de radiación en todo el espectro electromagnético, especialmente en rayos $\mathrm{X}$ y la banda ultravioleta extrema, la eyección de partículas energéticas aceleradas. Los fotones que llegan a la Tierra relacionados con estos eventos producen un aumento repentino en la ionosación de la ionosfera en la parte iluminada por el Sol (Hernández-Pajares et al., 2012) ; las partículas energéticas pueden penetrar a través de los casquetes polares y afectan fundamente la ionosfera en latitudes altas y medias (los electrones casi-relativistas pueden alcanzar la Tierra unos 10 minutos luego del arribo de los fotones, mientras que otras partículas llegan entre los 30 minutos y varias horas y aún varios días mas tarde). Las perturbaciones solares incluyen actividad geomagnética conocida como tormentas magnéticas.

I. Bibbó | La Tierra en el espacio. Origen y variabilidad de la lonosfera 


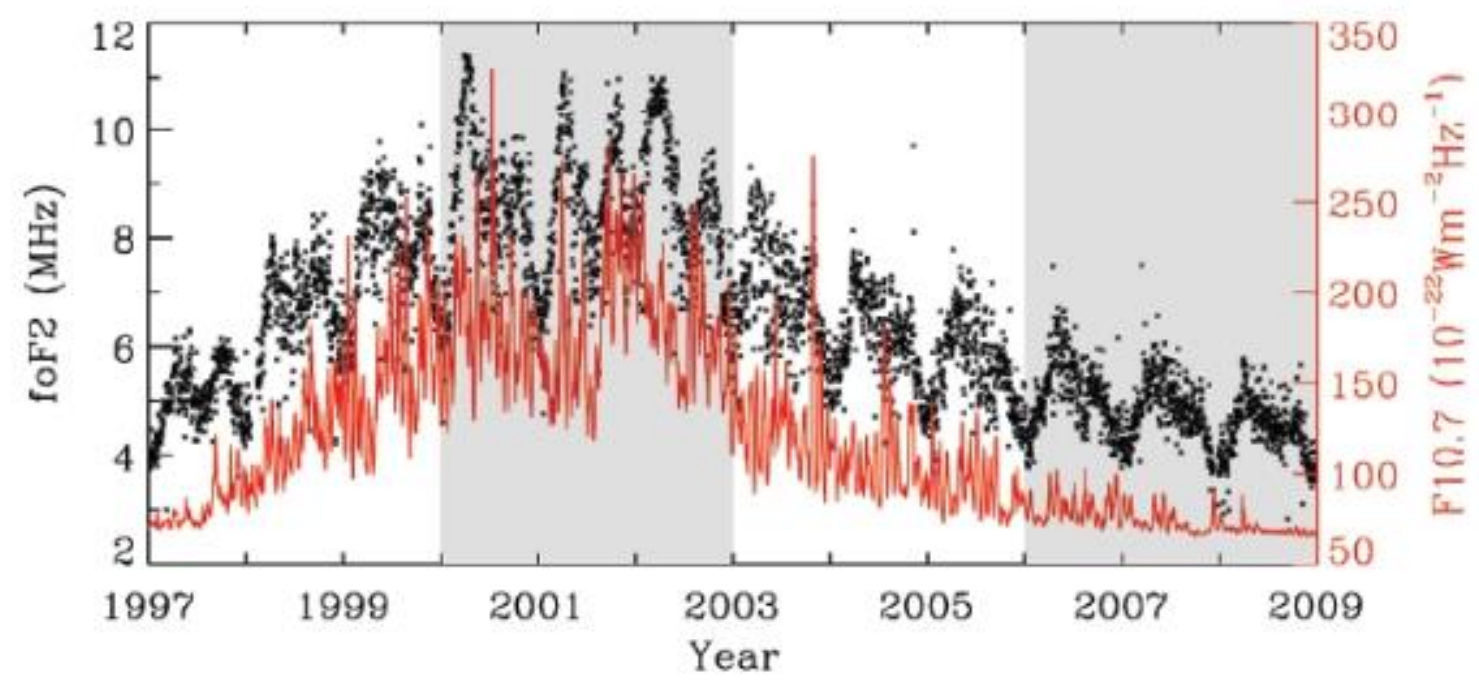

Figura 1.17. Relación entre el índice $F_{10.7}$ (en negro) y el promedio diario de foF $_{2}$ (en rojo) (Park et al., 2010).

Las tormentas magnéticas producen vientos termosféricos y generan corrientes eléctricas y cambios en la composición de la atmósfera superior, además de perturbaciones en la ionosfera conocidas como tormentas ionosféricas (Buonsanto, 1999). Las tormentas ionosféricas describen entonces las perturbaciones que aparecen en la ionosfera luego de las tormentas magnéticas.

Otro tipo de perturbaciones son las ondas atmosféricas de gravedad y las perturbaciones viajeras (Afraimovich et al., 2000). Las primeras involucran variaciones en la densidad electrónica, que abarcan desde una escala global hasta de decenas de kilómetros, y variaciones temporales de horas hasta minutos. Las perturbaciones producen fluctuaciones en la densidad electrónica, especialmente de la capa F2. En el extremo de la escala temporal, el centelleo es otra variación irregular de pocos segundos que se advierte en la ionosfera (Aarons et al., 1997).

\subsubsection{Modelos ionosféricos}

Los esfuerzos dirigidos a representar y predecir las características de la ionosfera descriptas en las secciones anteriores han conducido a la formulación de 
numerosos modelos. En términos generales, los modelos ionosféricos pueden agruparse en dos categorías: modelos teóricos o físicos y modelos empíricos.

Los modelos teóricos describen el comportamiento macroscópico de la ionosfera basados en la resolución de las ecuaciones de continuidad, momento, energía y flujo de calor para un fluido compuesto por iones atómicos y moleculares y electrones libres. El modelo de Chapman que representa la distribución de electrones en la atmósfera como función de la altura y la distancia cenital del Sol pertenece a esta categoría. El modelo físico más ambicioso es el SAMI (Huba et al., 2000).

Los modelos empíricos se basan en mediciones ionosféricas. Típicamente los datos se recogen durante largos períodos de tiempo y luego se ajustan funciones analíticas y empíricas (Bilitza, 2002).

El modelo empírico más difundido en la actualidad es el International Reference Ionosphere, IRI (Bilitza, 2001). IRI es un proyecto internacional (Committee on Space Research COSPAR e International Union of Radio Science URSI) que ha evolucionado a lo largo de los años. Utiliza los datos disponibles de distintas fuentes, como ionosondas distribuidas globalmente, los radares de dispersión incoherente de Jicamarca, Arecibo, Millstone Hill, Malvern, St. Santin, los ISIS y Alovette topside sounders, e instrumentos ubicados en satélites y cohetes. Provee, para cada instante y ubicación, en un rango de alturas comprendido entre los 50 y $2000 \mathrm{~km}$, la concentración de electrones, las temperaturas iónica y electrónica y la composición de iones. Otros ejemplos son los modelos NeQuick (Nava et al., 2008) y el Modelo Ionosférico La Plata LPIM, cuyas características serán descriptas en los capítulos siguientes.

La mayoría de los modelos operacionales combina dosis moderadas de teoría con altos grados de empirismo y la tendencia actual se orienta a adecuarlos para que puedan asimilar de manera consistente los datos proporcionados por las diferentes técnicas de observación (Wilson et al., 2005). Dentro de esa tendencia se inscribe, precisamente, la presente contribución. 


\section{Capítulo 2: GPS y altimetría satelital para estudios ionosféricos}

La exploración de la ionosfera comenzó con los experimentos llevados a cabo por dos grupos independientes, Briet y Tuve en USA y Appleton y Barnet en Inglaterra, en el año 1925. Estos investigadores mostraron que los pulsos de radiofrecuencia dirigidos verticalmente hacia la atmósfera eran reflejados por la capa conductora que hoy llamamos ionosfera, cuya existencia había sido propuesta 20 años antes por Heaviside y Kennelly para explicar la transmisión de ondas a través del Atlántico realizada por Marconi. Calculando el tiempo de retraso entre los pulsos trasmitido y reflejado y conocida la velocidad de propagación de la onda en el aire, fue posible determinar la altura de la capa.

El mismo principio, es decir el efecto de los electrones libres de la ionosfera en la propagación de las ondas de radio, es ampliamente utilizado en nuestros días para explorar la ionosfera. Instrumentos ubicados sobre la superficie de la Tierra como ionosondas y radares permiten deducir características ionosféricas a partir del análisis de pulsos reflejados en la capa. Las ionosondas reconstruyen el perfil de densidad electrónica por debajo del pico de la capa F2. En la actualidad se encuentran operativas más de 100 ionosondas distribuidas en los seis continentes. Los radares de dispersión incoherente permiten observar irregularidades en el plasma ionosférico, pero requieren la instalación de grandes y costosas antenas y por lo tanto tienen una distribución muy limitada. Por este motivo, el lanzamiento de los primeros satélites artificiales representó una nueva era para las investigaciones ionosféricas. Lanzados para diferentes usos (defensa, climatología, meteorología, información geográfica, etc.) los satélites orbitando el planeta constituyen un nuevo sistema de observación espacial de la ionosfera con cobertura global. Las señales que emiten los satélites y llegan a los receptores ubicados cerca de la superficie de la Tierra se ven afectadas por la atmósfera. Este efecto, indeseable en la mayoría de los casos, es la principal fuente de información para la investigación de la ionosfera.

En el presente capítulo se describen los efectos de la ionosfera sobre la propagación de las ondas electromagnéticas y se presenta al Sistema de Posicionamiento Global y a las misiones de altimetría satelital TOPEX/Poseidon y Jason como fuentes de datos para la investigación de la ionosfera. 


\subsection{Propagación de ondas electromagnéticas en la atmósferera}

Una onda electromagnética es una onda que se auto-propaga con sus campos eléctrico y magnético generados por la oscilación de partículas cargadas. Las ecuaciones que describen este fenómeno son las ecuaciones de Maxwell, cuya solución en el vacío para el campo eléctrico $\mathbf{E}$ (y para el campo magnético) es un frente de onda plana sinusoidal que se propaga con velocidad constante $\mathrm{c}=299792458.108 \mathrm{~m} \mathrm{~s}^{-1}$ y frecuencia $\omega$ (Feynman, 1964).

El frente de onda emitido por un punto es esférico y no plano; sin embargo, un frente de onda esférico localizado lejos del punto emisor puede ser considerado como un frente de onda plano. En este caso el campo eléctrico en un punto del espacio, en un instante t, puede describirse matemáticamente como

$$
\mathbf{E}(\mathbf{r}, \mathrm{t})=\mathrm{E}_{\mathrm{o}} \mathrm{e}^{\mathrm{i}\left(\omega t-\mathbf{k} \cdot \mathbf{r}+\phi_{\mathrm{E}}\right),}
$$

donde $\mathbf{r}$ es el vector que describe la posición del punto, $\mathbf{E}_{\mathbf{o}}$ es la amplitud de la onda, $\mathbf{k}=\omega / \mathrm{c}$ es el vector de onda (su módulo es el número de onda y su dirección y sentido son los de propagación) y $\phi_{\mathrm{E}}$ es una constante de fase. En el vacío los campos eléctrico y magnético son perpendiculares entre sí y al mismo tiempo son perpendiculares a la dirección de propagación de la onda.

Variando de forma controlada los parámetros de la onda, es posible transmitir información montada sobre ella. El proceso se llama modulación y la onda que lleva la información se llama portadora. La modulación de amplitud (AM) es utilizada para emisoras de largo alcance, la modulación de frecuencia (FM) para emisiones de radio de alta fidelidad, y la modulación de fase (PM) se usa para la transmisión de datos.

\subsection{1. Índice de refracción}

La velocidad de propagación de una onda que se transmite en el vacío es la velocidad de la luz en el vacío c. Pero cuando una onda se transmite un medio diferente del vacío, como es la atmósfera de la Tierra, la velocidad cambia debido a la interacción con las partículas presentes. El cociente entre la velocidad de propagación en el vacío c y la velocidad de propagación en un medio o velocidad de fase $\mathrm{v}$ es, por definición, el índice de refracción $\mathrm{n}$ del medio:

$$
\mathrm{n}=\frac{\mathrm{c}}{\mathrm{v}}
$$


Esta expresión es válida para ondas monocromáticas. Un grupo de ondas con diferentes frecuencias centradas en la frecuencia $\omega$ de la onda portadora se propaga con una velocidad llamada velocidad de grupo $\mathrm{v}_{\mathrm{g}}$ dada por:

$$
\mathrm{v}_{\mathrm{g}}=\frac{\mathrm{d} \omega}{\mathrm{dk}}
$$

El índice de refracción para el grupo será

$$
n_{g}=\frac{c}{v_{g}}=c \frac{d k}{d \omega}=c \frac{d}{d \omega}\left(n-\frac{v}{c} k\right)=\frac{d}{d \omega}(n \omega)=n+\omega \frac{d n}{d \omega}
$$

Para analizar la interacción de las señales satelitales con las partículas que componen la atmósfera de la Tierra es conveniente separar los efectos del gas neutro de los efectos de las partículas cargadas. Para frecuencias del orden de los $\mathrm{GHz}$, propias de las señales satelitales, la parte neutra de la atmósfera, la tropósfera, se comporta como un medio homogéneo (el índice de refracción es independiente de la posición), isotrópico (independiente de la dirección de propagación de la onda) y no dispersivo (no depende de la frecuencia de la señal). En cambio, para las frecuencias utilizadas en la transmisión de señales satelitales, la ionosfera tiene un comportamiento diferente. La teoría de Appleton-Hartree da la expresión para el índice de refracción $n$ en un medio ionizado, macroscópicamente neutro, con un campo magnético uniforme presente:

$$
\mathrm{n}=\sqrt{1-\frac{\mathrm{X}}{1-\mathrm{iZ}-\frac{\mathrm{Y}_{\mathrm{T}}^{2}}{2(1-\mathrm{X}-\mathrm{iZ})} \pm\left(\frac{\mathrm{Y}_{\mathrm{T}}^{4}}{4(1-\mathrm{X}-\mathrm{iZ})^{2}}+\mathrm{Y}_{\mathrm{L}}^{2}\right)^{\frac{1}{2}}}}
$$

$\operatorname{con} \mathrm{X}=\frac{\omega_{\mathrm{P}}^{2}}{\omega^{2}}, \quad \mathrm{Y}_{\mathrm{L}}=\frac{\omega_{\mathrm{S}}}{\omega} \cos \Theta, \quad \mathrm{Y}_{\mathrm{T}}=\frac{\omega_{\mathrm{S}}}{\omega} \operatorname{sen} \Theta, \quad \mathrm{Z}=\frac{\omega_{\mathrm{C}}}{\omega}$,

donde $\omega$ es frecuencia de la onda portadora, $\omega_{\mathrm{P}}$ es la frecuencia natural de oscilación del plasma ante perturbaciones electrostáticas, $\omega_{\mathrm{s}}$ es la frecuencia sincrotrón para los electrones, $\Theta$ es el ángulo entre el vector de campo magnético y la dirección de propagación de la onda y $\omega_{\mathrm{C}}$ es la frecuencia de colisión de los electrones.

El término X representa la interacción pura entre la onda y los electrones. La frecuencia del plasma es (Hargreaves, 1995):

$$
\omega_{\mathrm{P}}=\sqrt{\frac{\mathrm{n}_{\mathrm{e}} \mathrm{e}^{2}}{\varepsilon_{0} \mathrm{~m}_{\mathrm{e}}}}
$$


donde $\mathrm{n}_{\mathrm{e}}$ es la densidad de electrones libres en el medio, e y $\mathrm{m}_{\mathrm{e}}$ representan la carga y la masa del electrón y es la permitividad del vacío. Entonces, el término X da cuenta de la inhomogeneidad de la atmósfera, ya que la densidad electrónica es función, fundamentalmente, de la altura.

Los términos $\mathrm{Y}_{\mathrm{L}}$ y $\mathrm{Y}_{\mathrm{T}}$ representan la anisotropía del medio frente a la propagación de ondas, que se pone de manifiesto a través del ángulo@; los subíndices $\mathrm{T}$ y $\mathrm{L}$ identifican las componentes transversal y longitudinal del vector de campo magnético en la dirección de propagación de la onda. El término Z expresa el efecto colisional de los electrones.

Para una onda portadora que se propaga a través de la ionosfera de la Tierra con una frecuencia $\omega \cong 10^{10} \mathrm{~s}^{-1}=10 \mathrm{GHz}$, resulta $\omega_{\mathrm{P}} \ll \omega, \omega_{\mathrm{S}} \ll \omega \mathrm{y} \omega_{\mathrm{C}} \ll \omega$. En este caso, es válida la siguiente aproximación de la fórmula de Appleton-Hartree:

$$
\mathrm{n} \cong \sqrt{1-\frac{\mathrm{X}}{1 \pm \mathrm{Y}_{\mathrm{L}}}}=\sqrt{1-\left(\frac{\omega_{\mathrm{P}}}{\omega}\right)^{2}\left(1 \pm \frac{\omega_{\mathrm{S}} \cos \Theta}{\omega}\right)^{-1}} \cong \sqrt{1-\left(\frac{\omega_{\mathrm{P}}}{\omega}\right)^{2}}
$$

donde se ha considerado que $\left(1 \pm \frac{\omega_{\mathrm{S}} \cos \Theta}{\omega}\right)^{-1} \cong 1$

Desarrollando la ecuación anterior en serie de potencias y despreciando los términos de orden superior a $\left(\frac{\omega_{\mathrm{P}}}{\omega}\right)^{2}$ se obtiene:

$$
\sqrt{1-\left(\frac{\omega_{\mathrm{P}}}{\omega}\right)^{2}} \cong 1-\frac{1}{2}\left(\frac{\omega_{\mathrm{P}}}{\omega}\right)^{2}\left[1+\frac{1}{4}\left(\frac{\omega_{\mathrm{P}}}{\omega}\right)^{2}+\frac{1}{8}\left(\frac{\omega_{\mathrm{P}}}{\omega}\right)^{3}+\ldots\right] \cong 1-\frac{1}{2}\left(\frac{\omega_{\mathrm{P}}}{\omega}\right)^{2}=1-\frac{1}{2} \frac{\mathrm{n}_{\mathrm{e}} \mathrm{e}^{2}}{\varepsilon_{0} \mathrm{~m}_{\mathrm{e}} \omega^{2}}
$$

Finalmente, reemplazando las constantes por sus valores, el índice de refracción de la ionosfera resulta

$$
\mathrm{n} \cong 1-\frac{40.28 \mathrm{n}_{\mathrm{e}}}{\mathrm{f}^{2}}
$$

donde $\mathrm{f}=\omega / 2 \pi$ es la frecuencia de la portadora expresada en $\mathrm{Hz}$ y $\mathrm{n}_{\mathrm{e}}$ es la densidad electrónica dada en electrones $/ \mathrm{m}^{3}$. En esta aproximación, la ionosfera resulta ser un medio inhomogéneo y dispersivo.

De acuerdo con el resultado previo, el índice de refracción ionosférico es $\mathrm{n}<1$; de esta forma, la velocidad de fase resulta mayor que la velocidad de la luz en el vacío (ecuación 2.1). La información se transmite a la velocidad de grupo y ésta resulta ser menor que c debido a que el índice de refracción para el grupo de ondas es, reemplazando la ecuación 2.3 en la ecuación 2.2:

$$
\mathrm{n}_{\mathrm{g}}=\mathrm{n}+\omega \frac{\mathrm{dn}}{\mathrm{d} \omega} \cong 1+\frac{40.28 \mathrm{n}_{\mathrm{e}}}{\mathrm{f}^{2}}>1
$$




\subsubsection{Camino óptico}

De acuerdo con el principio de Fermat, de todos los caminos que una señal puede seguir para ir de un punto $S_{1}$ a otro $S_{2}$ en un medio refractivo inhomogéneo, toma el que requiere el menor tiempo, o, de forma equivalente el que minimiza el camino óptico.

El camino óptico L se define como la integral del índice de refracción a lo largo de una trayectoria entre $S_{1}$ y $_{2}$ :

$$
L=\int_{S_{1}}^{S_{2}} n(s) d s
$$

Sumando y restando 1 en el integrando, es posible separar el efecto de la atmósfera sobre el camino óptico:

$$
\begin{aligned}
& \mathrm{L}=\int_{\mathrm{S}_{1}}^{\mathrm{S}_{2}}[\mathrm{n}(\mathrm{s})-1] \mathrm{d} s+\int_{\mathrm{S}_{1}}^{\mathrm{S}_{2}} \mathrm{~d} s \\
& \mathrm{~L}=\int_{\mathrm{S}_{1}}^{\mathrm{S}_{2}}[\mathrm{n}(\mathrm{s})-1] \mathrm{d} s+\rho+\Delta \rho
\end{aligned}
$$

El primer término representa el incremento/decremento en el camino óptico cuando la señal atraviesa la atmósfera; la integral $\int_{\mathrm{S}_{1}}^{\mathrm{S}_{2}} \mathrm{ds}$ puede escribirse como la suma de dos términos: $\rho$ representa la distancia geométrica que separa los puntos $S_{1}$ y $S_{2}$, y $\Delta \rho$ tiene en cuenta el efecto de curvatura que sufre el rayo cuando ingresa a la atmósfera con un ángulo de incidencia no nulo; en el caso de las señales GPS y de satélites altimétricos $\Delta \rho$ puede despreciarse.

El efecto atmosférico tiene una componente troposférica y otra ionosférica:

$$
\int_{S_{1}}^{S_{2}}[n(s)-1] d s=\int_{S_{1}}^{S_{2}}\left[n_{\text {trop }}-1\right] d s+\int_{S_{1}}^{S_{2}}\left[n_{\text {ion }}-1\right] d s=\Delta \rho_{\text {trop }}+\Delta \rho_{\text {ion }}
$$

Para calcular el efecto de la ionosfera sobre la señal es necesario tener en cuenta las características de la onda. Si se trata de una onda monocromática, con una frecuencia $\mathrm{f}$, el índice de refracción $\mathrm{n}_{\text {ion }}$ está dado por la ecuación 2.3. En este caso, la ionósfera altera el camino en una cantidad $\Delta \rho_{\text {ion }}$ dada por:

$$
\Delta \rho_{\text {ion }}=\int_{S_{1}}^{s_{2}}\left[n_{\text {ion }}-1\right] d s=-\int_{S_{1}}^{S_{2}} \frac{40.28 n_{e}}{f^{2}} d s=-\frac{40.28}{f^{2}} \int_{S_{1}}^{s_{2}} n_{e} d s
$$

$\Delta \rho_{\text {ion }}$ es una cantidad menor que cero; el camino óptico es menor que la distancia geométrica que separa los puntos $S_{1}$ y $S_{2}$. 
Si en cambio se trata de una señal modulada en frecuencia, el índice de refracción para el grupo de ondas $\mathrm{n}_{\mathrm{g}}$ está dado por la ecuación 2.4, donde f es la frecuencia de la onda portadora. En este caso, la ionosfera produce una variación en el camino dada por la cantidad:

$$
\Delta \rho_{\text {ion }}=\int_{S_{1}}^{S_{2}}\left[n_{\text {ion }}-1\right] d s=\frac{40.28}{f^{2}} \int_{S_{1}}^{S_{2}} n_{e} d s
$$

Para la onda que transmite la información, el camino óptico es mayor que la distancia geométrica.

\subsubsection{Contenido electrónico total}

Es oportuno definir el contenido electrónico total TEC (Total Electron Content). El TEC es una cantidad usada con frecuencia en el estudio de la ionosfera y se define como la integral de la densidad electrónica $\mathrm{n}_{\mathrm{e}}$ a lo largo de un camino determinado que une los puntos $\mathrm{S}_{1} \mathrm{y} \mathrm{S}_{2}$ :

$$
\mathrm{TEC}=\int_{\mathrm{S}_{1}}^{\mathrm{S}_{2}} \mathrm{n}_{\mathrm{e}} \mathrm{ds}
$$

Dado que $\mathrm{n}_{\mathrm{e}}$ es una densidad volumétrica, el TEC puede pensarse como el número total de electrones contenido dentro de un volumen con un área transversal unitaria y longitud igual a la longitud del camino entre $S_{1}$ y $S_{2}$. Si el camino de integración es perpendicular a la superficie de la Tierra se habla de TEC vertical o vTEC; en cambio, si forma un ángulo no nulo con la vertical, nos referimos al contenido electrónico total como sTEC (slant TEC).

El contenido electrónico total se expresa en TECU (Total Electron Content Unit), cuya equivalencia es: 1 TECU $=10^{16}$ electrones $/ \mathrm{m}^{2}$

Con la definición previa, el efecto dispersivo de la ionosfera sobre la señal satelital pude sintetizarse de la siguiente forma:

$$
\Delta \rho_{\text {ion }}= \pm \frac{40.28 \text { sTEC }}{\mathrm{f}^{2}}
$$

El signo positivo corresponde a la señal modulada en frecuencia y negativo para la portadora. 


\subsection{Sistema de Posicionamiento Global}

El Sistema de Posicionamiento Global (NAVigation Satellite Timing and Ranging Global Positioning System, NAVSTAR o simplemente GPS) es un sistema global de posicionamiento y navegación por satélite desarrollado, instalado y operado por el Departamento de Defensa de los Estados Unidos. Provee la hora y la posición absoluta de un punto con una cobertura global e independiente de las condiciones climáticas.

GPS y los sistemas equivalentes GLONASS, desplegado por la Unión Soviética, y Galileo y Compass, iniciativas europea y china respectivamente, en etapa de desarrollo, integran el Sistema Global de Navegación Satelital GNSS (de Global Navigation Satellite System). GNSS es un servicio que agrupa más de 200 agencias distribuidas mundialmente dedicadas a la generación de datos precisos para usos geodésicos, geofísicos, comerciales y de investigación.

\subsubsection{Arquitectura del sistema GPS}

El sistema GPS consta de una constelación de por lo menos 24 satélites disponibles orbitando la Tierra y transmitiendo señales de forma continua.

Figura 2.1. Orbitas de los

satélites GPS

http://www.gps.gov/multim

edia/images/constellation.

jpg)

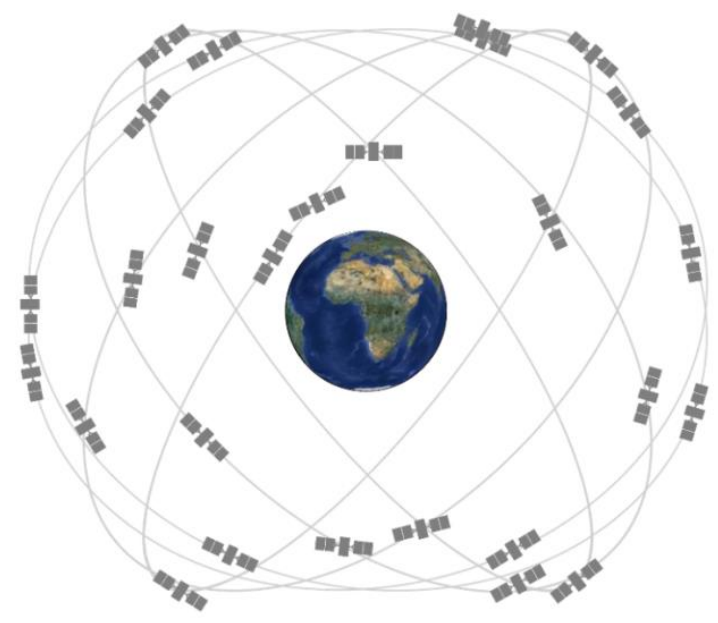

El primer satélite fue lanzado a estos fines en el año 1987 y la constelación de 24 satélites se completó y estuvo operativa en diciembre de 1993. En la actualidad, el sistema GPS está integrado por diferentes generaciones de satélites que suman un total de 31 satélites operativos. 
Los satélites están dispuestos en 6 órbitas planas inclinadas aproximadamente $55^{\circ}$ con respecto al ecuador de la Tierra y con una separación de $60^{\circ}$ sobre el ecuador. Esta configuración garantiza la visibilidad de al menos 4 satélites en cada instante y ubicación sobre o cerca de la superficie de la Tierra, mínimo requerido para un posicionamiento tridimensional.

De acuerdo con las leyes de Kepler, las orbitas tienen forma elíptica, con el centro de masa de la Tierra en uno de los focos. Para las órbitas GPS la excentricidad es muy pequeña, e=0.02, son casi circulares. El semieje mayor de la elipse es de aproximadamente $26000 \mathrm{~km}$, de modo que los satélites orbitan a una altitud aproximada de $20200 \mathrm{~km}$ sobre la superficie de la Tierra. El período de revolución orbital es de 11 horas 58 minutos, exactamente medio día sidéreo. De esta forma, mientras cada satélite completa dos revoluciones, la Tierra rota $360^{\circ}$ con respecto a un sistema inercial espacial; entonces la trayectoria de los satélites se repite diariamente pero cada satélite se adelanta 4 minutos cada día solar.

El desarrollo y puesta en órbita de los satélites constituyen el segmento espacial de la arquitectura GPS. Ésta comprende además los segmentos de control y de usuario. El segmento de control tiene a su cargo la operación del sistema; monitorea el estado de los satélites y sus órbitas, predice las efemérides satelitales, introduce correcciones a los relojes, actualiza los mensajes de navegación y provee la mejor reubicación de los satélites en caso de fallas. El segmento está integrado por una red de estaciones terrestres de seguimiento: una estación maestra (ubicada en Colorado Spring, USA) y quince estaciones de monitoreo equipadas con relojes y receptores de gran precisión (tres de ellas poseen además antenas para transmitir las actualizaciones a los satélites). El segmento de usuario abarca el desarrollo de equipamiento apto para recibir las señales de los satélites y utilizar la información transmitida para calcular la hora y la posición.

\subsubsection{Las señales GPS}

Los satélites del sistema GPS transmiten dos ondas portadoras sinusoidales $\mathrm{L}_{1}$ y $\mathrm{L}_{2}$. Las frecuencias de estas señales, $\mathrm{f}_{1}$ y $\mathrm{f}_{2}$, son múltiplos de una frecuencia fundamental $\mathrm{f}_{0}$ generada por un oscilador a bordo del satélite (los valores figuran en la Tabla 2.1).

El posicionamiento mediante GPS se basa en medida del tiempo aparente de propagación entre el transmisor GPS y el receptor que permite la determinación de la distancia entre el satélite y el receptor; esto se logra comparando la señal proveniente del satélite con una réplica de ella generada en el receptor. 


\begin{tabular}{|l|l|}
\hline Frecuencia fundamental & $\mathrm{f}_{0}=10.23 \mathrm{Mhz}\left(\lambda_{0}=\frac{\mathrm{c}}{\mathrm{f}_{0}} \cong 29.3 \mathrm{~m}\right)$ \\
\hline Portadora $\mathrm{L}_{1}$ & $\mathrm{f}_{1}=154 \times \mathrm{f}_{0}=1.57542 \mathrm{GHz}\left(\lambda_{1}=\frac{\mathrm{c}}{\mathrm{f}_{1}} \cong 19.0 \mathrm{~cm}\right)$ \\
\hline Portadora $\mathrm{L}_{2}$ & $\mathrm{f}_{2}=120 \times \mathrm{f}_{0}=1.22760 \mathrm{GHz}\left(\lambda_{2}=\frac{\mathrm{c}}{\mathrm{f}_{2}} \cong 24.4 \mathrm{~cm}\right)$ \\
\hline Código P & $\mathrm{f}_{\mathrm{P}}=\mathrm{f}_{0}=10.23 \mathrm{MHz}\left(\lambda_{\mathrm{P}}=\frac{\mathrm{c}}{\mathrm{f}_{\mathrm{P}}} \cong 29,3 \mathrm{~m}\right)$ \\
\hline Código C/A & $\mathrm{f}_{\mathrm{C}}=\frac{\mathrm{f}_{0}}{10}=1.023 \mathrm{MHz}\left(\lambda_{\mathrm{C}}=\frac{\mathrm{c}}{\mathrm{f}_{\mathrm{C}}} \cong 293 \mathrm{~m}\right)$ \\
\hline Mensaje de navegación $\mathrm{D}$ & $\frac{\mathrm{f}_{0}}{204600}=50 \mathrm{~Hz}$ \\
\hline
\end{tabular}

Tabla 2.1. Frecuencias de las señales GPS

La distancia se calcula a partir del corrimiento de fase de la señal recibida, conocida la fase en el instante de emisión. Si la señal emitida es una onda electromagnética sinusoidal pura que se repite, el corrimiento de fase sería insuficiente para determinar el recorrido de la señal, restaría conocer el número de ciclos completos transmitidos. Por este motivo, las señales $L_{1}$ y $L_{2}$ son moduladas en fase por dos códigos binarios pseudo-aleatorios (Pseudo Random Noise, PRN): el código C/A (de adquisición grosera, Coarse/Acquisition) y el código P (de Precision).

El código C/A es modulado sobre la portadora $\mathrm{L}_{1}$ y es único para cada satélite. La frecuencia fundamental es $\mathrm{f}_{\mathrm{C}}=\frac{\mathrm{f}_{0}}{10}=1.023 \mathrm{MHz}$, es decir que la onda se repite cada un milisegundo aproximadamente, que equivale a una longitud de aproximadamente 293 metros $\left(\lambda_{C}=c / f_{1}\right)$. La secuencia tiene una longitud de 1023 bits.

El código $P$ se modula sobre ambas señales portadoras $L_{1}$ y $L_{2}$. La frecuencia fundamental es $\mathrm{f}_{P}=\mathrm{f}_{0}$, o sea que se repite cada décimo de milisegundo con una longitud de onda de 29,3 metros. La longitud de la secuencia es de aproximadamente $2.3510^{14}$ bits, y su transmisión toma 266 días. El código P es particionado en 37 segmentos de una semana y cada satélite GPS genera uno de los segmentos. Esto permite identificar el satélite emisor.

El código P está encriptado al código Y a través de su modulación con un código secreto W. Este es un procedimiento de seguridad conocido como AS (antispoofing). Cuando este procedimiento está activado, la mayor precisión del sistema queda reservada únicamente a los usuarios autorizados. 
El mensaje de navegación, que contiene la hora GPS, las correcciones a los relojes satelitales, las efemérides de los satélites e información del sistema, se modula sobre las dos señales portadoras mediante un código D.

\subsubsection{Observables GPS}

Las señales emitidas por los satélites del sistema GPS son captadas por receptores apropiados. El tiempo que tarda la señal desde que es emitida hasta que es recibida, multiplicado por la velocidad de propagación, es una medida de la pseudo-distancia que separa ambos instrumentos.

\subsection{3.a. Pseudo-distancia con códigos}

La determinación de la pseudo-distancia con código, C/A O P, se basa en la medición del tiempo de desfasaje entre el código emitido y el replicado en el receptor. Si el satélite $\mathrm{k}$ emite la señal en el instante $\mathrm{t}^{\mathrm{k}} \mathrm{y}$ es recibida por el receptor i en el instante $t_{i}$, la pseudo-distancia $P_{i}^{k}$ es:

$$
\mathrm{P}_{\mathrm{i}}^{\mathrm{k}}=\mathrm{c}\left(\mathrm{t}_{\mathrm{i}}-\mathrm{t}^{\mathrm{k}}\right)
$$

$\mathrm{P}_{\mathrm{i}}^{\mathrm{k}}$ está dada en unidades de longitud, c es la velocidad de la luz en el vacío, $\mathrm{t}_{\mathrm{i}}$ y $\mathrm{t}^{\mathrm{k}}$ están medidos en los relojes del receptor y del satélite respectivamente.

Teniendo en cuenta el retraso que sufre la señal al atravesar la atmósfera de la Tierra y la respuesta de los instrumentos, llevando los tiempos de emisión y recepción a un marco común dado por el tiempo GPS, la pseudo-distancia se relaciona con la distancia geométrica $\rho_{\mathrm{i}}^{\mathrm{k}}$ que separa al satélite del receptor a través de la siguiente ecuación:

$$
\mathrm{P}_{\mathrm{i}}^{\mathrm{k}}=\rho_{\mathrm{i}}^{\mathrm{k}}+\mathrm{c}\left(\Delta \mathrm{t}_{\mathrm{i}}-\Delta \mathrm{t}^{\mathrm{k}}\right)+\Delta \rho_{\mathrm{i}, \text { trop }}^{\mathrm{k}}+\Delta \rho_{\mathrm{i}, \text { ion }}^{\mathrm{k}}+\mathrm{c}\left(\mathrm{B}^{\mathrm{k}}+\mathrm{B}_{\mathrm{i}}\right)+\mathrm{M}_{\mathrm{i}}^{\mathrm{k}}+\varepsilon_{\mathrm{P}}
$$

$\Delta \mathrm{t}^{\mathrm{k}}$ y $\Delta \mathrm{t}_{\mathrm{i}}$ representan las compensaciones de los relojes del satélite y receptor con respecto al tiempo GPS. Los satélites están equipados con relojes atómicos (dos de rubidio y dos de cesio) de muy alta estabilidad. El sistema de tiempo GPS se obtiene estadísticamente procesando información horaria de los relojes atómicos a bordo de los satélites y de las estaciones de monitoreo.

$\Delta \rho_{\mathrm{i}, \text { trop }}^{\mathrm{k}}$ y $\Delta \rho_{\mathrm{i}, \text { ion }}^{\mathrm{k}}$ son los retrasos que sufre la señal en la troposfera y en la ionosfera respectivamente; de acuerdo con la ecuación $2.11, \Delta \rho_{\mathrm{i}, \text { ion }}^{\mathrm{k}}>0$. 
$B^{k}$ y $B_{i}$ son los retrasos instrumentales en el satélite y el receptor, en unidades de tiempo;

$\mathrm{M}_{\mathrm{i}}^{\mathrm{k}}$ es el error de multicamino; tiene en cuenta el efecto de distorsión en la señal que llega al receptor por diferentes caminos, por ejemplo luego de ser reflejada por objetos próximos al receptor;

$\varepsilon_{\mathrm{P}}$ es el error de medición.

\subsection{3.b. Pseudo-distancia con fase}

Los errores relativos de las mediciones GPS son del orden del 1\% de la longitud de onda de la señal. De esta forma, las mediciones realizadas con código C/A están afectadas por errores del orden de los 3 metros, mientras que los errores se reducen a $30 \mathrm{~cm}$ si las mediciones se realizan con código $P$. Los errores serían del orden de los $2 \mathrm{~mm}$ si se utilizaran las ondas portadoras $\mathrm{L}_{1} \circ \mathrm{L}_{2}$.

Como se ha mencionado, la determinación de la distancia con GPS se basa en la medición de la diferencia de fase entre de la onda que llega del satélite y la réplica que se genera en el receptor. Utilizando las señales portadoras $L_{1} \circ L_{2}$, que son ondas sinusoidales puras, los receptores son capaces de medir el corrimiento en la fase, pero no el número $\mathrm{N}$ de ciclos completos en que difieren las dos señales. El número entero $\mathrm{N}_{\mathrm{i}}^{\mathrm{k}}$ representa la ambigüedad entre el receptor i y el satélite k. Además, esta cantidad cambia arbitrariamente cada vez que se interrumpe la recepción de la señal del satélite. Entonces, observando la fase de la portadora $\varphi_{\mathrm{i}}^{\mathrm{k}}$ se reducen los errores relativos pero se incorpora una incógnita.

En este caso, la pseudo-distancia $\mathrm{L}_{\mathrm{i}}^{\mathrm{k}}$ está dada por:

$$
L_{i}^{k}=\lambda\left(\varphi_{i}^{k}+N_{i}^{k}\right)=\lambda \varphi_{i}^{k}+\lambda N_{i}^{k}=\Phi_{i}^{k}+\lambda N_{i}^{k}
$$

$\lambda$ es la longitud de onda de la portadora, $\varphi_{i}^{k}$ es la fase observada medida en ciclos (siempre menor que 1) y $\Phi_{\mathrm{i}}^{\mathrm{k}}$ la fase observada en unidades de longitud. La pseudo-distancia $\mathrm{L}_{\mathrm{i}}^{\mathrm{k}}$ resulta medida en unidades de longitud.

Como en el caso de la medición con códigos, la fase de la portadora $\Phi_{\mathrm{i}}^{\mathrm{k}}$ es una cantidad observacional que está alterada por el efecto de la atmósfera, desfasajes en los relojes y errores de distinto origen, de modo que la pseudodistancia en fase puede escribirse de la siguiente forma: 


$$
\mathrm{L}_{\mathrm{i}}^{\mathrm{k}}=\rho_{\mathrm{i}}^{\mathrm{k}}+\mathrm{c}\left(\Delta \mathrm{t}_{\mathrm{i}}-\Delta \mathrm{t}^{\mathrm{k}}\right)+\Delta \rho_{\mathrm{i}, \text { trop }}^{\mathrm{k}}-\Delta \rho_{\mathrm{i}, \text { ion }}^{\mathrm{k}}+\lambda \mathrm{N}_{\mathrm{i}}^{\mathrm{k}}+\mathrm{c}\left(\mathrm{b}^{\mathrm{k}}+\mathrm{b}_{\mathrm{i}}\right)+\mathrm{m}_{\mathrm{i}}^{\mathrm{k}}+\lambda \phi+\varepsilon_{\mathrm{L}}
$$

donde

$\rho_{\mathrm{i}}^{\mathrm{k}}$ es la distancia geométrica satélite-receptor;

$\Delta \mathrm{t}^{\mathrm{k}}$ y $\Delta \mathrm{t}_{\mathrm{i}}$ representan las compensaciones de los relojes del satélite y receptor con respecto al tiempo GPS;

$\Delta \rho_{\mathrm{i}, \text { trop }}^{\mathrm{k}} \Delta \rho_{\mathrm{i}, \mathrm{ion}}^{\mathrm{k}}$ son los retrasos que sufre la señal en la troposfera y en la ionosfera respectivamente; el signo negativo de este último término surge en la ecuación 2.11, según la cual $\Delta \rho_{\mathrm{i}, i o n}^{\mathrm{k}}<0$.

$\mathrm{b}^{\mathrm{k}}$ y $\mathrm{b}_{\mathrm{i}}$ son los retrasos instrumentales en el satélite y el receptor, en unidades de tiempo;

$\mathrm{m}_{\mathrm{i}}^{\mathrm{k}}$ es el error de multicamino;

\$ da cuenta del efecto de wind-up; este efecto se debe a la naturaleza electromagnética de las señales GPS, polarizadas circulamente: a medida que el satélite avanza en su órbita, debe rotar para mantener los paneles solares en dirección al sol mientras que la antena se mantiene apuntando al centro de la Tierra; esta ratación causa una variación en la fase que debe ser tenida en cuenta; $\phi$ es expresado en ciclos (Wu et al., 1993);

$\varepsilon_{\mathrm{L}}$ es el error de medición.

\subsection{3.c. Combinación lineal libre de geometría}

Dada la naturaleza dispersiva de la ionosfera, la transmisión de dos señales con frecuencias diferentes $\mathrm{f}_{1}$ y $\mathrm{f}_{2}$ permite separar la información ionosférica de toda aquella que es independiente de la frecuencia de la onda. Esto se logra simplemente haciendo la diferencia entre las mediciones realizadas en dos frecuencias diferentes o combinación lineal libre de geometría $\mathrm{L}_{4}=\mathrm{L}_{1}-\mathrm{L}_{2}$

Para observaciones con código, C/A o P, el observable que se obtiene restando

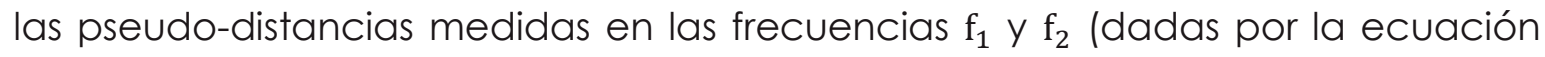
2.13) es $\mathrm{P}_{4}$ :

$$
\mathrm{P}_{4}=\mathrm{P}_{1}-\mathrm{P}_{2}=\Delta \rho_{\text {ion }}^{1}-\Delta \rho_{\text {ion }}^{2}+\mathrm{c}\left(\mathrm{B}^{1, \mathrm{k}}-\mathrm{B}^{2, \mathrm{k}}\right)+\mathrm{c}\left(\mathrm{B}_{1, \mathrm{i}}-\mathrm{B}_{2, \mathrm{i}}\right)+\left(\varepsilon_{\mathrm{P}}^{1}-\varepsilon_{\mathrm{P}}^{2}\right)
$$


De acuerdo con la ecuación 2.11 la diferencia de los retrasos ionosféricos resulta

$$
\Delta \rho_{\text {ion }}^{1}-\Delta \rho_{\text {ion }}^{2}=\left(\frac{1}{\mathrm{f}_{1}^{2}}-\frac{1}{\mathrm{f}_{2}^{2}}\right) 40.28 \text { sTEC }=\text { K sTEC }
$$

con $\mathrm{K}=\left(\frac{1}{\mathrm{f}_{1}^{2}}-\frac{1}{\mathrm{f}_{2}^{2}}\right) 40.28=-1.0510^{-17}\left(\frac{e}{m^{3}}\right)^{-1}=-0.105 \frac{\mathrm{m}}{\mathrm{TECUs}}$

$\Delta \mathrm{B}^{\mathrm{k}}=\mathrm{B}^{1, \mathrm{k}}-\mathrm{B}^{2, \mathrm{k}}$ es el retraso instrumental inter-frecuencia $O \mathrm{DCB}$ (diferencial code bias) en el satélite $k$

$\Delta \mathrm{B}_{\mathrm{i}}=\mathrm{B}_{1, \mathrm{i}}-\mathrm{B}_{2, \mathrm{i}}$ es el retraso instrumental inter-frecuencia o DCB en el receptor $\mathrm{i}$

$\varepsilon_{\mathrm{P}}^{4}=\left(\varepsilon_{\mathrm{P}}^{1}-\varepsilon_{\mathrm{P}}^{2}\right)$ es el error de medición

Con todo, $\mathrm{P}_{4}$ resulta:

$$
\mathrm{P}_{4}=\mathrm{KsTEC}+\mathrm{c}\left(\Delta \mathrm{B}^{\mathrm{k}}+\Delta \mathrm{B}_{\mathrm{i}}\right)+\varepsilon_{\mathrm{P}}^{4}
$$

De forma equivalente, el observable libre de geometría para mediciones de fase de la portadora es $\mathrm{L}_{4}=\mathrm{L}_{1}-\mathrm{L}_{2}$ :

$$
\mathrm{L}_{4}=-\mathrm{K} \mathrm{sTEC}+\lambda_{1} \mathrm{~N}_{1}-\lambda_{2} \mathrm{~N}_{2}+\mathrm{c}\left(\Delta \mathrm{b}^{\mathrm{k}}+\Delta \mathrm{b}_{\mathrm{i}}\right)+\left(\lambda_{1}-\lambda_{2}\right) \phi+\varepsilon_{\mathrm{L}}^{4}
$$

donde

$\Delta \mathrm{b}^{\mathrm{k}}=\mathrm{b}^{1, \mathrm{k}}-\mathrm{b}^{2, \mathrm{k}}$ es retraso instrumental inter-frecuencia en el satélite $\mathrm{k}, \mathrm{y}$

$\Delta \mathrm{b}_{\mathrm{i}}=\mathrm{b}_{1, \mathrm{i}}-\mathrm{b}_{2, \mathrm{i}}$ es el retraso instrumental inter-frecuencia en el receptor $\mathrm{i}$

$\varepsilon_{\mathrm{L}}^{4}=\left(\varepsilon_{\mathrm{L}}^{1}-\varepsilon_{\mathrm{L}}^{2}\right)$ es el error de medición.

\subsection{3.d. Combinación lineal libre de geometría suavizada}

Como se vio en la sección 2.2.3.b las distancias calculadas con fase son dos órdenes de magnitud más precisas que las calculadas con código, pero tienen la desventaja de estar afectadas por el término de ambigüedad. La combinación lineal libre de geometría suavizada combina las observaciones en código y fase, manteniendo la precisión de las observaciones con fase pero eliminando las ambigüedades (Blewitt, 1990).

Esta técnica requiere la identificación de mediciones interrumpidas con código y con fase en dos frecuencias a medida que el satélite avanza en su órbita, es decir, a lo largo de un arco. Esta condición garantiza que el número de ciclos completos $\mathrm{N} 1$ y N2 no cambia en el intervalo considerado. El procedimiento 
consiste en calcular el valor medio de la suma de los observables libres de geometría con código y con fase para cada arco continuo:

$$
\left\langle\mathrm{L}_{4}+\mathrm{P}_{4}\right\rangle=\frac{1}{\mathrm{~N}} \sum_{i=1}^{\mathrm{N}}\left(\mathrm{L}_{4}+\mathrm{P}_{4}\right)_{i}
$$

donde $\mathrm{N}$ es el número de mediciones continuas realizadas.

Reemplazando $\mathrm{L}_{4}$ y $\mathrm{P}_{4}$ por las ecuaciones 2.18 y 2.19 , suponiendo que los retardos instrumentales son constantes en el intervalo considerado y despreciando el término de wind-up frente a los restantes (en posisionamiento preciso este efecto debe ser tenido en cuenta), resulta

$$
\left\langle\mathrm{L}_{4}+\mathrm{P}_{4}\right\rangle=\lambda_{1} \mathrm{~N}_{1}-\lambda_{2} \mathrm{~N}_{2}+\mathrm{c}\left(\Delta \mathrm{b}^{\mathrm{k}}+\Delta \mathrm{b}_{\mathrm{i}}\right)+\mathrm{c}\left(\Delta \mathrm{B}^{\mathrm{k}}+\Delta \mathrm{B}_{\mathrm{i}}\right)
$$

Como los errores de medición son aleatorios, su valor medio se anula.

Restando ahora $\mathrm{L}_{4}$ (ecuación 2.19) a la ecuación anterior los términos de ambigüedad se cancelan:

$$
\begin{aligned}
& \tilde{\mathrm{L}}_{4}=\left\langle\mathrm{L}_{4}+\mathrm{P}_{4}\right\rangle-\mathrm{L}_{4} \\
& \tilde{\mathrm{L}}_{4}=\mathrm{K} \operatorname{sTEC}+\mathrm{c}\left(\Delta \mathrm{B}^{\mathrm{k}}+\Delta \mathrm{B}_{\mathrm{i}}\right)-\varepsilon_{\mathrm{L}}^{4}
\end{aligned}
$$

El nuevo observable de fase nivelado $\tilde{\mathrm{L}}_{4}$, libre de ambigüedades, contiene la información ionosférica pero continúa afectado por los retardos instrumentales inter-frecuencia. El Modelo Ionosférico La Plata utiliza este observable.

\subsubsection{Fortalezas y limitaciones de los datos GPS}

Entre las principales ventajas que ofrece el Sistema Global de Posicionamiento para estudiar la ionosfera se pueden reconocer:

- que provee series largas (mayores que un ciclo solar) y continuas de datos en dos frecuencias sobre la parte continental y regiones insulares de la Tierra,

- que los datos son de fácil acceso, en un formato estandarizado (RINEX),

- y que la resolución espacial y temporal de los datos a escala global es buena.

Las principales limitaciones que tiene son:

- que los datos son escasos sobre las regiones oceánicas del planeta,

- que, debido a la geometría radial de la línea entre los receptores ubicados en tierra y los satélites GPS, las observaciones no dan información sobre la 
distribución del contenido electrónico total vertical, sino sobre el contenido electrónico oblicuo,

- que las estimaciones del TEC son muy precisas (del orden de \pm 0.03 TECu), pero la exactitud depende de la incerteza en la estimación de los retardos diferenciales instrumentales de los satélites y receptores (esto si se utiliza el observable $\tilde{L}_{4}$; si se emplean otros observables, los datos además están sesgados por las ambigüedades).

\subsection{Altimetría satelital}

La altimetría es una técnica para medir alturas. La altimetría satelital surge con el propósito de medir el nivel del mar a partir de la combinación de dos técnicas: el radar y el posicionamiento. La técnica de radar consiste en medir el tiempo que le toma a un pulso de radar viajar desde la antena de un satélite hasta la superficie y regresar al satélite y, combinada con la ubicación precisa del satélite en su órbita, permite determinar la topografía de la superficie de los océanos.

Los primeros satélites altimétricos fueron lanzados por los Estados Unidos; fueron las misiones Skylab (1973-1979), Geos3 (1975-1978), Seasat (1978, por 105 días) y el satélite Geosat (1985-1990) que produjo la primera serie de tres años de información altimétrica para la comunidad científica. En el año 1987, la agencia francesa CNES (Centre National d'Estudes Spatiales) responsable del desarrollo espacial europeo y la NASA (National Aeronautics and Space Administration, USA) aunaron sus esfuerzos para llevar a cabo un proyecto de observación oceanográfica global. En este proyecto confluyeron la iniciativa norteamericana de poner en órbita un satélite topográfico, la misión TOPEX (Topography Experiment) y el desarrollo europeo del altímetro Poseidón. El resultado fue la misión TOPEX/Poseidón.

El satélite TOPEX/Poseidón fue lanzado el 10 de agosto del año 1992 y estuvo operativo hasta enero de 2006. Permitió medir la superficie topográfica oceánica con una precisión de pocos centímetros, determinar patrones de circulación de los océanos y sus efectos sobre el clima global, estudiar las mareas y ondas oceánicas, además de aplicaciones geodésicas y geofísicas (Fu \& Cazenave, 2001). Si bien se esperaba que los instrumentos a bordo del satélite TOPEX/Poseidón no excedieran los 8 años de vida útil, los 13 años continuos de observación superaron las aplicaciones esperadas y aumentaron el interés en este tipo de datos. Así, la misión tuvo su continuidad en los satélites Jason. 
Jason-1 fue el segundo proyecto conjunto de las agencias espaciales CNES y NASA. Fue lanzado el 7 de diciembre del año 2001 con el propósito de ampliar la serie de datos de su antecesor. En el año 2008 se sumó a la observación de los océanos el satélite Jason-2 y en el año 2016 se incorporó la misión Jason-3. En estas misiones participan la CNES, la NASA y las agencias Eumentsat (European Organisation for the Exploitation of Meteorological Satellites) y Noaa (National Oceanic and Atmospheric Administration, USA Departmet of Commerce). Cada misión cuenta con una nueva generación de instrumentos que mejora la calidad de los datos y extiende la serie temporal de mediciones de la topografía de la superficie oceánica.

\subsubsection{Satélites TOPEX/Poseidón y Jason}

La altimetría satelital entre sus múltiples aplicaciones provee, a partir de la misión TOPEX/Poseidón, una medición directa del contenido electrónico vertical. El instrumento principal a bordo de los satélites TOPEX/Poseidón y Jason es el radar altímetro. El radar envía un pulso de radio en las frecuencias de $13.6 \mathrm{GHz}$ y 5.3 $\mathrm{GHz}$ hacia la superficie de la Tierra y mide las características del eco. Combinando las mediciones realizadas en ambas frecuencias es posible calcular el retardo que producen los electrones libres de la ionosfera y, de esta forma, obtener una estimación del contenido electrónico debajo del satélite.

Los satélites además llevan un radiómetro. El radiómetro es un sensor que mide en tres canales separados, de frecuencias $23.8 \mathrm{GHz}, 18.7 \mathrm{GHz}$ y $34.0 \mathrm{GHz}$, con el objeto de determinar el retraso en la señal de radar producido por contenido de agua líquida y de vapor de agua en la atmósfera.

Una componente importante de la altimetría satelital es la caracterización precisa de la altura del satélite con respecto al centro de la Tierra. Esto se logra determinando la órbita precisa del satélite a través de su rastreo con tres instrumentos a bordo:

- Un receptor GPS provee el rastreo preciso y continuo de la posición del satélite con señales pertenecientes a más de 12 satélites del sistema GPS. Con técnicas de post-procesamiento se logran posiciones en la órbita con un error del orden de los $2 \mathrm{~cm}$.

- Un arreglo de retro-reflectores laser LRA (Laser Retroreflector Array) trabaja con estaciones terrestres para rastrear el satélite y calibrar y verificar las medidas del altímetro. El arreglo es el blanco de pulsos de laser emitidos 
desde una red de estaciones terrestres; midiendo el tiempo que tarda la señal en llegar al reflector y regresar se consigue la ubicación del satélite en su órbita, con una precisión de $3 \mathrm{~cm}$ en su componente radial.

- Un receptor DORIS (Doppler Orbitography and Radiopositioning Integrated by Satellite) provee la ubicación del satélite en tiempo real. Alrededor de 60 balizas DORIS ubicadas sobre la superficie de la Tierra transmiten señales en dos frecuencias separadas (2.04 GHZ y $0.40 \mathrm{GHz}$ ). El receptor a bordo del satélite analiza el corrimiento Doppler de las señales para calcular su velocidad relativa a la Tierra. Esta velocidad, introducida en modelos orbitales, da la posición del satélite en la órbita con una precisión de $2 \mathrm{~cm}$ en la componente radial. Las mediciones en dos frecuencias permiten determinar el contenido de electrones en la atmósfera. (Fuentes: http://sealevel.jpl.nasa.gov y http://www.aviso.oceanobs.com).

Una descripción detallada de los principios de funcionamiento de cada instrumento y las técnicas de medición puede encontrase en Satellite Altimetry and Earth Sciences. A Handbook of Techniques and Aplications (Fu \& Cazenave, 2001), principal referencia bibliográfica para las próximas secciones.

\subsubsection{Configuración orbital}

El objetivo primordial de la altimetría satelital es medir el nivel del mar con una precisión cercana al centímetro. En función de ello, para definir la órbita de los satélites debieron analizarse múltiples factores. Los parámetros orbitales fueron seleccionados para la misión TOPEX/Poseidón y se han mantenido para dar continuidad a la serie de datos, aunque algunos de los factores que determinaron la configuración orbital en los años 80 estuvieran superados al momento del lanzamiento de las siguientes misiones.

\subsection{2.a. Altitud, excentricidad e inclinación}

La altura de la órbita de los satélites altimétricos surge de la necesidad de:

- minimizar los errores en el modelado de la órbita, dominados por las perturbaciones inducidas por la gravedad y la resistencia del aire, ambos fuertemente dependientes de la altura,

- conseguir una relación señal/ruido óptima para las características del radar y

- evitar la exposición a la radiación de Van Allen que limita la vida del satélite. 
La selección de la excentricidad estuvo condicionada por el diseño de los componentes electrónicos del altímetro, que requieren que la diferencia en la altura medida con el radar en pulsos sucesivos sea mínima.

En consecuencia, los satélites altimétricos describen órbitas prácticamente circulares, con una excentricidad e $=0.0006$ y un semieje mayor de $7714 \mathrm{~km}$.

La inclinación de la órbita fue definida para garantizar la medición de la altura del mar en un amplio rango latitudinal y la observación de fenómenos periódicos como son las mareas. Se optó por una órbita con una inclinación de $66^{\circ}$, sobre la cual el satélite se mueve en la dirección de la rotación de la Tierra.

\subsection{2.b. Cobertura espacial y temporal}

De acuerdo con los parámetros orbitales definidos en el apartado anterior, el satélite se mueve a una altura de $1336 \mathrm{~km}$ con un período orbital de 112 minutos. Este es el tiempo que media entre cruces ascendentes sucesivos del plano ecuatorial.

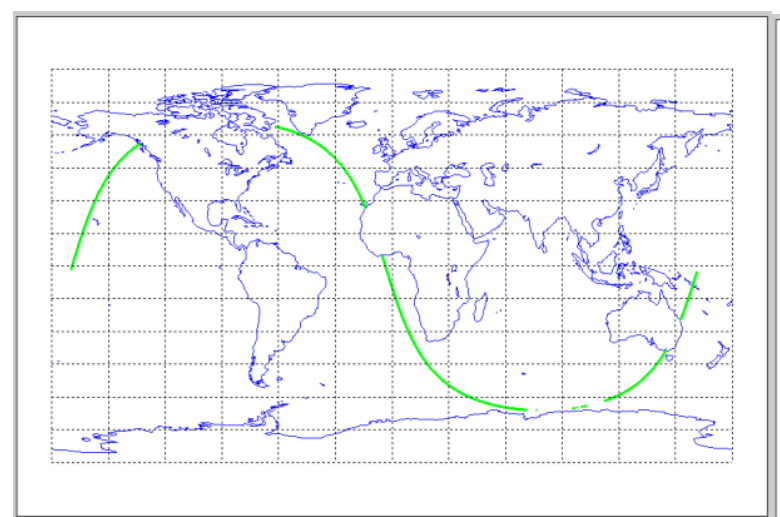

a)

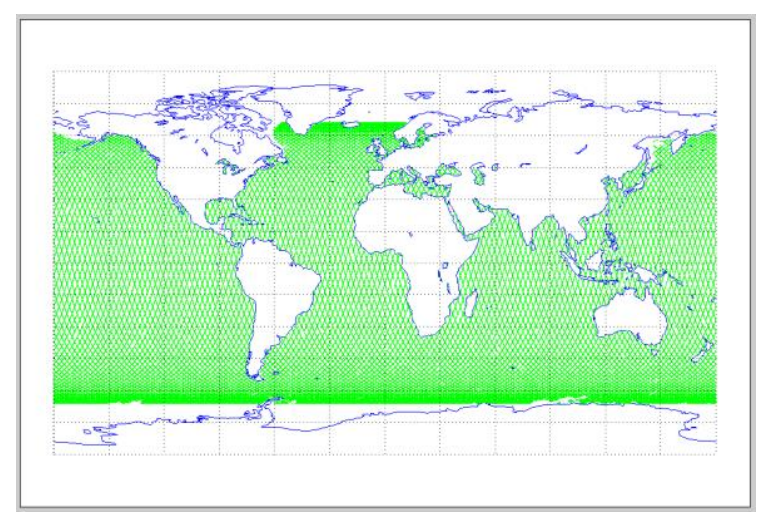

c)

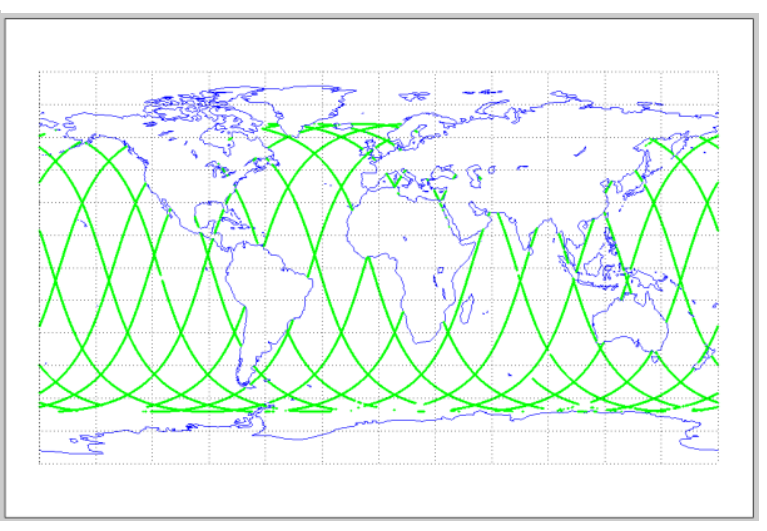

b)

Figura 2.2. Recorrido del satélite TOPEX/Poseidón a) en un período, 112 minutos, b) en un día, c) en un ciclo ( 10 días) 
Debido a que la Tierra rota $0.25^{\circ}$ cada minuto en relación al plano orbital del satélite los puntos sobre el ecuador iluminados por el radar en órbitas sucesivas migran $28^{\circ}$ en longitud hacia el oeste, como muestra la Figura 2.2.a). Al cabo de un día el satélite completa 12.85 revoluciones trazando el recorrido que se muestran en la Figura 2.2.b).

La misión TOPEX/Poseidón fue diseñada de forma tal que, al cabo de cierto número de revoluciones, el radar ilumine exactamente los mismos puntos de la superficie del mar. Esto sucede cada 9.9156 días solares. Al cabo de este tiempo, conocido como ciclo, el satélite completa 127 revoluciones. La Figura 2.2.c) muestra el recorrido del satélite en un ciclo.

Luego de un ciclo el satélite revisita el mismo punto de la superficie, pero existe una diferencia temporal, llega al mismo punto 2.5 horas más temprano. Para remuestrear un punto a la misma hora local es necesario que transcurran 96 días. Esta es la principal debilidad de la altimetría satelital como fuente de información ionosférica.

\subsubsection{Las señales altimétricas}

La combinación de propiedades físicas de la atmósfera de la Tierra y de la superficie del mar establece el rango de frecuencias adecuado para la altimetría satelital. A frecuencias superiores a los $18 \mathrm{GHz}$ la atenuación de la señal por causa de la atmósfera se incrementa rápidamente, reduciendo la potencia de la señal transmitida hacia la superficie del mar y de la señal reflejada recibida por el altímetro. A frecuencias inferiores a los $2 \mathrm{GHz}$ se incrementan los efectos de la ionosfera y aumentan las interferencias de origen terrestres producidas por diferentes fuentes de radiación electromagnética.

Dentro del rango de frecuencias señalado se ubican las bandas $C$ (4.20-5.75 GHz) y $\mathrm{Ku}$ (10.9-22.0 GHz). En respuesta a los factores mencionados, los radares altimétricos operan en dos bandas pertenecientes a estas regiones del espectro: la señal primaria centrada en $13.6 \mathrm{GHz}$, en la banda $K_{u}$, y la secundaria centrada en $5.3 \mathrm{GHz}$, en la banda C, utilizada para corregir el error que introduce la ionosfera en la medición de la distancia.

El ancho de banda de las señales está determinado por otros dos factores primarios en el diseño de un sistema altimétrico, como son el tamaño de la antena, totalmente condicionado por la posibilidad de ser transportado y desplegado, y el tamaño de la superficie sobre la cual se va a medir la distancia entre el altímetro y superficie media del mar. Esta región debe ser tal que, sobre 
ella, el campo de ondas y las irregularidades inducidas por el viento sean prácticamente homogeneas. Esta condición se cumple para una región circular con un diámetro de 1-10 km.

La antena de la misión TOPEX/Poseidón es un disco de $1.5 \mathrm{~m}$ de diámetro. Definidos el tamaño de la antena y la frecuencia del pulso, el diámetro de la región del mar sobre la cual se va a efectuar la medición está dado por la duración del pulso emitido. En la Figura 2.3. se esquematiza la forma de la región de intersección del frente de onda y la superficie plana del mar (footprint) para pulsos de duración creciente.

Un pulso de una duración de unos pocos nanosegundos satisface el requerimiento de un diámetro de entre 1 y $10 \mathrm{~km}$ para la región iluminada. Se optó por un pulso de 102.4 us de duración, que determina un ancho de banda de $320 \mathrm{MHz}$ para ambas señales.
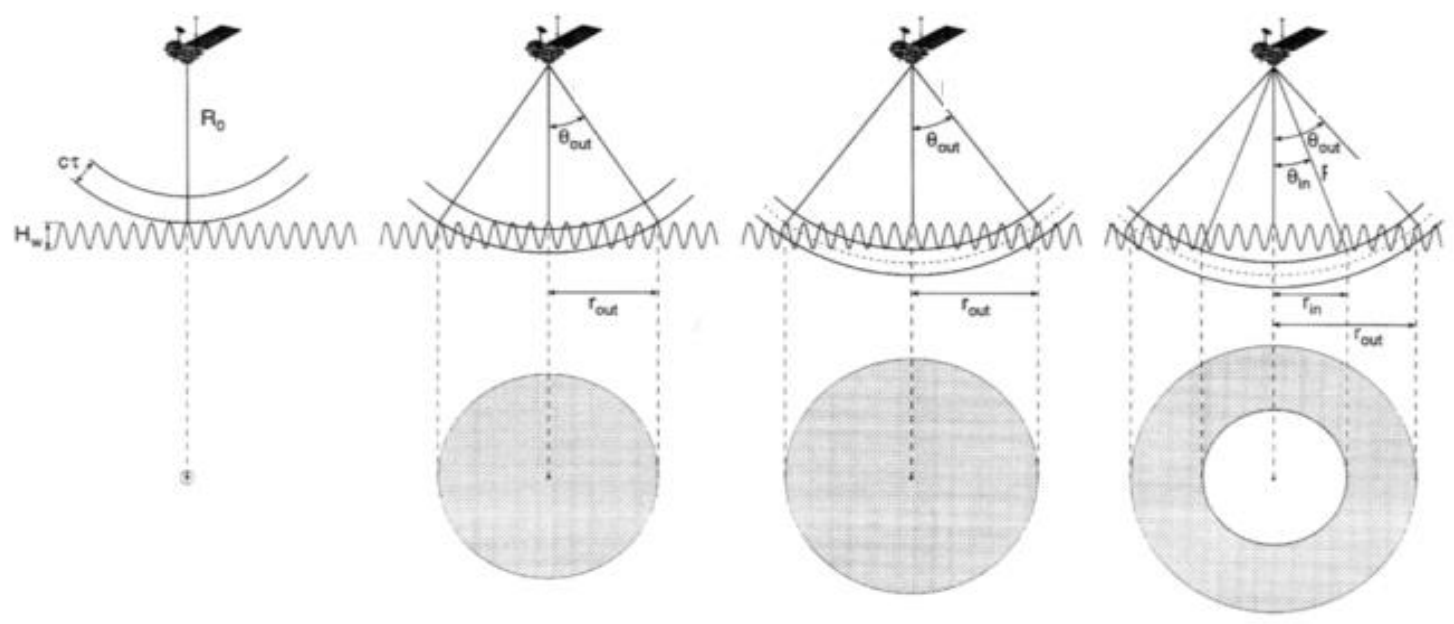

Figura 2.3. TOPEX/Poseidón footprint (Chelton et al., 2001).

\subsubsection{Observable altimétrico}

El concepto básico de la altimetría satelital es simple. El objetivo principal es medir la distancia $R$ entre el satélite y la superficie del mar. El altímetro transmite un pulso corto hacia la superficie, el pulso interactúa con la superficie rugosa del mar y parte de la radiación incidente se refleja y regresa al altímetro. La distancia $\rho$ del satélite al nivel medio del mar se estima a partir del tiempo completo que transcurre desde que la señal sale hasta que regresa al altímetro, t, como

I. Bibbó | GPS y altimetría satelital para estudios ionosféricos 


$$
\rho=\hat{\rho}-\sum_{\mathrm{j}} \Delta \rho_{\mathrm{j}}
$$

donde $\hat{\rho}=\mathrm{ct} / 2$ es la distancia calculada a partir del tiempo t observado despreciando la refracción y considerando la velocidad de la luz en el vacío c. $\Delta \rho_{\mathrm{j}}$, con $\mathrm{j}=1,2 \ldots$. , son correcciones para las diferentes componentes de la refracción atmosférica y errores relacionados con la interface aire-mar. Se llama $\Delta \rho_{\text {ion }}$ a la corrección que tiene en cuenta el efecto de la ionósfera.

En la sección 2.1 se demostró que en un medio dispersivo como la ionósfera, para frecuencias del orden de los $\mathrm{GHz}$, el índice de refracción de grupo puede aproximarse (ecuación 2.4) como

$$
\mathrm{n}_{\mathrm{g}} \cong 1+\frac{40.28 \mathrm{n}_{\mathrm{e}}}{\mathrm{f}^{2}}
$$

donde $\mathrm{f}$ es la frecuencia central del grupo expresada en $\mathrm{Hz}$ y $\mathrm{n}_{\mathrm{e}}$ es la densidad electrónica dada en electrones $/ \mathrm{m}^{3}$. En este caso, de acuerdo con la ecuación 2.9. la corrección ionosférica a la distancia geométrica $\rho$ es

$$
\Delta \rho_{\text {ion }}=\int_{S_{1}}^{S_{2}}\left[n_{g}-1\right] \mathrm{ds}=\frac{40.28}{\mathrm{f}^{2}} \int_{0}^{\mathrm{R}} \mathrm{n}_{\mathrm{e}} \mathrm{ds}
$$

donde la integración se realiza desde el nivel del mar hasta la altura del satélite $\mathrm{R}=1336 \mathrm{~km}$. Como el pulso de radar está dirigido verticalmente, la integral $\int_{0}^{R} n_{e} d s$ representa el contenido electrónico total vertical vTEC (ver sección 2.1.3), entonces resulta:

$$
\Delta \rho_{\text {ion }}=\frac{40.28}{\mathrm{f}^{2}} \text { vTEC }
$$

Con anterioridad al lanzamiento de la misión TOPEX/Poseidón la corrección ionosférica se calculaba en base a estimaciones de VTEC realizadas con modelos semi-empíricos con errores que podían superar los $8 \mathrm{~cm}$ (Mannucci et al., 1998). La precisión alcanzada en la determinación de la órbita de los satélites altimétricos y la búsqueda de una precisión de $1 \mathrm{~cm}$ en la medición de la distancia satélite-nivel medio del mar, hicieron necesario el mejoramiento en la precisión de $\Delta \rho_{\text {ion }}$. Como hemos visto en la sección 2.2.3.c, la dependencia de $\Delta \rho_{\text {ion }}$ con la frecuencia permite calcular el contenido electrónico total a partir de mediciones realizadas en dos frecuencias. Con este propósito, TOPEX/Poseidón fue el primer satélite que llevó a bordo un altímetro de doble frecuencia.

La técnica para estimar la distancia con doble frecuencia y los errores asociados puede entenderse expresando la distancia verdadera $\rho$ desde el satélite hasta la superficie del mar en términos de la distancia medida $\hat{\rho}_{i}$ : 


$$
\rho=\hat{\rho}_{\mathrm{i}}-\Delta \rho_{\mathrm{ion}, \mathrm{i}}+\varepsilon_{\mathrm{i}}
$$

$\hat{\rho}_{i}$ se obtiene midiendo el tiempo que tarda la señal de frecuencia $f_{\mathrm{i}}$ en el trayecto completo despreciando los efectos de la refracción ionosférica, $\hat{\rho}_{i}=c t_{i} / 2 . \Delta \rho_{\text {ion, } i}$ es la corrección ionosférica y $\varepsilon_{i}$ es el error total de origen no ionosférico. Sustituyendo en esta expresión el término $\Delta \rho_{\text {ion, } i}$ por la ecuación 2.25 y multiplicando por $\mathrm{f}_{\mathrm{i}}^{2}$ ambos miembros, se obtiene:

$$
\rho \mathrm{f}_{\mathrm{i}}^{2}=\hat{\rho}_{\mathrm{i}} \mathrm{f}_{\mathrm{i}}^{2}-40.28 \mathrm{vTEC}+\varepsilon_{\mathrm{i}} \mathrm{f}_{\mathrm{i}}^{2}
$$

Para el altímetro de dos frecuencias TOPEX/Poseidón, se reemplaza el subíndice i por $\mathrm{k}$ y $\mathrm{C}$ para identificar las bandas $\mathrm{Ku}$ y $\mathrm{C}$ respectivamente, y obtienen dos expresiones, una con $\mathrm{f}_{\mathrm{K}}=13.6 \mathrm{GHz}$ y la otra con $\mathrm{f}_{\mathrm{C}}=5.3 \mathrm{GHz}$. Restando ambas $\mathrm{y}$ normalizando con $\left(\mathrm{f}_{\mathrm{k}}^{2}-\mathrm{f}_{\mathrm{c}}^{2}\right)$ se obtiene:

$$
\rho=\tilde{\rho}+\tilde{\varepsilon}
$$

donde

$$
\tilde{\rho}=\mathrm{a}_{\mathrm{k}} \hat{\mathrm{p}}_{\mathrm{k}}-\mathrm{a}_{\mathrm{c}} \hat{\rho}_{\mathrm{c}}
$$

es la distancia combinada estimada con el altímetro de doble frecuencia y

$$
\tilde{\varepsilon}=a_{k} \varepsilon_{k}-a_{c} \varepsilon_{c}
$$

es el error combinado de medición de la distancia con dos frecuencias.

Los coeficientes adimensionales $\mathrm{a}_{\mathrm{k}}$ y $\mathrm{a}_{\mathrm{c}}$ son

$$
\begin{aligned}
& a_{k}=\frac{1}{1-\delta_{\mathrm{f}}^{2}} \\
& \mathrm{a}_{\mathrm{c}}=\frac{\delta_{\mathrm{f}}^{2}}{1-\delta_{\mathrm{f}}^{2}}
\end{aligned}
$$

donde $\delta_{\mathrm{f}}=\mathrm{f}_{\mathrm{c}} / \mathrm{f}_{\mathrm{k}}$ es el cociente entre las dos frecuencias.

En la práctica se procede de la siguiente forma. En primer término se calculan las distancias individuares $\hat{\rho}_{\mathrm{k}} \mathrm{y} \hat{\rho}_{\mathrm{c}}$ a partir del tiempo que tardan las señales de radar despreciando los efectos de la refracción atmosférica. Luego se corrige cada una de ellas por separado por efecto del estado de mar; esta corrección tiene en cuenta que los elementos de la superficie del mar iluminados por el radar dispersan la señal de forma no homogénea. Finalmente se calcula la corrección ionosférica a la distancia en la banda Ku. Igualando las ecuaciones 2.26 y 2.28 y despejando $\Delta \rho_{\text {ion, } \mathrm{k}}$ resulta

$$
\Delta \rho_{\text {ion, } \mathrm{k}}=\hat{\rho}_{k}+\varepsilon_{k}-\tilde{\rho}-\tilde{\varepsilon}
$$


Reemplazando $\tilde{\rho}$ y $\tilde{\varepsilon}$ por las ecuaciones 2.29 y 2.30 , respectivamente, y considerando que a partir de su definición las constantes $\mathrm{a}_{k} \mathrm{y} \mathrm{a}_{c}$ son tales que $\mathrm{a}_{k}-\mathrm{a}_{c}=1$, resulta:

$$
\Delta \rho_{\text {ion,k }}=\mathrm{a}_{c}\left(\hat{\rho}_{c}-\hat{\rho}_{k}\right)+\mathrm{a}_{c}\left(\varepsilon_{c}-\varepsilon_{k}\right)
$$

De esta forma se calcula, entonces, la corrección ionosférica en la banda $K_{u}$ a partir de las cantidades observacionales $\hat{\rho}_{c}$ y $\hat{\rho}_{k}$.

Finalmente, a través de la ecuación 2.25 se obtiene la relación entre el contenido electrónico total vertical y la corrección ionosférica altimétrica

$$
\mathrm{vTEC}=\frac{\mathrm{f}_{\mathrm{k}}^{2}}{40.28} \Delta \rho_{\text {ion, } \mathrm{k}}
$$

Es importante tener en cuenta que, de acuerdo con la ecuación anterior, cualquier error sistemático en las distancias $\hat{\rho}_{c}$ y $\hat{\rho}_{k}$ contaminará el cálculo de la corrección ionsférica $\Delta \rho_{\text {ion,k. }}$. Los errores instrumentales en las distancias altimétricas en las bandas $\mathrm{C}$ y $\mathrm{K}_{u}$ son esencialmente al azar y por lo tanto no constituyen un error sistemático en la determinación de $\Delta \rho_{\text {ion,k }}$. Las correcciones troposféricas húmeda y seca son independientes de la frecuencia y no contaminan a $\Delta \rho_{\text {ion,k. }}$. Las correcciones por estado del mar sí dependen de la frecuencia, entonces cualquier error sistemático en su determinación será malinterpretado como un error ionosférico.

\subsubsection{Fortalezas y limitaciones de los datos altimétricos}

Las ventajas que ofrecen los satélites altimétricos para estudiar la ionosfera complementan las debilidades de los satélites GPS, y son:

- que las misiones TOPEX/Poseidón proveen series largas y continuas en el tiempo de TEC sobre las regiones oceánicas de la Tierra, en latitudes geográficas comprendidas entre los $+66^{\circ}$ y $-66^{\circ}$,

- que las estimaciones del TEC vertical son directas, no involucran función de mapeo alguna,

- que a lo largo del camino orbital, tanto la resolución espacial como temporal de los datos son muy altas (una muestra por segundo).

Como limitaciones se observa que:

- la resolución temporal y espacial de los datos a escala global es muy pobre, 
- Ios satélites altimétricos no muestrean la parte continental del planeta,

- si bien los datos tienen una precisión estimada de \pm 1 TECu haciendo un promedio móvil con ventanas de $\sim 20$ seg los datos contienen un error sistemático de algunas TECu (Imel, 1994). 


\section{Capítulo 3: Asimilación de datos en LPIM}

En la actualidad la mayoría de los modelos, ya sean físicos o empíricos, son capaces de reproducir las variaciones del contenido electrónico de la atmósfera de la Tierra en altitud, latitud, longitud, diurnas, estacionales y asociadas al ciclo solar. Estos cambios, descriptos en el Capítulo 1 (sección 1.4.4), son conocidos como el clima espacial. Sin embargo, para modelar y predecir el tiempo, es decir la variabilidad de la concentración de electrones hora a hora, hacen falta enormes esfuerzos teóricos y computacionales.

Los modelos más promisorios para especificar y predecir el tiempo ionosférico son los modelos de asimilación de datos (Scherliess et al., 2006). Los modelos de asimilación e ingestión de datos han sido utilizados en las décadas pasadas en meteorología y oceanografía, pero la implementación de estas técnicas en la ionosfera no resultaba conveniente debido a la insuficiencia de datos observacionales. Esta realidad está cambiando rápidamente y la asimilación de los nuevos datos en los modelos ionosféricos existentes representa un nuevo desafío.

El Modelo Ionosférico La Plata LPIM es un modelo empírico que hasta ahora se nutre con los datos que provee la red permanente de estaciones GPS. Las estaciones receptoras están ubicadas sobre la parte continental del planeta, con excepción de unas pocas estaciones insulares. De este modo, sobre los océanos el modelo de La Plata estima el contenido electrónico en base a los datos registrados sobre los continentes. Por su parte, las misiones altimétricas TOPEX/Poseidón y Jason proporcionan una medida directa del contenido electrónico sobre los mares. El presente trabajo propone asimilar al modelo ionosférico de La Plata los datos altimétricos para subsanar la escasa cobertura de sistema GPS sobre los océanos.

Por otra parte, el contenido electrónico medido con GPS está contaminado por biases instrumentales (sección 2.2.3). En la actualidad los biases de los receptores constituyen la principal fuente de error en la estimación del contenido electrónico con GPS (Sardón, 1997). Se espera que la asimilación de datos altimétricos impacte también en la calibración de los biases instrumentales. 


\subsection{El Modelo Ionosférico de La Plata}

El Modelo Ionosférico La Plata (La Plata Ionospheric Model LPIM) es un desarrollo iniciado en la Facultad de Ciencias Astronómicas y Geofísicas de la Universidad Nacional de La Plata hace más de veinte años. Se trata de un modelo ionosférico empírico que permite calcular la distribución global del contenido electrónico total vertical a partir de observaciones realizadas con GPS.

La primera versión de LPIM (Brunini, 1998) asimilaba datos de 40 estaciones pertenecientes a la red IGS distribuidas globalmente para generar dos mapas globales diarios de VTEC con una resolución espacial limitada. A partir de entonces se ha logrado una continua actualización y uso del modelo (Gende, 2002; Azpilicueta et al., 2005; Azpilicueta, 2006; Cueto et al., 2007; Mosert et al., 2007; Sahai et al., 2008; Azpilicueta and Brunini, 2009; Sahai et al., 2009-a y b; de Jesus et al., 2010; Brunini et al., 2011 a y b). LPIM permite representaciones tanto globales como locales y regionales del vTEC con una resolución espacial de unos 15 grados y una resolución temporal de aproximadamente 2 horas; admite el uso de distintos observables GPS y la elección de diferentes coordenadas.

Brevemente, en el modelo LPIM la ionósfera se aproxima mediante una capa esférica delgada ubicada a una altura aproximada de $400 \mathrm{~km}$. La distribución espacial del VTEC sobre la capa está representada por una combinación lineal de funciones bidimensionales dependientes de la latitud y la longitud, mientras que la variabilidad temporal del VTEC queda representada por los coeficientes de la combinación lineal, que son funciones dependientes del tiempo. Los valores de los coeficientes son ajustados con datos observacionales mediante el método de mínimos cuadrados.

\subsubsection{La capa delgada}

Para modelar el contenido electrónico total con LPIM se hace uso de una aproximación simple, justificada en la sección 1.4.1.c, y ampliamente utilizada (Mannucci et al, 1998, Schaer, 1999), como es suponer que todos los electrones libres de la atmósfera se hallan contenidos en una cáscara esférica de espesor infinitesimal situada a una altura próxima a la ubicación del máximo del perfil de densidad electrónica, es decir, entre los 350 y $450 \mathrm{~km}$ de altura. 


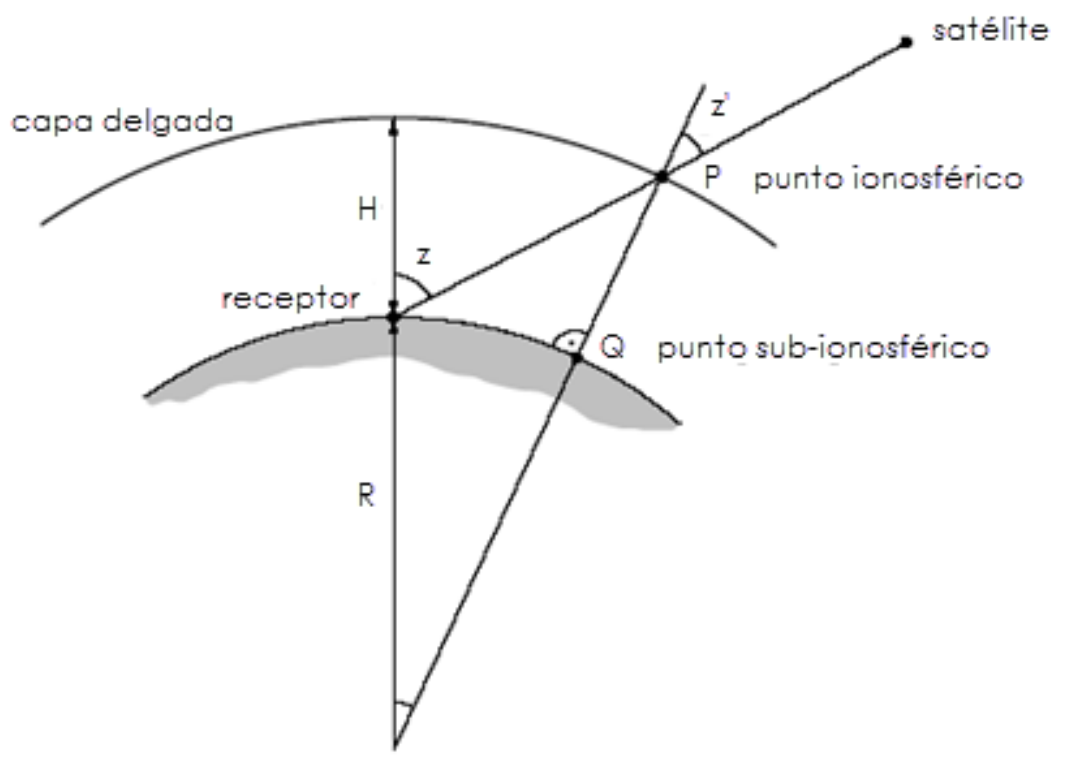

Figura 3.1. Representación esquemática del modelo de capa delgada (Schaer, 1999).

Como se esquematiza en la Figura 3.1, la señal proveniente de un satélite atraviesa la lámina delgada en el punto $\mathrm{P}$ (conocido como ionospheric pierce point) con un ángulo cenital $\mathbf{z}^{\prime}$ y llega al receptor con una distancia cenital z. La proyección del punto P sobre la superficie de la Tierra es el punto sub-ionosférico Q de latitud y longitud geográficas $\varphi$ y $\lambda$.

\subsubsection{La función de mapeo}

En la sección 2.1 se vio que el retardo que sufre la señal GPS en la ionosfera es función del contenido electrónico a lo largo del camino que une el receptor con el satélite, o sea del contenido electrónico total oblicuo sTEC.

El sTEC depende de la posición relativa entre la estación de monitoreo y el satélite emisor de la señal y por lo tanto no es una cantidad ideal para mapear el contenido electrónico global, como sería el vTEC. Ambas cantidades están relacionadas por una función de mapeo $\mathrm{M}$ que permite la conversión de una a la otra:

$$
M=\frac{\text { sTEC }}{\text { vTEC }}
$$


Suponiendo que la ionosfera es uniforme regionalmente, es posible obtener una función de mapeo geométrica simple proyectando de sTEC en la dirección vertical:

$$
\mathrm{M}\left(\mathrm{z}^{\prime}\right)=\frac{1}{\cos \left(\mathrm{z}^{\prime}\right)}
$$

donde $\mathrm{z}^{\prime}$ es la distancia cenital del satélite en el punto ionosférico P.

Es posible expresar M como función de la distancia cenital z del satélite en la estación de monitoreo. De acuerdo a la Figura 3.1, aplicando el teorema del seno en el triángulo formado por el centro de la Tierra, el receptor y el punto ionosférico se obtiene la relación:

$$
\operatorname{sen}\left(z^{\prime}\right)=\frac{R}{R+H} \operatorname{sen}(z)
$$

donde $\mathrm{R}$ es el radio medio de la Tierra, $\mathrm{R} \cong 6371 \mathrm{~km}$, y $\mathrm{H}$ es la altura de la capa delgada.

Haciendo uso de la relación anterior, la función de mapeo (ecuación 3.2) resulta entonces:

$$
M(z)=\frac{1}{\sqrt{1-\left(\frac{R}{R+H} \operatorname{sen}(z)\right)^{2}}}
$$

\subsubsection{Sistema de coordenadas}

Para mapear la distribución global del contenido electrónico es conveniente utilizar un sistema de coordenadas donde las estructuras espaciales a representar presenten gradientes suaves y no correlacionados en cada coordenada.

Dado que la principal fuente de ionización de la atmósfera es la radiación solar, la mayor concentración de iones se encuentra próxima al punto sub-solar, esto es, la proyección del Sol sobre la superficie de la Tierra.

Por esta razón, en el sistema de coordenadas utilizado, en una primera aproximación, el Sol permanece fijo y las principales estructuras de VTEC congeladas. Este sistema, llamado sistema de coordenadas Sol fijo, es un sistema geocéntrico con el eje z paralelo al dipolo magnético. El sistema rota alrededor del eje $z$ con el eje $x$ dirigido hacia el meridiano terrestre que contiene al Sol y el 
eje y dirigido perpendicularmente a ambos. El plano fundamental está definido por el ecuador magnético y sobre él se mide la coordenada ángulo horario $h$.

Figura 3.2. Plano fundamental del sistema Sol fijo

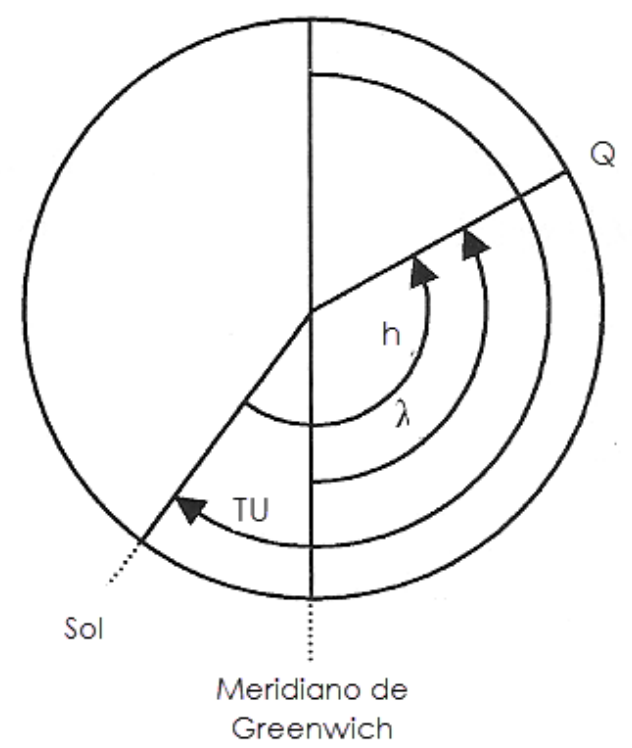

En la Figura 3.2 se halla representado el plano fundamental. Sea Q la proyección sobre este plano de un punto sub-ionosférico cuya longitud geográfica es $\lambda$; el ángulo horario h del punto $Q$ está dado por:

$$
\mathrm{h}=\lambda+\mathrm{UT}-12
$$

donde UT es el tiempo universal de la observación (con $\lambda$, UT y h expresados en horas).

Por otro lado, en la sección 1.3 se vio que los electrones libres se redistribuyen en la atmósfera de la Tierra bajo la influencia de las fuerzas de origen magnético. Entonces, un sistema latitudinal apropiado para representar la distribución de VTEC debería estar asociado al campo magnético de la Tierra. El sistema de coordenadas geomagnético definido en la sección 1.3.1 ha sido utilizado tradicionalmente para modelar el contenido electrónico. Sin embargo, evidencias observacionales llevaron a reformular el sistema latitudinal utilizado por LPIM (Azpilicueta, 2006) de forma tal que se adapte al campo magnético real; en este sistema la coordenada latitudinal se llama dip modificada o modip $\mu$ y está definida por la ecuación

$$
\tan \mu=\frac{\mathrm{I}}{\sqrt{\cos \varphi}}
$$


donde I es la inclinación magnética (magnetic dip), ángulo que forma el vector campo magnético con el plano horizontal (usualmente a $350 \mathrm{~km}$ de altura) y $\varphi$ es la latitud geográfica. De acuerdo con esta definición, el ecuador modip está determinado por los puntos donde la inclinación magnética es cero. En la región ecuatorial modip, las líneas de modip constante son prácticamente iguales a las de inclinación magnética, pero a medida que la latitud se incrementa las líneas se aproximan a las de latitud geográfica constante. Los polos modip coinciden con los polos geográficos.

\subsubsection{Parametrización de vTEC}

Para representar la variabilidad espacio-temporal del VTEC sobre la capa delgada, LPIM utiliza un desarrollo en funciones armónicas esféricas dependiente del tiempo universal $\mathrm{t}$, el ángulo horario $\mathrm{h}$ y la latitud modip $\mu$ expresada a través de la siguiente ecuación:

$\operatorname{vTEC}(\mathrm{h}, \mu)=\sum_{\mathrm{l}=0}^{\mathrm{L}} \sum_{\mathrm{m}=0}^{\mathrm{l}}\left\{\mathrm{a}_{\mathrm{l}, \mathrm{m}, \mathrm{k}}(\mathrm{t}) \cos \left(\frac{2 \pi \mathrm{mh}}{24}\right)+\mathrm{b}_{\mathrm{l}, \mathrm{m}, \mathrm{k}}(\mathrm{t}) \operatorname{sen}\left(\frac{2 \pi \mathrm{mh}}{24}\right)\right\} \mathrm{P}_{\mathrm{l}, \mathrm{m}}(\operatorname{sen} \mu)$

$\mathrm{P}_{1, \mathrm{~m}}(\operatorname{sen} \mu)$ es la función asociada de Legendre normalizada de grado l y orden $\mathrm{m}$.

El factor de normalización utilizado es este trabajo es $\Lambda_{\mathrm{l}, \mathrm{m}}=\sqrt{2 \frac{(2 \mathrm{l}+1)(1-\mathrm{m}) !}{1+\delta_{0, \mathrm{~m}}(1+\mathrm{m}) !}}$, donde $\delta_{0, \mathrm{~m}}$ es la delta de Kronecker.

Los coeficientes armónicos $\mathrm{a}_{\mathrm{l}, \mathrm{m}, \mathrm{k}}(\mathrm{t})$ y $\mathrm{b}_{\mathrm{l}, \mathrm{m}, \mathrm{k}}(\mathrm{t})$ representan la variación temporal, son las incógnitas, y se ajustarán utilizando los datos observacionales. Son funciones escalón con saltos horarios:

$$
\begin{aligned}
& \mathrm{a}_{\mathrm{l}, \mathrm{m}, \mathrm{k}}(\mathrm{t})=\mathrm{a}_{\mathrm{l}, \mathrm{m}, \mathrm{k}} \\
& \mathrm{b}_{\mathrm{l}, \mathrm{m}, \mathrm{k}}(\mathrm{t})=\mathrm{b}_{\mathrm{l}, \mathrm{m}, \mathrm{k}}
\end{aligned}
$$

En este trabajo se considerarán 12 intervalos horarios diarios de 2 horas, entonces $\mathrm{k}=1,2, \ldots 12$.

El número de parámetros en la ecuación 3.4 está dado por $n=(L+1)^{2}$, o si se trunca la serie en un orden máximo $\mathrm{M} \leq \mathrm{L}$, por $\mathrm{n}=(\mathrm{L}+1)^{2}-(\mathrm{L}-\mathrm{M})(\mathrm{L}-\mathrm{M}+1)$. 
Los valores máximos L y M establecen la resolución espacial de la expansión en armónicos esféricos truncada:

$$
\begin{aligned}
& \Delta \varphi=\frac{2 \pi}{\mathrm{L}} \\
& \Delta \mathrm{h}=\frac{2 \pi}{\mathrm{M}}
\end{aligned}
$$

La elección del grado máximo L de expansión es un compromiso entre el tiempo de cálculo requerido para el ajuste y la resolución espacial requerida para la representación de $\mathrm{VTEC}$. En este trabajo se tomará $\mathrm{L}=15$ para distinguir la estructura de doble pico de la anomalía ecuatorial.

\subsubsection{Ecuación de observación y restricciones}

En la sección 2.2.3.d fue definido el observable GPS $\tilde{L}_{4}$. $\tilde{\mathrm{L}}_{4}$ es la combinación lineal libre de geometría de las observaciones de los códigos $\mathrm{P}_{1}$ y $\mathrm{P}_{2}$, suavizada con las observaciones de las fases de las portadoras $L_{1}$ y $L_{2}$.

De acuerdo con la ecuación 2.22, la ecuación de observación GPS es

$$
\tilde{\mathrm{L}}_{4}=\mathrm{KsTEC}+\mathrm{c}\left(\Delta \mathrm{B}^{\mathrm{k}}+\Delta \mathrm{B}_{\mathrm{i}}\right)-\varepsilon
$$

donde sTEC es el contenido de electrones total oblicuo a lo largo de la línea de visión receptor-satélite,

$$
\mathrm{K}=\left(\frac{1}{\mathrm{f}_{1}^{2}}-\frac{1}{\mathrm{f}_{2}^{2}}\right) 40.28=-0.105 \frac{\mathrm{m}}{\mathrm{TECUs}}
$$

$\Delta \mathrm{B}^{\mathrm{k}}$ y $\Delta \mathrm{B}_{\mathrm{i}}$ son los retardos instrumentales que se producen en el hardware $\mathrm{y}$ firmware del satélite $\mathrm{k}$ y del receptor $\mathrm{i}$, y $\varepsilon$ representa los errores no modelados.

Dividiendo miembro a miembro la ecuación de observación por la constante K, trasformado el TEC oblicuo en TEC vertical a través de la función de mapeo M(z) dada por la ecuación 3.3 y reemplazado vTEC por el desarrollo propuesto (ecuación 3.4), la ecuación de observación GPS resulta:

$$
\mathrm{l}_{\mathrm{G}}-\varepsilon_{\mathrm{G}}=\mathrm{M}(\mathrm{z}) \sum_{\mathrm{l}=0}^{\mathrm{L}} \sum_{\mathrm{m}=0}^{\mathrm{l}}\left\{\mathrm{a}_{\mathrm{l}, \mathrm{m}, \mathrm{k}}(\mathrm{t}) \cos \left(\frac{2 \pi \mathrm{mh}}{24}\right)+\mathrm{b}_{\mathrm{l}, \mathrm{m}, \mathrm{k}}(\mathrm{t}) \operatorname{sen}\left(\frac{2 \pi \mathrm{mh}}{24}\right)\right\} \mathrm{P}_{\mathrm{l}, \mathrm{m}}(\operatorname{sen} \mu)+\beta_{\mathrm{G}}^{\mathrm{S}}+\beta_{\mathrm{G}}^{\mathrm{R}}
$$


donde $l_{G}$ es el observable GPS, $\varepsilon_{G}$ representa el error en la medición de $l_{G}$, $\beta_{G}^{S}=\frac{c \triangle B^{k}}{K}$ y $\beta_{G}^{R}=\frac{C \Delta B_{i}}{K}$ son los retardos instrumentales o DCBs (diferencial code biases), todos expresados en TECUs. Los DCBs son tratados como incógnitas adicionales y son estimados junto con los coeficientes $\mathrm{a}_{\mathrm{l}, \mathrm{m}, \mathrm{k}}(\mathrm{t})$ y $\mathrm{b}_{\mathrm{l}, \mathrm{m}, \mathrm{k}}(\mathrm{t})$ del modelo ionosférico.

Expresado en forma matricial, el sistema de ecuaciones de observación GPS resulta

$$
\left(\mathbf{l}_{\mathrm{G}}\right)-\left(\boldsymbol{\varepsilon}_{\mathrm{G}}\right)=\left(\begin{array}{llll}
\mathbf{A}_{\mathrm{G}} & \mathbf{B}_{\mathrm{R}} & \mathbf{B}_{\mathrm{S}}
\end{array}\right)\left(\begin{array}{c}
\mathbf{x}_{\mathrm{G}} \\
\mathbf{y}_{\mathrm{G}}^{\mathrm{R}} \\
\mathbf{y}_{\mathrm{G}}^{\mathrm{S}}
\end{array}\right)
$$

donde $\mathbf{A}_{\mathrm{G}}$ contiene valores dados por $\cos \left(\frac{2 \pi m h}{24}\right) \mathrm{P}_{\mathrm{l}, \mathrm{m}}(\operatorname{sen} \mu)$ y $\operatorname{sen}\left(\frac{2 \pi m \mathrm{~m}}{24}\right) \mathrm{P}_{\mathrm{l}, \mathrm{m}}(\operatorname{sen} \mu)$ correspondientes a cada observación, mientras que $\mathbf{B}_{R}$ y $\mathbf{B}_{S}$ contienen unos en las columnas correspondientes al satélite y receptor que intervienen y ceros para los restantes. O simplemente:

$$
\mathbf{L}-\boldsymbol{\varepsilon}=\mathbf{A} \mathbf{x}
$$

donde $\mathbf{L}$ es el vector que contiene los datos, $\boldsymbol{\varepsilon}$ es el vector que contiene los errores de medición, $\mathbf{A}$ es la matriz de diseño y $\mathbf{x}$ es el vector que contiene a las incógnitas del problema: los coeficientes armónicos obtenidos a partir de datos GPS, $\mathbf{x}_{\mathrm{G}}, \mathrm{y}$ los retardos instrumentales de los receptores y los satélites del sistema GPS, $\mathbf{y}_{\mathrm{G}}^{\mathrm{R}}$ e $\mathbf{y}_{\mathrm{G}}^{\mathrm{S}}$ respectivamente.

En este trabajo, se estimará un conjunto de coeficientes para cada intervalo de dos horas y un valor diario de los retardos instrumentales para cada satélite y para cada receptor. Utilizando datos de aproximadamente 300 estaciones, al cabo de un día los datos GPS permiten formar un sistema de $10^{6}$ ecuaciones de observación.

El sistema se resuelve por el método de cuadrados mínimos. Imponiendo la condición $\boldsymbol{\varepsilon}^{\mathrm{T}} \boldsymbol{\varepsilon}=$ mínimo se obtiene la solución:

$$
\overline{\mathbf{x}}=\left(\mathbf{A}^{\mathrm{T}} \mathbf{A}\right)^{-1} \mathbf{A}^{\mathrm{T}} \mathbf{L}
$$

donde $\bar{x}$ es la estimación de los parámetros.

Reemplazando $\bar{x}$ en la ecuación 3.6, se obtiene el ajuste de las observaciones:

$$
\overline{\mathbf{L}}=\mathbf{A} \overline{\mathbf{x}}
$$

Luego, es posible estimar los errores como 


$$
\mathbf{L}-\overline{\mathbf{L}}=\overline{\boldsymbol{\varepsilon}}
$$

En un sentido riguroso, $\bar{\varepsilon}$ absorbe tanto los errores de mediciones como las limitaciones del modelo, por esta razón una denominación correcta para $\bar{\varepsilon}$ sería errores residuales. El error residual cuadrático medio está dado por:

$$
\sigma_{0}=\sqrt{\frac{\boldsymbol{\varepsilon}^{\mathrm{T}} \boldsymbol{\varepsilon}}{\mathrm{n}-\mathrm{k}}}
$$

donde $\mathrm{n}$ representa la cantidad de mediciones y $\mathrm{k}$ el número de parámetros a determinar.

Finalmente, es posible obtener una estimación de la propagación de los errores en los parámetros del modelo a través la matriz de varianza-covarianza de los parámetros:

$$
\sum=\sigma_{0}^{2}\left(\mathbf{A}^{\mathrm{T}} \mathbf{A}\right)^{-1}
$$

Los datos GPS permiten, a través de la ecuación 3.5, formar un sistema de más de medio millón de ecuaciones de observación que resuelve, como se dijo, usando el método de mínimos cuadrados. Para separar los retardos instrumentales de los satélites y receptores (que aparecen sumados en todas las ecuaciones provocando una deficiencia de rango de orden uno en el sistema de ecuaciones) es necesario agregar una ecuación de condición. En el caso de LPIM, esa ecuación de condición consiste en imponer que la suma de los retardos instrumentales de todos los satélites GPS sea igual a cero:

$$
\sum_{S} \beta_{\mathrm{G}}^{S}=0
$$

Esta estrategia es la misma que utiliza el International GNSS Service IGS; es equivalente a decir que el valor medio de los retardos de los satélites es nulo. Esto no es estrictamente cierto pero es razonable debido a los retardos en los satélites son pequeños en comparación con los retardos que sufre la señal en los receptores.

Por otra parte, con el objeto de atenuar las discontinuidades del VTEC entre los diferentes intervalos de una hora, en LPIM se imponen las siguientes condiciones estadísticas sobre los coeficientes armónicos:

$$
\mathrm{E}\left[\mathrm{a}_{\mathrm{l}, \mathrm{m}, \mathrm{k}+1}-\mathrm{a}_{\mathrm{l}, \mathrm{m}, \mathrm{k}}\right]=0 ; \mathrm{E}\left[\left(\mathrm{a}_{\mathrm{l}, \mathrm{m}, \mathrm{k}+1}-\mathrm{a}_{\mathrm{l}, \mathrm{m}, \mathrm{k}}\right)^{2}\right]=\sigma_{\mathrm{S}}^{2}
$$




$$
\mathrm{E}\left[\mathrm{b}_{\mathrm{l}, \mathrm{m}, \mathrm{k}+1}-\mathrm{b}_{\mathrm{l}, \mathrm{m}, \mathrm{k}}\right]=0 ; \mathrm{E}\left[\left(\mathrm{b}_{\mathrm{l}, \mathrm{m}, \mathrm{k}+1}-\mathrm{b}_{\mathrm{l}, \mathrm{m}, \mathrm{k}}\right)^{2}\right]=\sigma_{\mathrm{S}}^{2}
$$

$\mathrm{l}, \mathrm{m}=1,2, \ldots, 15 \mathrm{y} \mathrm{k}=1,2, \ldots, 11$

donde E[.] denota al operador esperanza matemática y $\sigma_{\mathrm{S}}^{2}$ es un factor de varianza establecido empíricamente.

\subsection{Asimilación de datos altimétricos}

Las técnicas de asimilación de datos combinan un modelo ionosférico subyacente con mediciones para estimar y predecir las características de la ionosfera. Formalmente, la asimilación de datos consiste en la fusión de información observacional de una o más fuentes en un modelo (Wilson et al. 2008). En la práctica depende de tres elecciones: un modelo subyacente (que puede ser físico o empírico), una representación de estado (por ejemplo, armónicos esféricos) y una estrategia de estimación.

En este trabajo se propone asimilar información observacional de los sistemas GPS y altimétricos TOPEX/Poseidón y sus sucesores Jason 1 y 2 en el modelo empírico LPIM, en el cual la ionosfera es aproximada por una capa de espesor infinitesimal, sin forzar un conjunto de datos hacia el otro. Las ventajas que ofrece cada grupo de datos han sido discutidas en el capítulo precedente.

El primer paso para lograr un modelo consistente demanda la definición de una estrategia de asimilación. En función de ella se actualiza el código LPIM y se analizan los efectos de la asimilación de datos en la determinación de la distribución global del contenido electrónico total vertical.

\subsubsection{Ecuación de observación TOPEX/Poseidón}

En la sección 2.3.4 se mostró que la corrección aplicada a las distancias altimétricas por efecto de la presencia de electrones libres en la atmósfera de la Tierra está relacionada con el contenido electrónico total vertical según la ecuación:

$$
\operatorname{vTEC}=\frac{\mathrm{f}_{\mathrm{k}}^{2}}{40.28} \Delta \rho_{\text {ion, }}
$$


donde vTEC es el contenido electrónico total vertical expresado en electrones $/ \mathrm{m}^{2}$, $\Delta \rho_{\text {ion, } \mathrm{k}}$ es la corrección altimétrica en la banda Ku expresada en $\mathrm{m}$ y $\mathrm{f}_{\mathrm{k}}=13.610^{9} \mathrm{~Hz}$ es la frecuencia central de la banda Ku expresada en $\mathrm{Hz}$.

Llamando $\mathrm{l}_{\mathrm{T}}$ a la cantidad $\frac{\mathrm{f}_{\mathrm{k}}^{2}}{40.28} \Delta \rho_{\mathrm{ion}, \mathrm{k}}$ expresada en TECUs, resulta

$$
\mathrm{l}_{\mathrm{T}}=\frac{1}{2.16} \Delta \rho_{\text {ion, } \mathrm{k}}
$$

$\operatorname{con} \Delta \rho_{\text {ion, } \mathrm{k}}$ expresada en $\mathrm{mm}$.

De acuerdo con la ecuación 3.8, el observable altimétrico $\mathrm{l}_{\mathrm{T}}$ es una medida directa de vTEC

$$
\mathrm{l}_{\mathrm{T}}=\mathrm{vTEC}
$$

Finalmente, reemplazando vTEC por el desarrollo en funciones armónicas esféricas propuesto (ecuación 3.4), se obtiene la ecuación de observación altimétrica

$$
\mathrm{l}_{\mathrm{T}}-\varepsilon_{\mathrm{T}}=\sum_{\mathrm{l}=0}^{\mathrm{L}} \sum_{\mathrm{m}=0}^{\mathrm{l}}\left\{\mathrm{a}_{\mathrm{l}, \mathrm{m}, \mathrm{k}}(\mathrm{t}) \cos \left(\frac{2 \pi \mathrm{mh}}{24}\right)+\mathrm{b}_{\mathrm{l}, \mathrm{m}, \mathrm{k}}(\mathrm{t}) \operatorname{sen}\left(\frac{2 \pi \mathrm{mh}}{24}\right)\right\} \mathrm{P}_{\mathrm{l}, \mathrm{m}}(\operatorname{sen} \mu)
$$

en la cual el término $\varepsilon_{\mathrm{T}}$ tiene en cuenta el error de medición de $\mathrm{l}_{\mathrm{T}}$.

\subsubsection{Estrategia de asimilación}

La reformulación del modelo propone el uso simultáneo de datos del sistema GPS y los satélites altimétricos TOPEX/Poseidón y Jason. Analíticamente, se parte del sistema de ecuaciones GPS, expresado por las ecuaciones 3.5, y se incorporan los datos altimétricos mediante la ecuación de observación 3.10. El nuevo sistema toma la forma

$$
\left\{\begin{array}{l}
\mathrm{l}_{\mathrm{G}}-\varepsilon_{\mathrm{G}}=\mathrm{M}(\mathrm{z}) \sum_{\mathrm{l}=0}^{\mathrm{L}} \sum_{\mathrm{m}=0}^{\mathrm{l}}\left\{\mathrm{a}_{\mathrm{l}, \mathrm{m}, \mathrm{k}}(\mathrm{t}) \cos \left(\frac{2 \pi \mathrm{mh}}{24}\right)+\mathrm{b}_{\mathrm{l}, \mathrm{m}, \mathrm{k}}(\mathrm{t}) \operatorname{sen}\left(\frac{2 \pi \mathrm{mh}}{24}\right)\right\} \mathrm{P}_{\mathrm{l}, \mathrm{m}}(\operatorname{sen} \mu)+\beta_{\mathrm{G}+\mathrm{T}}^{\mathrm{S}}+\beta_{\mathrm{G}+\mathrm{T}}^{\mathrm{R}} \\
\mathrm{l}_{\mathrm{T}}-\varepsilon_{\mathrm{T}}=\sum_{\mathrm{l}=0}^{\mathrm{L}} \sum_{\mathrm{m}=0}^{\mathrm{l}}\left\{\mathrm{a}_{\mathrm{l}, \mathrm{m}, \mathrm{k}}(\mathrm{t}) \cos \left(\frac{2 \pi \mathrm{mh}}{24}\right)+\mathrm{b}_{\mathrm{l}, \mathrm{m}, \mathrm{k}}(\mathrm{t}) \operatorname{sen}\left(\frac{2 \pi m h}{24}\right)\right\} \mathrm{P}_{\mathrm{l}, \mathrm{m}}(\operatorname{sen} \mu)
\end{array}\right.
$$


El sistema, expresado matricialmente resulta:

$$
\left(\begin{array}{l}
\mathbf{l}_{\mathrm{G}} \\
\mathbf{l}_{\mathrm{T}}
\end{array}\right)-\left(\begin{array}{c}
\boldsymbol{\varepsilon}_{\mathrm{G}} \\
\boldsymbol{\varepsilon}_{\mathrm{T}}
\end{array}\right)=\left(\begin{array}{ccc}
\mathbf{A}_{\mathrm{G}} & \mathbf{B}^{\mathrm{R}} & \mathbf{B}^{\mathrm{S}} \\
\mathbf{A}_{\mathrm{T}} & \mathbf{0} & \mathbf{0}
\end{array}\right) \cdot\left(\begin{array}{c}
\mathbf{x}_{\mathrm{G}+\mathrm{T}} \\
\mathbf{y}_{\mathrm{G}+\mathrm{T}}^{\mathrm{R}} \\
\mathbf{y}_{\mathrm{G}+\mathrm{T}}^{\mathrm{S}}
\end{array}\right)
$$

donde $\mathbf{A}_{\mathrm{G}}, \mathbf{B}_{\mathrm{R}}$ y $\mathbf{B}_{\mathrm{S}}$ tienen los elementos explicados para la ecuación 3.6 y $\mathbf{A}_{\mathrm{T}}$

contiene los $\cos \left(\frac{2 \pi m h}{24}\right) P_{1, m}(\operatorname{sen} \mu)$ y $\operatorname{sen}\left(\frac{2 \pi m h}{24}\right) P_{1, m}(\operatorname{sen} \mu)$ correspondientes a cada observación altimétrica. O de forma equivalente:

$$
\mathbf{L}-\boldsymbol{\varepsilon}=\mathbf{A} \cdot \mathbf{x}
$$

donde $\mathbf{L}$ es el vector que contiene los datos pertenecientes a las dos fuentes ( $\mathbf{l}_{\mathrm{G}}$ contiene los datos GPS y $\mathbf{l}_{\mathrm{T}}$ los datos TOPEX), $\boldsymbol{\varepsilon}$ es el vector que contiene los errores no modelados, $\mathbf{A}$ es la matriz de diseño y $\mathbf{x}$ es el vector que contiene las incógnitas del problema: los coeficientes armónicos calculados a partir de datos GPS y TOPEX $\mathbf{x}_{\mathrm{G}+\mathrm{T}}$ y los retardos instrumentales de los receptores $\mathbf{y}_{\mathrm{G}+\mathrm{T}}^{\mathrm{R}}$ y satélites $\mathbf{y}_{\mathrm{G}+\mathrm{T}}^{\mathrm{S}}$.

Con la incorporación de los datos altimétricos, la matriz de varianza-covarianza de los parámetros es $\boldsymbol{\Sigma}=\sigma_{0}^{2}\left(\mathbf{A}^{\mathrm{T}} \mathbf{A}\right)^{-1}$ suponiendo que los datos obtenidos con las dos técnicas tienen la misma dispersión.

En esta primera etapa del trabajo se asimilan bloques de 24 horas de información para obtener mapas ionosféricos globales con una resolución espacial de $\sim 15^{\circ}$ y una resolución temporal de 2 horas, suponiendo que los DCBs instrumentales se mantienen constantes en cada intervalo de 2 horas. Entonces, los parámetros a determinar para cada bloque de 24 horas son $15 \times(15-1) \times 12$ coeficientes del desarrollo en armónicos esféricos, 12 DCBs para cada receptor y 12 DCBs para cada satélite GPS.

\subsubsection{Datos observacionales}

Para este trabajo se ha seleccionado un periodo de alta actividad solar y por lo tanto de elevado contenido electrónico en la ionosfera. Específicamente se procesa una serie temporal que abarca los 100 primeros días del año calendario 2002. 


\subsection{3.a. Datos GPS}

En la actualidad existen miles de estaciones GPS de doble frecuencia distribuidas globalmente. Sin embargo, muchas de ellas se hallan concentradas en pequeñas regiones del planeta, o no alcanzan los estándares de control de calidad de los datos y por lo tanto no forman parte de las redes internaciones. Para este trabajo se utilizan datos de estaciones pertenecientes en su mayoría a la red global de monitoreo continuo IGS (International GNSS Service (http://igscb.jpl.nasa.gov) disponibles via ftp en ftp//garner.ucsd.edu/pub. Para evitar información redundante y reducir el tiempo de cálculo, en las zonas de mayor concentración de estaciones se seleccionó una estación por cada región de $5^{\circ}$ de latitud por $5^{\circ}$ de longitud. Se procesaron así datos de 298 estaciones; en el anexo 1 figura la lista completa de las estaciones utilizadas y sus coordenadas. La distribución geográfica de las mismas se aprecia en la Figura 3.3.

Figura 3.3. Estaciones IGS de monitoreo continuo utilizadas.

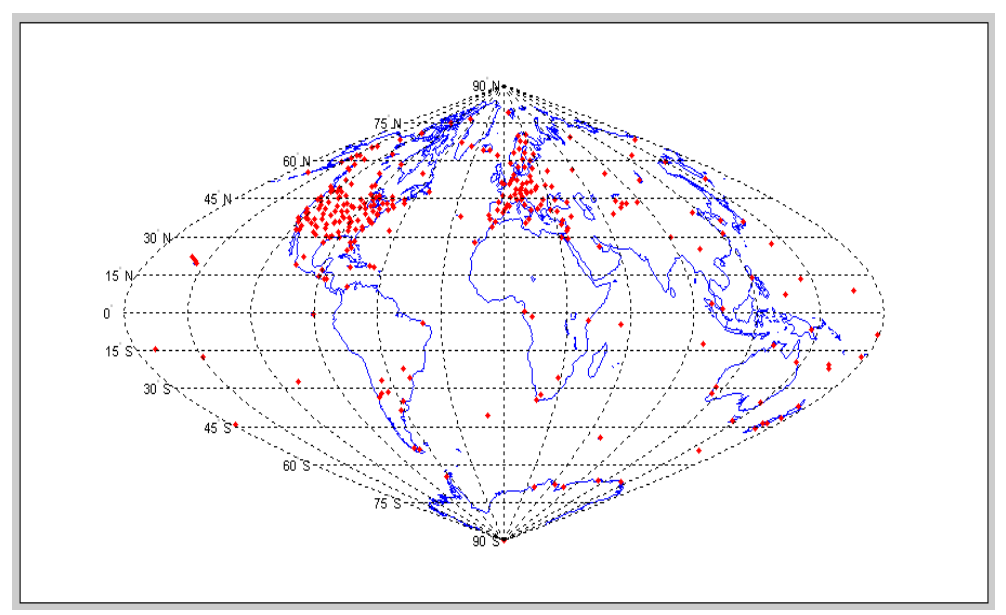

Es importante notar que la mayor parte de las estaciones GPS se encuentran sobre la parte continental del planeta, fundamentalmente en el hemisferio Norte, pero son escasas en el hemisferio sur y sobre la parte oceánica del globo.

\subsection{3.b. Datos altimétricos}

Por su parte, la altimetría satelital aporta información ionosférica sobre la superficie de los océanos. Dada la configuración orbital de las misiones altimétricas descriptas en la sección 2.3.2, en cada intervalo de tiempo los 
satélites TOPEX/Poseidón y Jason proveen un conjunto localizado de mediciones del VTEC, circunscripto a la trayectoria iluminada por el radar en ese lapso. Puntualmente, en cada intervalo de dos horas los satélites altimétricos muestrean la ionosfera sobre la parte oceánica del planeta comprendida entre los \pm 66 a lo largo de una trayectoria como la que se aprecia en la Figura 2.2.a. del capítulo anterior. En el transcurso de un día el satélite completa 12.85 revoluciones y la cobertura se amplía como muestra la Figura 2.2.b.

Sabiendo que se requieren 10 días corridos (un ciclo completo) para muestrear el contenido electrónico con la mayor resolución espacial que ofrecen las misiones altimétricas (Figura 2.2.c.) y un mínimo de 96 días para muestrear el contenido electrónico sobre cada punto con una cobertura horaria de 24 horas (ver sección 2.3.2.b), en esta etapa del trabajo se procesa una serie de 100 días continuos, asimilados en bloques de 24 horas. Para el año 2002 los datos altimétricos corresponden a la misión TOPEX/Poseidón.

Los datos de la misión TOPEX/Poseidón son distribuidos por los dos centros responsables de la misma, la NASA y la CNES, a través de sus respectivas agencias:

- PO.DAAC (Oceanography Distributed Active Archive Center, http://podaac.jpl.nasa.gov) perteneciente al Jet Propulsion Laboratory Physical, y

- AVISO (Archiavage, Validation et Interprétation des données des Satellites Océanographiques, http://www-aviso.cns.fr).

Se utilizaron los datos de la serie de gdr_c (geophisical data record, en su versión c) que constituyen un producto completamente validado. Se desarrolló un módulo de pre-procesamiento para filtrar los valores de la corrección ionosférica en la banda Ku registrados sobre la superficie del agua y corregidos por efecto del estado del mar (sección 2.3.4), para luego obtener el contenido electrónico mediante la ecuación 3.9.

Considerando un grupo de casi 300 estaciones de monitoreo GPS, en cada intervalo de un día el sistema de posicionamiento provee un conjunto de $\sim 10^{6}$ mediciones del contenido electrónico ionosférico, mientras que la altimetría satelital representa un incremento de aproximadamente un $10 \%$ en la cantidad de datos observacionales. 


\subsection{Resultados}

Como se ha señalado, siguiendo la estrategia de asimilación de datos altimétricos propuesta en la sección 3.2.3, se logró una versión actualizada del modelo ionosférico de La Plata que utiliza simultáneamente datos de la red de estaciones GPS y del satélite TOPEX/Poseidón. Se denominó LPIMG+T a esta versión para distinguirla del modelo original LPIMG basado en datos GPS únicamente. En la Figura 3.4 han sido representados los mapas ionosféricos globales (GIMs) obtenidos con la nueva versión del Modelo lonosférico de La Plata para intervalos de 2 horas correspondientes al día 7 del año 2002.

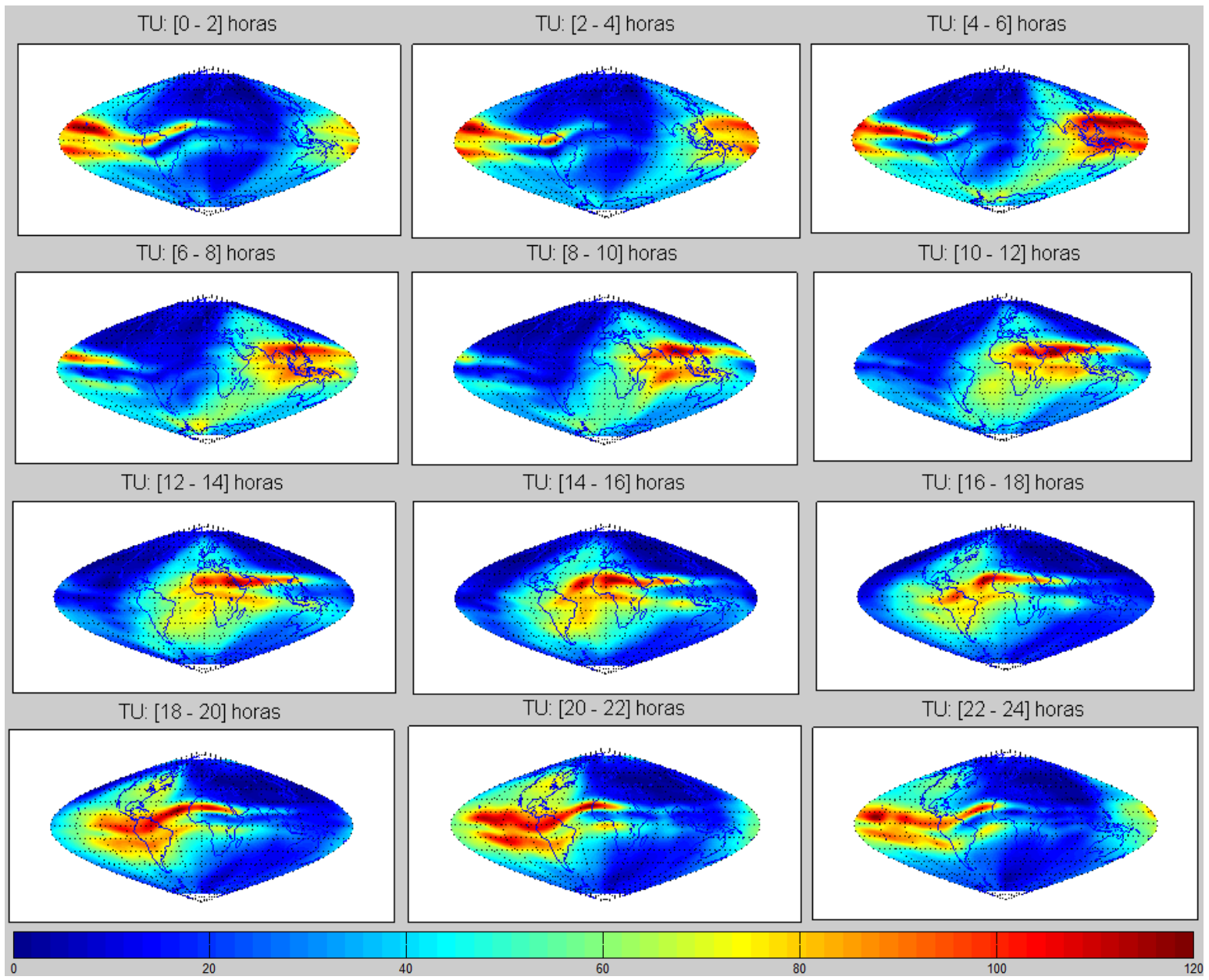

Figura 3.4. Mapas ionosféricos globales. En ellos se representa el vTEC obtenido con LPIMG+T para el día 7 del año 2002. 
A continuación se analiza el impacto de la asimilación de datos altimétricos tanto en el contenido electrónico global como en la calibración de los biases instrumentales.

\subsubsection{Contenido electrónico total vertical}

En primer término, se analiza la influencia de la asimilación de información de origen altimétrico comparando el contenido electrónico total estimado con el modelo ionosférico de La Plata en sus dos versiones, LPIMG+T y LPIMG.

\subsection{1.a. $\vee T E C_{T}, \vee T E C_{G}$ y $\vee T E C_{T+G}$}

Se dispone de un valor observacional puntual (en el sentido que se explicó en el capítulo 2, sección 2.3.3 ) del contenido electrónico vertical, VTEC , medido por el satélite TOPEX/Poseidón cada un segundo. Para cada uno de estos puntos, se calculan dos valores de VTEC, uno utilizando LPIMG, identificado como VTECG, y otro utilizando $\mathrm{LPIMG}_{\mathrm{G}+\mathrm{T}}$, identificado como $\mathrm{VTEC}_{\mathrm{G}+\mathrm{T}}$. Ambos valores se obtienen interpolando los valores del contenido electrónico total vertical en los mapas ionosféricos globales generados con sendas versiones de LPIM.

En la primera columna de la Figura 3.5 se grafican los valores del contenido electrónico total vertical $\operatorname{VTEC}_{G}$ (en rojo) y $\operatorname{VTEC}_{G+T}$ (en verde), calculados de acuerdo con la descripción realizada en el párrafo anterior, junto con el valor observado por TOPEX/Poseidón VTEC (en azul) en función del tiempo universal en intervalos de dos horas. El gráfico corresponde al día 07 del año 2002. Como puede observarse, ambas versiones de LPIM son capaces de reproducir con detalle las variaciones espacio-temporales del contenido electrónico ionosférico. A medida que avanza el tiempo, el satélite atraviesa regiones con diferente contenido electrónico. En los mapas ionsféricos del centro de la figura se ha superpuesto el recorrido del satélite en cada intervalo de dos horas. Para seguir su trayectoria sobre el mapa, en cada intervalo es necesario comenzar en la región en que aparecen dos trazos paralelos levemente separados (por ejemplo en el sur del continente africano para el intervalo [0-2] horas de TU) y tener presente que el movimiento se realiza hacia el este.

Figura 3.5 (dos páginas siguientes). Izquierda: Contenido electrónico total vTEC medido por TOPEX/Poseidón (en azul), modelado con LPIMG (en rojo) y modelado con LPIMG+T (en verde), en función del tiempo universal, en intervalos de 2 horas. Centro: Track del satélite TOPEX/Poseidón sobre mapas ionosféricos globales obtenidos con LPIMG+T . Derecha: Diferencia [GIMG+T - GIMG] entre los GIM obtenidos con LPIMG+T y LPIMG. Día 7 del año 2002. 

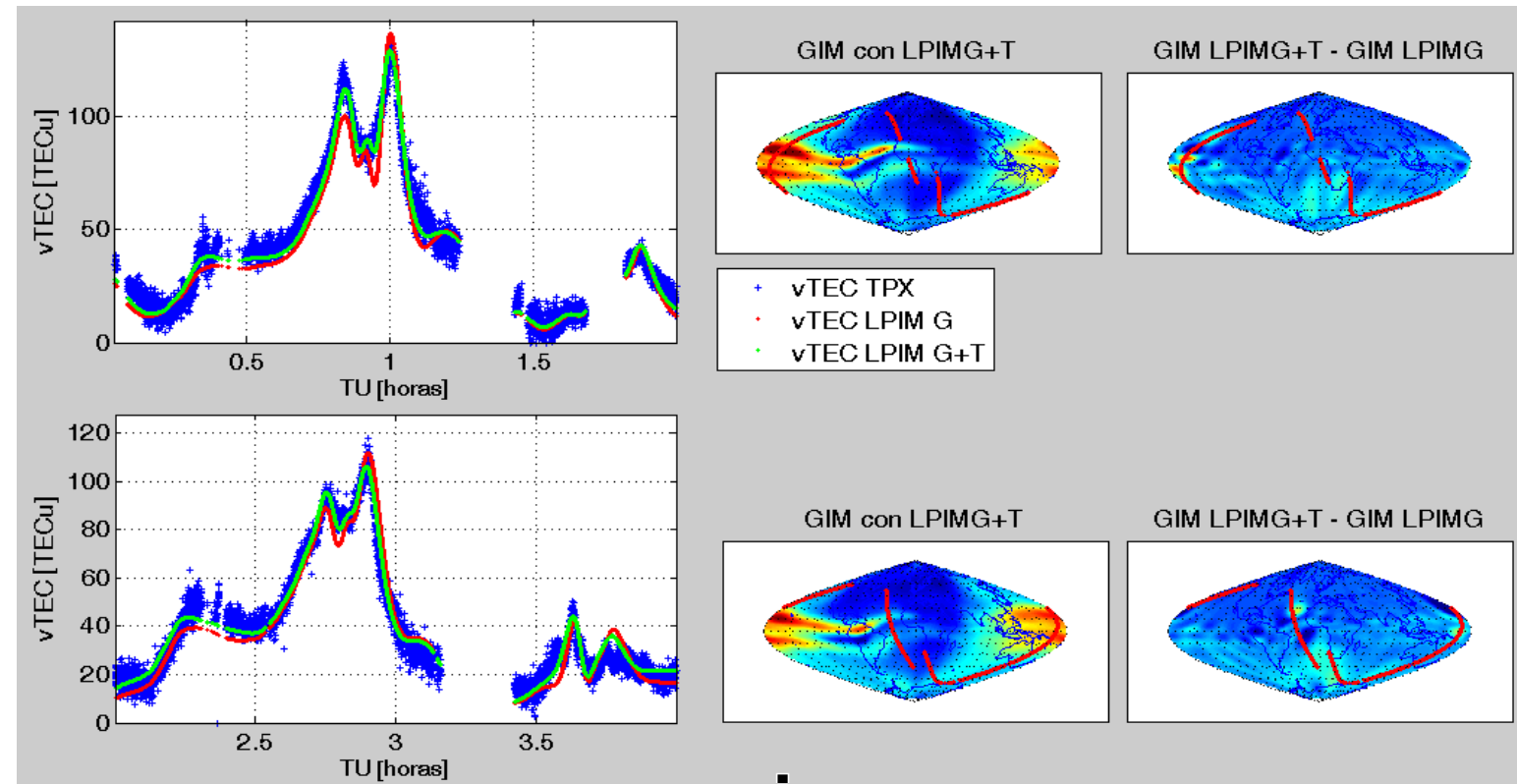

GIM LPIMG+T - GIM LPIMG
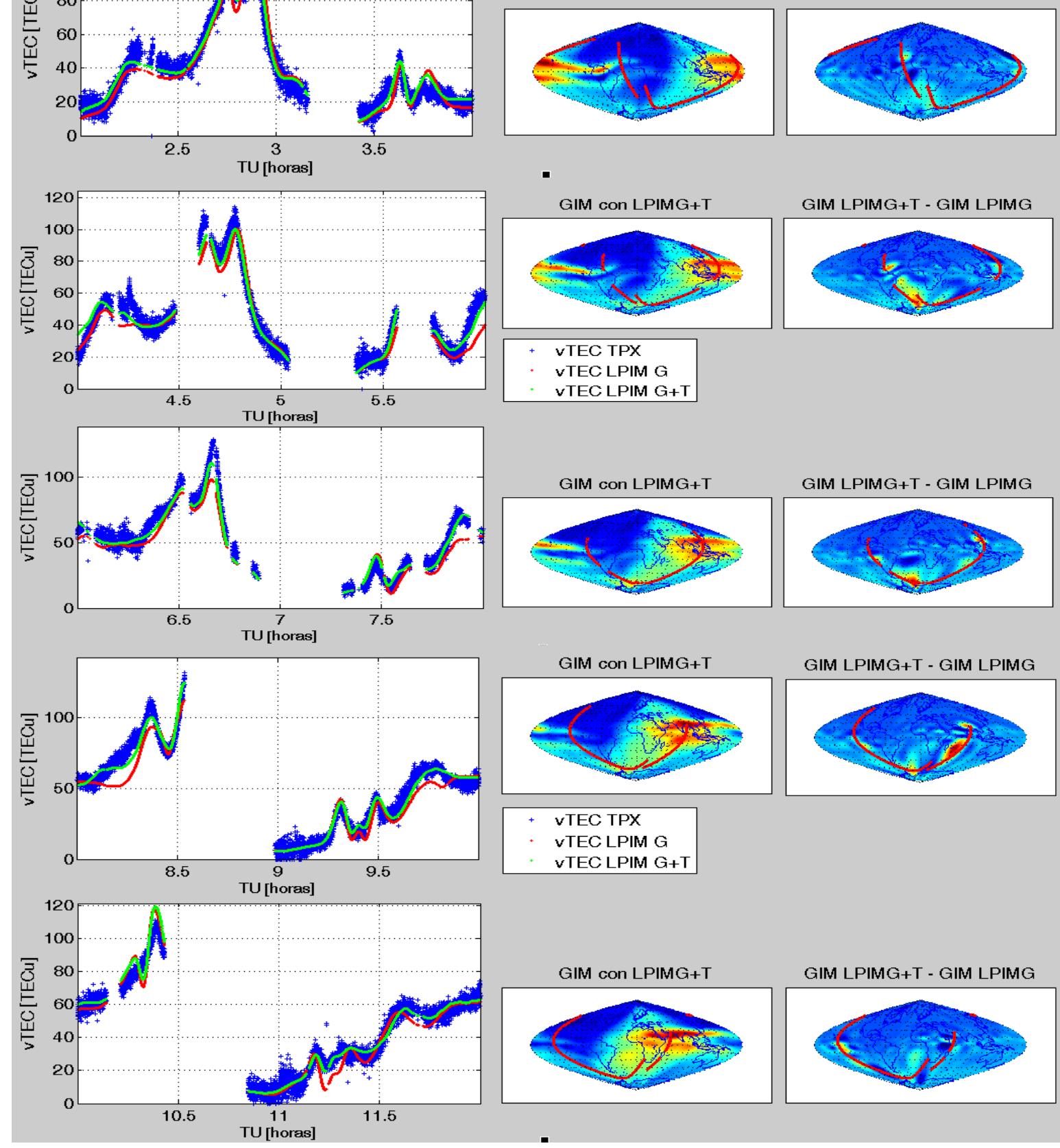




I. Bibbó | Asimilación de datos en LPIM 86 
En los gráficos de la izquierda de la Figura 3.5, en cada intervalo sobresale la estructura de doble pico correspondiente al paso del satélite sobre la Anomalía Ecuatorial. En esta región el VTEC puede alcanzar valores máximos cercanos a los 140 TECU por tratarse de una época de alta actividad solar. Las interrupciones en la serie obedecen al paso del satélite sobre las regiones continentales.

En estos gráficos es posible advertir la influencia de la incorporación de los datos altimétricos en la estimación del contenido electrónico total vertical. Con la nueva versión del modelo ionosférico de La Plata (en verde) en las regiones oceánicas se obtienen sistemáticamente valores del contenido electrónico más elevados que con la versión basada en datos GPS únicamente (en rojo). Como se mencionó, sobre los océanos LPIMg debe extrapolar los valores de contenido electrónico a partir de los datos continentales; es evidente que la versión LPIMG+T produce mapas globales con valores del VTEC desplazados hacia los valores observacionales incorporados en esa región del planeta, pero es llamativo el sistematismos observado. En las próximas secciones se retoma el tema.

\subsection{1.b. Diferencias en los mapas ionosféricos globales con LPIMG y $\vee T_{E} C_{T+G}$}

Los gráficos de la izquierda de la Figura 3.5 ponen de manifiesto las diferencias entre el VTEC calculado con uno y otro modelo a lo largo del recorrido del satélite altimétrico. En la columna derecha de la misma figura se ha representado, para cada intervalo horario, la diferencia entre los mapa ionosféricos obtenidos con

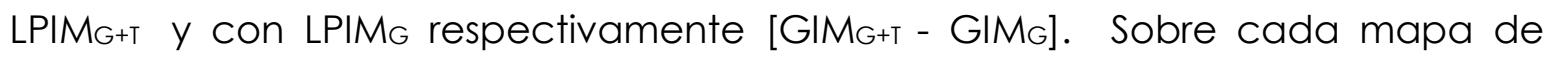
diferencias se ha superpuesto el recorrido del satélite TOPEX/Poseidón en el intervalo correspondiente.

De acuerdo con la escala desplegada en la parte inferior del gráfico, los mapas generados con las dos versiones de LPIM prácticamente coinciden en la región continental del planeta (color azul), mientras que las diferencias son apreciables sobre los océanos. Específicamente, la resolución espacial a nivel global de los datos altimétricos en cada intervalo de dos horas se traduce en diferencias localizadas circunscriptas al curso del satélite entre los mapas obtenidos con ambas versiones. Las diferencias entre los mapas generados con los dos modelos son del orden de \pm 5 TECs en la mayor parte del planeta, excepto en las regiones donde se han incorporado datos altimétricos, en las cuales las diferencias llegan a superar los 20 TECU.

Para tener una idea de la importancia de estas diferencias es necesario tener presente que la determinación de la posición de un punto sobre la superficie de la Tierra mediante el sistema GPS con receptores de simple frecuencia requiere 
de una corrección debida al retardo que sufre la señal al atravesar la ionósfera. El contenido electrónico afecta principalmente la componente vertical de la posición (Gende et al., 2011). Suponiendo que los satélites sobre el horizonte tienen en promedio una elevación de $45^{\circ}$, un error de 20 TECU ( 2 $\mathrm{m}$ teniendo en

cuenta que $\mathrm{K}=0.105 \frac{\mathrm{m}}{\mathrm{TECU}}$ ) en la estimación del contenido electrónico se traduce en un error del orden de $\sqrt{2} 2 \mathrm{~m}$ en la determinación de la altura con un receptor de simple frecuencia.

\subsection{1.c. Diferencias $\Delta_{\mathbf{G}}$ y $\Delta_{\mathbf{G}+\mathrm{T}}$}

En las secciones anteriores se han mostrado los resultados obtenidos para el día 7 del año 2002, un día particular del período de 100 días procesado. Si bien las características sobresalientes del VTEC modelado con el agregado de mediciones altimétricas y su diferencia con el VTEC basado en datos GPS únicamente se repiten día a día, en esta sección se establece una comparación estadística entre las dos versiones de LPIM que comprende los primeros 100 días del año 2002. Para la serie de 100 días se ha calculado la diferencia entre los valores de VTEC modelados a lo largo del track del satélite altimétrico y el valor observado por TOPEX/Poseidón (como se explica en primer párrafo de la sección 3.3.1.a). La diferencia entre el valor modelado con LPIMG y el valor medido por el satélite altimétrico ha sido llamada $\Delta_{\mathrm{G}}$ y la diferencia entre el valor modelado con la versión de LPIMG+T y el observado por TOPEX/P es referida como $\Delta_{\mathrm{G}+\mathrm{T}}$ :

$$
\begin{aligned}
& \Delta_{\mathrm{G}}=\mathrm{vTEC}_{\mathrm{G}}-\mathrm{vTEC}_{\mathrm{T}} \\
& \Delta_{\mathrm{G}+\mathrm{T}}=\mathrm{vTEC}_{\mathrm{G}+\mathrm{T}}-\mathrm{vTEC}_{\mathrm{T}}
\end{aligned}
$$

Las diferencias entre valores modelados y el valor observado del contenido electrónico vertical fueron agrupadas en bandas diarias, horarias, en longitud y en latitud. Los valores medios de las diferencias agrupadas, $\Delta_{\mathrm{G}}$ en rojo y $\Delta_{\mathrm{G}+\mathrm{T}}$ en verde, y sus desviaciones estándares han sido representadas en la figura 3.6. También se calculó, para cada punto muestreado por el satélite altimétrico en los 100 días, la diferencia entre el contenido electrónico total vertical modelado con LPIMG y con LPIMG+T: vTEC $G+T=$ vTEC $_{G}$.

En primer término, las diferencias entre los valores modelados y el observado por TOPEX/Poseidón y las diferencias entre los valores modelados fueron agrupadas y representadas en función del día del año. Es posible observar (primer gráfico de la Figura 3.6) que en los primeros 100 días del año 2002, las diferencias entre los valores modelados y observado se mantienen prácticamente constantes. Se advierte que mientras el valor medio de la diferencia $\Delta_{G}$ (graficado en rojo) es de 


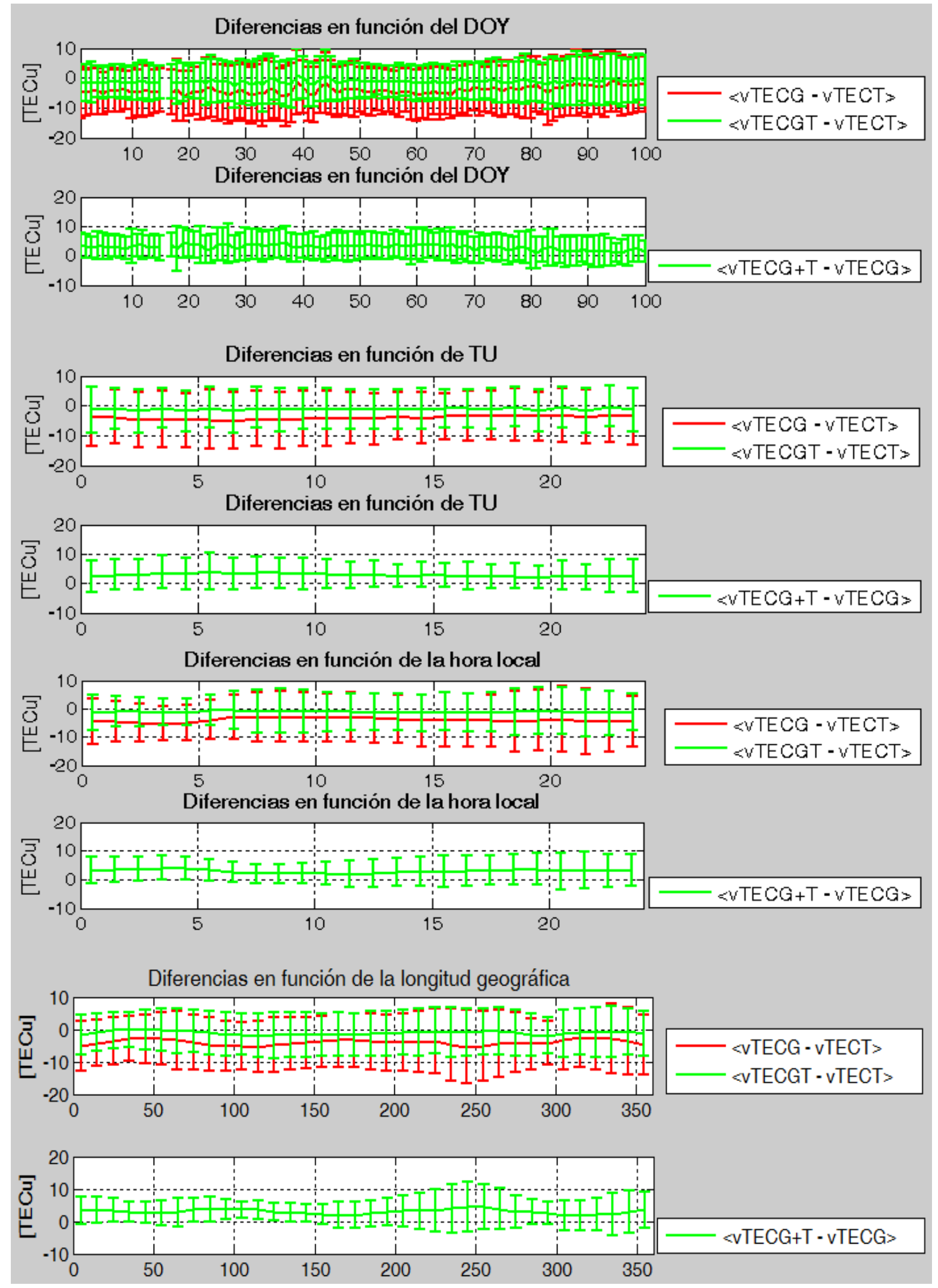




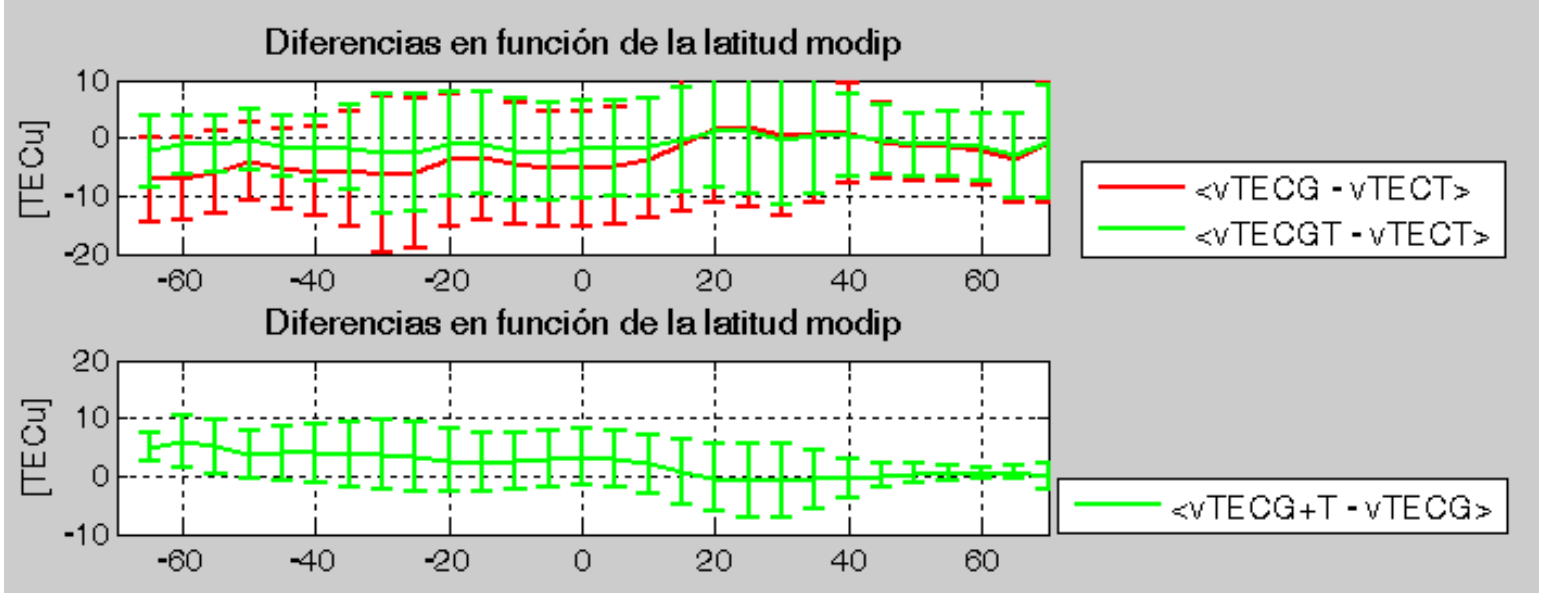

Figura 3.6. Diferencias $\Delta_{\mathrm{G}}$ y $\Delta_{\mathrm{G}+\mathrm{T}}$ entre cada modelo y las mediciones altimétricas y diferencia vTEC $_{\mathrm{G}+\mathrm{T}}-$ vTEC $_{\mathrm{G}}$ entre modelos.

algunos TECUs y negativo, el valor medio $\Delta_{\mathrm{G}+\mathrm{T}}$ (graficado en verde) es prácticamente nulo y su desviación estándar es menor. Este resultado es esperable debido a que la versión LPIMG+T está desplazando el VTEC modelado hacia los valores $\mathrm{vTEC}_{\mathrm{T}}$ observados incorporados. Sí es importante señalar que la diferencia entre los dos modelos (segundo gráfico de la Figura 3.6) resulta independiente del día del año y siempre positiva, con un valor medio

$$
\left\langle\mathrm{vTEC}_{\mathrm{G}+\mathrm{T}}-\mathrm{vTEC}_{\mathrm{G}}\right\rangle=2.89 \mathrm{TECu}
$$

En los siguientes gráficos de la Figura 3.6 es posible observar que las diferencias $\Delta_{\mathrm{G}+\mathrm{T}}$ y $\Delta_{\mathrm{G}}$ son independientes de TU, mientras que cuando son agrupadas en intervalos de una hora local, las discrepancias entre los dos modelos se acentúan en horas nocturnas.

Para comparar el comportamiento de los modelos en longitud, los datos fueron agrupados en bandas de $10^{\circ}$ de ancho. Como puede apreciarse en el cuarto par de gráficos de la Figura 3.6, las mayores diferencias se observan en las bandas que atraviesan los océanos.

Finalmente, los resultados agrupados en bandas de latitud modip de $5^{\circ}$ de ancho ponen en evidencia que las dos versiones son prácticamente coincidentes entre ellas y con los datos altimétricos en el hemisferio norte modip pero se apartan hacia latitudes negativas (último par de gráficos de la Figura 3.6).

A continuación, otra forma de presentar estos estos resultados ayudará en la interpretación. 


\subsection{1.d. Diferencias en los mapas ionosféricos globales medios}

Los resultados comentados en la sección anterior pueden visualizarse sobre el mapa. Para los 100 días, se obtuvieron mapas ionosféricos globales medios para cada período de 2 horas con cada versión de $L P I M,\left\langle v^{2 T E C} C_{G+T}\right\rangle$ y $\left\langle v_{T E C}{ }_{G}\right.$. Las diferencias entre ambos mapas medios en cada intervalo de 2 horas han sido representadas en la Figura 3.7.

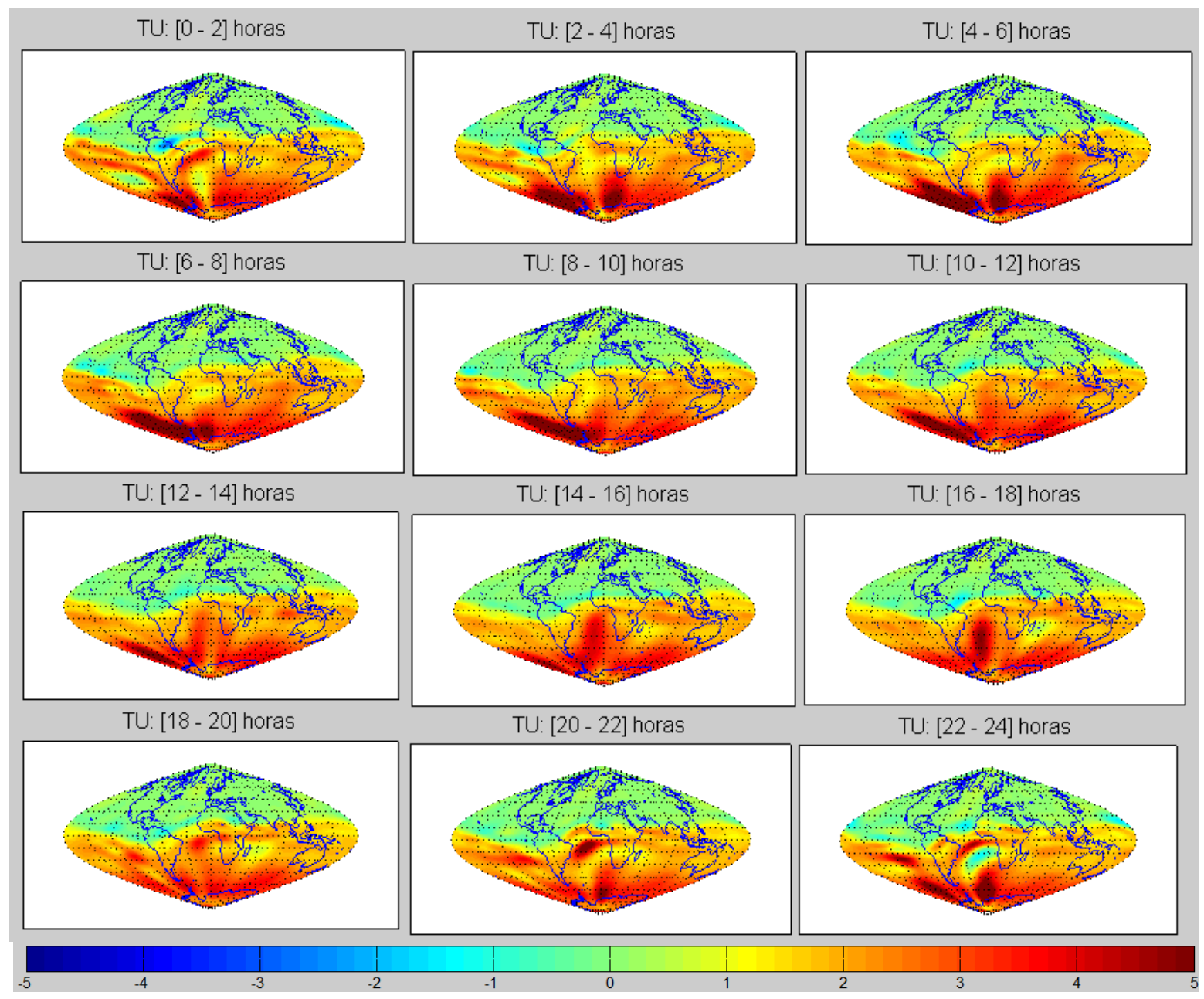

Figura 3.7. Diferencia $\left\langle\mathbf{v T E C}_{\mathrm{G}+\mathrm{T}}\right\rangle-\left\langle\mathbf{v T E C}_{\mathrm{G}}\right\rangle$ en los 100 primeros días del año 2002, expresada en TECUs.

Es posible observar que la diferencia entre los mapas globales medios es mínima en la región continental del hemisferio norte modip (el color verde corresponde a 0 TECUs en la escala que figura en la parte inferior del gráfico) pero se acentúa en el hemisferio sur, particularmente en la región oceánica. Al norte del Ecuador modip el valor medio de la diferencia es prácticamente constante, del orden de 
0.2 TECu en cada uno de los 12 mapas, mientras que en hemisferio sur el valor medio de la diferencia llega a 2.83 TECU.

Estos resultados ponen en evidencia la respuesta de LPIM a la asimilación de datos sobre los océanos, dado que las mayores diferencias se observan en regiones donde la relación entre la cantidad de datos altimétricos respecto a los datos GPS cobra importancia. El corrimiento sistemático hacia valores positivos de la diferencia $\left\langle\mathrm{vTEC}_{\mathrm{G}+\mathrm{T}}\right\rangle-\left\langle\mathrm{vTEC}_{\mathrm{G}}\right\rangle$ evidencia la existencia de un sesgo entre el contenido electrónico observacional provisto por la constelación de satélites GPS y el estimado a partir de la altimetría satelital. Se retoma este tema en la sección 3.3.3.

\subsubsection{Retardos instrumentales}

De acuerdo con el procedimiento descripto en la sección 3.2.3, los DCBs de los receptores y de los satélites fueron tratados como incógnitas adicionales. En esta etapa del trabajo se supuso que los instrumentos son estables a lo largo del día, entonces se calculó un retardo diario para cada satélite, $\beta_{G}^{S}$, con la condición de suma nula dada en la sección 3.1.6jError! No se encuentra el origen de la

referencia., y uno para cada receptor que intervino en el ajuste, $\beta_{G^{\prime}}^{R}$ en cada período de 24 horas.

\subsection{2.a. DCBs de los satélites}

A modo de ejemplo, en la Figura 3.8 se muestran los valores de los DCBs (expresados en ns) hallados para 6 satélites (PNR1 a PNR6) a lo largo de los 100 días procesados; en rojo se grafican los valores calculados utilizando datos GPS únicamente y en verde los valores hallados con la versión LPIMG+T que incorpora los datos altimétricos. En el anexo 2 pueden observarse los resultados obtenidos para los 28 satélites operativos en el año 2002.

En términos generales, e independientemente de la versión de LPIM utilizada, los instrumentos a bordo de los satélites se muestran estables en el intervalo de 100 días procesados, con valores medios de los retardos $\left\langle\beta_{\mathrm{G}}^{\mathrm{S}}\right\rangle$ y $\left\langle\beta_{\mathrm{G}+\mathrm{T}}^{\mathrm{S}}\right\rangle$ comprendidos entre los -4 y 3 ns. Las diferencias en los valores medios de los retardos hallados con una y otra versión de LPIM, en valor absoluto, $\left|\left\langle\beta_{G+T}^{S}\right\rangle-\left\langle\beta_{G}^{S}\right\rangle\right|$, en ningún caso superan los 0,04 ns. 


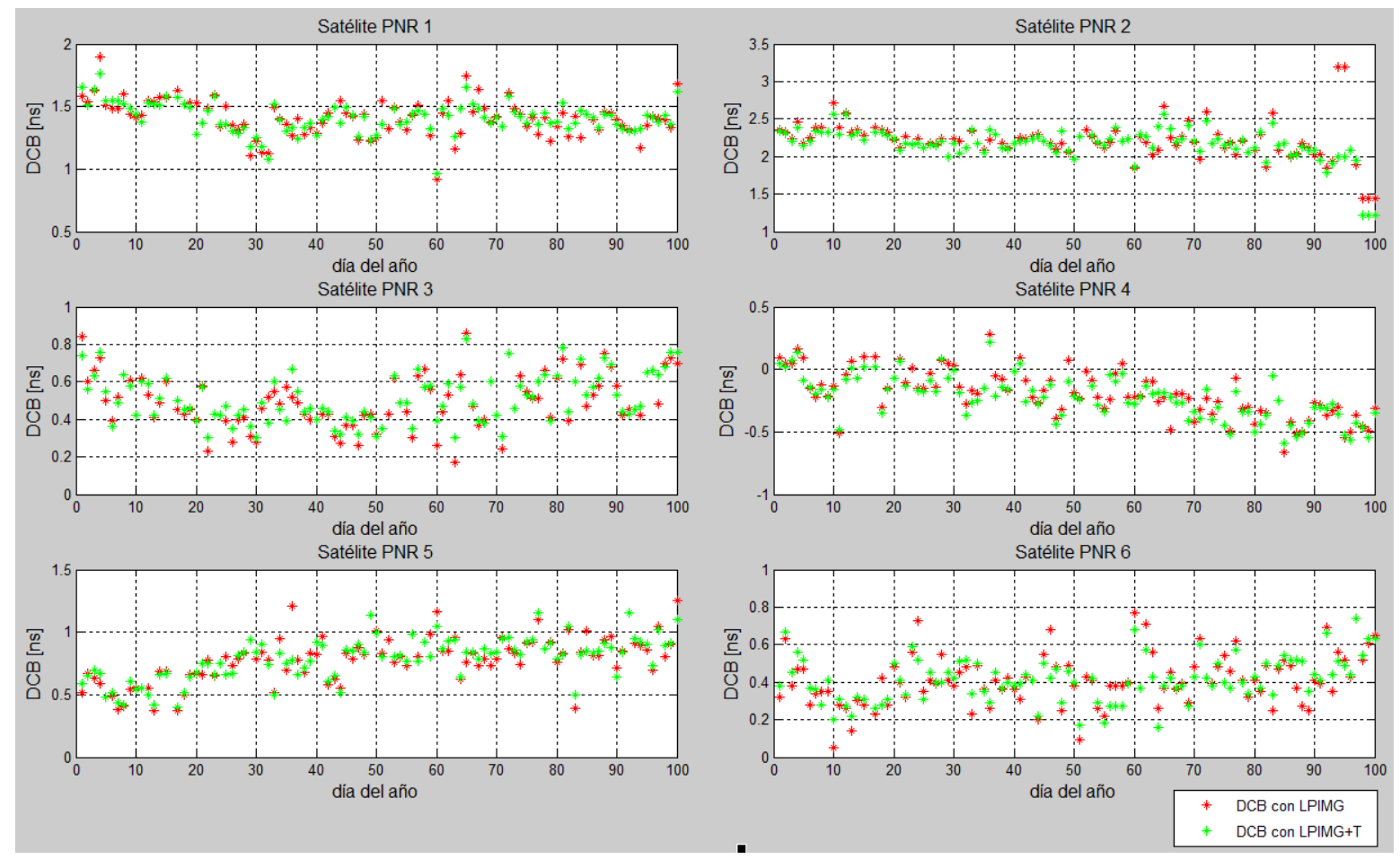

Figura 3.8. Valores diarios de los DCBs de 6 satélites al cabo de los primeros 100 días del año 2002 obtenidos con LPIMG (en rojo) y LPIMG+T (en verde)

Un resultado importante de destacar cuando se comparan las series de DCBs satelitales calculados con ambas versiones de LPIM, es que la dispersión alrededor del valor medio resulta menor cuando intervienen los datos altimétricos que cuando sólo se utiliza el modelo basado únicamente en datos GPS. En la Figura 3.9 es posible apreciar este comportamiento; si bien en términos absolutos las diferencias son pequeñas, en términos porcentuales son variables y llegan a ser importantes $y$, fundamentalmente, la reducción en la dispersión se observa sistemáticamente en la totalidad de los satélites.

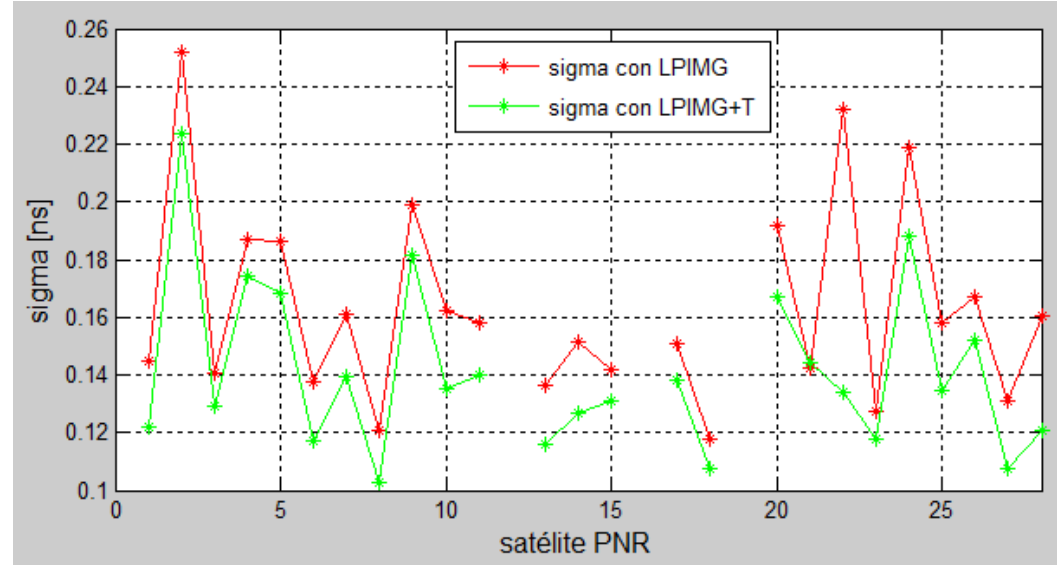

Figura 3.9. Dispersión en los DCBs de los satélites calculados con LPIMG (en rojo) y LPIMG+T (en verde) 


\subsection{2.b. DCBs de los receptores}

En la figura 3.10 se represen los valores diarios (100 primeros días del año 2002) de los DCBs calculados con LPIMG (en rojo) y con LPIMG+T (en verde) para seis de los receptores que intervienen en el ajuste.

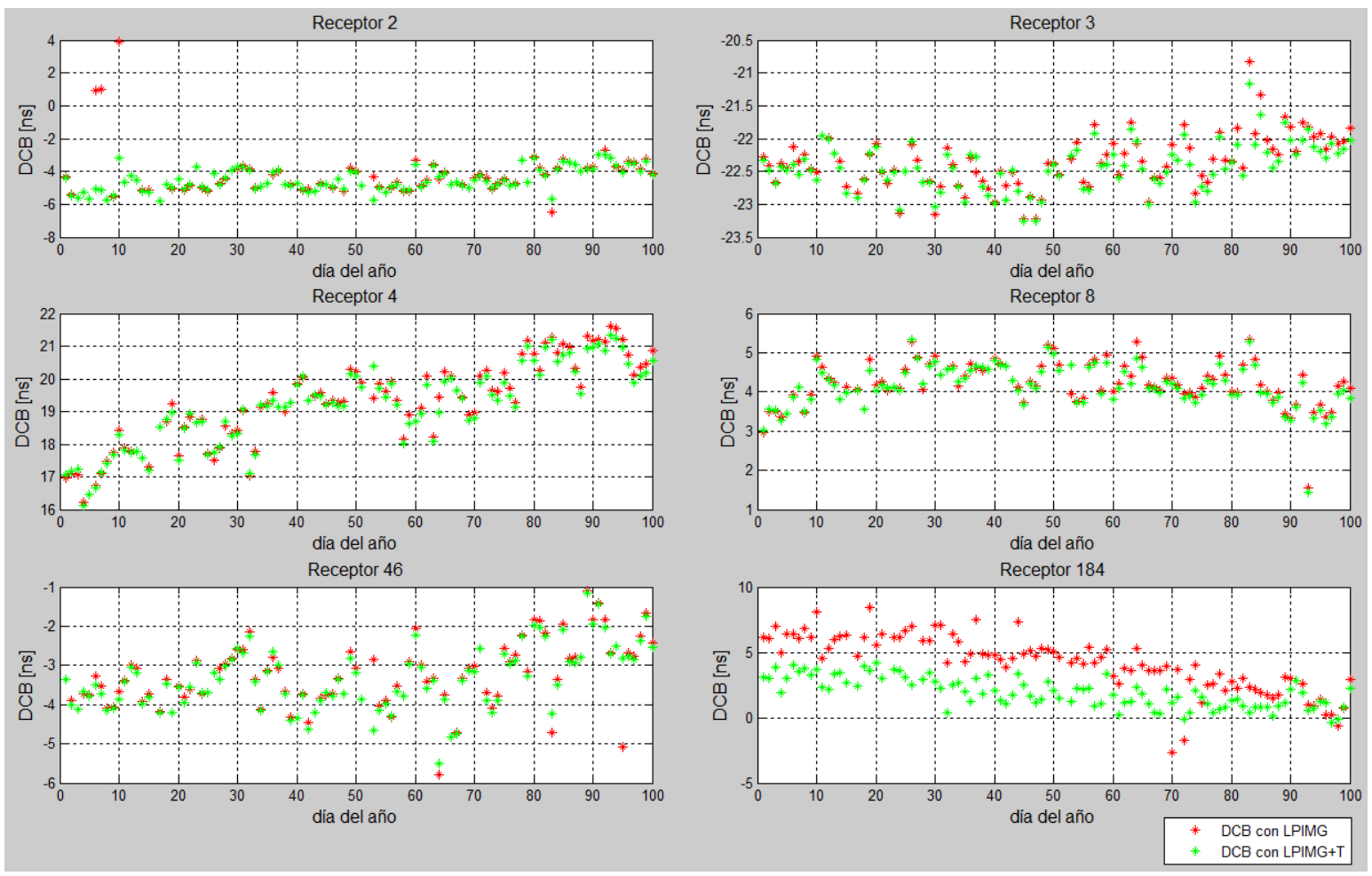

Figura 3.10. Valores diarios de los DCBs de 6 receptores al cabo de los primeros 100 días del año 2002 obtenidos con LPIMG (en rojo) y LPIMG+T (en verde).

En el anexo 3 se grafican los resultados obtenidos para el conjunto de 298 receptores utilizados en esta etapa del trabajo. En la mayoría de las estaciones se observa un funcionamiento continuo y estable de los receptores en el período estudiado. En el $95 \%$ de las estaciones los valores medios de los DCBs en los 100 días, $\left\langle\beta_{\mathrm{G}}^{\mathrm{R}}\right\rangle$ y $\left\langle\beta_{\mathrm{G}+\mathrm{T}}^{\mathrm{R}}\right\rangle$, se hallan comprendidos entre $\pm 20 \mathrm{~ns}$, con valores excepcionales que pueden alcanzar los $-40 \mathrm{~ns}$.

Como en el caso de los satélites, cuando se comparan las series de retardos calculados con ambas versiones de LPIM, la dispersión alrededor del valor medio es en todos los casos menor cuando intervienen los datos altimétricos que cuando se utiliza el modelo basado únicamente en datos GPS. En la Figura 3.11 es posible apreciar este resultado para 60 de los 298 receptores que intervienen en el ajuste. 
La dispersión en los valores de los retardos calculados con LPIMG+T es menor a los 2 ns en el $95 \%$ de las estaciones.

Figura 3.11. Dispersión en los DCBs de receptores calculados con LPIMG (en rojo) y LPIMG+T (en verde)

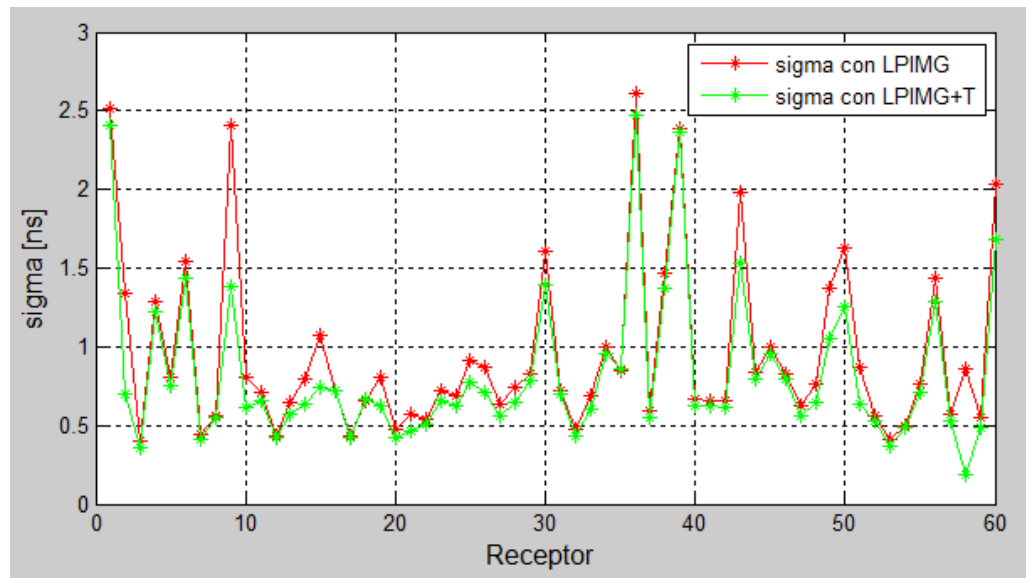

Si se comparan los valores medios de los retardos hallados con una y otra versión de LPIM, se observa que las diferencias $\left\langle\beta_{\mathrm{G}}^{\mathrm{R}}\right\rangle-\left\langle\beta_{\mathrm{G}+\mathrm{T}}^{\mathrm{R}}\right\rangle$ son positivas en el $95 \%$ de los casos y pueden alcanzar valores próximos a los 2.5 ns.

Figura 3.12. Diferencia entre los valores medios de los DCBs de los receptores calculados con LPIMG $_{\mathrm{G}}$ LPIMG+T $_{\text {(DCB LPIMG - DCB }}$ LPIM $_{G+T}$ )

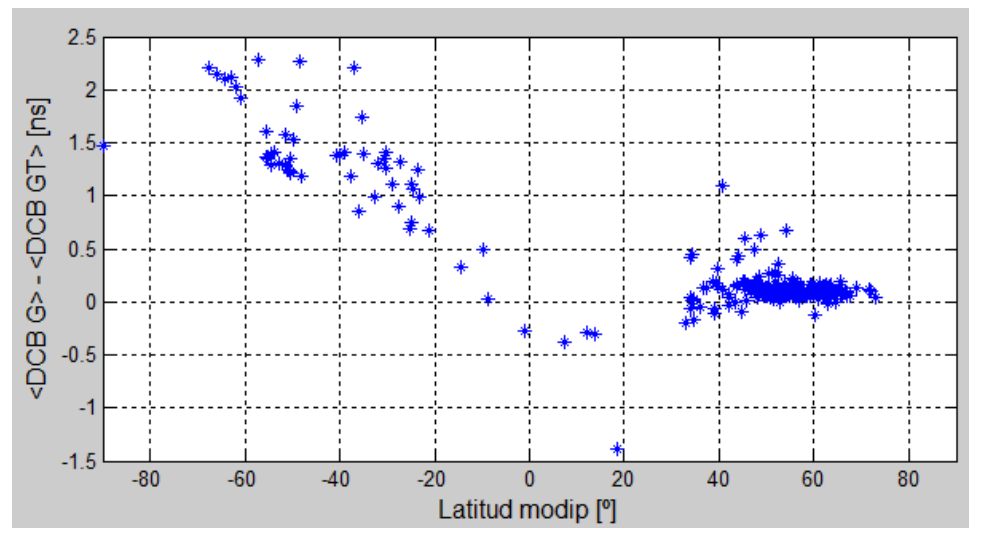

En la figura 3.12 han sido representadas las diferencias $\left\langle\beta_{G}^{R}\right\rangle-\left\langle\beta_{G+T}^{R}\right\rangle$ en función de la latitud modip de la estación; en el hemisferio norte las diferencias entre los DCBs calculados con una y otra versión de LPIM son pequeñas y no exhiben ninguna tendencia; sin embargo, en el hemisferio sur las diferencias son más importantes y se acentúan desde el ecuador modip hacia el sur. En estos casos, las diferencias entre los resultados hallados con cada versión pueden ser notables en relación con el valorer medio del DCB; en particular, para las estaciones con 
latitud modip $\mu<-20^{\circ}$ y $\left\langle\beta_{\mathrm{G}}^{\mathrm{R}}\right\rangle>2.5 \mathrm{~ns}$, las diferencias representan, en promedio, variaciones del orden del $20 \%$ de los respectivos $\left\langle\beta_{\mathrm{G}}^{\mathrm{R}}\right\rangle$.

Estos resultados son consistentes con las diferencias entre GIM comentadas en los párrafos anteriores. Si en las proximidades de una estación de monitoreo, la asimilación de datos altimétricos redunda en un valor de vTEC modelado mayor que el que se obtiene con datos GPS únicamente, de acuerdo con la primera ecuación del sistema 3.11,

$$
\left\{\begin{array}{c}
\mathrm{l}_{\mathrm{G}}-\varepsilon_{\mathrm{G}}=\mathrm{M}(\mathrm{z}) \mathrm{vTEC}+\beta_{\mathrm{G}+\mathrm{T}}^{\mathrm{S}}+\beta_{\mathrm{G}+\mathrm{T}}^{\mathrm{R}} \\
\mathrm{l}_{\mathrm{T}}-\varepsilon_{\mathrm{T}}=\mathrm{vTEC}
\end{array}\right.
$$

para los mismos valores observacionales $l_{G}$ medidos por cada estación, los bias calculados con las dos fuentes de datos, $\beta_{\mathrm{G}+\mathrm{T}}^{\mathrm{S}}$, deberían ser menores que cuando no intervienen datos altiméticos, $\beta_{\mathrm{G}}^{\mathrm{S}}$. Esto es efectivamente lo que ocurre. Además, las diferencias son más evidentes en las estaciones del hemisferio sur, donde la cantidad de datos TOPEX/Posiedón asimilados cobra importancia frente a los datos GPS.

\subsection{2.c. Tendencias lineales y variabilidad en los DCBs}

Observando en detalle el comportamiento diario de los retardos instrumentales de los receptores se advierte que, independientemente de la versión de LPIM utilizada, los DCBs de algunas estaciones exhiben cierta tendencia en el tiempo, en algunos casos creciente, como es la estación 4 de la Figura 3.10 y en otros decreciente, como la estación 184 de la misma figura. A su vez, es posible distinguir una variabilidad de corto período en los valores de los retardos calculados.

\section{cl. Tendencias lineales}

En primer término se analizan las tendencias observadas en los retardos de los receptores calculados con LPIMG. Para esto, se seleccionó el grupo de estaciones que mostró un funcionamiento continuo durante el período de 100 días estudiados. Se descartaron aquellas estaciones cuya prestación estuvo interrumpida durante más de 20 días corridos o presentó algún salto en el valor del retardo, claramente atribuible a cambios en el receptor o sus componentes (ver como ejemplo la estación 39 del anexo 3). De esta forma, se estudió el comportamiento de los retardos en 247 estaciones en los 100 días procesados. Se observó que en el $68 \%$ de los casos, las pendientes resultan menores a 0.01 ns/día; 
estas estaciones se hallan mayoritariamente (el 90\%) distribuidas en la parte continental del hemisferio norte.

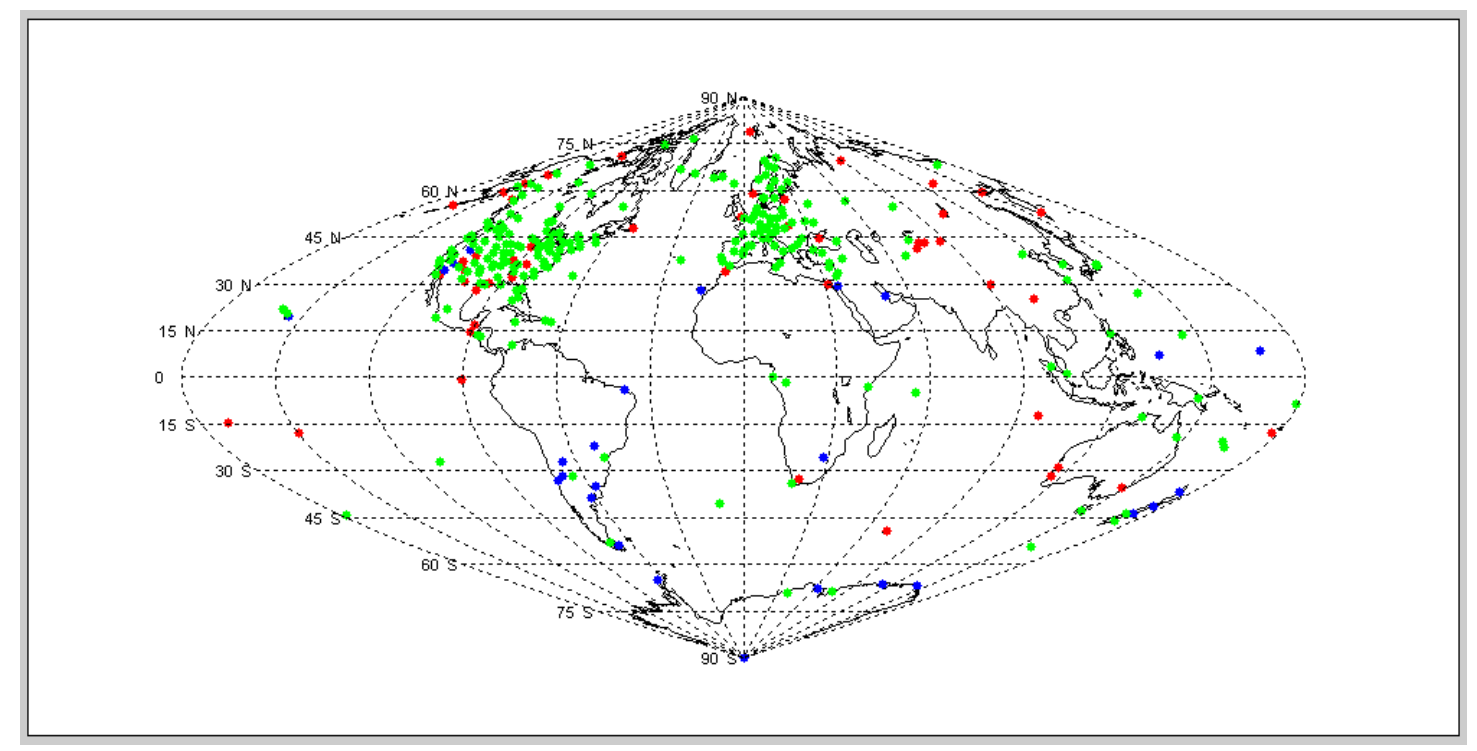

Figura 3.13. Tendencia lineal en los DCBs de los receptores. En verde se representan las estaciones con pendientes, en valor absoluto, menores que $0.01 \mathrm{~ns} /$ día; en rojo las pendientes mayores que $0.01 \mathrm{~ns} /$ día y en azul las pendientes menores que $-0.01 \mathrm{~ns} / \mathrm{d}$ día.

Por otra parte, se identificaron 77 estaciones en las cuales los DCBs mostraron tendencias lineales con pendientes superiores a 0.01ns/día. Estudiando la distribución geográfica de estas estaciones, se observó que de las 26 estaciones con pendiente negativa, el $65 \%$ se encuentra en el hemisferio sur, mientras que el $35 \%$ restante se halla en zonas costeras u oceánicas del hemisferio norte. Entre las de pendiente positiva (51 estaciones), el $80 \%$ está en el hemisferio norte y el resto en zonas costeras o insulares del hemisferio sur.

La distribución geográfica preferencial de las estaciones con retardos instrumentales variables en el tiempo (crecientes en el hemisferio Norte y decrecientes en el hemisferio Sur, en un período que va desde enero hasta abril) sugiere una posible influencia de la temperatura ambiental en el comportamiento de los receptores.

Para profundizar la idea, se identificaron estaciones meteorológicas próximas a las estaciones de monitoreo continuo y se obtuvieron sus registros históricos de temperatura. Se utilizaron datos de la National Oceanic and Atmospheric Administration NOAA (http://www.noaa.gov/about-noaa.html) dependiente del Departamento de Comercio de los Estados Unidos. Se correlacionaron las series de valores de DCBs calculados con LPIMgps al cabo de los 100 días con los valores medios diarios de la temperatura del lugar. El índice de correlación resultó 
$|\rho|>0.60$ para 7 estaciones de las 77 con tendencia superior a 0.01 ns/día (menos del $4 \%$ del total de estaciones) y el valor máximo del índice de correlación fue de 0.81 .

Si bien es sabido que la respuesta de los receptores puede ser función de la temperatura (Coster et al., 2013), en este trabajo no se encontró correlación alguna entre la temperatura del medio y los valores diarios de los DCBs calculados con LPIMG como para atribuir a ella las variaciones observadas.

Prestando luego atención al comportamiento de los retardos de los receptores calculados teniendo en cuenta observaciones GPS y altimétricas combinadas y comparándolas con los valores basados en observaciones GPS únicamente, se encontró que la cantidad de estaciones con tendencias superiores a $0.01 \mathrm{~ns} /$ día se reduce de 77 a 62 estaciones. Este resultado da un indicio de que los valores de los retardos calculados por LPIM no son independientes de los valores observacionales del contenido electrónico asimilados.

Entonces, con el objeto de explicar las variaciones de los DCBs de cada receptor a lo largo de los 100 días procesados, se correlacionaron los valores diarios de los retardos con los valores medios del contenido electrónico vertical medido por cada una de las estaciones día por día.

El índice de correlación resultó $\rho>0.60$ para 28 de las 62 estaciones con tendencia superior a $0.01 \mathrm{~ns} /$ día, representando el $45 \%$ de los casos comparados. Una única estación (Fortaleza Latitud: $3^{\circ} .88$, Longitud: $321^{\circ} .57$ ) mostró un índice de correlación significativo menor que cero $(\rho=-0.66)$.

En la columna de la izquierda de las figuras 3.14 y 3.15 es posible apreciar la correlación entre los DCBs calculados con LPIMG (en rojo) y con LPIMG+T (en verde) y el VTEC medio diario observado por cada estación (en azul). En la Figura 3.14 se han agrupado cuatro de las 28 estaciones con tendencias lineales crecientes (en el anexo 4 se encuentra la lista completa) y en la figura 3.15, aquéllas que exhiben tendencias decrecientes. Las primeras se distribuyen en latitudes medias y altas, tanto en el hemisferio norte como en el sur, mientras que las segundas están confinadas a la región costera oriental de Sudamérica. Es importante tener presente que el período considerado comprende la transición entre el solsticio de verano y el equinoccio de otoño para el hemisferio sur, lo que equivale a una disminución progresiva de la radiación solar, y en consecuencia del contenido electrónico ionosférico, sobre las estaciones del hemisferio sur y a un aumento de la radiación sobre las estaciones que se encuentran al norte del ecuador. De ahí que el vTEC y, como se ha visto, los retardos instrumentales disminuyan en las 

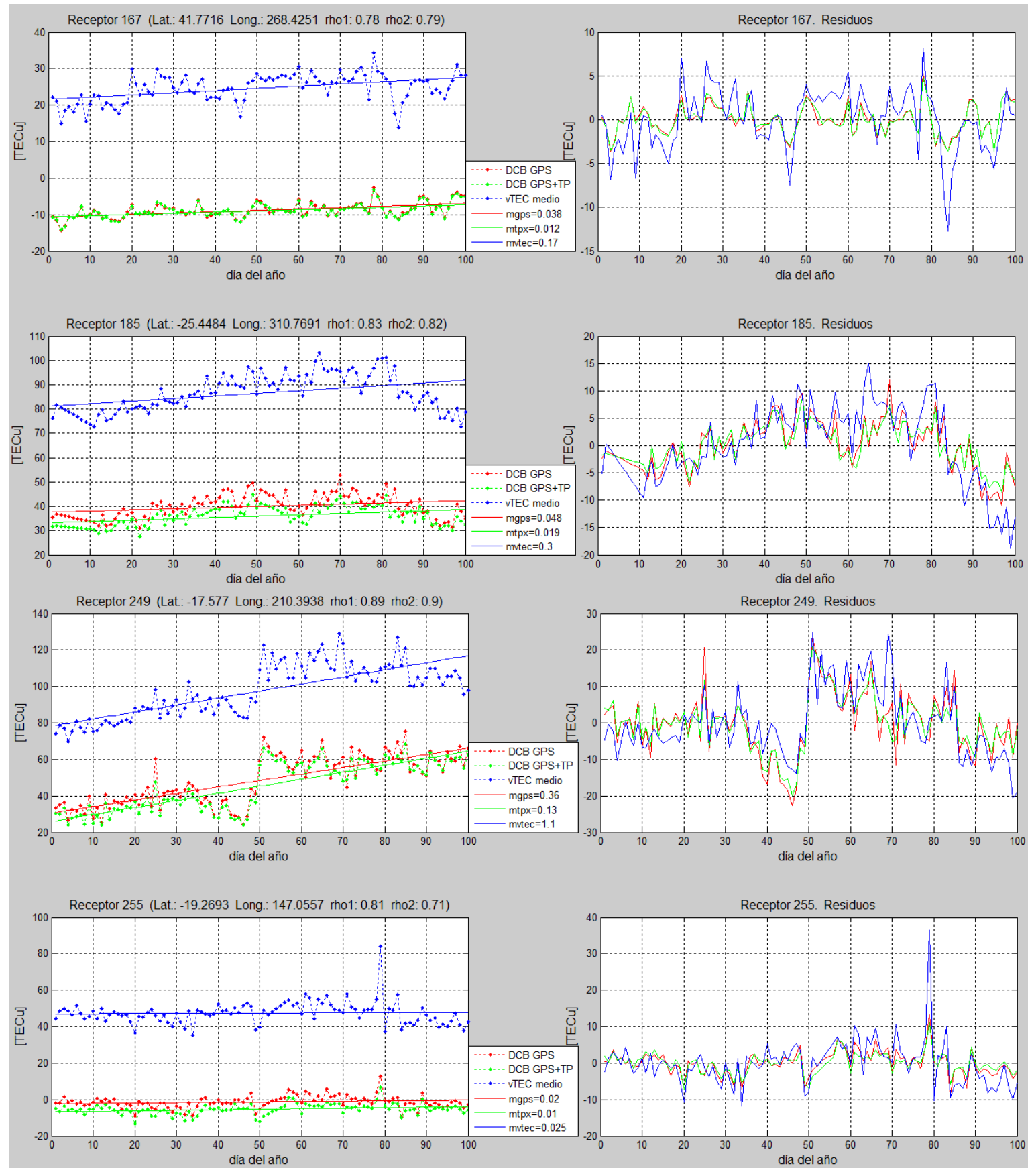

Figura 3.14. Tendencias lineales crecientes en los DCBs de los receptores calculados con

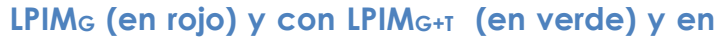
el VTEC medio diario medido por la estación (en azul), expresados en TECu. Rhol es el coeficiente de correlación entre los DCBs calculados con LPIMG y el VTEC y rho2 es el coeficiente entre los DCBs calculados con LPIM $_{G+T}$ y el VTEC. En la columna de la derecha figuran los residuos y el mapa con la ubicación geográfica de las estaciones.

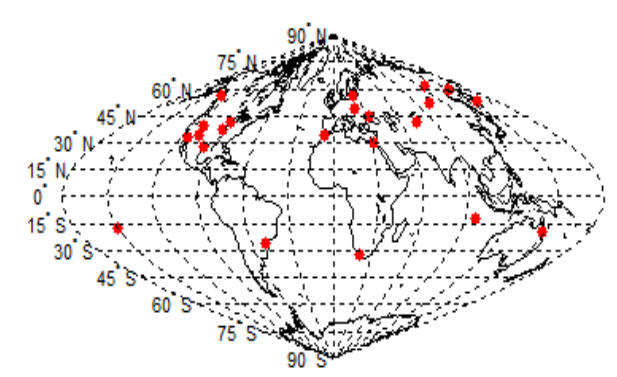



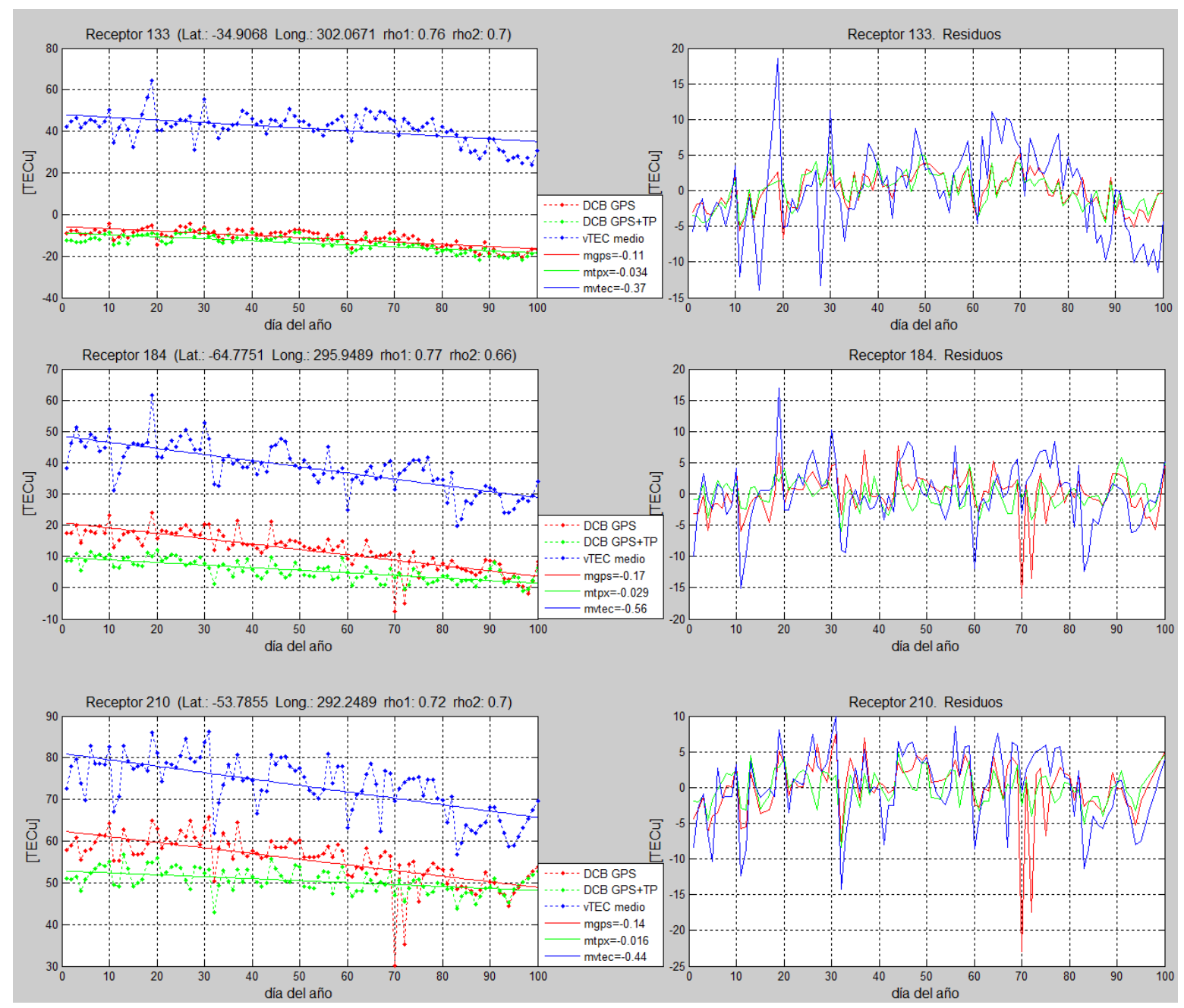

Figura 3.15. Tendencias lineales decrecientes en los DCBs de los receptores calculados con

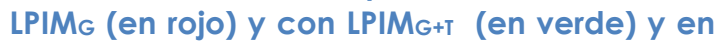
el VTEC medio diario medido por la estación (en azul), expresados en TECu. Rhol es el coeficiente de correlación entre los DCBs calculados con LPIMG y el VTEC y rho2 es el coeficiente entre los DCBs calculados con

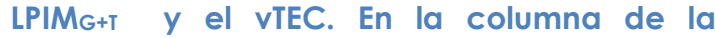
derecha figuran los residuos y el mapa con la ubicación geográfica de las estaciones.

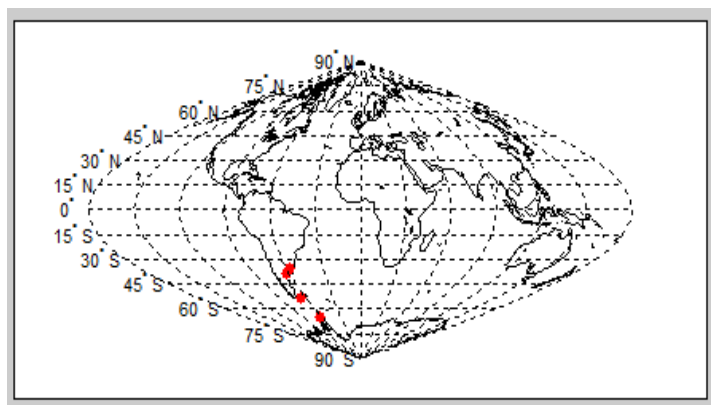

estaciones ubicadas en el hemisferio sur entre el día 1 y 100 del año y aumenten para las estaciones ubicadas en el hemisferio norte en el mismo período.

La existencia de estaciones ubicadas en latitudes bajas y medias del hemisferio sur con tendencias crecientes da cuenta de la complejidad del fenómeno de ionización, que no puede ser reducido a una relación simple entre la radiación 
solar incidente sobre cierta región del planeta y el contenido electrónico en la ionosfera.

\section{c2. Variabilidad}

Una vez removidas las tendencias lineales en los DCBs a lo largo de los 100 días se estudiaron los residuos. Un análisis mediante la transformada rápida de Fourier no arrojó períodos preferenciales para los apartamientos de la linealidad en el intervalo de tiempo analizado. Sin embargo, como puede observarse en los gráficos de la columna derecha de las figuras 3.14 y 3.15, existe una marcada relación entre la variabilidad diaria de los DCBs y del VTEC medio diario medido por la estación durante el día. Es importante notar la concordancia tanto en el tiempo como en los órdenes de magnitud de las variaciones en los DCBs y en el VTEC medio.

En síntesis, de un total de 298 estaciones pertenecientes al Servicio Internacional GNSS utilizadas, 247 funcionaron de forma ininterrumpida durante los 100 días procesados. El $68 \%$ de ellas, mayoritariamente ubicadas sobre Europa y América del Norte, se mostró estable a lo largo del período, con tendencias menores a 0.01 ns/día.

En el resto de las estaciones, los retardos instrumentales resultaron variables en el tiempo. Como se discutió en la presente sección y se ilustra en las Figuras 3.14 y 3.15, los DCBs estimados están correlacionados con el VTEC medio diario medido por la estación. Este resultado es consistente con otras investigaciones (Hernández-Pajares et al. 1999) pero es importante señalar que no se trata de una dependencia causal; si volvemos a la ecuación de observación GPS (ecuación 3.14)

$$
l_{G}-\varepsilon_{G}=\operatorname{sTEC}+\beta_{G+T}^{S}+\beta_{G+T}^{R},
$$

para cada estación, el valor observacional del contenido electrónico $l_{G}$ tiene una componente física, el sTEC, y otra instrumental como son los DCBs. La posibilidad de que ambas sean separadas depende de contar con observaciones de la misma estación en un intervalo de tiempo suficientemente largo, en el cual mientras los retardos se mantienen constantes el contenido electrónico es función del ángulo cenital.

Otro factor que favorece el desacople de las variables es la incorporación de datos observacionales independientes del instrumento en una región próxima a la estación en el intervalo de tiempo considerado. En el caso de las estaciones estudiadas, por un motivo o el otro, los DCBs y el contenido electrónico no han 
sido perfectamente desacoplados. No obstante, la asimilación de datos altimétricos representa un gran aporte: en la totalidad de las estaciones que se observa una variación de los DCBs en el tiempo (anexo 4) la incorporación de los datos TOPEX/Poseidón reduce la tendencia (la pendiente de la recta es menor) y en la mayoría de los casos el índice de correlación entre los DCBs calculados y el valor medio del VTEC medido disminuye.

\subsubsection{Bias de TOPEX/Poseidón}

En la sección 3.3.1. se vio que en el período de 100 días analizado, el contenido electrónico medio diario calculado a partir de datos GPS+TP resulta superior al valor modelado con la versión basada en datos GPS únicamente. Resulta llamativo que la diferencia sea sistemáticamente positiva, o sea que $\mathrm{vTEC}_{\mathrm{G}+\mathrm{T}}>$ $\mathrm{vTEC}_{\mathrm{G}}$, especialmente si se tiene en cuenta que el satélite TOPEX/Poseidón sondea la ionosfera comprendida por debajo de los $1300 \mathrm{~km}$, mientras que GPS lo hace hasta $22000 \mathrm{~km}$ de altura. El resultado previo estaría indicando una sobreestimación del contenido electrónico total ionosférico por parte del satélite altimétrico. Esto sería consistente con diversos estudios que comparan el contenido electrónico total obtenido a partir de la misión TOPEX/Poseidón y el calculado por otros medios (Imel 1994; Ho et al. 1997; Codrescu et al., 2001; Hernandez-Pajares, 2003; Delay and Doherty 2004; Brunini et al., 2005). En particular, cuando se han comparado los valores de VTEC medidos por TOPEX/P con los valores obtenidos con GPS, los estudios señalan la existencia de un bias de 2-5 TECU, siempre TOPEX/P mayor que GPS.

En esta sección se propone un método para calcular el bias, no por el camino de la comparación, sino a partir de la técnica de asimilación de datos GPS y TOPEX/P ya descripta.

Aceptando la existencia de un error sistemático $\beta_{\mathrm{T}}$ en la medición del vTEC con TOPEX/P, la ecuación de observación para los datos altimétricos es:

$\mathrm{l}_{\mathrm{T}}-\varepsilon_{\mathrm{T}}=\sum_{\mathrm{l}=0}^{\mathrm{L}} \sum_{\mathrm{m}=0}^{\mathrm{l}}\left\{\mathrm{a}_{\mathrm{l}, \mathrm{m}, \mathrm{k}}(\mathrm{t}) \cos \left(\frac{2 \pi \mathrm{mh}}{24}\right)+\mathrm{b}_{\mathrm{l}, \mathrm{m}, \mathrm{k}}(\mathrm{t}) \operatorname{sen}\left(\frac{2 \pi \mathrm{mh}}{24}\right)\right\} \mathrm{P}_{\mathrm{l}, \mathrm{m}}(\operatorname{sen} \varphi)+\beta^{\mathrm{T}}$

El correspondiente sistema de ecuaciones de observación que combina datos GPS y altimétricos se obtiene a partir del sistema dado por la ecuación 3.15. En este sistema se agrega el coeficiente 1 en la matriz de diseño debido a que el observable altimétrico $\mathbf{l}_{\mathrm{T}}$ es una medida de contenido electrónico total vertical expresado en TECU y la incógnita $\mathbf{y}_{\mathrm{G}+\mathrm{T}}^{\mathrm{ST}}$ que representa el bias del satélite TOPEX/P es expresada en la misma unidad: 


$$
\left(\begin{array}{l}
\mathbf{l}_{\mathrm{G}} \\
\mathbf{l}_{\mathrm{T}}
\end{array}\right)-\left(\begin{array}{c}
\boldsymbol{\varepsilon}_{\mathrm{G}} \\
\boldsymbol{\varepsilon}_{\mathrm{T}}
\end{array}\right)=\left(\begin{array}{cccc}
\mathbf{A}_{\mathrm{G}} & \mathbf{B}^{\mathrm{R}} & \mathbf{B}^{\mathrm{S}} & \mathbf{0} \\
\mathbf{A}_{\mathrm{T}} & \mathbf{0} & \mathbf{0} & \mathbf{1}
\end{array}\right) \cdot\left(\begin{array}{l}
\mathbf{x}_{\mathrm{G}+\mathrm{T}} \\
\mathbf{y}_{\mathrm{G}+\mathrm{T}}^{\mathrm{R}} \\
\mathbf{y}_{\mathrm{G}}^{\mathrm{SG}} \\
\mathbf{y}_{\mathrm{G}+\mathrm{T}}^{\mathrm{ST}}
\end{array}\right)
$$

El código LPIM es modificado suponiendo que el bias permanece constante en intervalos de un día y se calcula su valor para los primeros 100 días del año 2002.

Figura 3.16. Valores diarios

(días 1-100 del año 2002)

del bias del satélite TOPEX/Poseidón.

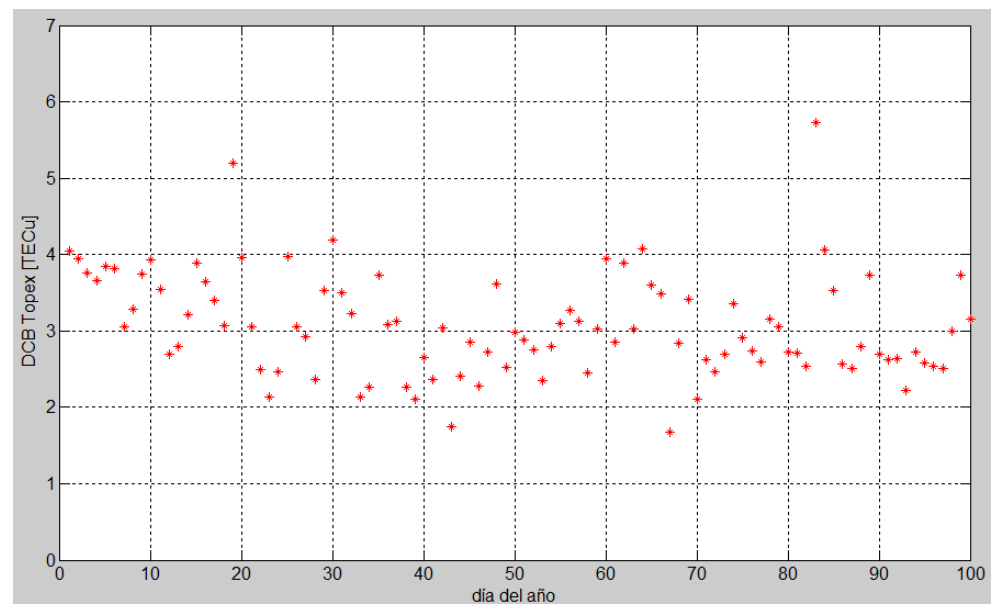

Los valores diarios de $\beta^{\mathrm{T}}$ obtenidos se hallan representados en la Figura 3.16. En el $92 \%$ de los casos el bias resulta entre 2 y 4 TECu, con valores extremos de 1.68 y 5.73 TECu y una leve tendencia decreciente en el tiempo. El valor medio en el período de 100 días es

$$
<\beta^{\mathrm{T}}>=3.068 \pm 0.675 \mathrm{TECu}
$$

A diferencia de los retardos de los receptores GPS, los valores del bias altimétrico hallados en el período de 100 días no se encuentran correlacionados con el contenido electrónico asimilado.

Estos resultados concuerdan con los reportados en los estudios citados anteriormente. Como se explicó en el capítulo 2 (sección 2.3), la altimetría satelital proporciona una medida del vTEC como un subproducto en la determinación de la distancia satélite-superficie del mar; es una cantidad que debe ser removida luego de aplicar diferentes correcciones al rango observado en dos bandas, C y Ku. Chelton et al. (2001) pusieron de manifiesto la posibilidad de que el bias observado estuviera relacionado con los errores sistemáticos en las correcciones dependientes de la frecuencia, no ionosféricos, aplicados a las mediciones en cada frecuencia por separado antes de calcular el vTEC. Para Azpilicueta y Brunini (2008) el bias del orden de 3-4 TECU puede explicarse como 
un problema de falta de calibración de los errores de sistema, particularmente en la banda $\mathrm{C}$ que, como reconociera Philip Callahan (responsable de la calibración de los datos TOPEX) el bias en la banda C estimado entre 80 y $100 \mathrm{~mm}$ fue elegido de forma arbitraria, y quizá desafortunada, próximo a su límite superior. Independientemente del origen del bias $\beta^{T}$, en este trabajo es interpretado como un error de calibración entre las mediciones realizadas con GPS y con TOPEX/Poseidón, que no puede ser ignorado si se pretende dar consistencia a un modelo de asimilación basado en ambas fuentes observacionales.

\subsection{Conclusiones del capítulo}

En esta etapa del trabajo se ha logrado una versión actualizada de LPIM capaz de utilizar datos GPS y altimétricos simultáneamente. La estrategia de asimilación propuesta produce mapas ionosféricos globales con una resolución de 2 horas y un juego diario de retardos instrumentales a partir del procesamiento de bloques de 24 horas de información. Se analizó un periodo de 100 días corridos (días 1 al 100 del año 2002) para asegurar la asimilación de datos altimétricos sobre cada punto de observación con una cobertura de 24 horas.

Por un lado se encontró que:

- los mapas ionosféricos globales que se obtienen considerando las dos fuentes de información, GPS y TOPEX/Poseidón, simultáneamente difieren de los mapas ionosféricos clásicos (basados en datos GPS), especialmente en las regiones próximas al paso del satélite altimétrico;

- los retardos instrumentales de los satélites muestran leves diferencias si se usan datos altimétricos o si sólo intervienen datos GPS y no varían significativamente día a día en el periodo de 100 días analizado;

- los retardos instrumentales de los receptores calculados con una y otra versión de LPIM prácticamente coinciden en el hemisferio norte modip pero la diferencia entre ellos es apreciable en el hemisferio sur;

- la incorporación de datos altimétricos reduce la dispersión, tanto en los retardos instrumentales de los satélites como de los receptores.

Estos resultados ponen en evidencia que el modelo ionosférico de La Plata es sensible a la asimilación de datas altimétricos, tanto en la generación de mapas ionosféricos globales como en el cálculo de los DCBs de los receptores, con un resultado alentador como es la reducción de la dispersión de los retardos instrumentales. 
Por otro lado, analizando el comportamiento de los retardos de los receptores a lo largo de 100 días se encontró que

- más de $80 \%$ de los receptores funcionaron de manera ininterrumpida y sin cambios bruscos en la trasmisión de la señal durante el período analizado;

- de ellos, el $75 \%$ de los receptores producen retardos en la señal prácticamente constantes, con variaciones inferiores a 0.01 ns/día, mientras que un cuarto de los receptores producen retardos variables en el tiempo;

- en las estaciones que se aprecian variaciones en los DCBs, tanto las tendencias lineales observadas, crecientes o decrecientes, como las variaciones de corto período superpuestas, pueden relacionarse con el VTEC medio diario medido por la estación.

Las variaciones en el tiempo de los retardos que produce en la señal GPS la parte física de los receptores pueden ser aleatorias o pueden asociarse a condiciones del medio en el que se encuentran, básicamente la temperatura exterior de la estación. En este trabajo no se encontró relación evidente entre las variaciones en los retardos y las condiciones físicas del medio que rodea al receptor; sí se pudo establecer que en estas estaciones las variaciones pueden asociarse al acoplamiento entre el efecto que produce la ionósfera sobre la señal GPS y el debido a la parte física del instrumento de medición como resultado de una configuración desfavorable del conjunto de datos observacionales. A su vez,

- la incorporación de datos altimétricos como fuente de información independiente favorece la separación de las componentes física e instrumental de la ecuación de observación, reduciendo tanto las tendencias observadas en los DCBs a lo largo de los 100 días procesados como el índice de correlación con el VTEC medido por la estación.

Este último resultado, junto con el hecho de que en la mayoría de los receptores los valores calculados de los retardos no se apartan de un valor medio, será el fundamento para plantear una nueva estrategia de asimilación (Capítulo 4).

Finalmente se encontró que, en promedio,

- los mapas ionosféricos obtenidos con LPIMG+P tienden a sobre-estimar el contenido electrónico total vertical, con respecto a los valores obtenidos con LPIMG, acentuándose esta diferencia en el hemisferio sur modip desde el ecuador hacia el polo.

Este resultado, contradictorio con la configuración orbital de los dos tipos de satélites (los satélites GPS orbitan la Tierra a una altura que equivale a 17 veces la 
altura de los satélites altimétricos), llevó a replantear la ecuación de observación altimétrica introduciendo un bias o error de calibración entre las mediciones realizadas con GPS y con TOPEX/Poseidón.

El bias fue calculado considerado constante a lo largo del día, resultando su valor medio en el período de 100 días asimilados $\left\langle\beta^{\mathrm{T}}\right\rangle=3.068 \pm 0.675 \mathrm{TECu}$. La técnica de asimilación que se propone en el capítulo siguiente tiene en cuenta la existencia de este bias entre los datos de diferente origen. 


\section{Capítulo 4: Nueva técnica de asimilación de datos en LPIM}

El hecho más alentador de la incorporación de datos altimétricos en un modelo global de distribución del contenido electrónico ionosférico basado en GPS es el aporte de información sobre la parte oceánica del planeta, justamente donde la cobertura GPS es pobre. La técnica de asimilación propuesta en el capítulo anterior es un primer paso en la búsqueda de una mejor representación del contenido electrónico, que deja ver la sensibilidad del modelo ionosférico de La Plata a la incorporación de observaciones TOPEX/Poseidón. Sin embargo, dada la distribución geográfica acotada de los datos altimétricos en períodos característicos de las variaciones del contenido electrónico en la ionosfera, el principal efecto de la asimilación sobre los mapas ionosféricos globales es apreciable en una escala regional.

La configuración orbital de las misiones TOPEX/Poseidón y sus sucesoras Jason I y II es tal que los satélites altimétricos necesitan 10 días para muestrear la superficie completa de los océanos y recabar información de la ionosfera sobre esa parte del globo. Entonces, para sacar mayor provecho a la altimetría satelital como fuente de información ionosférica a escala global sería necesario asimilar información GPS y altimétrica simultáneamente en bloques de datos de 10 días corridos. A su vez, para incorporar información de cada punto en diferentes momentos del día, el tratamiento requiere el manejo conjunto de bloques de datos de 100 días aproximadamente. En cualquier caso, el volumen de datos involucrados es tal que, siguiendo la estrategia de asimilación desarrollada en el capítulo anterior, es técnicamente imposible resolver el problema. Por ese motivo, el desafío de esta etapa es el desarrollo de un algoritmo numérico apropiado para procesar grandes bloques de datos. La técnica que se propone consiste en acumular las ecuaciones normales diarias sobre la hipótesis de que los bias instrumentales, tanto de satélites y receptores GPS como del satélite altimétrico, se mantienen constantes en el período considerado. 


\subsection{Distribución espacial y temporal de los datos}

En esta etapa del trabajo se utiliza el grupo de 298 estaciones de monitoreo permanente pertenecientes al segmento terrestre del sistema GPS seleccionado para el tratamiento descripto en el capítulo anterior. Antes de desarrollar el nuevo método de asimilación es útil discutir la distribución espacial de los datos observacionales. Como se sabe, a partir del retraso que sufre la señal GPS al atravesar la ionosfera se infiere el contenido electrónico total a lo largo de la línea que une cada satélite con la estación. En cada instante, un mínimo de cuatro satélites se halla sobre el horizonte en cualquier punto sobre la superficie de la Tierra, por lo tanto, al cabo de un día cada estación habrá muestreado el contenido electrónico total oblicuo STEC en diferentes direcciones cubriendo fundamentalmente la parte continental del planeta como se muestra en la Figura 4.1 (mapa superior) en rojo.

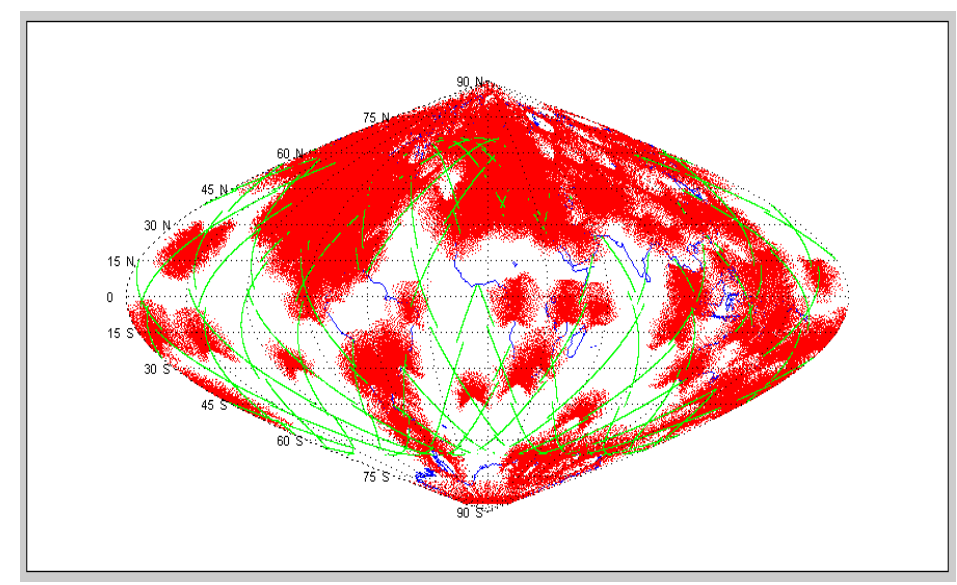

Figura 4.1. Cobertura espacial GPS (en rojo) + TOPEX (en verde), en un día (mapa superior) y en un ciclo de 10 días (mapa inferior).

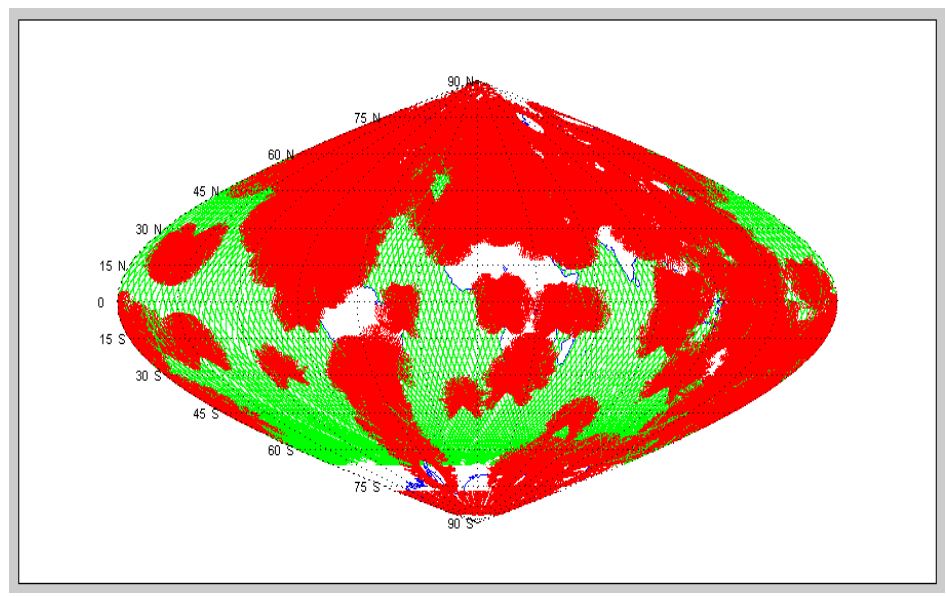

En el mismo período, los satélites altimétricos miden el contenido electrónico total vertical VTEC bajo la zona iluminada por el radar a lo largo del recorrido del 
satélite, con una cobertura mucho más estrecha como la representada en la misma figura en color verde. El planteo desarrollado en el capítulo anterior produce mapas ionosféricos a partir de la ingestión de bloques de 24 horas de datos. En ese intervalo de tiempo la distribución espacial de datos combinando las dos fuentes de información, GPS (en rojo) y Topex/Poseidón, es la que se observa en el mapa superior de la Figura 4.1.

Ampliando el intervalo de tiempo, la distribución geográfica de los datos GPS no varía sustancialmente, aunque sí se densifica. Pero, como se vio en la sección 2.3.2, las órbitas de los satélites altimétricos se van desplazando, barriendo zonas nuevas sobre los océanos, hasta completar un ciclo de 127 revoluciones en 10 días, al cabo de los cuales el radar vuelve a iluminar el primer punto. Por este motivo, la distribución geográfica de los datos correspondientes a un bloque de 10 días corridos se extiende como puede observarse en el mapa inferior de la Figura 4.1 en verde. Por otra parte, como ya se discutió en la sección 2.3.2, para asegurar la incorporación de observaciones altimétricas de cada punto en diferentes momentos del día, debemos considerar como mínimo un periodo de 96 días. Procesando entonces bloques de 100 días corridos la cobertura geográfica no se ampliará con respecto a los bloques de 10 días, pero sí la cobertura temporal.

Volviendo al mapa inferior de la Figura 4.1, las estaciones terrestres pertenecientes al sistema de posicionamiento GPS junto con el satélite altimétrico muestrean la ionosfera de modo tal que apenas una muy pequeña región del planeta, sobre la parte central de África y el norte de Sudamérica, queda sin cobertura.

Figura 4.2. Cantidad de

datos GPS y altimétricos asimilados en 100 días

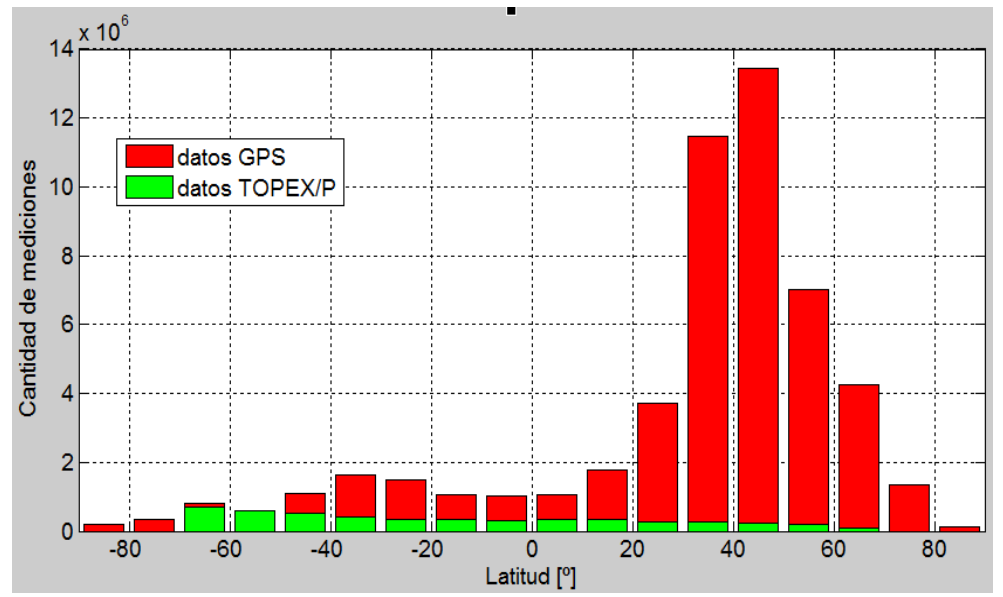


Si se presta ahora atención a la distribución de datos en latitud, se encontra que la relación entre la cantidad de observaciones de diferente origen no es uniforme. En la Figura 4.2 se representa la cantidad de datos GPS (en rojo) y altimétricos (en verde) correspondientes a los 100 primeros días del año 2002, agrupados en bandas de 10 grados de latitud geográfica.

En el hemisferio norte predominan los datos GPS sobre los atimétricos, mientras que en el hemisferio sur las observaciones del satélite TOPEX/Poseidón representan una fracción importante de los datos asimilados, llegando a superar las observaciones del sistema GPS entre los 50 y 60 grados de latitud sur.

El análisis precedente justifica el interés que despierta el uso de paquetes de datos altimétricos en estudios ionosféricos como fuente incomparable de información sobre los océanos, a la vez que pone de manifiesto los desafíos que plantea su asimilación en un modelo consistente.

\subsection{Acumulando los sistemas normales diarios}

El sistema de ecuaciones de observación que combina datos GPS y altimétricos, según se discutió en las secciones 3.2 y 3.3, es expresado como

$$
\left\{\begin{array}{l}
\mathrm{l}_{\mathrm{G}}-\varepsilon_{\mathrm{G}}=\mathrm{M}(\mathrm{z}) \sum_{\mathrm{l}=0}^{\mathrm{L}} \sum_{\mathrm{m}=0}^{\mathrm{l}}\left\{\mathrm{a}_{\mathrm{l}, \mathrm{m}, \mathrm{k}}(\mathrm{t}) \cos \left(\frac{2 \pi \mathrm{mh}}{24}\right)+\mathrm{b}_{\mathrm{l}, \mathrm{m}, \mathrm{k}}(\mathrm{t}) \operatorname{sen}\left(\frac{2 \pi \mathrm{mh}}{24}\right)\right\} \mathrm{P}_{\mathrm{l}, \mathrm{m}}(\operatorname{sen} \mu)+\beta_{\mathrm{G}+\mathrm{T}}^{\mathrm{S}}+\beta_{\mathrm{G}+\mathrm{T}}^{\mathrm{R}} \\
\mathrm{l}_{\mathrm{T}}-\varepsilon_{\mathrm{T}}=\sum_{\mathrm{l}=0}^{\mathrm{L}} \sum_{\mathrm{m}=0}^{\mathrm{l}}\left\{\mathrm{a}_{\mathrm{l}, \mathrm{m}, \mathrm{k}}(\mathrm{t}) \cos \left(\frac{2 \pi \mathrm{mh}}{24}\right)+\mathrm{b}_{\mathrm{l}, \mathrm{m}, \mathrm{k}}(\mathrm{t}) \operatorname{sen}\left(\frac{2 \pi \mathrm{mh}}{24}\right)\right\} \mathrm{P}_{\mathrm{l}, \mathrm{m}}(\operatorname{sen} \mu)+\beta^{\mathrm{T}}
\end{array}\right.
$$

o, en una forma más sintética:

$$
\mathbf{L}-\boldsymbol{\varepsilon}=\mathbf{A} \cdot \mathbf{x}
$$

donde $\mathbf{L}$ es el vector que contiene los datos GPS $\left(\mathbf{l}_{\mathrm{G}}\right)$ y altimétricos $\left(\mathbf{l}_{\mathrm{T}}\right)$, $\boldsymbol{\varepsilon}$ es el vector que contiene los errores no modelados, A es la matriz de diseño y $\mathbf{x}$ es el vector de las incógnitas del problema, que ahora son los coeficientes armónicos, los retardos instrumentales de los receptores y de los satélites GPS y el bias del satélite TOPEX/Poseidón.

En el capítulo 3 el sistema planteado fue resuelto día por día, obteniendo un conjunto de coeficientes cada dos horas y un juego diario de retardos instrumentales; luego se hizo un análisis estadístico para un período de 100 días. La resolución de un conjunto de 100 días de forma simultánea está limitada por las capacidades informáticas; este planteo se traduciría en la necesidad de 
resolver un sistema de aproximadamente $6.10^{7}$ ecuaciones con $4.10^{6}$ incógnitas: [(3400 coeficientes $\times 12$ intervalos) +350 retardos] $\times 100$ días. Para salvar este inconveniente se propone resolver los bloques de 100 días acumulando las ecuaciones normales diarias como se detalla a continuación.

En primer término, el sistema de ecuaciones para un día, dado por la ecuación 4.1, es reescrito de la forma:

$$
(\mathbf{A} \mid \mathbf{B})\left(\begin{array}{l}
\mathbf{x} \\
\mathbf{y}
\end{array}\right)=(\mathbf{L})
$$

donde $\mathbf{A}=\left(\begin{array}{l}\mathbf{A}_{\mathrm{G}} \\ \mathbf{A}_{\mathrm{T}}\end{array}\right), \quad \mathbf{B}=\left(\begin{array}{ccc}\mathbf{B}^{\mathrm{R}} & \mathbf{B}^{\mathrm{S}} & \mathbf{0} \\ \mathbf{0} & \mathbf{0} & \mathbf{1}\end{array}\right)$ y $\mathbf{L}=\left(\begin{array}{l}\mathbf{l}_{\mathrm{G}} \\ \mathbf{I}_{\mathrm{T}}\end{array}\right)-\left(\begin{array}{c}\boldsymbol{\varepsilon}_{\mathrm{G}} \\ \boldsymbol{\varepsilon}_{\mathrm{T}}\end{array}\right)$

A y B son las matrices de diseño (la primera contiene valores dados por $\cos \left(\frac{2 \pi m h}{24}\right) P_{1, m}(\operatorname{sen} \mu)$ y $\operatorname{sen}\left(\frac{2 \pi m h}{24}\right) P_{1, m}(\operatorname{sen} \mu)$ correspondientes a cada observación $y$, la segunda, unos en las columnas correspondientes al satélite y al receptor que interviene y ceros para las restantes). $\mathbf{L}$ es el vector que contiene la observaciones (incluye los datos GPS y TOPEX/Poseidón) y los errores no modelados. $\mathbf{x}$ e $\mathbf{y}$ representan las incógnitas del problema, por un lado los coeficientes de los armónicos esféricos y por otro los retardos instrumentales.

Para formar el sistema normal se pre-multiplica cada miembro de la ecuación 4.1 por la matriz transpuesta de (A | B), (A | B $)^{\mathrm{t}}$, y se obtiene el sistema:

$$
\left(\begin{array}{c|c}
\mathbf{A}^{\mathrm{t}} \mathbf{A} & \mathbf{A}^{\mathrm{t}} \mathbf{B} \\
\mathbf{B}^{\mathrm{t}} \mathbf{A} & \mathbf{B}^{\mathrm{t}} \mathbf{B}
\end{array}\right)\left(\begin{array}{l}
\mathbf{x} \\
\mathbf{y}
\end{array}\right)=\left(\begin{array}{c}
\mathbf{A}^{\mathrm{t}} \\
\mathbf{B}^{\mathrm{t}}
\end{array}\right)(\mathbf{L})
$$

Luego, separando el sistema en dos ecuaciones de la forma

$$
\left\{\begin{array}{l}
\mathbf{A}^{\mathrm{t}} \mathbf{A} \mathbf{x}+\mathbf{A}^{\mathrm{t}} \mathbf{B} \mathbf{y}=\mathbf{A}^{\mathrm{t}} \mathbf{L} \\
\mathbf{B}^{\mathrm{t}} \mathbf{A} \mathbf{x}+\mathbf{B}^{\mathrm{t}} \mathbf{B} \mathbf{y}=\mathbf{B}^{\mathrm{t}} \mathbf{L}
\end{array}\right.
$$

el método de eliminación Gaussiana permite reescribirlo como

$$
\left\{\begin{array}{c}
\mathbf{X}=\left(\mathbf{A}^{\mathrm{t}} \mathbf{A}\right)^{-1} \mathbf{A}^{\mathrm{t}}(\mathbf{L}-\mathbf{B y}) \\
\mathbf{y}=\left(\mathbf{B}^{\mathrm{t}} \mathbf{C} \mathbf{B}\right)^{-1} \mathbf{B}^{\mathrm{t}} \mathbf{C} \mathbf{L}
\end{array}\right.
$$

donde $\mathbf{C}=\mathbf{A}\left(\mathbf{A}^{\mathrm{t}} \mathbf{A}\right)^{-1} \mathbf{A}^{\mathrm{t}}-\mathbf{I}$, siendo $\mathbf{I}$ la matriz identidad .

En el capítulo anterior, en la sección 3.2.3, se mostró que los retardos instrumentales diarios no varían significativamente a lo largo del período de 100 días considerado. Este resultado es la suposición que permitirá resolver el problema. Si los retardos instrumentales permanecen constantes a largo de los 
100 días, los sistemas normales diarios para y (segunda ecuación del sistema 4.4) pueden ser apilados y los retardos instrumentales calculados como

$$
\mathbf{y}=\left(\sum_{\mathrm{i}=1}^{100} \mathbf{B}_{\mathrm{i}}^{\mathrm{t}} \mathbf{C}_{\mathrm{i}} \mathbf{B}_{\mathrm{i}}\right)^{-1} \sum_{\mathrm{i}=1}^{100} \mathbf{B}_{\mathrm{i}}^{\mathrm{t}} \mathbf{C}_{\mathrm{i}} \mathbf{L}_{\mathrm{i}}
$$

De esta forma, los retardos instrumentales son obtenidos teniendo en cuenta la totalidad de las observaciones disponibles durante los 100 días.

Una vez calibrados los instrumentos, la primera ecuación del sistema 4.4,

$$
\mathbf{x}=\left(\mathbf{A}^{\mathbf{t}} \mathbf{A}\right)^{-\mathbf{1}} \mathbf{A}^{\mathbf{t}}(\mathbf{L}-\mathbf{B y})
$$

permite calcular los coeficientes del modelo para producir los 12 mapas iosoféricos globales para cada día.

Para estimar los errores residuales se calcula

$$
\overline{\boldsymbol{\varepsilon}}=\mathbf{L}-\overline{\mathbf{L}}
$$

como la diferencia entre los valores observacionales y modelados para los 100 días, y luego el error residual cuadrático como

$$
\sigma_{0}=\sqrt{\frac{\boldsymbol{\varepsilon}^{\mathrm{T}} \boldsymbol{\varepsilon}}{\mathrm{n}-\mathrm{k}}}
$$

donde $\mathrm{n}$ representa la cantidad de mediciones y $\mathrm{k}$ el número de parámetros a determinar en el intervalo de 100 días.

Finalmente, teniendo en cuanta que, de acuerdo con la ecuación 4.6, los retardos instrumentales dependen linealmente de $\mathbf{L}$ es posible obtener una estimación de la propagación de los errores en los retardos instrumentales a través de la matriz de varianza-covarianza para los parámetros constantes:

$$
\Sigma=\sigma_{0}^{2}(\mathbf{M})^{-1}
$$

con

$$
\mathbf{M}=\sum_{\mathrm{i}=1}^{100} \mathbf{A}_{\mathrm{i}}^{\mathrm{t}} \mathbf{A}_{\mathrm{i}}
$$




\subsubsection{Validación de la técnica: DCBs de satélites y receptores GPS con datos GPS únicamente}

Se adaptó el código del modelo ionosférico de La Plata LPIM de acuerdo con el procedimiento de acumulación de sistemas normales diarios descripto en la sección anterior. Como primer paso, con el objeto de chequear la técnica de acumulación, se trabajó con mediciones GPS únicamente. Se utilizaron datos de las 298 estaciones de monitoreo permanente seleccionadas en el capítulo anterior y se procesaron de forma simultánea observaciones correspondientes a los 100 primeros días del año 2002. Como resultado se obtuvo un conjunto de retardos instrumentales para los 28 satélites operativos y los 298 receptores que intervinieron en el ajuste, suponiendo que permanecen invariantes a lo largo de los 100 días de procesamiento. Llamamos $\boldsymbol{\beta}_{\mathrm{G}}^{\mathrm{S}}$ a los DCBs de los satélites y $\boldsymbol{\beta}_{\mathrm{G}}^{\mathrm{R}}$ a los retardos de los receptores GPS calculados utilizando datos GPS únicamente y constantes para los 100 días. Se espera que, para cada satélite, el retardo calculado de esta forma resulte comparable con el valor medio $\left\langle\beta_{G}^{S}\right\rangle$ de los retardos calculados día por día con LPIMG, y que lo mismo suceda para los receptores. Esto es efectivamente lo que se encuentra. En el caso de los satélites, el módulo de la diferencia entre el valor constante en los 100 días y el valor medio de los DCBs diarios en 100 días $\left|\boldsymbol{\beta}_{\mathrm{G}}^{\mathrm{S}}-\left\langle\beta_{\mathrm{G}}^{\mathrm{S}}\right\rangle\right|$ no supera los $0.3 \mathrm{~ns}$. Para los receptores la diferencia $\left|\boldsymbol{\beta}_{\mathrm{G}}^{\mathrm{R}}-\left\langle\beta_{\mathrm{G}}^{\mathrm{R}}\right\rangle\right|$ es menor que 1.0 ns en el $94 \%$ de las estaciones.

Además, se pudo establecer que el módulo de la diferencia entre el valor constante en los 100 días y el valor medio de los DCBs diarios en 100 días guarda cierta relación con la dispersión en los valores $\beta_{\mathrm{G}}^{\mathrm{R}}$ calculados día por día. En la

Figura 4.3. Diferencias $\left|\boldsymbol{\beta}_{\mathrm{G}}^{\mathrm{R}}-\left\langle\boldsymbol{\beta}_{\mathrm{G}}^{\mathrm{R}}\right\rangle\right|$ vs la dispersión en los DCBs calculados día por día.

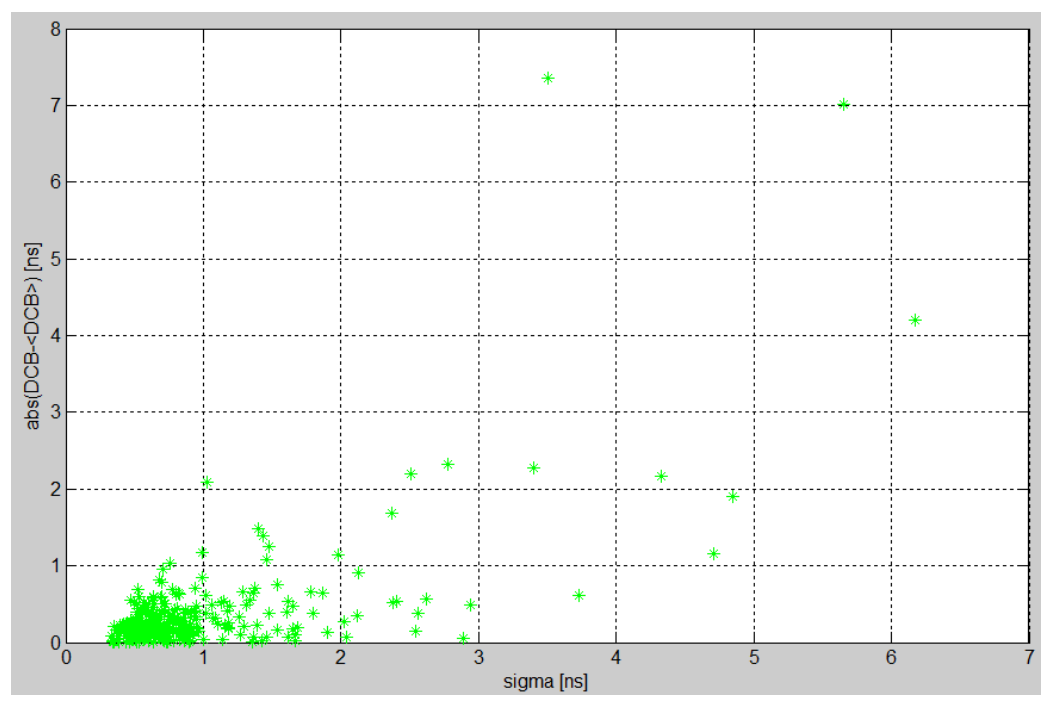


Figura 4.3 se ha representado, para cada receptor, el módulo de las diferencias entre el valor constante y el valor medio de los DCBs, $\left|\boldsymbol{\beta}_{\mathrm{G}}^{\mathrm{R}}-\left\langle\beta_{\mathrm{G}}^{\mathrm{R}}\right\rangle\right|$, versus la desviación estándar en la serie de 100 retardos calculados día por día. Las estaciones que exhiben las mayores diferencias son aquellas que han mostrado variaciones abruptas en los retardos en el intervalo de 100 días, para cuales es evidente que la hipótesis de estabilidad en el período completo no sería aplicable. Por este motivo, en la siguiente etapa se utilizan 284 de las 298 estaciones, para las cuales la diferencia $\left|\boldsymbol{\beta}_{G}^{R}-\left\langle\beta_{G}^{R}\right\rangle\right|$ resulta menor que 1 ns (con este corte se descartan estaciones con dispersiones en los DCBs mayores que las diferencias $\left\langle\beta_{\mathrm{G}}^{\mathrm{R}}\right\rangle-\left\langle\beta_{\mathrm{G}+\mathrm{T}}^{\mathrm{R}}\right\rangle$ hallados en el capítulo anterior).

\subsection{Resultados}

Probada la técnica de acumulación de sistemas normales diarios se asimilaron las observaciones altimétricas en el período comprendido entre el 1 de enero al 4 de abril del año 2002. Utilizando simultáneamente información de 284 estaciones GPS y del satélite TOPEX/Poseidón correspondiente al bloque de 100 días continuos, se obtuvieron mapas iosoféricos globales con una resolución temporal de 2 horas y un conjunto de DCBs, suponiendo que se mantienen constantes ese período. Se ha llamado LPIMBC (bias constantes) a la versión de LPIM actualizada que introduce las modificaciones en el código propuestas en este capítulo. A continuación se discuten los resultados.

\subsubsection{Calibración de satélites y receptores con datos GPS + TOPEX/Poseidón}

Se analizan en primer término los DCBs instrumentales. Llamamos respectivamente $\boldsymbol{\beta}_{\mathrm{G}+\mathrm{T}}^{\mathrm{S}}, \boldsymbol{\beta}_{\mathrm{G}+\mathrm{T}}^{\mathrm{R}}$ y $\boldsymbol{\beta}_{\mathrm{G}+\mathrm{T}}^{\mathrm{T}}$ a los retardos inter-frecuencia de los satélites $\mathrm{Y}$ receptores GPS y al bias altimétrico supuestos constantes calculados con la nueva técnica de acumulación que usa datos GPS + TOPEX/Poseidón.

\subsection{1.a. DCB de satélites GPS}

Los valores de los retardos instrumentales inter-frecuencia correspondientes a los 28 satélites GPS operativos en el periodo procesado y calculados con el método 
descripto en este capítulo se listan en el anexo 5. Es importante señalar que estos valores difieren de los valores medios de los retardos calculados día por día con datos GPS únicamente, $\left\langle\beta_{\mathrm{G}}^{\mathrm{S}}\right\rangle$, en cantidades muy pequeñas: $\left|\boldsymbol{\beta}_{\mathrm{G}+\mathrm{T}}^{\mathrm{S}}-\left\langle\beta_{\mathrm{G}}^{\mathrm{S}}\right\rangle\right| \leq 0.13 \mathrm{~ns}$. En la Figura 4.4 se representan estas diferencias.

Figura 4.4. Diferencia entre los DCBs de los satélites supuestos constantes (calculados con datos GPS + altimétricos) y el valor medio de los DCBs calculados día por día (con datos GPS) expresados en ns: $\boldsymbol{\beta}_{\mathrm{G}+\mathrm{T}}^{\mathrm{S}}-\left\langle\boldsymbol{\beta}_{\mathrm{G}}^{S}\right\rangle$

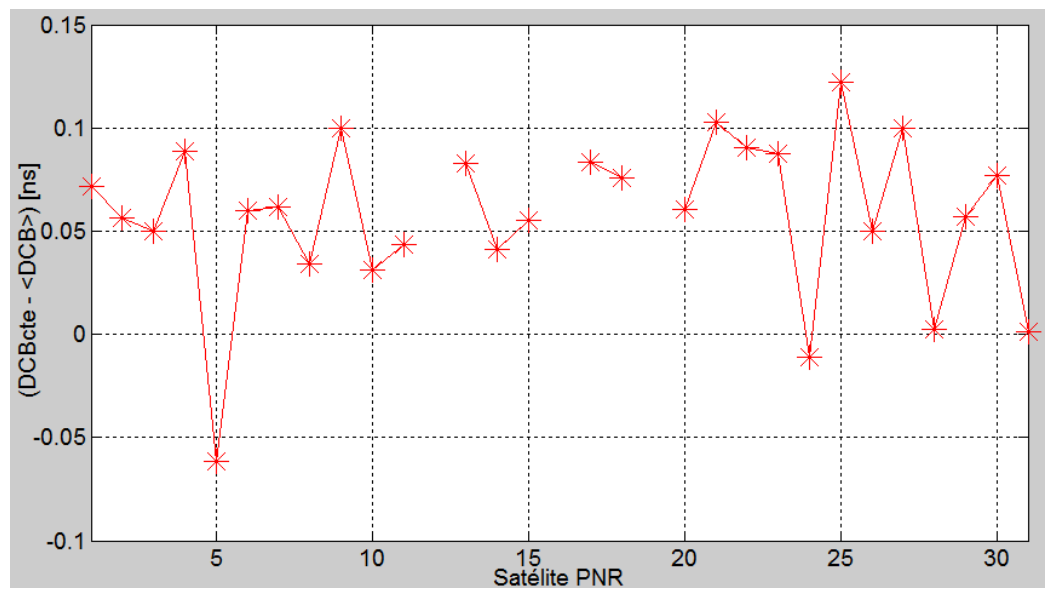

\subsection{1.b. Bias de TOPEX/Poseidón}

El bias del satélite altimétrico supuesto constante en el período de 100 días calculado usando simultáneamente datos GPS y TOPEX/P resultó:

$$
\boldsymbol{\beta}^{\mathrm{T}}=2.836 \pm 0.005 \mathrm{TECu}
$$

En el capítulo precedente se discutieron los posibles orígenes de este error. El resultado hallado ahora, con la técnica de acumulación de sistemas normales, es consistente con los estudios mencionados en la sección 3.3.3 y con el valor medio $\left\langle\beta^{\mathrm{T}}\right\rangle=3.068 \pm 0.675 \mathrm{TECu}$ de los bias calculados día por día en la misma sección.

\subsection{1.c. DCB de receptores GPS}

El método de asimilación propuesto permite calibrar los 284 receptores GPS suponiendo que se mantienen estables a lo largo de los 100 días. Los resultados para el conjunto de estaciones se muestran en el Anexo 5. 
Es interesante comparar los valores de los DCBs supuestos constantes durante 100 días, $\boldsymbol{\beta}_{\mathrm{G}+\mathrm{T}}^{\mathrm{R}}$, con los valores medios de los retardos calculados día por día utilizando datos GPS únicamente, $\left\langle\beta_{\mathrm{G}}^{\mathrm{S}}\right\rangle$. En la Figura 4.5 han sido representados sobre el mapa los valores de las diferencias $\boldsymbol{\beta}_{\mathrm{G}+\mathrm{T}}^{\mathrm{R}}-\left\langle\beta_{\mathrm{G}}^{\mathrm{R}}\right\rangle$ entre los DCBs calculados con ambas técnicas, expresados en ns.

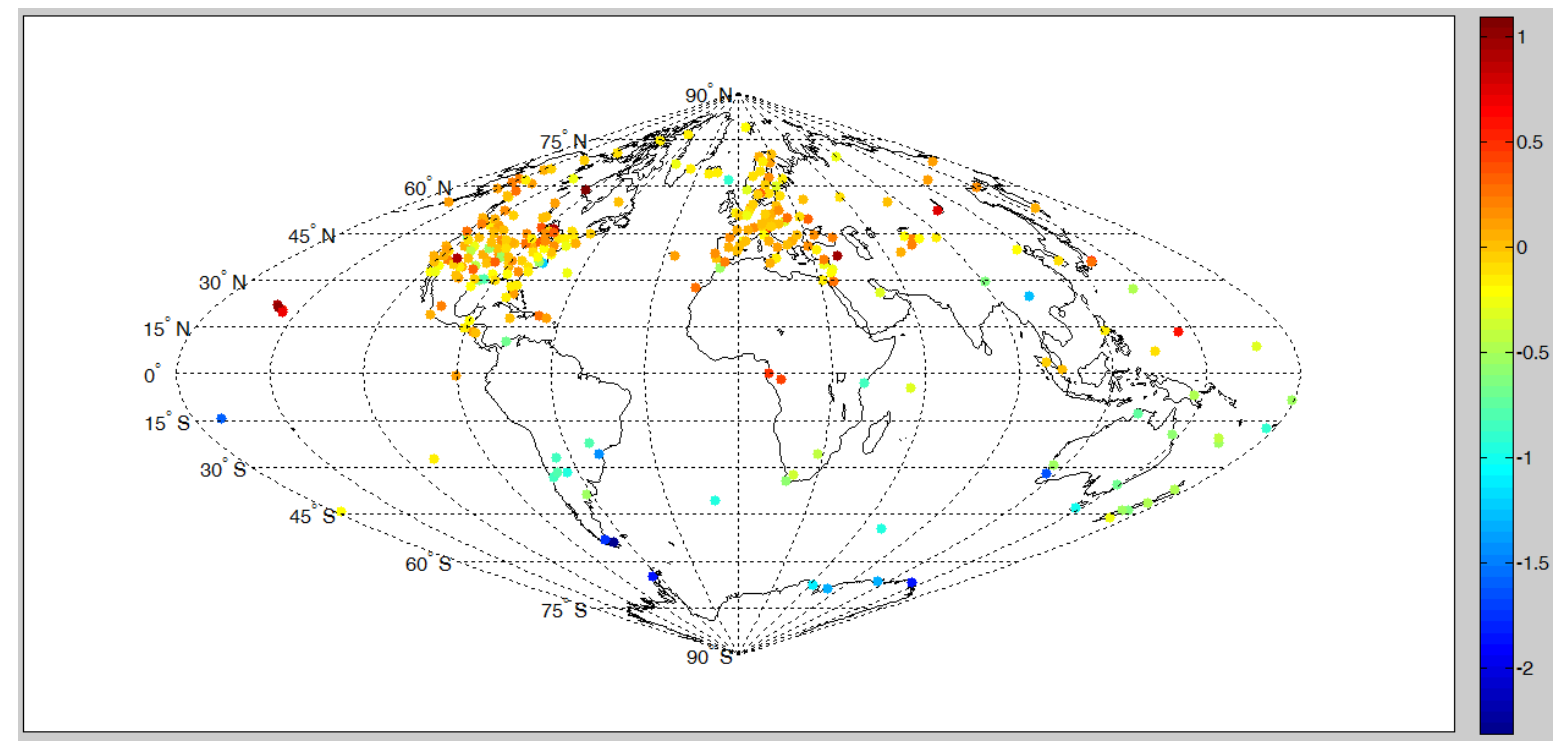

Figura 4.5. Diferencia entre los DCBs de los receptores GPS supuestos constantes (calculados con datos GPS + altimétricos) y el valor medio de los DCBs calculados día por día (con datos GPS) expresados en ns: $\beta_{\mathrm{G}+\mathrm{T}}^{\mathrm{R}}-\left\langle\beta_{\mathrm{G}}^{\mathrm{R}}\right\rangle$

De acuerdo con la escala de colores de referencia desplegada en la parte derecha de la figura, las diferencias son próximas a cero para las estaciones ubicadas sobre la parte continental del hemisferio norte, mientras que en el hemisferio sur se amplían en tanto las estaciones son más australes. Estos resultados son consistentes con la distribución geográfica de los datos de diferente origen. Dado que en el hemisferio norte hay una preponderancia de datos GPS con respecto a los datos altimétricos, es esperable que la asimilación de datos altimétricos no modifique de forma significativa la calibración de los receptores ubicados en esa región. Sin embargo, en el hemisferio sur donde la relación entre la cantidad de datos altimétricos asimilados con respecto a la cantidad de datos GPS es importante los retardos instrumentales hallados con la nueva técnica de asimilación difieren de los obtenidos con la técnica convencional. En el hemisferio sur, los DCBs supuestos constantes resultan menores que el valor medio de los DCBs hallados a partir de datos GPS únicamente; estas diferencias pueden superar los $2 n s$, y si se toman en relación a $\left\langle\beta_{\mathrm{G}}^{\mathrm{R}}\right\rangle$ representan reducciones entre el $10 \%$ y el $40 \%$. Se retoma la interpretación de estos resultados en la sección 4.4. 


\subsubsection{Mapas ionosféricos globales}

Es importante evaluar de qué forma la asimilación de datos altimétricos a través de la técnica de acumulación de sistemas normales influye en la representación del contenido electrónico total. Los mapas ionosféricos globales obtenidos con la versión actualizada de LPIM, LPIMBC, en intervalos de 2 horas para un día (día 007 del año 2002) han sido representados en la Figura 4.6 (columna derecha).

Para establecer una comparación entre el VTEC calculado con las diferentes técnicas se obtuvieron, por un lado, los GIMs con el modelo LPIMG en su versión clásica, esto es utilizando datos GPS únicamente y calculando los retardos instrumentales diarios simultáneamente con los parámetros del modelo; por otro lado se obtuvieron los mapas ionosféricos utilizando datos GPS + TOPEX/Poseidón, primero con bias que varían día a día (versión LPIMG+T) y luego con bias constantes en el período de100 días (versión LPIMBC).

En la Figura 4.6 ha sido representado el contenido electrónico modelado con cada versión; el VTEC ha sido calculado mediante una interpolación cúbica en los diferentes GIMs a lo largo del track del satélite TOPEX/Poseidón; se ha graficado el VTEC calculado con LPIMG en rojo, con LPIMG+T en amarillo y con LPIMBC en verde, todos superpuestos al VTEC medido por el satélite altimétrico en azul. Las tres versiones representan las principales variaciones espacio-temporales del VTEC; claramente, las versiones que asimilan los datos altimétricos (series amarilla y verde) se ven desplazadas hacia los datos incorporados (azul) si las comparamos con la serie correspondiente al modelo LPIMG (rojo) que sólo usa datos GPS. La comparación con el valor observacional altimétrico resultó menor para la versión LPIMBC para los 100 días procesados. En particular, para el día graficado, el RMS resultó de 7.17 para LPIMG, de 5,72 LPIMG+T y de 5,42 para LPIMBC.

Como hemos mencionado, las mediciones del VTEC que proveen las misiones de altimetría satelital se consideran estimaciones de referencia en muchos trabajos de investigación. El hecho de que estas estén siendo asimiladas en el LPIM nos propone un nuevo reto como es la validación del vTEC y de los bias instrumentales hallados. Este tema será tratado en la siguiente sección.

Figura 4.6. (Dos páginas siguientes). Izquierda: Contenido electrónico total vTEC medido por TOPEX/Poseidón (en azul), modelado con LPIMG (en rojo), modelado con LPIMG+T (en amarillo) y modelado con LPIMBC (en verde), en función del tiempo universal, en intervalos de 2 horas. Derecha: Mapas ionosféricos globales obtenidos con LPIMBC con el track del satélite TOPEX/Poseidón superpuesto. Día 007 del año 2002. 

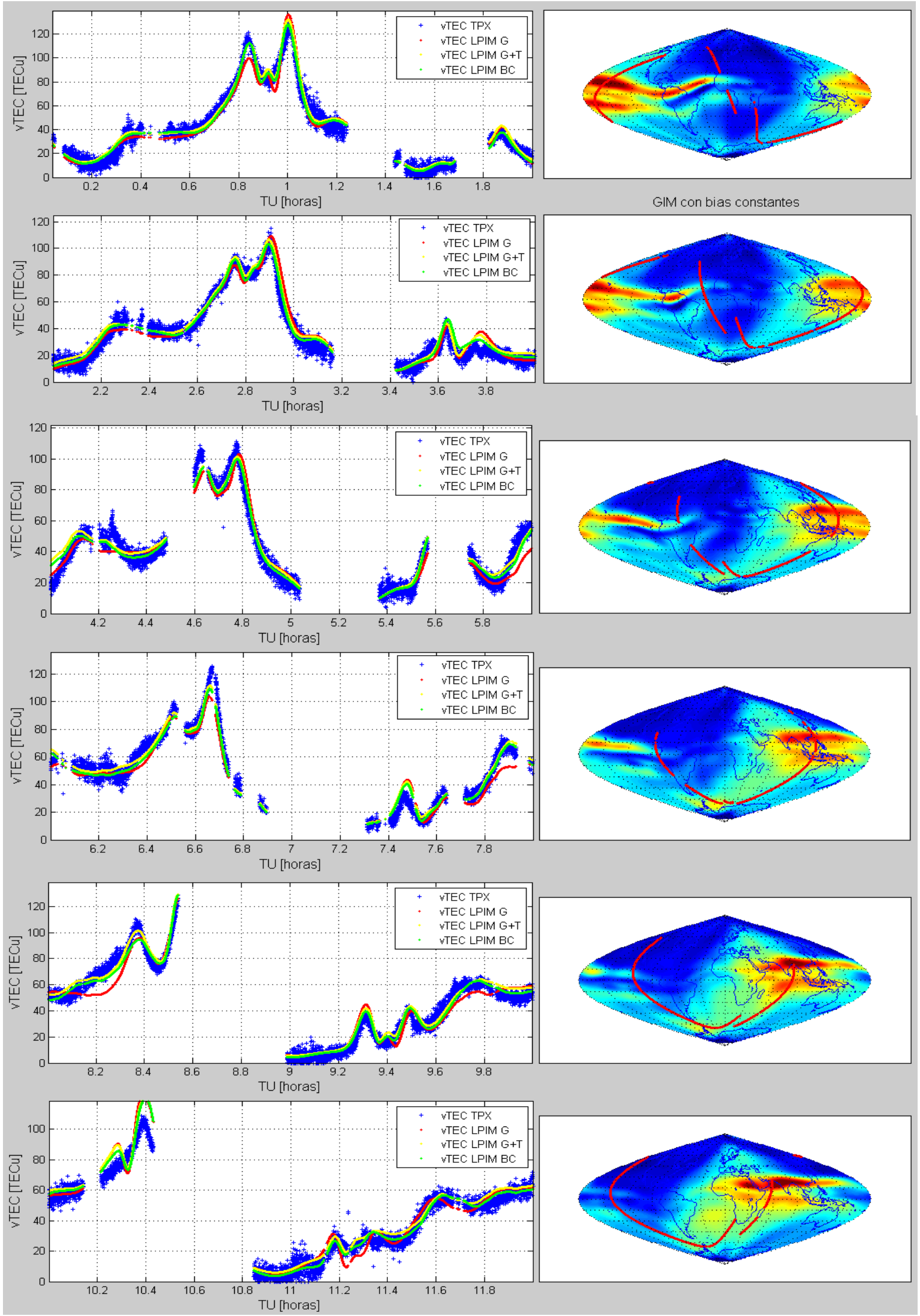

I. Bibbó | Nueva técnica de asimilación de datos en LPIM 118 

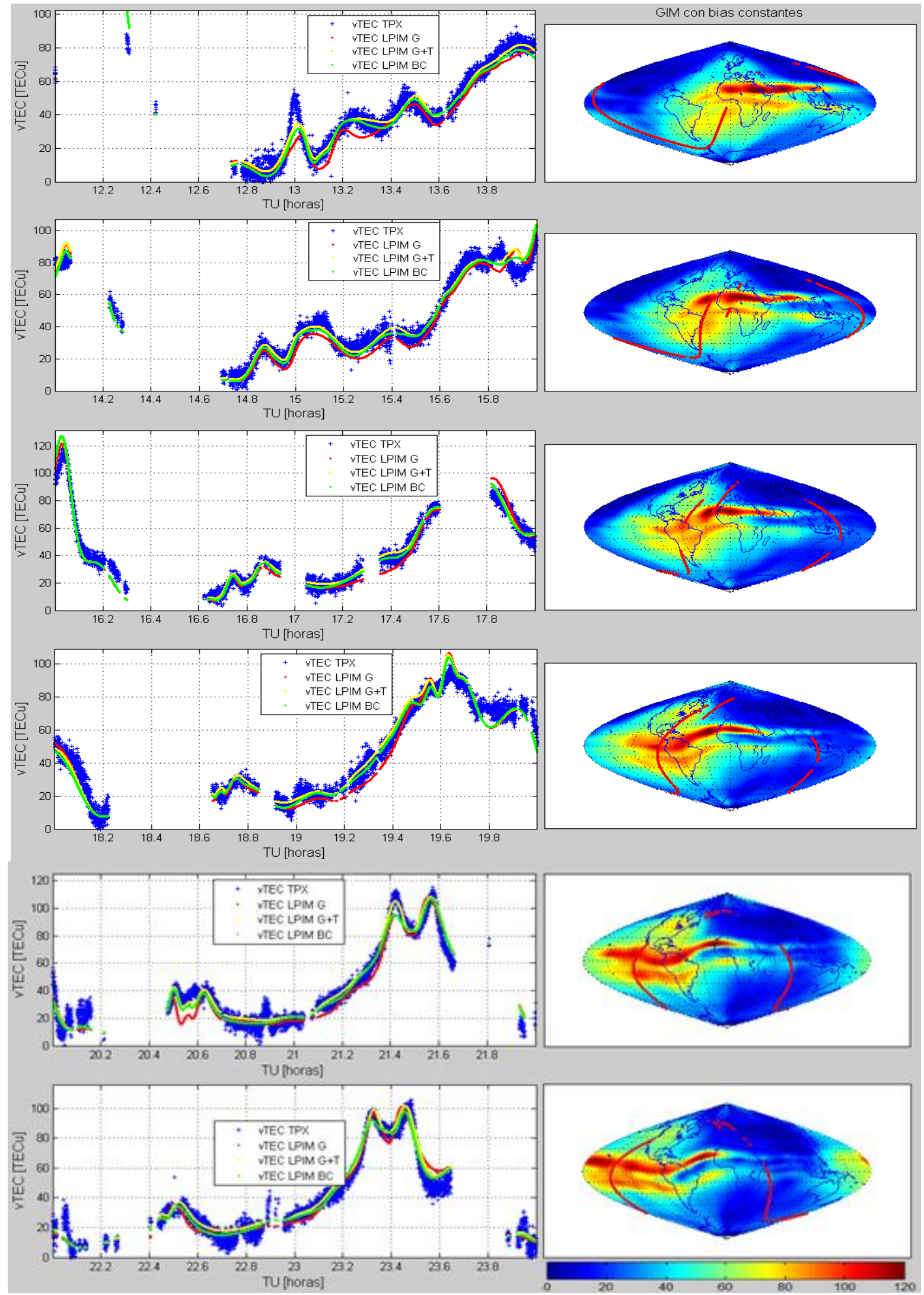

I. Bibbó | Nueva técnica de asimilación de datos en LPIM 119 


\subsection{Validación de los resultados}

La validación de los resultados alcanzados plantea un gran desafío por carecer de mediciones o estimaciones independientes que puedan ser tomadas como 'valores verdaderos' de las cantidades que se están modelando. La exactitud de los diferentes modelos de TEC vertical que existen en la actualidad es comparable a la del modelo que se está probando y resulta muy difícil evaluar si las diferencias que presenta este aporte cuando se los compara con aquellos constituye o no una mejora significativa. De allí que se optara por una validación indirecta, recurriendo a una simulación numérica. Para ello se generaron observaciones artificiales que reproducen la configuración geométrica de las observaciones reales y se utilizó el método desarrollado para estimar los parámetros cuyos valores son conocidos a priori. Para simular el contenido electrónico se usó el modelo NeQuick.

\subsubsection{Modelo NeQuick}

Nequick es un modelo desarrollado por el Laboratorio de Aeronomía y Radipropagación (T/ICT4D Laboratory) perteneciente al Centro Internacional de Física Teórica Abdus Salam (ICTP, Trieste, Italia) con la colaboración del Instituto de Geofísica, Astrofísica y Meteorología de la Universidad de Graz, Austria, especialmente diseñado para aplicaciones en transmisiones transionosféricas (Nava et al., 2008).

El modelo describe el perfil vertical de la densidad de electrones libres mediante la superposición de funciones semi-Epstein. Estas funciones representan las partes alta y baja de la región E y de la capa F1, la parte baja de la capa F2 y la región superior de la ionosfera situada por encima del máximo de concentración electrónica (topside). Cada función está ligada a un punto de anclaje definido por la densidad de electrones y la altura del pico de la capa correspondiente. Los puntos de anclaje de las capas E, F1 y F2 han sido modelados a partir de parámetros empíricos característicos de las mediciones realizadas con ionosondas, como son las frecuencias críticas foE, foFl y foF2 y el parámetro de transferencia M(3000)F2. La función que representa el topside depende de un parámetro de espesor determinado empíricamente que varía con la altura. Los valores modelados dependen de la actividad solar a través del número de manchas solares promedio $\mathrm{R} 12$ o del promedio del flujo de radiación f10.7, la estación del año y el tiempo. 
El modelo NeQuick permite calcular la densidad electrónica como función de la altura y las coordenadas geocéntricas latitud y longitud sobre una tierra esférica. Asimismo, es posible evaluar la densidad electrónica a lo largo de un camino y calcular el TEC mediante integración numérica. Los mapas ionosféricos que se obtienen con NeQuick reproducen las principales características que se observan en la ionosfera, como se muestra en la Figura 4.7.

Figura 4.7. VTEC modelado con NeQuick (http://tict4d.ictp.it/nequick2).

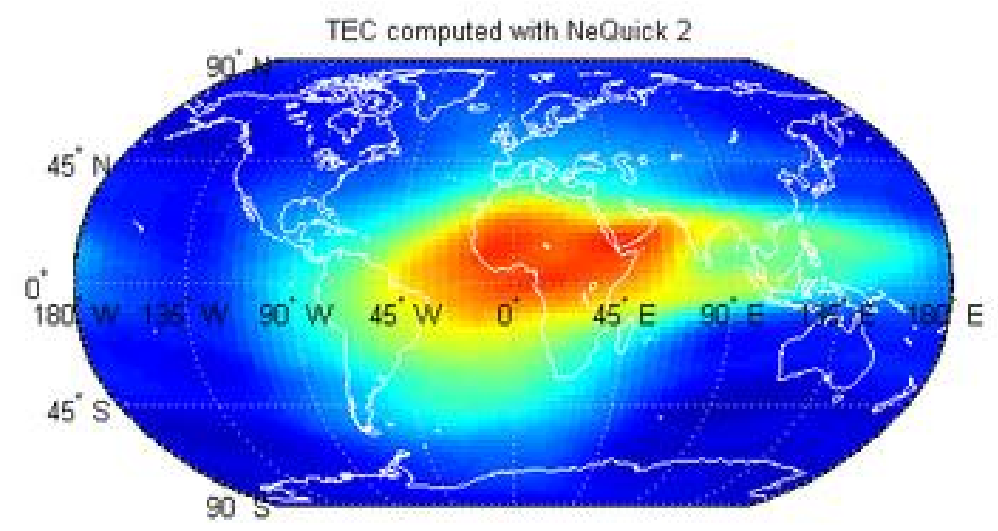

\subsubsection{Datos artificiales}

El modelo NeQuick representa de forma aproximada la ionosfera y permite calcular la densidad electrónica en un punto alrededor de la Tierra en un determinado instante, sin errores de calibración. Es decir, que si se toma un conjunto de datos generados con NeQuick para luego estimar el contenido electrónico global con LPIM se espera obtener retardos instrumentales nulos. Experimentos realizados en este sentido han mostrado que LPIM devuelve DCBs no nulos que han sido interpretados como una forma de compensar las limitaciones que el propio modelo LPIM impone, como son la aproximación de la ionosfera mediante una capa delgada, la introducción de una función de mapeo y el truncamiento de la serie de armónicos esféricos (Azpilicueta \& Brunini, 2009, Conte et al., 2011).

El propósito actual es evaluar la técnica de acumulación de sistemas normales diarios para procesar bloques de varios días simultáneamente. Para ello se han generado observaciones artificiales con NeQuick simulando la configuración geométrica de las observaciones reales. Concretamente, en las ecuaciones de observación 


$$
\left\{\begin{array}{c}
\mathrm{l}_{\mathrm{G}}-\varepsilon_{\mathrm{G}}=\mathrm{M}(\mathrm{z}) \mathrm{vTEC}+\beta_{\mathrm{G}+\mathrm{T}}^{\mathrm{S}}+\beta_{\mathrm{G}+\mathrm{T}}^{\mathrm{R}} \\
\mathrm{l}_{\mathrm{T}}-\varepsilon_{\mathrm{T}}=\mathrm{vTEC}+\beta_{\mathrm{T}}^{\mathrm{S}}
\end{array}\right.
$$

cada valor observacional $\mathrm{l}_{\mathrm{G}}$ y $\mathrm{l}_{\mathrm{T}}$ es reemplazado por un valor sintético $\mathrm{l}_{\mathrm{S}}$ para luego ajustar el contenido electrónico vTEC y los retardos instrumentales $\beta_{\mathrm{G}+\mathrm{T}}^{\mathrm{S}} \mathrm{y}$ $\beta_{\mathrm{G}+\mathrm{T}}^{\mathrm{R}}$ con LPIM. $\beta_{\mathrm{T}}^{\mathrm{S}}$ es considerado nulo debido a que en este planteo los datos tienen un origen común.

Los valores artificiales del contenido electrónico son obtenidos por integración numéricamente de la densidad electrónica volumétrica dada por el modelo NeQuick $\mathrm{N}_{\mathrm{e}}\left(\varphi, \lambda, \mathrm{h}, \mathrm{t}, \mathrm{F}_{10.7}\right)$ como función de la latitud geográfica $\varphi$, la longitud geográfica $\lambda$, la altura sobre la superficie de la Tierra $h$, el tiempo universal t y el índice de actividad solar $\mathrm{F}_{10.7}$ :

$$
\mathrm{l}_{\mathrm{S}}=\int_{\mathrm{S}_{1}}^{\mathrm{S}_{2}} \mathrm{~N}_{\mathrm{e}}\left(\varphi, \lambda, \mathrm{h}, \mathrm{t}, \mathrm{F}_{10.7}\right) \mathrm{ds}
$$

Dado que en el modelo NeQuick la densidad electrónica es bien representada hasta una altura de $1.000 \mathrm{~km}$, los límites de integración son calculados suponiendo que la señal atraviesa una región comprendida entre las alturas $\mathrm{h}_{1}=60 \mathrm{~km}$ y $\mathrm{h}_{2}=1.000 \mathrm{~km}$. Para reproducir los datos GPS, el camino de integración se realiza a lo largo de la línea que une la estación con el satélite, mientras que para los datos altimétricos el camino de integración es vertical.

\subsubsection{La técnica de acumulación con datos sintéticos}

El objeto de esta sección es reproducir el esquema de cálculo propuesto en las sección 4.2, ahora con datos sintéticos, libres de errores de calibración en principio. Se trabajó con una serie de 10 días corridos (días 050 a 059 del año 2002) calculando primero mapas ionosféricos cada dos horas y un juego de retardos diarios (versión LPIMG), y luego acumulado los sistemas diarios para obtener mapas ionosféricos cada dos horas y un juego de retardos para los 10 días (versión LPIMBC). Los retardos son evaluados por su apartamiento del valor nulo, mientras que cada GIM es contrastado con el mapa generado con NeQuick considerado como valor verdadero de VTEC; estos mapas se obtienen, para cada día e intervalo horario, calculando el VTEC de forma directa con el modelo NeQuick sobre una grilla equi-espaciada $2.5^{\circ} \times 2.5^{\circ}$. 


\subsection{3.a. Experiencia 1.}

En primer término se comparan los valores medios de los DCBs calculados día a día con la versión clásica LPIMG (simulando datos GPS) con los valores de los DCBs constantes en los 10 días calculados simulando datos GPS+TOPEX/Poseidón y asimilándolos con la técnica de acumulación de sistemas normales. Se espera que la nueva técnica contribuya a reducir los DCBs estimados por LPIM.

Para los satélites se obtienen con ambas técnicas DCBs que no superan, en valor absoluto, los 0.8 ns y las diferencias entre ellas no son significativas. En cambio, para los receptores, las diferencias entre los DCBs derivados de los diferentes métodos son importantes: en el $70 \%$ de los casos, con la técnica de asimilación de TEC vertical por acumulación de sistemas normales se obtienen DCBs menores en valor absouto que con los que se obtiene con la versión clásica de LPIM. En la Figura 4.8 es posible visualizar los resultados. La serie representada en color rojo es la que se obtiene con la versión original, esto es simulando observaciones GPS día por día y promediando los bias en 10 días. La serie verde corresponde a la técnica de asimilación de VTEC; en este caso los retardos se obtuvieron resolviendo el sistema de ecuaciones por acumulación de los sistemas normales diarios suponiéndolos constantes en 10 días (se simularon observaciones de sTEC

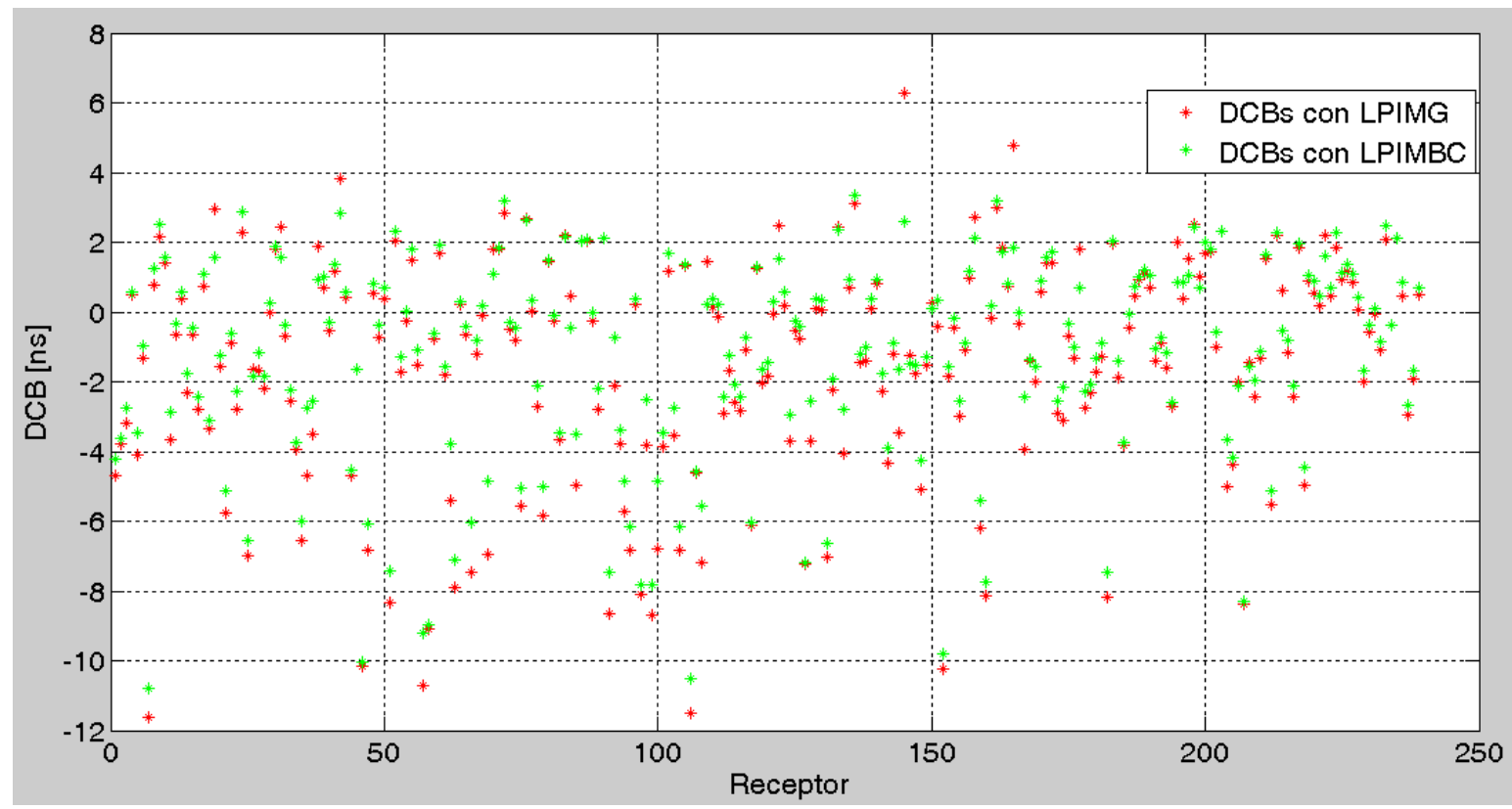

Figura 4.8. DCBs de receptores obtenidos a partir de datos artificiales para 10 días (días 050 a 059 del año 2002): simulando observaciones GPS y calculados promediando los valores diarios (en rojo), y simulando observaciones GPS+TOPEX/P y calculados con la técnica de acumulación de sistemas normales (en verde). 
para la configuración de satélites GPS y observaciones de VTEC para la configuración de la misión altimétrica).

Como se mencionó, en la mayor parte de las estaciones la asimilación de vTEC produce una reducción en los DCBs. En los casos en que LPIMBC no logra reducir los DCBs de los receptores, las diferencias en favor de LPIMG no superan los $0.5 \mathrm{~ns}$, mientras que las diferencias entre los DCBs en favor de LPIMBC llegan hasta los 3.69 ns, representando reducciones porcentuales importantes, especialmente para estaciones ubicadas en el hemisferio sur. En la Tabla 4 se resumen los principales parámetros estadísticos de ambas series; se advierte tanto la reducción del valor medio como del rango de los DCBs con el uso de LPIMBC.

\begin{tabular}{|l|r|r|}
\hline & DCBs con LPIMG [ns] & DCBs con LPIMBC [ns] \\
\hline Valor mínimo & -11.62 & -10.78 \\
\hline Valor máximo & 6.29 & 3.35 \\
\hline Valor medio & -1.53 & -1.23 \\
\hline Desviación estándar & 3.23 & 2.92 \\
\hline Rango & 17.91 & 14.13 \\
\hline
\end{tabular}

Tabla 4.1. Parámetros estadísticos de las series de DCBs de receptores calculados LPIMG Y LPIMBC.

En la Figura 4.9 se han representado los DCBs obtenidos con LPIMG (en rojo), los resultados que arroja $L_{P I M B C}$ (en verde) y las diferencias porcentuales entre los valores que se obtienen con cada versión, referidas al primero de ellos $\frac{\mathrm{DCB} \text { con LPIMG - DCB con LPIMBC }}{\text { DCB con LPIMG }}$ (en cian), en función de la latitud modip.

Para las estaciones con diferencias entre modelos significativas (se tomó como límite el valor 0.8 ns que es el máximo bias satelital), en todos los casos la versión LPIMBC logra reducir los DCBs; en promedio las diferencias representan reducciones del orden del $30 \%$ del valor del bias que se obtiene simulando observaciones GPS únicamente. Para estas estaciones, la incorporación de VTEC simulando la configuración de las misiones altimétricas asimilado a través de la técnica de acumulación de sistemas normales reduce los bias instrumentales; esto es interpretado como una ventaja respecto al modelo basado en la ingestión de STEC únicamente ya que en ambos casos se esperan DCBs nulos por tratarse de datos sintéticos. A continuación se analiza si esta diferencia se traduce en cambios apreciables en la representación de TEC. 


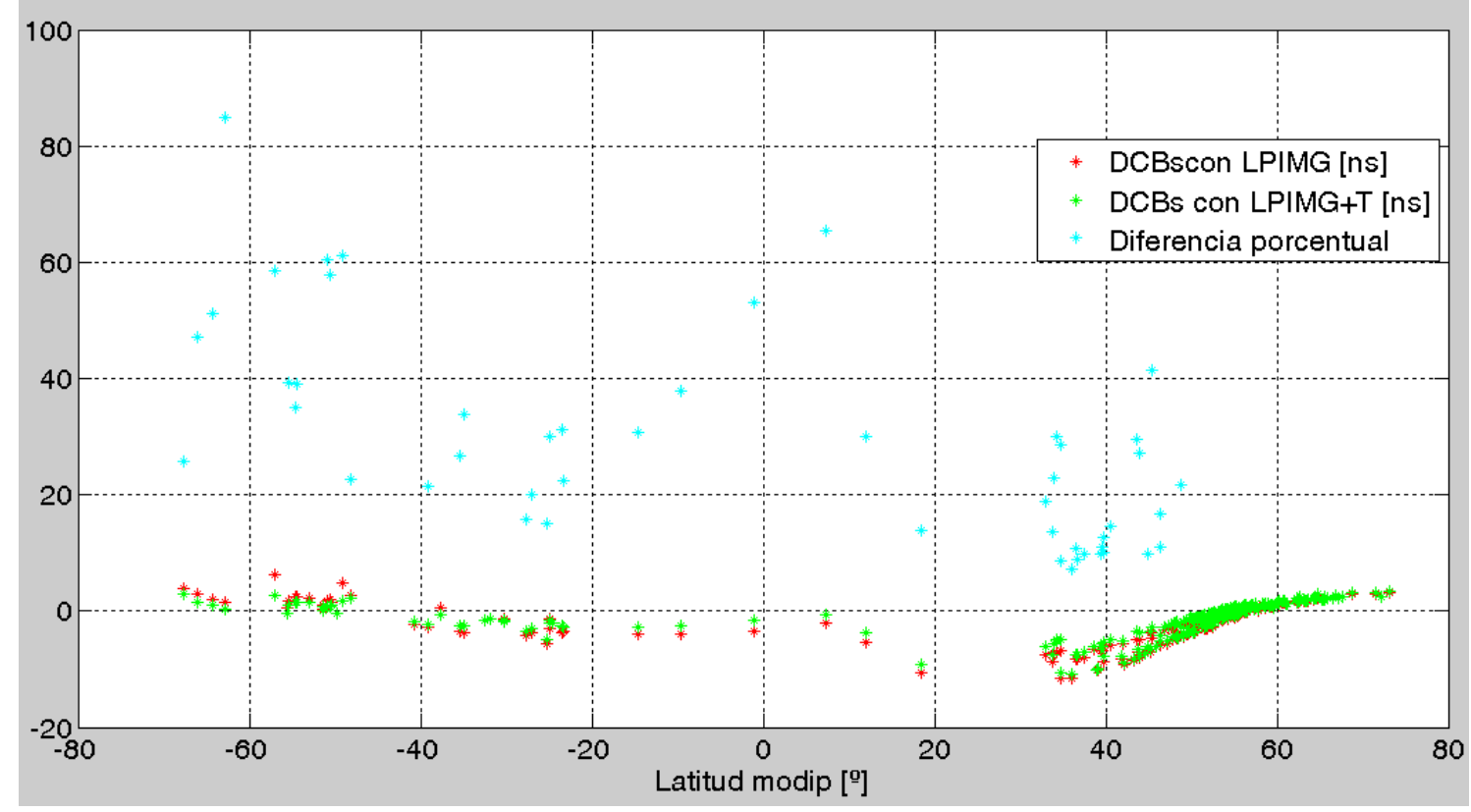

Figura 4.9. DCBs de receptores obtenidos a partir de datos artificiales calculados con LPIMG (en rojo) y LPIMBC (en verde) en función de la latitud modip y diferencia porcentual (para los casos en que las diferencias entre modelos superan los $0.8 \mathrm{~ns}$ )

Como se mencionó en el comienzo de la presente sección, se consideran como valores de VTEC de referencia los obtenidos integrando verticalmente la densidad electrónica provista por el modelo NeQuick sobre una grilla espaciada cada $2.5^{a}$ en latitud y longitud en intervalos de 2 horas de TU.
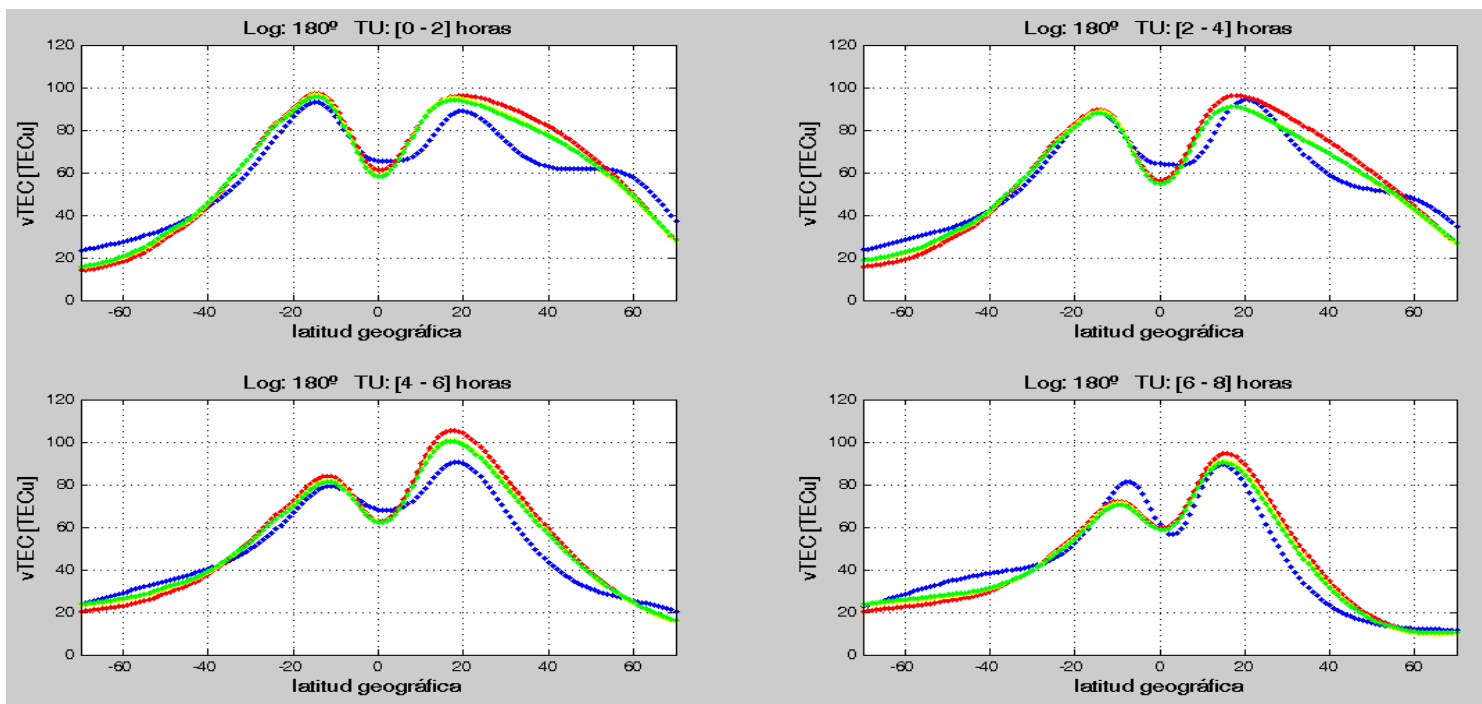

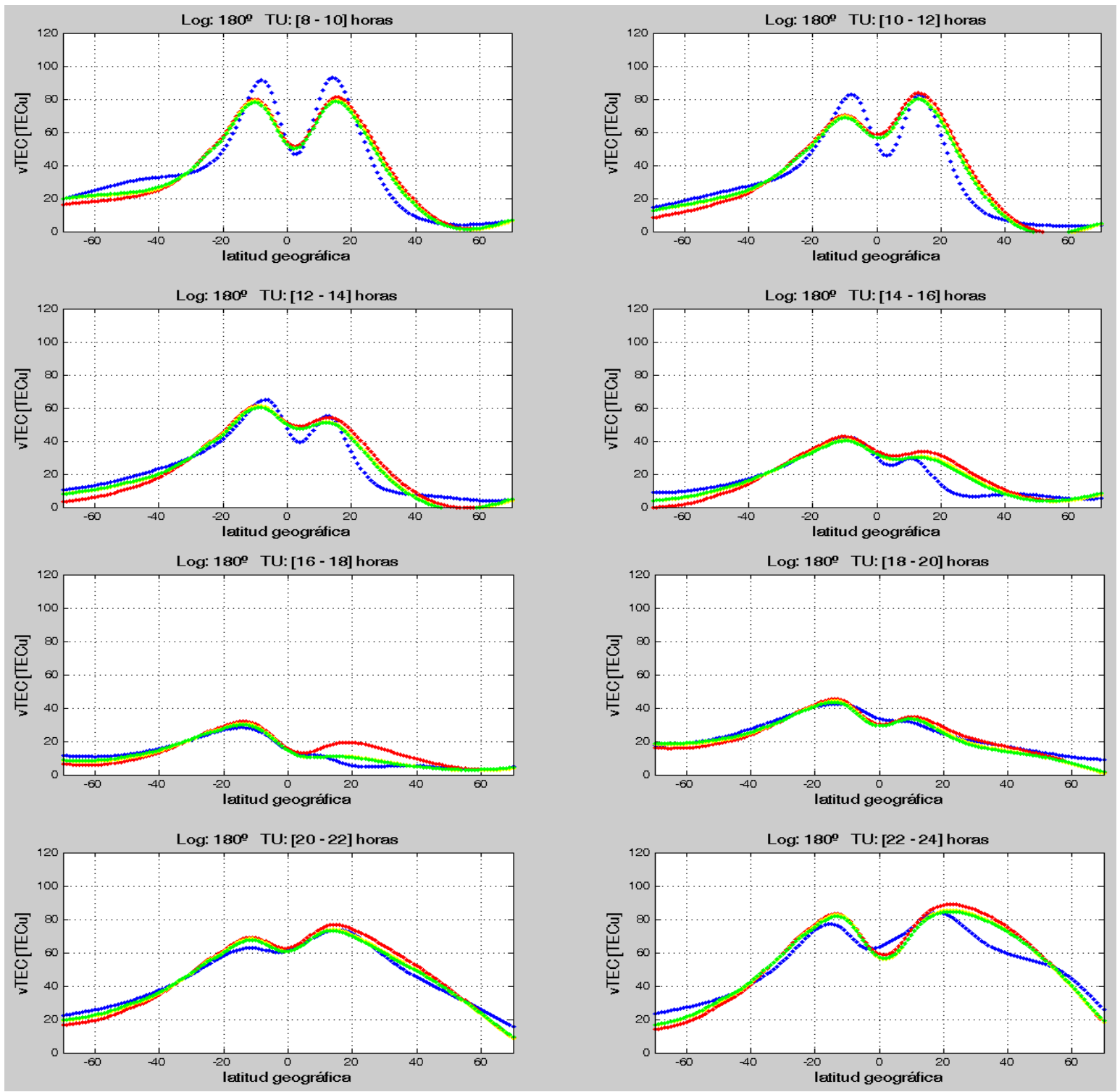

Figura 4.10. Contenido electrónico total vTEC modelado con NeQuick (en azul), modelado con LPIMG (en rojo) y modelado con LPIMBC (en verde), en función de la latitud geográfica, en intervalos de 2 horas. (Día 056 del año 2002).

En la Figura 4.10 el vTEC de referencia está representado en función de la latitud geográfica para un dado valor de longitud en los 12 intervalos horarios en color azul. En el mismo gráfico se han representado los valores de VTEC modelados con LPIM simulando datos GPS únicamente, en rojo, y los valores obtenidos mediante la técnica de acumulación de sistemas normales simulando datos GPS+TOPEX/Poseidón, en verde. Los gráficos corresponden a $\lambda=180^{\circ}$. A lo largo de este meridiano, con escasos datos asimilados, LPIMBC logra una mejor representación del contenido electrónico vertical, especialmente en el hemisferio sur. Los mayores apartamientos entre los valores modelados y verdaderos se 
observan en el hemisferio norte, en latitudes medias, pero aun en este caso con LPIMBC se obtiene una mejor respuesta. En esta región la cantidad de observaciones simuladas de STEC es muy grande en comparación con la de observaciones de VTEC (Figura 4.2); esta relación estaría determinando la escasa influencia de la asimilación en el modelado de la ionosfera en esta zona (se retoma este tema en la Experiencia 2).

Para evaluar de forma global la representación del contenido electrónico con los diferentes métodos, se calcula la dispersión alrededor del valor verdadero para cada modelo en cada intervalo de 2 horas. En la Figura 4.11 se muestran los resultados para uno de los días comprendido en el período analizado. La asimilación de datos que reproducen la configuración de los satélites altimétricos reduce el error en los 12 intervalos horarios; esta reducción representa una mejora del orden del $15 \%$ cuando se usa la técnica de asimilación día por día (descripta en el capítulo 3) y del orden del $20 \%$ cuando se utiliza la técnica de acumulación de sistemas normales.

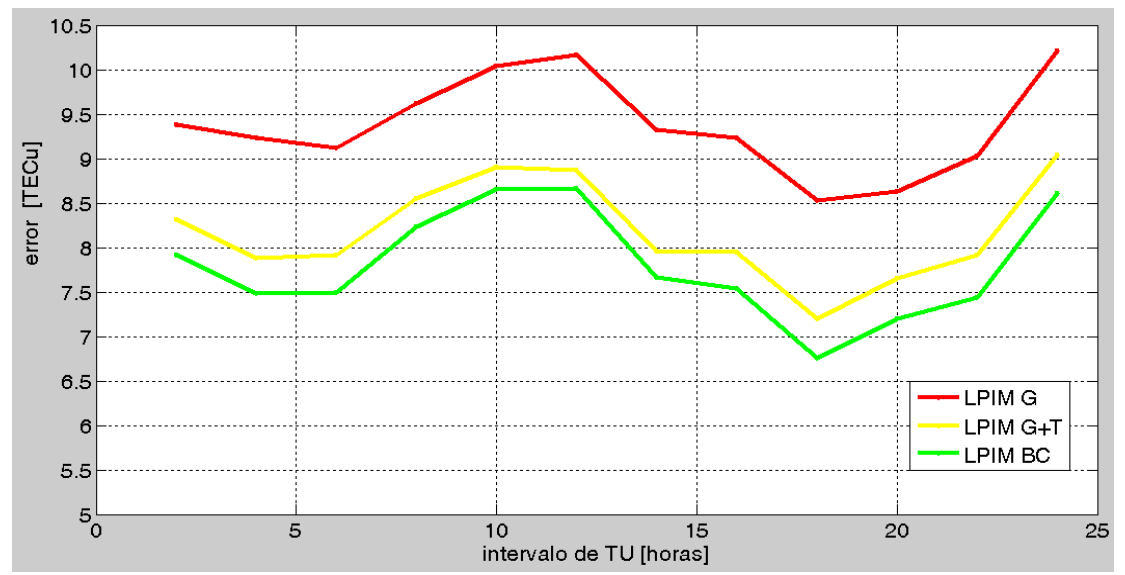

Figura 4.11. Errores típicos, aceptando como valor verdadero del contenido electrónico el vTEC modelado con NeQuick, de LPIMG (en rojo), con LPIMG+T (en amarillo) y LPIMBC (en verde), en intervalos de 2 horas. (Día 056 del año 2002).

\subsection{3.b. Experiencia 2.}

Comparando los valores observacionales del VTEC con los valores modelados en los diferentes intervalos horarios (Figura 4.10) se advierte que los mayores apartamientos se registran para las latitudes comprendidas entre los $20^{\circ}$ y los $50^{\circ}$ aproximadamente. Asimismo, los mayores DCBs, en valor absoluto, corresponden a estaciones ubicadas en esa región. En la Figura 4.2 del comienzo del presente 
capítulo es posible apreciar que en esta banda latitudinal, la cantidad de datos altimétricos representa una fracción pequeña del total de datos asimilables. Esta proporción se mantiene en los datos artificiales simulados con NeQuick, ya que reproducen la configuración geométrica de las observaciones reales. Con el propósito de dar importancia a la asimilación de TEC vertical en forma global, se planteó un experimento adicional que otorga distinta relevancia a las ecuaciones de observación según su origen o ubicación a través de la asignación de diferentes factores de peso. Con el objeto de relativizar la importancia de las observaciones GPS simuladas en regiones con gran cantidad de datos frente a las regiones con estaciones dispersas se aplicó a cada ecuación un factor de la forma

$$
p_{1}=\sqrt{\frac{n(\varphi)}{N}}
$$

donde $n(\varphi)$ es la cantidad de datos simulados en cada banda de $10^{\circ}$ de latitud geográfica y $N$ es la cantidad total de observaciones de sTEC simuladas en el período considerado. Para equiparar los datos de diferente origen se aplicó un segundo factor $p_{2}$ que tiene en cuenta la relación entre la cantidad de simulaciones de $V$ TEC que representan los datos altimétricos, $N_{T}$, y de simulaciones de STEC que representan los datos GPS, $N$ :

$$
p_{2}=\sqrt{\frac{N_{T}}{N}}
$$

En principio se resolvió el sistema de ecuaciones usando la técnica de acumulación y aplicando cada factor de forma independiente. En ambos casos se advirtió tanto una disminución en el valor absoluto de los DCBs instrumentales como en la dispersión del VTEC modelado. Finalmente se aplicó un factor de peso $p=p_{1} p_{2}$ a cada ecuación, obteniéndose una reducción apreciable en los DBCs. Estos resultados pueden observarse en la en la figura 4.12, donde se muestran los DCBS obtenidos de esta forma en color verde, en relación con los valores que se obtuvieron antes de asimilar observaciones altimétricas.

En la Tabla 4.2 se establece una comparación entre los DCBs de los receptores que se obtienen simulando datos con NeQuick para la misma configuración de satélites, por acumulación de sistemas normales, cuando el peso de cada fuente de información está dado por la distribución real de los datos (columna 1) y cuando la distribución se ve forzada por un factor de peso $p=p_{1} p_{2}$ (columna 2). 


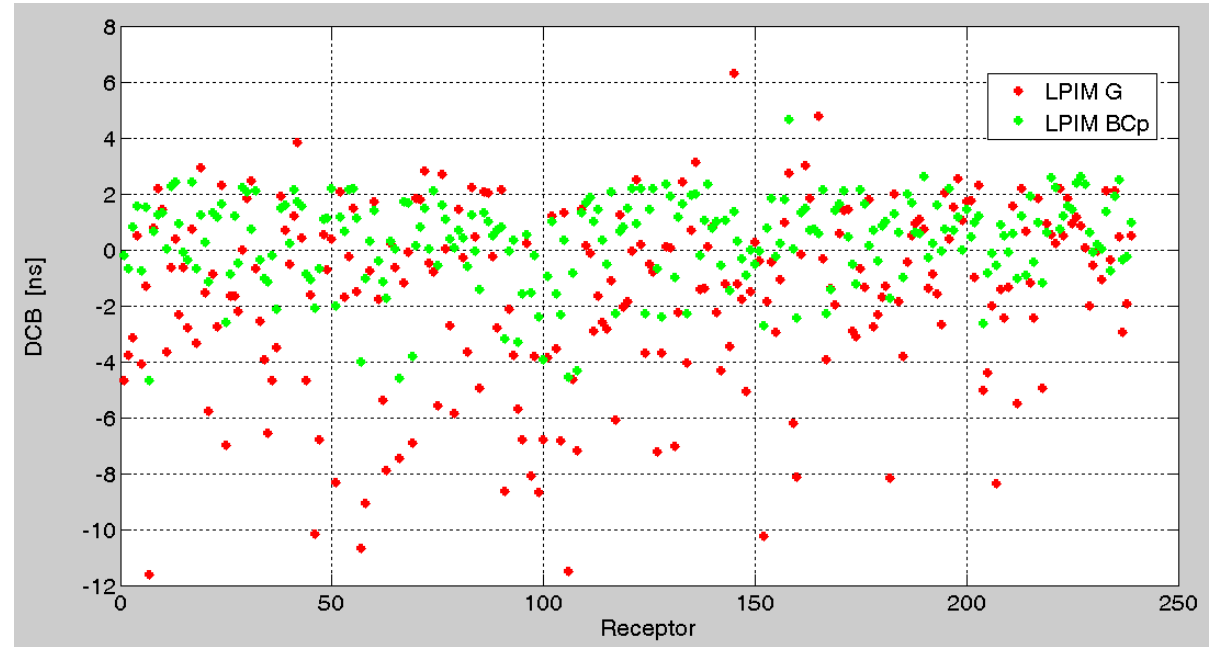

Figura 4.12. DCBs de receptores obtenidos a partir de datos artificiales para 10 días (días 050 a 059 del año 2002): simulando observaciones GPS y calculados promediando los valores diarios (en rojo), y simulando observaciones GPS+TOPEX/P y calculados con la técnica de acumulación de sistemas normales con $\mathbf{p}=\mathbf{p}_{1} \mathbf{p}_{2}$ (en verde).

\begin{tabular}{|l|r|r|}
\hline & DCBs con con LPIMBC1 [ns] & DCBs con LPIMBCp [ns] \\
\hline Valor mínimo & -10.78 & -4.70 \\
\hline Valor máximo & 3.35 & 4.65 \\
\hline Valor medio & -1.23 & 0.32 \\
\hline Desviación estándar & 2.92 & 1.55 \\
\hline Rango & 14.13 & 9.35 \\
\hline
\end{tabular}

Tabla 4.2. Parámetros estadísticos de las series de DCBs de receptores calculados $L_{P I M B C 1}$ Y $L_{P I M} M_{B C p}$ (con pesos $p=p_{1} p_{2}$ ).

El uso del factor de peso diferente de la unidad reduce los DCSs de los satélites con respecto a los valores que se obtienen con la versión LPIMBC con $p=1$; el mayor DCB (en valor absoluto) se reduce a la mitad de su valor, pero en la mayoría de los casos la reducción es más importante aún, del orden de $70 \%$ si se compara con los resultados que arroja LPIM en su versión clásica basada en GPS. En el anexo 6 se listan los valores de los DCBs obtenidos con las 3 diferentes versiones: LPIMG, LPIMBCI con $p=1$ y LPIMBCp con $p=p_{1} p_{2}$.

El empleo del factor de peso propuesto también impacta de forma positiva sobre los GIMs. En la Figura 4.13 se ha graficado la desviación alrededor del valor verdadero de VTEC para los 10 días simulados, utilizando LPIMG en rojo y LPIMBCp en verde. En promedio, para los 10 días, el error pasa de 8.27 TECu a 5.40 TECu, lo que representa una mejora del orden del $35 \%$. 


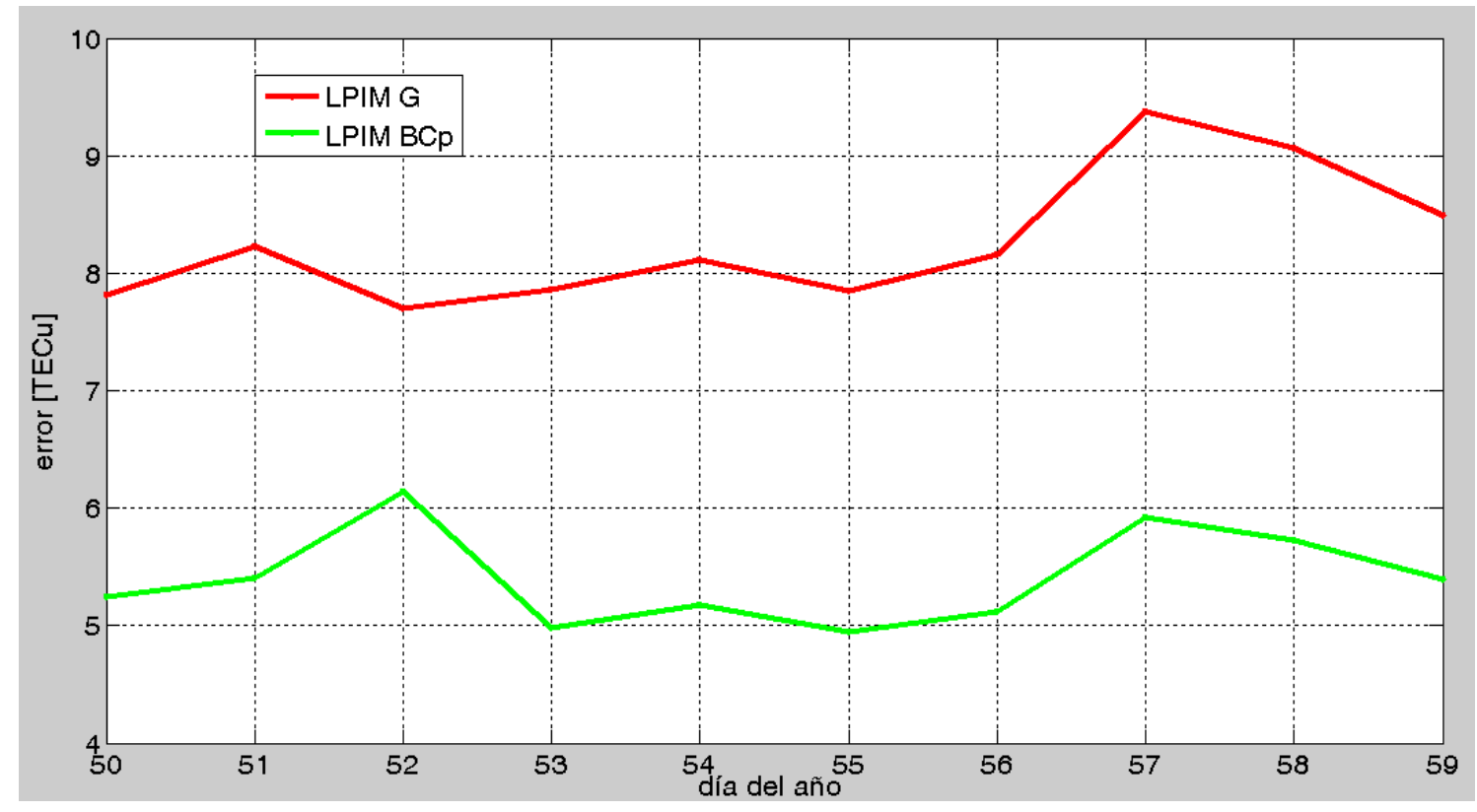

Figura 4.13. Errores típicos, aceptando como valor verdadero del contenido electrónico el VTEC modelado con NeQuick, de LPIMG (en rojo) y LPIMBC $p=p_{1} . p_{2}$ (en verde) (Días 050 al 059 del año 2002).

Para discutir el origen de las diferencias comentadas es necesario volver al sistema de ecuaciones de observación escrito en la sección 4.4.2

$$
\left\{\begin{array}{c}
\mathrm{l}_{\mathrm{G}}-\varepsilon_{\mathrm{G}}=\mathrm{M}(\mathrm{z}) \mathrm{vTEC}+\beta_{\mathrm{G}+\mathrm{T}}^{\mathrm{S}}+\beta_{\mathrm{G}+\mathrm{T}}^{\mathrm{R}} \\
\mathrm{l}_{\mathrm{T}}-\varepsilon_{\mathrm{T}}=\mathrm{vTEC}+\beta_{\mathrm{T}}^{\mathrm{S}}
\end{array}\right.
$$

En los intervalos de latitud en que la cantidad de datos GPS es mucho mayor que la cantidad de datos de origen altimétrico, la primera ecuación gobierna la solución; en ella, se considera que la función de mapeo $\mathrm{M}(\mathrm{z})$ tiene una dependencia conocida de la distancia cenital; sin embargo esto también constituye una aproximación que toma protagonismo en este caso. Cuando se asigna a cada ecuación un factor de peso como el propuesto, por un lado se simula una redistribución homogénea en latitud de las estaciones del sistema de posicionamiento GPS y por otro se equipara la influencia de los datos altimétricos asimilados a través de la segunda ecuación a los datos del sistema GPS. En síntesis, en esta situación controlada se resta importancia a la influencia de $\mathrm{M}(\mathrm{z})$ en el resultado, en nuestro caso para $20^{\circ} \leq \lambda \leq 50^{\circ}$, y se obtiene una reducción de los bias y una mejor aproximación del vTEC. 


\subsection{Conclusiones del capítulo}

La búsqueda de un mejor aprovechamiento de la amplia cobertura geográfica de las misiones altimétricas como fuente de información ionosférica demanda el desarrollo de novedosas estrategias de asimilación de datos en el modelo LPIM. Concretamente, el radar de las misiones TOPEX/Poseidón y sus sucesoras Jason I, II y III, ilumina cada punto sobre la superficie de los océanos y registra el VTEC con una diferencia de 10 días. En este capítulo hemos presentado un método de asimilación de observaciones altimétricas en LPIM que permite, mediante la acumulación de los sistemas de ecuaciones normales diarios, la incorporación de grandes bloques de datos.

El método fue probado satisfactoriamente para bloques de hasta 100 días, que es el tiempo necesario para re-muestrear cada punto a la misma hora local. Esto supone la resolución de un sistema de aproximadamente $6.10^{7}$ ecuaciones con $4.10^{6}$ incógnitas para obtener GIMs cada dos horas, un conjunto de DCBs para los satélites y receptores GPS y un bias de calibración entre datos de diferente origen únicos para el período considerado.

Se encontró que, respecto al modelo basado en datos GPS, la asimilación de datos altimétricos modifica tanto la representación global de VTEC como la calibración de los instrumentos, mientras que un bias constante $\boldsymbol{\beta}^{\mathbf{T}}=2.836 \pm$ $0.005 \mathrm{TECu}$ debe ser restado a las observaciones de VTEC dadas por la altimetría satelital para lograr consistencia con las observaciones de sTEC provistas por el sistema de posicionamiento.

Para estimar el alcance de la asimilación de datos altimétricos en LPIM se recurrió a un método indirecto, como fue el uso de datos sintéticos generados con el modelo NeQuick para la configuración real de los satélites GPS y TOPEX/Poseidón.

Se plantearon dos experimentos. El primero tuvo por objeto cuantificar la influencia de la asimilación de observaciones de vTEC mediante el método de acumulación de sistemas normales. Los resultados fueron contrastados con aquellos que se obtienen con la versión clásica de LPIM basada en datos GPS. Se encontró que la solución por acumulación de bloques de 10 días mejora la calibración de los receptores GPS. El impacto fue cuantificado en términos de la reduccción en el valor absoluto de los DCBs (en principio deberían ser nulos por tratarse de datos sintéticos y por lo tanto carrentes de errores instrumentales). Se encontró que en las estaciones donde las diferencias entre los DCBs fueron significativas, la nueva versión de LPIM logró en promedio reducciones del orden del $30 \%$ en el valor del bias con respecto a la versión clásica. Además, la asimilación de datos altimétricos reduce el error en la representación del VTEC en 
un orden que puede superar el $20 \%$ dependiendo del día y del intervalo horario. El segundo experimento estuvo orientado a maximizar la influencia de los datos altimétricos en la representación del VTEC. Esto se logró asignando factores de peso a cada ecuación de observación como forma de balancear el número de observaciones de acuerdo con su origen y localización. En este caso, se obtuvieron mejoras del orden $70 \%$ en la exactitud de los DCBs y del $35 \%$ en la representación del VTEC. Estos resultados permitieron confirmar la hipótesis planteada sobre el rol decisivo que tiene la función de mapeo en la limitación de una mejor representación del contenido electrónico globlal y a la vez validar la ventaja de asimilar mediciones altimétricas, que no requieren la intervención de tal aproximación, en un modelo ionosférico empírico como LPIM. 


\section{Capítulo 5: Modelo ionosférico y plasmasférico}

En el modelo ionosférico de La Plata subyace una representación simplificada de la componente ionizada de la atmósfera, como es suponer que los electrones se encuentran confinados en una cascara esférica de espesor infinitesimal que rodea a la Tierra. En el capítulo 1 se mostró que la densidad electrónica presenta un pico a una altura aproximada de $400 \mathrm{~km}$ sobre la superficie terrestre con el ion oxígeno atómico $0^{+}$como elemento dominante. A una altura variable que no supera los $2000 \mathrm{~km}$ el constituyente primario de la atmósfera pasa a ser el ion $\mathrm{H}^{+}$ definiendo el límite entre la ionosfera y la plasmasfera. Si bien la densidad típica del plasma en la plasmasfera es baja comparada con la densidad en la ionosfera, la gran extensión de esta región puede representar un aporte significativo al contenido electrónico total para las señales GPS que la atraviesan, especialmente para bajas latitudes magnéticas y en el hemisferio nocturno (Mazzella, 2009).

Para modelar la porción de TEC comprendida entre los 1.500 km y 20.200 km que separan las órbitas de los satélites altimétricos de los satélites GPS existen básicamente dos técnicas (Thompson et al., 2009): ignorar su efecto y asignar el TEC medido a la ionosfera en el modelo espacial de asimilación, como se hizo en el capítulo anterior, lo que genera una sobreestimación sistemática del TEC ionosférico, o corregir el TEC medido usando algún modelo de ionosfera superior y plasmasfera para sustraer su contribución.

En este capítulo se propone, a partir de un modelo plasmasférico simple, utilizar la diferencia entre las alturas de las orbitas de los satélites altimétricos y GPS y la técnica de acumulación de sistemas normales desarrollada en el capítulo precedente para derivar el contenido electrónico plasmasférico. 


\subsection{La plasmasfera}

La plasmasfera es esencialmente una extensión de la ionosfera a grandes altitudes. Es una región compuesta fundamentalmente por iones de hidrógeno (aproximadamente en un 80\%) y en menor medida de $\mathrm{He}^{+}$y $\mathrm{O}^{+}$, atrapados dentro por el campo magnético terrestre. En esta región el campo es prácticamente dipolar y las líneas son cerradas; esta configuración favorece el ascenso de plasma desde la ionosfera a lo largo de las líneas de campo geomagnético y el llenado de los tubos de flujo con plasma frío durante las horas del día. Este mecanismo junto con el efecto de rotación de la Tierra confiere a la plasmasfera el aspecto de una envoltura toroidal que rodea a la Tierra por el ecuador magnético. La plasmasfera actúa como un reservorio que devuelve el plasma a la ionosfera durante la noche. En la región externa la plasmasfera presenta un marcado gradiente de la densidad llamado plasmapausa.

Durante los períodos prolongados de baja actividad geomagnética, el efecto de llenado desde la ionosfera es importante y la plasmasfera se agranda (puede superar la distancia de las órbitas geosincrónicas). A grandes altitudes, la plasmasfera experimenta fuerzas debidas a los campos eléctricos inducidas por el viento solar; por este motivo, durante los períodos de alta actividad geomagnética la región externa de la plasmasfera es erosionada y la plasmapausa se acerca a la superficie de la Tierra (Singh et al., 2011).

En la plasmasfera el plasma se halla confinado por el campo gravitatorio de la Tierra; en la región ecuatorial la densidad electrónica decrece exponencialmente con la altura. Puede variar entre $5.10^{4}$ y $10^{3}$ electrones $\mathrm{cm}^{-3}$ para valores del parámetro de capa L entre 1.4 y 3.5 en una época de actividad solar moderada. En la plasmapausa la densidad cae abruptamente hasta 2 órdenes de magnitud a distancias radiales que varían entre 3 y 6 veces el radio de la Tierra dependiendo de la actividad solar (Singh et al., 2011). La densidad del plasma no es uniforme dentro de la plasmasfera. Por el contrario, hay evidencias observacionales de la existencia de diversas estructuras de formas y tamaños variados, algunas de origen aún desconocido; también se observan estructuras que superan el límite de la plasmapausa (Carpenter, 2004). Además, la plasmasfera alberga en su interior dos regiones de concentración de partículas energéticas, los cinturones de radiación de Van Allen.

En síntesis, en la plasmasfera tienen lugar una diversidad de fenómenos y su modelado juega un rol fundamental en la predicción del tiempo espacial. 


\subsection{Modelo de Gallagher}

El modelo plasmasférico presentado por Gallagher et al. (1988) fue diseñado a partir de las medidas plasmasféricas realizadas mediante el Espectrómetro de Masa lónica Retardante, RIMS (Chappell et al.,1981) situado a bordo del satélite Dynamics Explorer I (DE-1). Consiste en una expresión analítica que describe el comportamiento de la densidad del ion $\mathrm{H}^{+}$en un punto de la plasmasfera como función del tiempo magnético local (MLT), la altura y las coordenadas magnéticas.

La formulación analítica del modelo de Gallagher es muy simple: el logaritmo de la densidad de iones en la plasmasfera, $\mathrm{n}_{\mathrm{p}}$, está dado por el producto de tres funciones del parámetro de capa L (definido en la sección 1.3.1):

$$
\log \left(n_{p}\right)=a_{1} \cdot F(L) \cdot G(L) \cdot H(L)
$$

donde

$$
\begin{aligned}
& \mathrm{F}(\mathrm{L})=\mathrm{a}_{2}-\mathrm{e}^{\mathrm{a}_{3}\left(1-\mathrm{a}_{4} \mathrm{e}^{-\mathrm{h} / \mathrm{a}_{5}}\right)} \\
& \mathrm{G}(\mathrm{L})=\mathrm{a}_{6} \cdot \mathrm{L}+\mathrm{a}_{7} \\
& \mathrm{H}(\mathrm{L})=\left(1+\left(\frac{\mathrm{L}}{\mathrm{a}_{8}}\right)^{2\left(\mathrm{a}_{9}-1\right)}\right)^{-\frac{\mathrm{a}_{9}}{\mathrm{a}_{9}-1}} \\
& \text { con } \mathrm{a}_{1}=1.4, \mathrm{a}_{2}=1.53, \mathrm{a}_{3}=-0.036, \mathrm{a}_{4}=30.76, \mathrm{a}_{5}=159.9, \mathrm{a}_{7}=6.27, \\
& \mathrm{a}_{6}=-0.87+0.12 \mathrm{e}^{-\frac{\mathrm{x}^{2}}{9}}, \operatorname{con} \mathrm{x}=\left\{\begin{array}{cc}
\mathrm{MLT} & \text { para } 0 \leq \mathrm{MLT} \leq 12 \\
\mathrm{MLT}-24 & \text { para } 12<M L T<24
\end{array}\right. \\
& \mathrm{a}_{8}=0.7 \cos \left(\frac{2 \pi}{24}(\mathrm{MLT}-21)\right)+4.4 \\
& \mathrm{a}_{9}=15.3 \cos \left(\frac{2 \pi}{24} \mathrm{MLT}\right)+19.7
\end{aligned}
$$

Las constantes $\mathrm{a}_{\mathrm{i}}$ son parámetros libres utilizados para ajustar la ecuación 5.1 al logaritmo de la densidad iónica.

El parámetro de capa L está relacionado con la altura h sobre la superficie de la Tierra a través de la ecuación 


$$
\mathrm{L}=\frac{\left(1+\frac{\mathrm{h}}{\mathrm{R}}\right)}{\cos ^{2} \lambda}
$$

donde $\mathrm{R}$ es el radio terrestre, $\mathrm{R}=6371 \mathrm{~km}$ y $\lambda$ es la latitud geomagnética.

El tiempo magnético local MLT es, sobre la Tierra, análogo al tiempo local geográfico.

a)
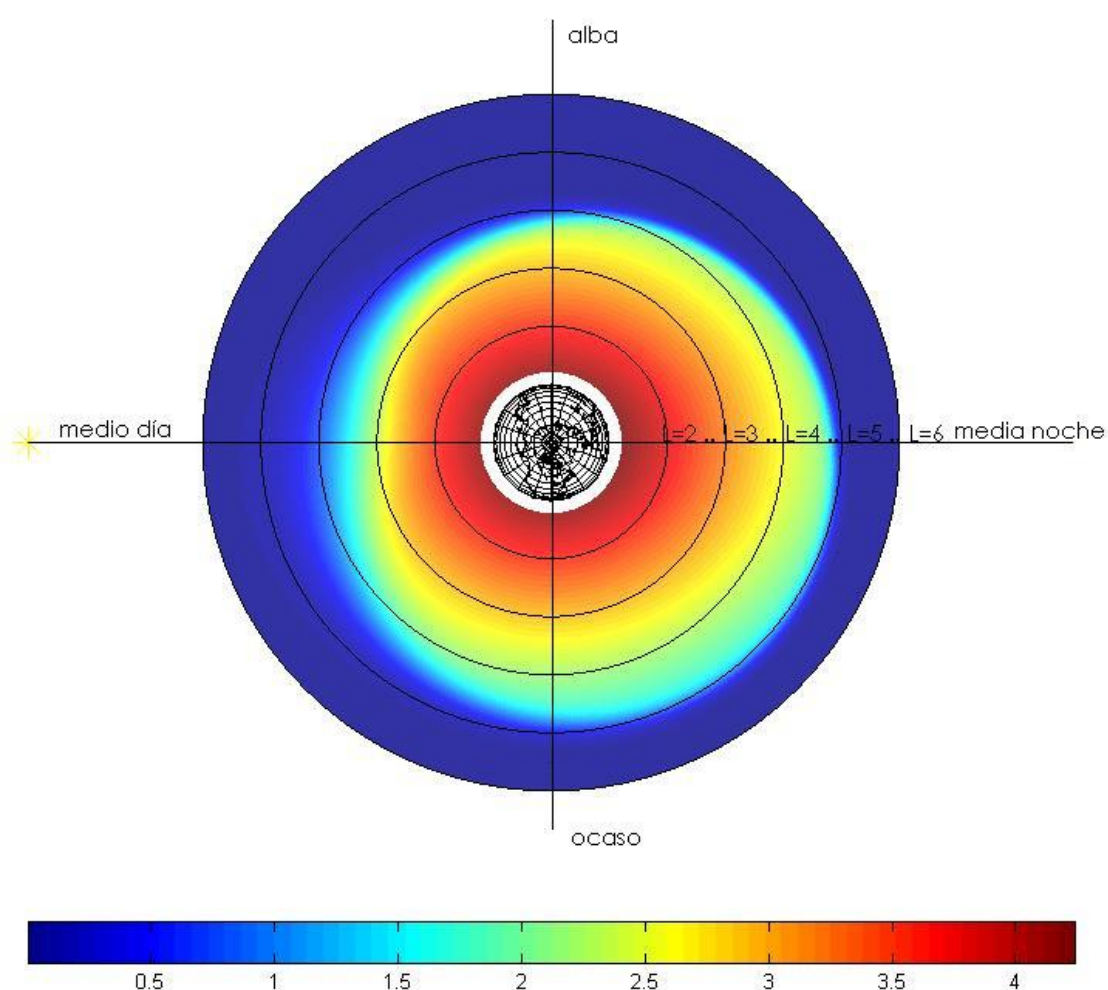

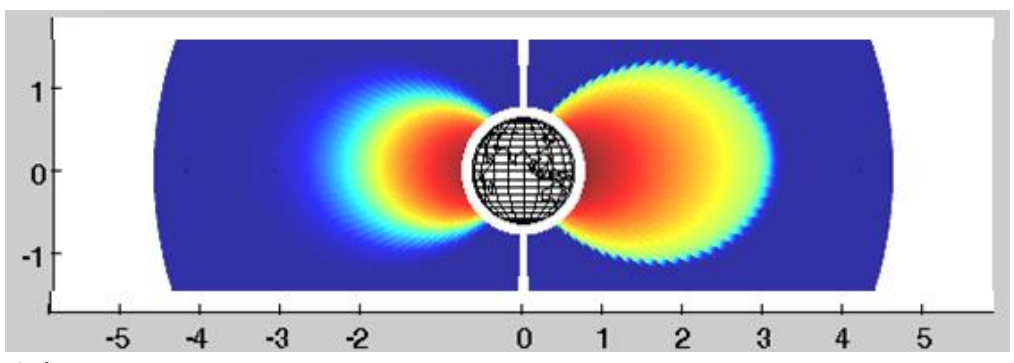

b)
Figura 5.1. Modelo plasmasférico de Gallagher. Densidad electrónica a) en el plano ecuatorial. b) en un plano meridiano (Longitud $=0^{\circ}, \mathrm{TU}=12$ hs). La barra de colores representa la densidad electrónica $\left(\mathrm{cm}^{-3}\right)$ en una escala logarítmica; distancias en $10^{4} \mathrm{Km}$. 
El modelo empírico de Gallagher reproduce las principales características observadas a gran escala de la plasmasfera y la plasmapausa para niveles bajos a moderados de actividad magnética. El modelo es aplicable a un amplio rango de altitudes, desde los $1300 \mathrm{~km}$ hasta más allá de la plasmapausa, y latitudes geomagnéticas comprendidas entre $\pm 40^{\circ}$.

Los principales rasgos del modelo de Gallagher se reproducen en la Figura 5.1, en la cual se ha representado la densidad electrónica expresada en electrones $/ \mathrm{cm}^{3}$ en escala logarítmica. La figura 5.1.a muestra la distribución de los electrones sobre el plano ecuatorial; en ella se pone en evidencia la simetría acimutal de la plasmasfera dentro de $\mathrm{L}=3$ y el característico aspecto de gota extendida hacia distancias radiales mayores en la dirección del anochecer derivado del modelo simple de corrotación combinada con campos eléctricos de convección. La estructura de toro alrededor del eje magnético terrestre de la plasmasfera se aprecia en la Figura 5.1.b, donde se muestra la intersección con un plano meridiano; el Sol se encuentra en el mismo plano, en el extremo izquierdo; en dirección opuesta al Sol, la plasmasfera se extiende hasta distancias mayores que $30.000 \mathrm{~km}$.

Otra característica de la plasmasfera es la caída abrupta de la densidad electrónica, que da lugar a la plasmapausa. El modelo de Gallagher reproduce este límite como función del MLT, lo que se muestra en la Figura 5.2. En la misma es posible también apreciar el comportamiento lineal del logaritmo de la densidad iónica con la altura en la plasmasfera, consecuencia de la dependencia del factor $\mathrm{G}(\mathrm{L})$ que reproduce la densidad electrónica a través de la ecuación 5.1.
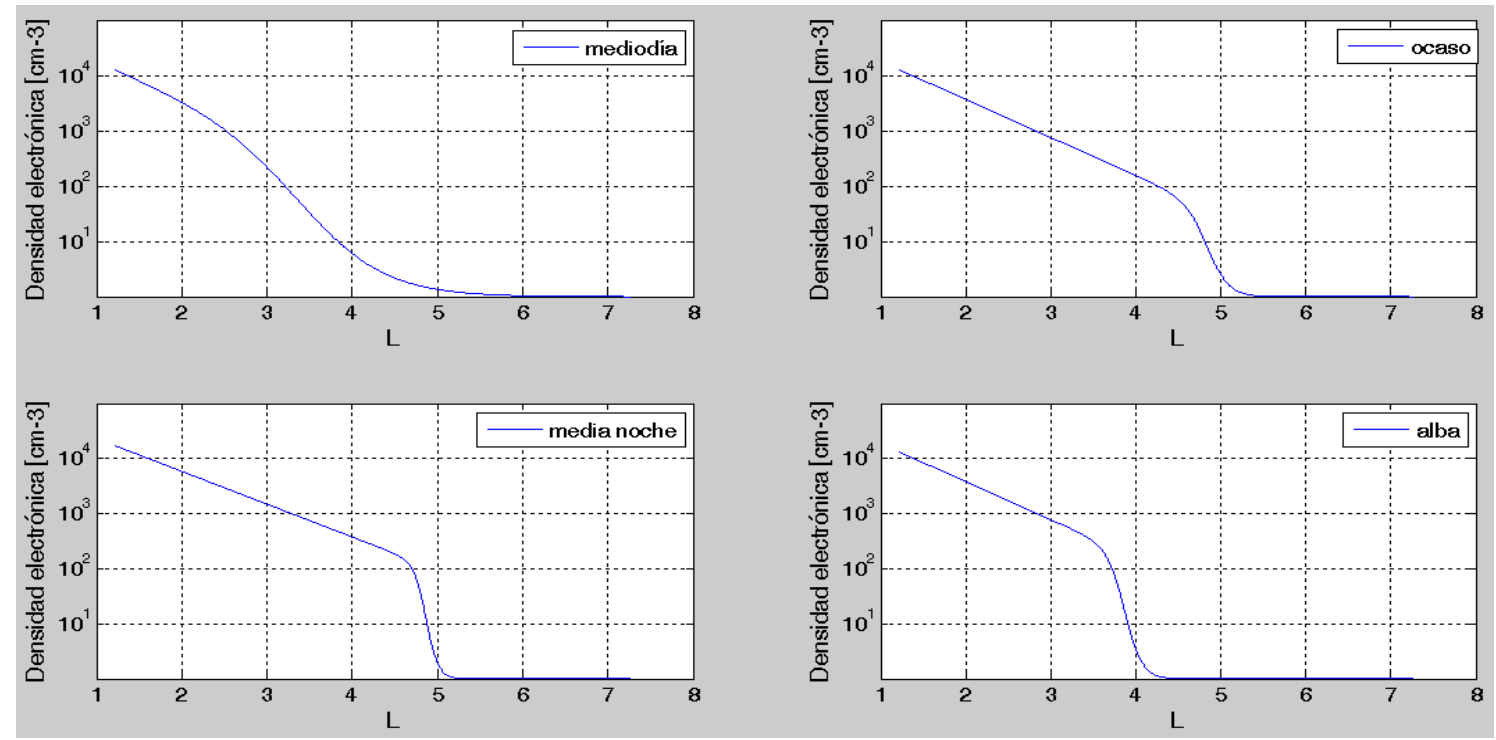

Figura 5.2. Modelo plasmasférico de Gallagher. Ubicación de la plasmapausa. 


\subsection{Modelo ionsoférico y plasmasférico de La Plata LPIPM}

En los capítulos 3 y 4 se ha supuesto una estructura simple para simular la componente ionizada de la atmósfera de la Tierra, que consiste en una cáscara esférica a una altura fija de $450 \mathrm{~km}$ sobre la superficie terrestre, y sobre ella se ha representado el contenido electrónico total mediante un desarrollo en armónicos esféricos, utilizando observaciones de los satélites GPS y TOPEX/Poseidón. Sin embargo, de acuerdo con la descripción general hecha en la sección precedente, la representación del material ionizado en la plasmasfera mediante una cáscara delgada no resultaría totalmente adecuada. En este capítulo, para representar, y luego determinar, el contenido electrónico plasmasférico PTEC (Plasmaspheric Total Electron Content) sobre cada estación de monitoreo se tendrá en cuenta explícitamente el aporte debido al material que se encuentra entre los 1.300 y $20.200 \mathrm{~km}$ incluyendo un término adicional $\mathrm{a}_{\mathrm{p}}$. sPTEC en la ecuación de observación de GPS.

sPTEC representa el contenido electrónico plasmasférico oblicuo obtenido mediante la integración de la densidad electrónica descripta por el modelo de Gallagher (ecuación 5.1) a lo largo del camino de la señal GPS entre $s_{1}$ y $s_{2}$ correspondientes a las alturas $\mathrm{h}_{1}=1.300 \mathrm{~km} \mathrm{y}_{2}=20.200 \mathrm{~km}$ respectivamente:

$$
s \text { PTEC }=\int_{s_{1}}^{s_{2}} n_{p} d s
$$

$a_{p}$ es el factor de escala y será tratado como una incógnita adicional.

Para abordar la resolución del problema, el sistema de ecuaciones de observación (ecuación 4.1) es re-escrito de la forma

$$
\left\{\begin{array}{c}
\mathrm{l}_{\mathrm{G}}-\varepsilon_{\mathrm{G}}=\mathrm{M}(\mathrm{z}) \cdot \mathrm{vTEC}+\mathrm{a}_{\mathrm{p}} \cdot \mathrm{sPTEC}+\beta_{\mathrm{I}+\mathrm{P}}^{\mathrm{S}}+\beta_{\mathrm{I}+\mathrm{P}}^{\mathrm{R}} \\
\mathrm{l}_{\mathrm{T}}-\varepsilon_{\mathrm{T}}=\mathrm{vTEC}+\beta_{\mathrm{I}+\mathrm{P}}^{\mathrm{T}}
\end{array}\right.
$$

donde se ha separado el medio ionizado en dos componentes: M(z).vTEC representa el contenido electrónico ionosférico y $\mathrm{a}_{\mathrm{p}}$. sPTEC representa la contribución plasmasférica.

Escrito en forma matricial, el sistema resulta: 


$$
\left(\begin{array}{l}
\mathbf{l}_{\mathrm{G}} \\
\mathbf{l}_{\mathrm{T}}
\end{array}\right)-\left(\begin{array}{c}
\boldsymbol{\varepsilon}_{\mathrm{G}} \\
\boldsymbol{\varepsilon}_{\mathrm{T}}
\end{array}\right)=\left(\begin{array}{ccccc}
\mathbf{A}_{\mathrm{GI}} & \mathbf{A}_{\mathrm{GP}} & \mathbf{B}^{\mathrm{R}} & \mathbf{B}^{\mathrm{S}} & \mathbf{0} \\
\mathbf{A}_{\mathrm{TI}} & \mathbf{0} & \mathbf{0} & \mathbf{0} & \mathbf{1}
\end{array}\right) \cdot\left(\begin{array}{c}
\mathbf{x}_{\mathrm{G}+\mathrm{T}}^{\mathrm{I}} \\
\mathbf{x}_{\mathrm{G}+\mathrm{T}}^{\mathrm{P}} \\
\mathbf{y}_{\mathrm{G}+\mathrm{T}}^{\mathrm{R}} \\
\mathbf{y}_{\mathrm{G}+\mathrm{T}}^{\mathrm{SG}} \\
\mathbf{y}_{\mathrm{G}+\mathrm{T}}^{\mathrm{ST}}
\end{array}\right)
$$

donde se han agregado los subíndices $\mathrm{G}$ y $\mathrm{T}$ para diferenciar a las observaciones GPS de las TOPEX o Jason, e I y P para diferenciar a las contribuciones ionosférica y plasmasférica; $\mathbf{x}_{\mathrm{G}+\mathrm{T}}^{\mathrm{I}}$ y $\mathbf{x}_{\mathrm{G}+\mathrm{T}}^{\mathrm{P}}$ son los vectores de los coeficientes armónicos esféricos más el factor de escala de la plasmasfera $a_{p}$, mientras que $\mathbf{y}_{\mathrm{G}+\mathrm{T}}^{\mathrm{R}}, \mathbf{y}_{\mathrm{G}+\mathrm{T}}^{\mathrm{S}} \mathrm{e}$ $\mathbf{y}_{\mathrm{G}+\mathrm{T}}^{\mathrm{ST}}$ son los nuevos vectores de parámetros instrumentales de los receptores GPS, de los satélites GPS y del satélite altimétrico respectivamente. Los errores son calculados de acuerdo con el tratamiento descripto en la sección 4.2.

\subsection{Resultados}

El primer paso fue adaptar el código LPIM de acuerdo con el planteo propuesto en esta sección. Se utilizó la estrategia de asimilación descripto en el capítulo 4, esto es por acumulación de los sistemas de ecuaciones normales diarios, y se resolvió el problema para el primer trimestre del año 2002. Se supuso que los retardos instrumentales permanecen constantes durante los 100 días. Además, se aceptó que la variación horaria y geográfica de la plasmasfera está bien representada por la expresión analítica de Gallagher y se mantuvo como incógnita el factor de escala $a_{p}$ para cada día con el objeto de cuantificar el contenido electrónico plasmasférico. Como resultado se obtuvo una nueva calibración instrumental para los receptores y satélites GPS y el satélite TOPEX/Poseidón, y mapas ionosféricos y plasmasféricos globales con una resolución de dos horas. El nuevo código ha sido llamado LPIPM (Modelo Ionosférico y Plasmasférico de La Plata) para distinguirlo del modelo LPIM tradicional que atribuye a la ionósfera el TEC hasta la altura de $20.200 \mathrm{~km}$.

\subsubsection{DCBs de satélites y receptores GPS}

En esta sección se analiza la influencia de la separación del contenido electrónico en dos componentes sobre la calibración de los instrumentos. Para 
esto se comparan los retardos instrumentales inter-frecuencia supuestos constantes durante 100 días que se obtienen separando la plasmasfera, con aquellos que se obtuvieron en el Capítulo 4, donde se atribuyó el contenido electrónico bajo los satélites a la ionosfera exclusivamente.

En primer término se encuentra que para los satélites de la constelación GPS, los DCBs resultan del mismo orden tanto si se distinguen dos regiones $\left(\boldsymbol{\beta}_{\mathrm{I}+\mathrm{P}}^{\mathrm{S}}\right)$ como si se considera un único medio $\left(\boldsymbol{\beta}_{1}^{S}\right)$. En la Figura 5.3 se muestran las diferencias entre los valores calculados con uno y otro modelo. Los apartamientos $\Delta \boldsymbol{\beta}^{\mathrm{S}}=\boldsymbol{\beta}_{\mathrm{I}}^{\mathrm{S}}-\boldsymbol{\beta}_{\mathrm{I}+\mathrm{P}}^{\mathrm{S}}$, en valor absoluto, resultan menores que 0.4 ns.

Figura 5.3. Diferencias en los DCBs de los satélites GPS supuestos constantes considerando la plasmasfera y sin ella, $\Delta \beta^{S}=\beta_{\mathrm{I}}^{\mathrm{S}}-\beta_{\mathrm{I}+\mathrm{P}}^{S}$ expresados en ns.

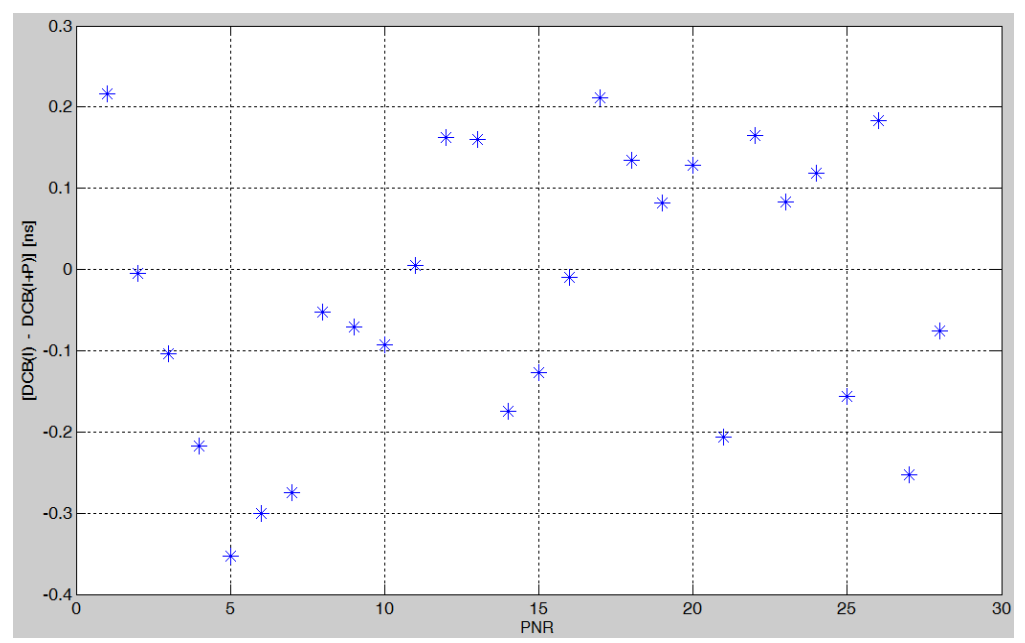

Para los receptores GPS, las diferencias $\Delta \boldsymbol{\beta}^{\mathrm{R}}=\boldsymbol{\beta}_{1}^{\mathrm{R}}-\boldsymbol{\beta}_{I+\mathrm{P}}^{\mathrm{R}}$ son inferiores a los 3 ns en el $99 \%$ de los casos. En la mayoría de los casos las diferencias $\Delta \boldsymbol{\beta}^{\mathrm{R}}$ resultan positivas, es decir que el modelo que separa el contenido electrónico plasmasférico del ionosférico estima retardos instrumentales para los receptores GPS menores que cuando se supone que los electrones de la atmósfera superior se hallan confinados en una capa delgada. Además, las diferencias son función de la latitud, como se muestra en la Figura 5.4, con valores mínimos en las estaciones de baja latitud.

Para la totalidad de receptores utilizados en el procesamiento, los bias obtenidos con la versión que separa la plamasfera difieren de la versión tradicional en valores que se encuentran muy por debajo de los $12 \mathrm{~ns}$, valor que, según vimos en el capítulo anterior (sección 4.4), podríamos establecer como límite para la exactitud de los DCB de los receptores calculados con LPIM. 
Figura 5.4. Diferencias en los DCBs de los receptores GPS supuestos constantes en 100 días, considerando la plasmasfera y sin ella, $\Delta \beta^{R}=\beta_{\mathrm{I}}^{\mathrm{R}}-\beta_{\mathrm{I}+\mathrm{P}}^{\mathrm{R}}$, expresadas en ns. a) En función de la latitud modip de la estación. b) Sobre el mapa.

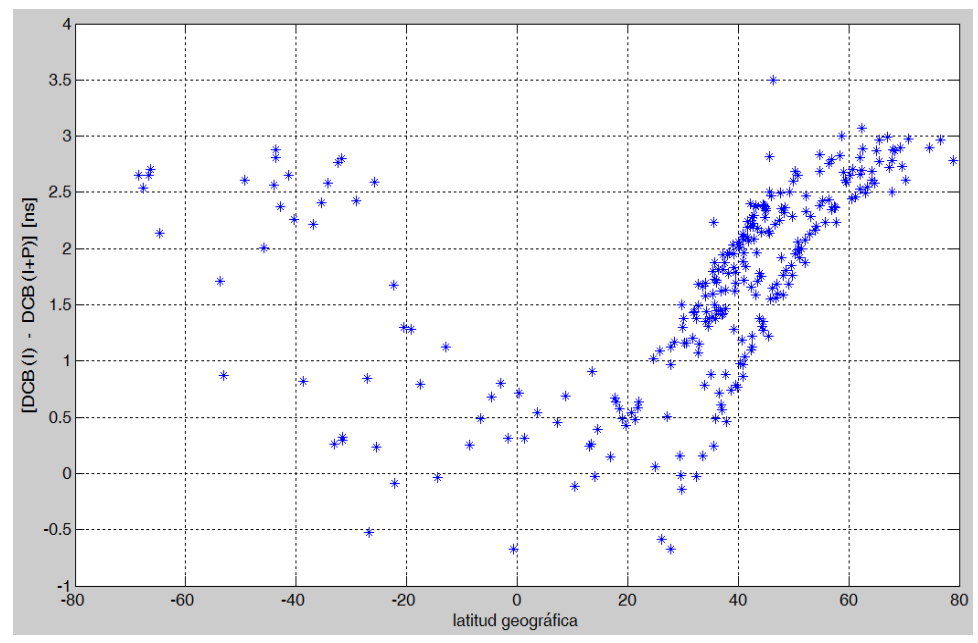

a)

b)

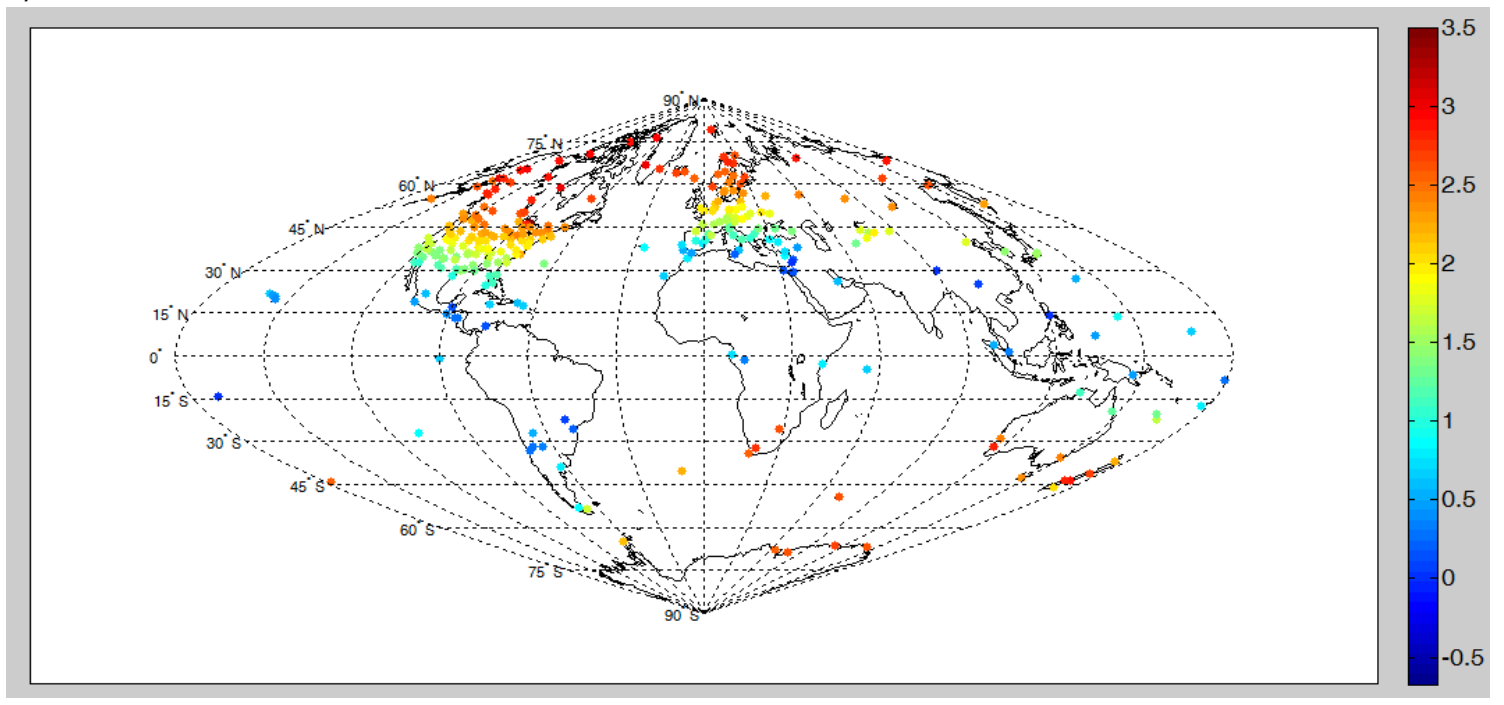

\subsubsection{Bias TOPEX/Poseidón}

El modelo ionosférico y plasmasférico estima un error de calibración entre las mediciones realizadas con GPS y con TOPEX/Poseidón $\boldsymbol{\beta}^{\mathrm{T}}=3.450 \pm 0.005 \mathrm{TECu}$.

El bias resulta levemente superior al valor calculado en el capítulo anterior, con la misma técnica de acumulación de ecuaciones normales y sin plasmasfera, que es $\boldsymbol{\beta}_{\mathrm{I}+\mathrm{P}}^{\mathrm{T}}=2.836 \pm 0.005 \mathrm{TECu}$. 


\subsubsection{Mapas ionosféricos globales}

La asimilación de una larga serie datos GPS y altimétricos en forma simultánea en LPIPM permite confeccionar mapas globales del contenido electrónico ionosférico exclusivamente, estableciendo como límite superior de esta región la altura de $1300 \mathrm{~km}$ de la órbita de los satélites altimétricos. Estos mapas (Figura 5.5) continúan mostrando la compleja distribución espacial y temporal de la ionósfera, que acompaña al ecuador magnético.

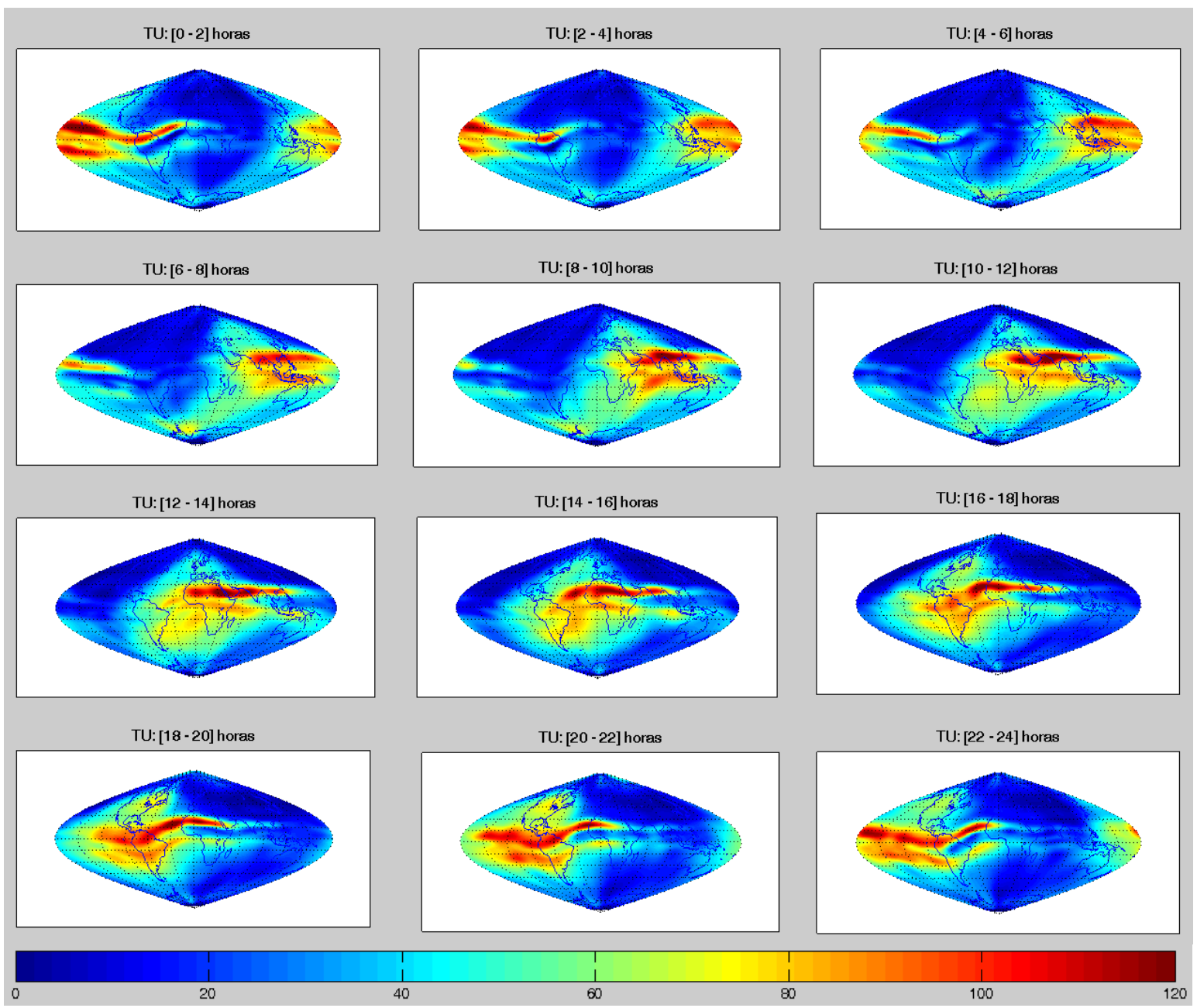

Figura 5.5. Contenido electrónico ionosférico hasta la altura de $1300 \mathrm{~km}$ obtenidos con LPIPM. (Día 007 de 2002).

Comparando los mapas ionosféricos globales con los obtenidos en el capítulo 4, que asigan a la ionosfera el contenido electrónico hasta la altura de 20.200 km, 
correspondiente a las órbirtas de los satélites del sistema de posicionamiento, encontramos que las diferencias mas notables son función de la hora local. Sistemáticamente, para los 100 días procesados, los mapas ionosféricos obtenidos con LPIM sobre-estiman el VTEC en horas de la noche y lo subestiman en horas del mediodía local si se comparan con los valores que se obtienen con LPIPM. Estas diferencias son, en promedio, del orden de \pm 5 TECUs.

\subsubsection{Mapas plasmasféricos globales}

El planteo propuesto en este capítulo permite confeccionar mapas plasmasféricos globales GPM con una resolución horaria de 2 horas.

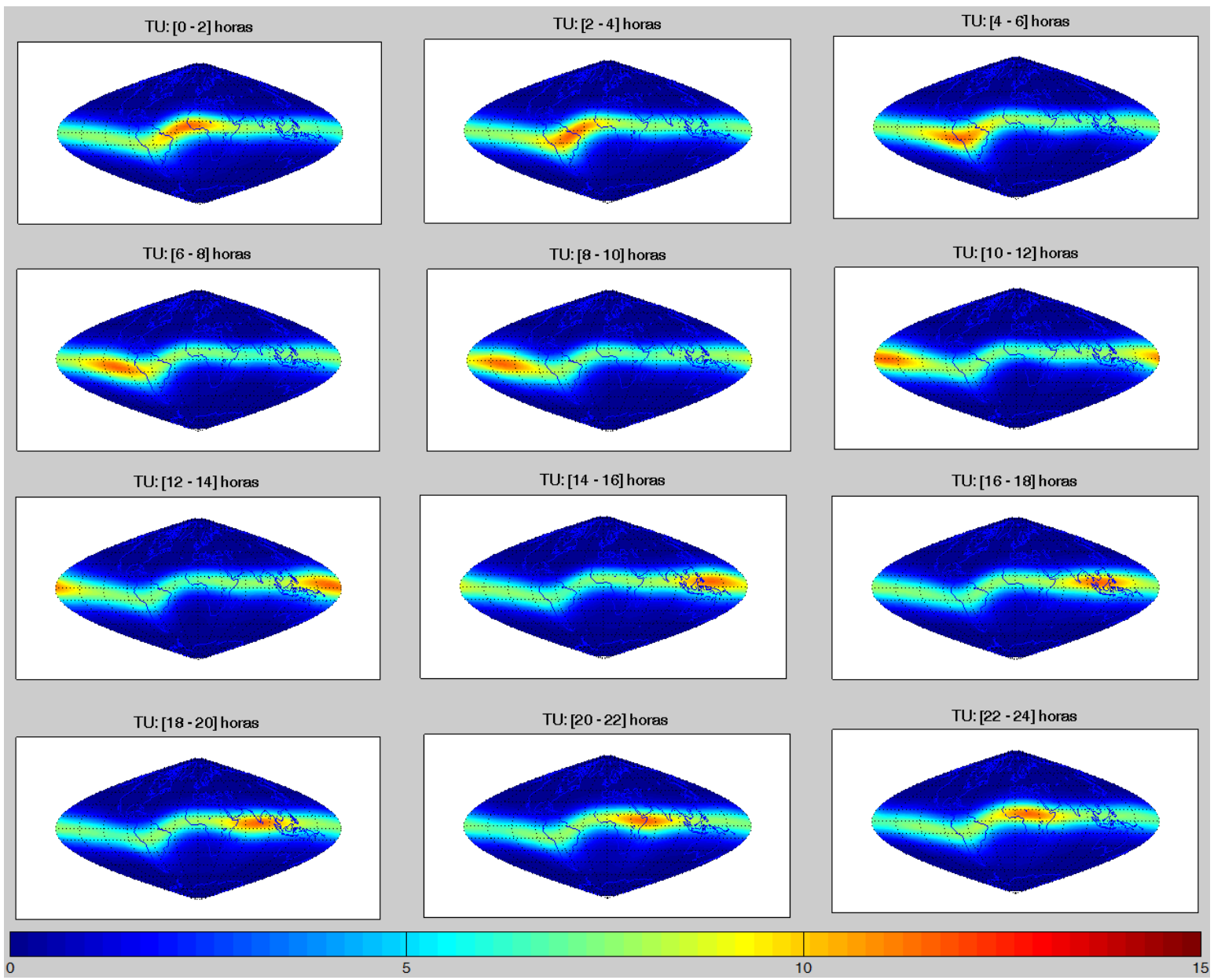

Figura 5.6. Contenido electrónico plasmasférico obtenido con LPIPM. Los mapas corresponden a los intervalos horarios de 2 horas de TU del 7 de enero de 2002. La escala de colores abarca de 0 a 15 TECUs. 
En la figura 5.6 es posible apreciar los GPM obtenidos con LPIPM para el día 7 de enero de 2002 en intervalos de dos horas de TU. Como puede observarse, la contribución es importante a lo largo de todo el ecuador magnético, consistente con la geometría de toro desplegado y proyectado sobre la superficie de la Tierra con que aproximamos la plasmasfera. Para esta fecha, el factor de escala resultó $\mathrm{a}_{\mathrm{p}}=1.44 \pm 0.02$. Con este valor, el PTEC alcanza valores máximos del orden de 10 TECU, en horas de noche local, en respuesta al modelo de Gallagher.

En el período de 100 días analizado, el aspecto de los mapas plasmsféricos es similar para cada intervalo horario; sin embargo se aprecian variaciones en el factor de escala y por lo tanto en el contenido electrónico plasmasférico diario, como se verá en la sección 5.4.7.

EI PTEC muestra una marcada dependencia con la latitud y la hora en un día. En promedio, en el período de 100 días procesados, la distribución del contenido electrónico en la plasmasfera como función de la latitud modip (en bandas de 10 grados) y del tiempo magnético local LMT (en bandas de una hora) se halla representada en la Figura 5.7.

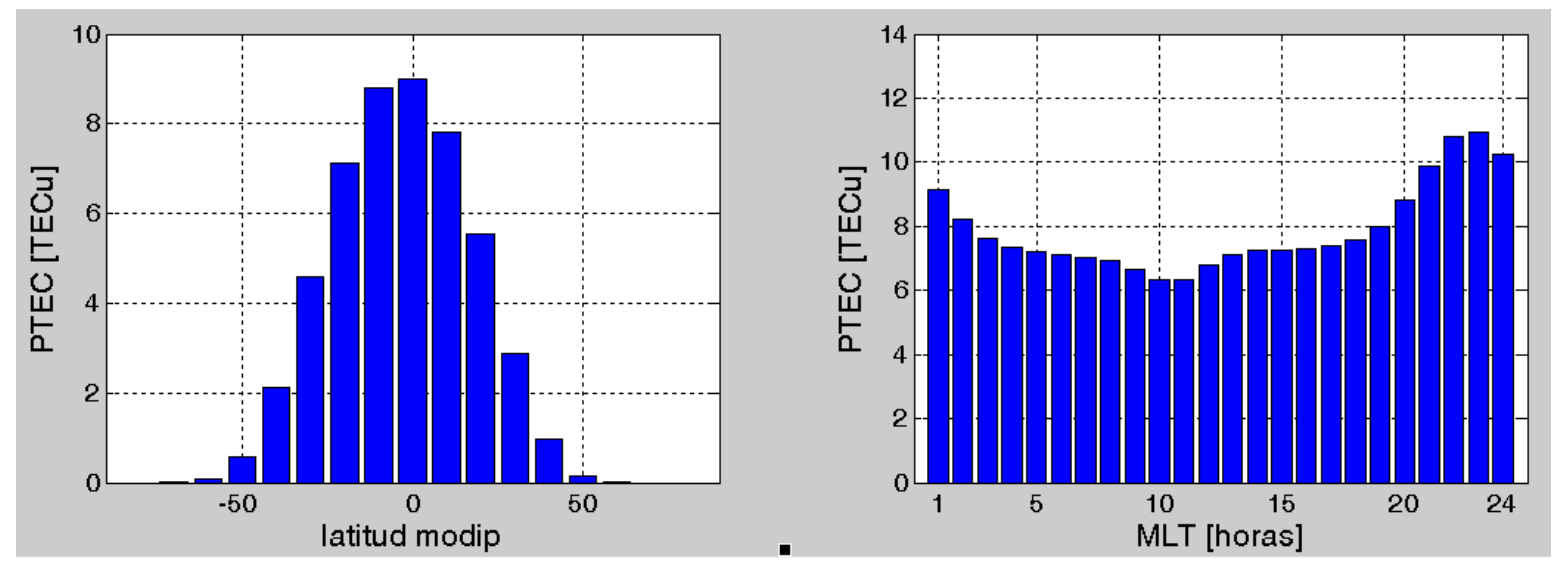

Figura 5.7. Contenido electrónico total plasmasférico PTEC medio en los 100 primeros días del año 2002, en intervalos de la latitud modip (izquierda) y en intervalos horarios para $-20 \leq \mu \leq 20$ (derecha).

El aporte que hace la plasmasfera al contenido electrónico es importante, en promedio cercano a los 8-9 TECUs en bajas latitudes magnéticas (Figura 5.7. izquierda). A su vez, en la región de latitud modip $-20^{\circ} \leq \mu \leq 20^{\circ}$ el mayor aporte se da durante la noche, a partir de las 19 horas (MLT), como se puede observar en el gráfico de la misma figura (derecha). 


\subsubsection{Contribución relativa al TEC}

Es interesante hacer una estimación de la importancia que tiene el contenido electrónico plasmasférico frente al ionosférico en diferentes regiones y momentos del día.
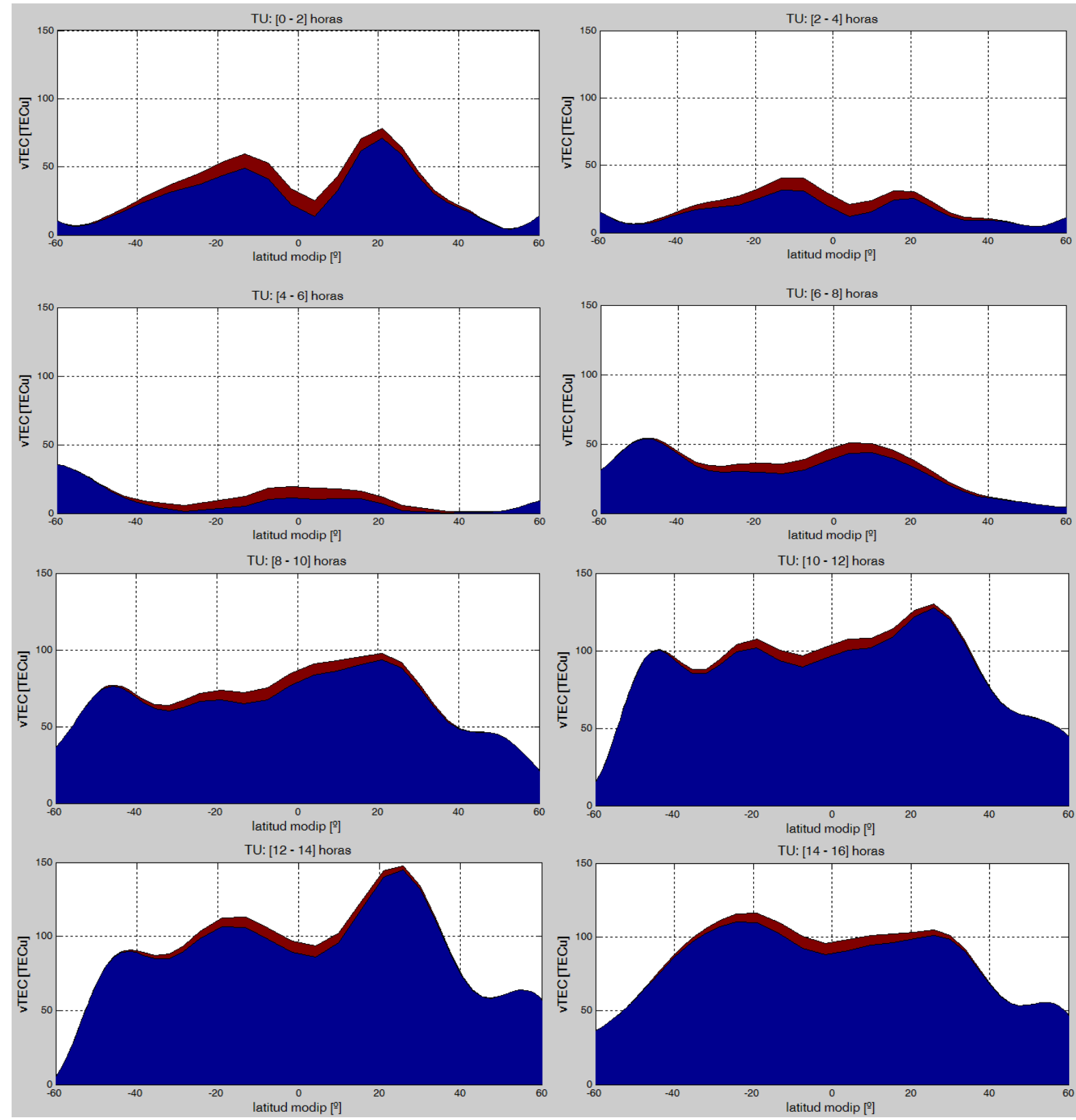


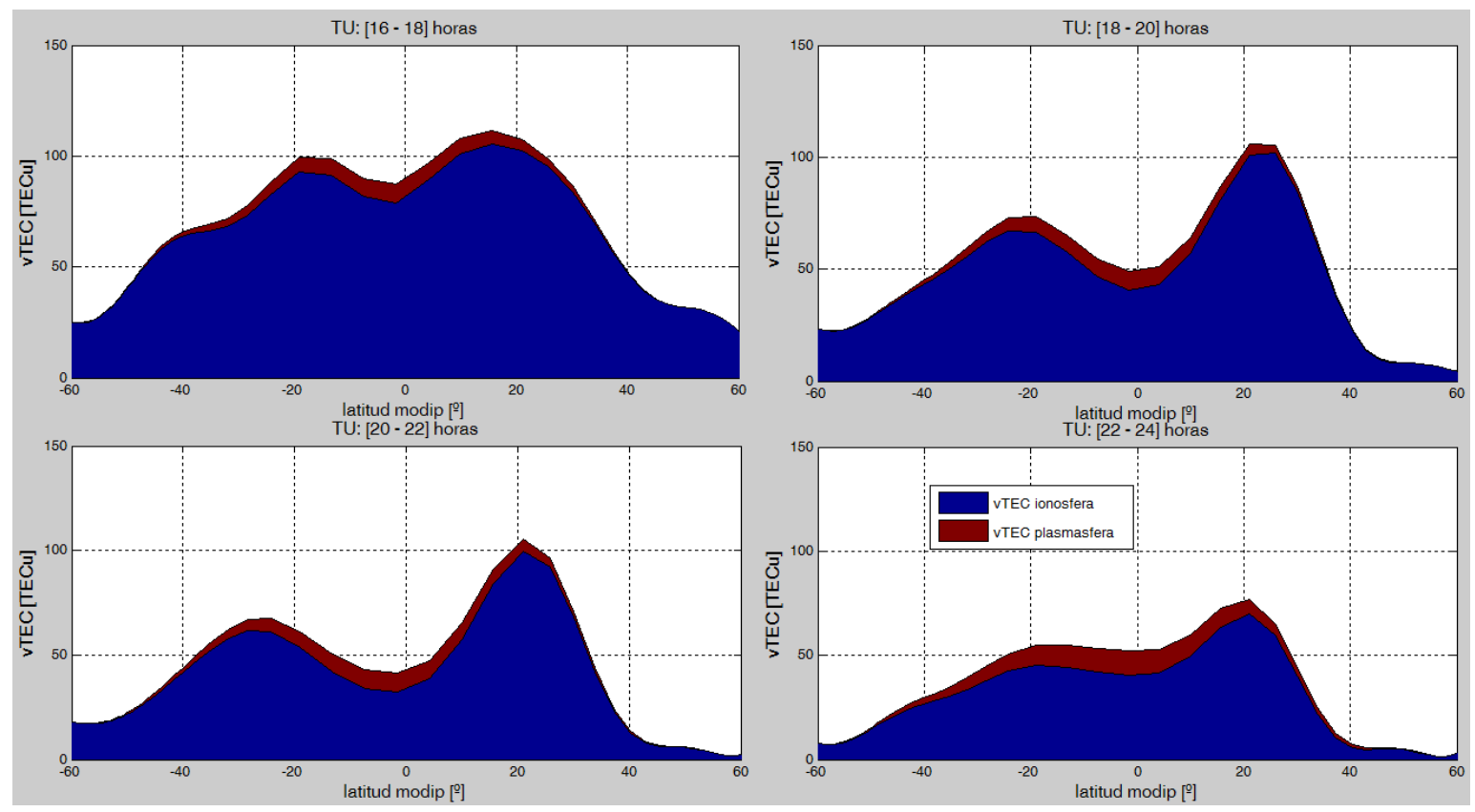

Figura 5.8. (Página actual y anterior). Contribución relativa al VTEC de la ionosfera (azul) y la plasmasfera (morado) en función de la latitud modip (longitud geográfica $=0$ ) en intervalos de 2 horas de TU del 1 de enero de 2002 (factor de escala $a_{p}=1.53 \pm 0.02$ ).

Para esto, ambas contribuciones han sido representadas en el mismo gráfico en función de la coordenada modip para intervalos de dos horas. En la Figura 5.8 es posible apreciar la contribución inosférica en azul y la plasmasférica en morado para del día 1 de enero de 2002 sobre el meridiano de Greenwich. Cada gráfico de esta figura se corresponde con el contenido electrónico plasmasférico mapeado en la Figura 5.6 para la longitud geográfica cero. En principio, independientemente del momento del día, el aporte plasmasférico es significativo para bajas latitudes modip.

Para la fecha graficada, la actividad solar es alta y la componente ionosférica diurna puede alcanzar valores próximos a 150 TECU. Para este día, en horas próximas al mediodía local y sobre el ecuador magnético (en una banda comprendida entre los $\pm 5^{\circ}$ de latitud modip) la contribución plasmasférica representa una fracción inferior al $10 \%$ de la componente ionosférica, pero en horas de la noche, la relación es del orden del 50\% y aún superior antes del amanecer. Esta tendencia se repite para el periodo de 100 días analizados. En la Figura 5.9 (izquierda) se aprecia la relación porcentual de la contribución de la plasmasfera relativa a la ionosfera en intervalos de latitud modip para el período completo. 

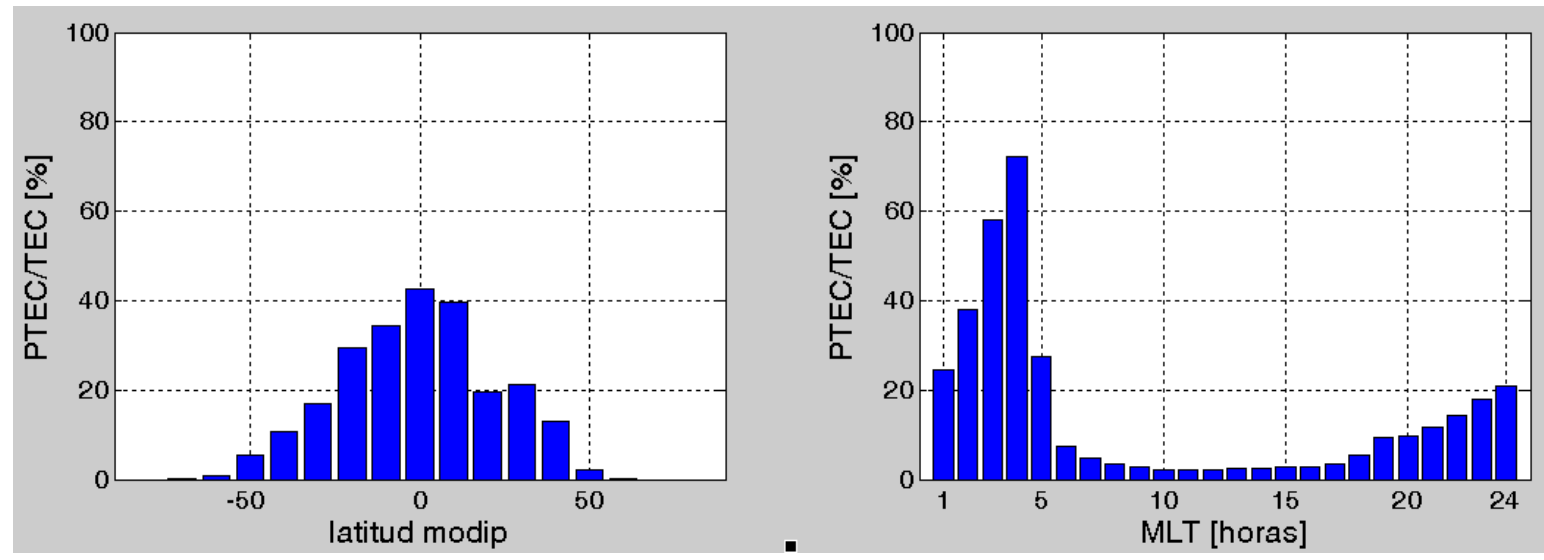

Figura 5.9. Relación porcentual entre la componente plasmasférica y la ionosférica en los 100 priemros días del año 2002, en intervalos de la latitud modip (izquierda) y en intervalos horarios (derecha).

La contribución de la plasmasfera relativa a la ionosfera es máxima sobre el ecuador modip y decrece hacia los polos, siendo levemente más importante en el hemisferio sur modip que en el norte.

La relación entre componentes en diferentes momentos del día para el período completo de 100 días es tal que el material completamente ionizado que se encuentra por encima de los $1300 \mathrm{~km}$ representa una pequeña fracción del contenido electrónico que se atribuye a la ionósfera durante el día, pero la relación cobra importancia en horas de la noche, con un pico que supera el $70 \%$ entre las 3 y las 4 de la mañana (Figura 5.9, derecha).

\subsubsection{Contenido electrónico plasmasférico en el tiempo}

El factor de escala $\mathrm{a}_{\mathrm{p}}$ es representativo de la cantidad total de iones $\mathrm{H}^{+}$presentes en la plasmasfera. En el intervalo de [1-100] del año 2002 procesado, el factor $a_{p}$ toma valores que oscilan entre 1.2 y 1.94 , con un valor medio $\left\langle a_{p}\right\rangle=1.58 \pm 0.14$.

En la Figura 5.10 (serie azul) se representa el factor $a_{p}$ obtenido para cada uno de los 100 días. En una rápida mirada podría decirse que el factor varía de forma aleatoria en este intervalo de tiempo. Sin embargo, a continuación se verá que estas variaciones pueden ser interpretadas como una respuesta de la plasmasfera a la actividad geomagnética.

Como se mencionó en el capítulo 1 (sección 1.3.1), las perturbaciones que sufre el campo magnético terrestre por acción de partículas provenientes del Sol son 
cuantificadas a través del índice observacional K. Este índice representa las variaciones de las componentes horizontales del campo geomagnético en intervalos de 3 horas en estaciones fijas distribuidas sobre la superficie de la Tierra. A partir de estos valores es posible derivar un indicador planetario de la actividad geomagnética conocido como índice Kp.

El índice Kp caracteriza entonces la actividad geomagnética global en intervalos de 3 horas; varía entre 0 (para una época de actividad muy baja) y 9 (para tormentas geomagnéticas extremas) en una escala logarítmica. (http://www.swpc.noaa.gov/products/planetary-k-index). En la Figura 5.10 (en rojo) se ha superpuesto el índice Kp medio diario para los días 1 a 100 del año 2002.

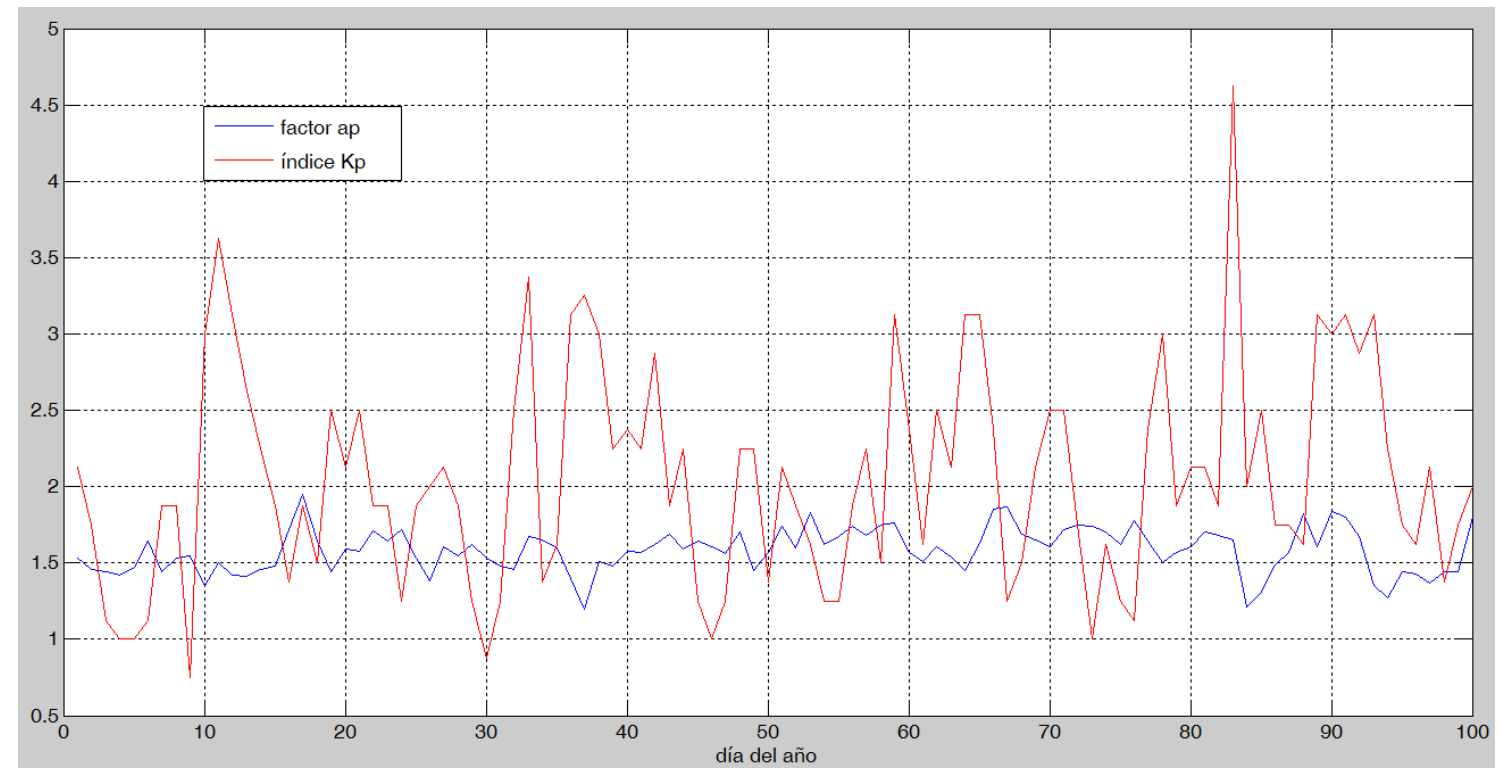

Figura 5.10. Factor de escala plasmasférico a para los 100 primeros días del año 2002 (en azul) e índice Kp medio diario (en rojo) (http://www.swpc.noaa.gov/products/planetary-k-index).

En primer lugar, se observa que los tres valores mínimos del factor $a_{p}$ obtenido en el presente trabajo, correspondientes a los días 37,84 y 94, están precedidos de picos en la actividad geomagnética. Por otra parte, en el período de tiempo analizado es posible identificar 12 días con índice Kp medio diario mayor que 3, es decir con actividad magnética significativa. Si se calcula la variación del factor $\mathrm{a}_{\mathrm{p}}$ entre cada uno de estos días y el siguiente, se encuentra que en 8 de los 12 casos se produce una disminución del factor dentro de las 24 horas posteriores al día geomagnéticamente activo (Tabla 5.1). A su vez, al día con actividad 
geomagnética más intensa en el período analizado sigue la caída más abrupta del factor $\mathrm{a}_{\mathrm{p}}$ registrada en el mismo período (día 83).

Tabla 5.1. Días del año 2002 con índice Kp medio diario elevado y variación del factor $a_{p}$ $\Delta a_{p}=a_{p}(d+1)-a_{p}(d)$

\begin{tabular}{|r|r|r|}
\hline \multicolumn{1}{|c|}{ Día } & $\begin{array}{c}\text { Índice } \\
\mathrm{Kp}\end{array}$ & \multicolumn{1}{c|}{$\Delta \mathrm{a}_{\mathrm{p}}$} \\
\hline 11 & 3,63 & $-0,08$ \\
\hline 12 & 3,13 & $-0,01$ \\
\hline 33 & 3,38 & $-0,02$ \\
\hline 36 & 3,13 & $-0,20$ \\
\hline 37 & 3,25 & 0,31 \\
\hline 59 & 3,13 & $-0,19$ \\
\hline 64 & 3,13 & 0,18 \\
\hline 65 & 3,13 & 0,22 \\
\hline 83 & 4,63 & $-0,44$ \\
\hline 89 & 3,13 & 0,23 \\
\hline 91 & 3,13 & $-0,13$ \\
\hline 93 & 3,13 & $-0,08$ \\
\hline
\end{tabular}

La densidad electrónica descripta por el modelo de Gallagher es función del tiempo magnético local, la altura sobre la superficie de la Tierra y las coordenadas magnéticas; esta aproximación no tiene en cuenta la declinación del sol ni parámetros representativos de la actividad solar que contemplen variaciones de la plasmasfera en el tiempo más allá del MLT. En nuestra formulación, el factor de escala $a_{p}$ introduce esta dependencia. Los valores mínimos del factor $a_{p}$ identificados en el período de 100 días precedidos de alta actividad geomagnética son consistentes con el mecanismo de erosión de la plasmasfera que se observa luego de una tormenta magnética (Reinisch, 2004). Este efecto es considerado como la principal causa de pérdida de masa de la plasmasfera y LPIM sería capaz de percibirlo.

\subsubsection{Estructuras a gran escala en la plasmasfera}

Como se mencionó en la sección 5.1, en la plasmasfera la densidad del plasma no es uniforme. Especialmente cerca del límite exterior, se han observado estructuras de gran tamaño de material denso conectadas a la plasmasfera extendiéndose hacia afuera. Estas estructuras han sido reconocidas mediante diferentes técnicas a lo largo de más de 40 años y se conocen con el nombre de 
plumas plasmasféricas. Las misiones satelitales como IMAGE (NASA) y CLUSTER (ESA/NASA) han permitido una mejor caracterización de estas irregularidades (Sandel et al., 2003, Darrouzet et al., 2004). Ha sido posible establecer que el aumento en la densidad se observa predominantemente en horas del anochecer, a menudo luego de tormentas magnéticas de moderada intensidad, a partir de $L \sim 2$, mayoritariamente en el hemisferio norte, hasta latitudes magnéticas próximas a los 40 (García et al., 2003).

En la Figura 5.9 se ha representado el contenido electrónico plasmasférico en relación con el contenido electrónico en la ionosfera en función de la latitud modip y del MLT en 100 días. Si se grafica esta relación día por día se encuentran situaciones que se apartan de los valores medios mostrados en esa sección, como es posible observar en la Figura 5.11. En este gráfico se muestra la contribución relativa del contenido electrónico de la componente plasmasférica frente la ionosférica para el día 72 del año 2002 en función de la latitud modip (izquierda) y del MLT en la región $-20^{\circ} \leq \mu \leq 20^{\circ}$ (derecha). Para este día es posible apreciar un pico inusual en la relación plasmasfera/ionosfera que se ubica en la banda centrada en $10^{a}$ de latitud modip y en el intervalo 18:00 - 19:00 MLT. Este apartamiento de la relación plamafera/ionosfera media podría estar dando cuenta de la presencia de una pluma plasmasférica, ya que tanto el momento del día como la latitud en que se registra el pico es compatible con la probabilidad de ocurrencia de este fenómeno. Así ha sido interpretado también por Yizengaw et al. (2008), quienes detectan picos similares en un estudio comparativo entre mediciones del contenido electrónico plasmasférico medido por los receptores GPS a bordo del satélite Jason 1 y el TEC estimado con receptores GPS basados en tierra. Otro indicio a favor de la presencia de una pluma plasmasférica es que la actividad magnética dentro de las 24 horas previas registra un pico moderado en índice Kp.
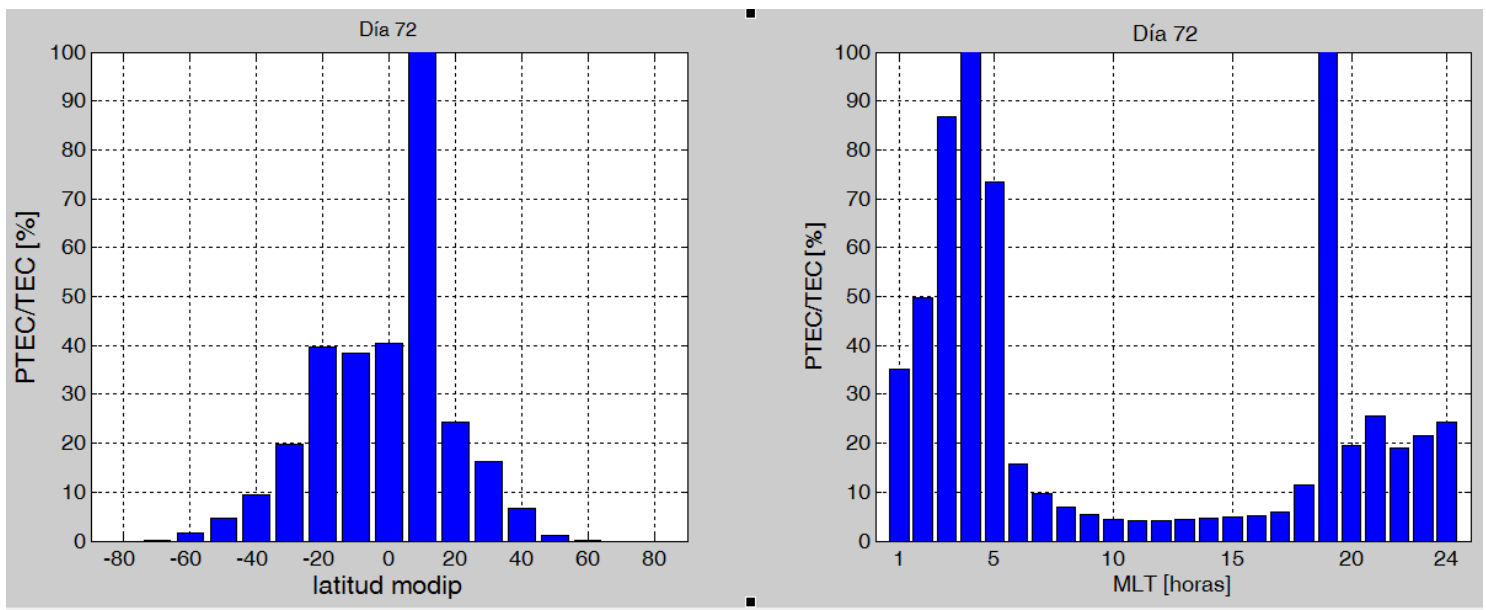

Figura 5.11. Relación porcentual entre la componente plasmasférica y la ionosférica para el día 72 del año 2002, en intervalos de la latitud modip (izquierda) y en intervalos horarios (derecha). 
Analizado el período completo, fue posible detectar un aumento significativo (superior al 40\%) en el contenido electrónico en la plasmasfera en horas próximas al anochecer en 8 de los 100 primeros días del año 2002. De los 8 casos, 6 se dan en el hemisferio norte modip y están precedidos por picos moderados en el índice $\mathrm{Kp}$, mientras que 2 se registran en el hemisferio sur y coinciden con épocas de actividad magnética creciente. Esta asimetría espacial de las extensiones de la plasmasfera en favor del hemisferio norte también ha sido reportada, aunque en algunos casos ha sido asociada a una distribución irregular de los detectores y no a una característica intrínseca del fenómeno (García et al., 2003, Lee et al., 2016).

\subsection{Conclusiones del capítulo}

En este capítulo se discutió la posibilidad de utilizar la diferencia entre las alturas de las orbitas de los satélites altimétricos y GPS para derivar el contenido electrónico plasmasférico. Como es sabido, el material en la plasmasfera, principalmente hidrógeno, se encuentra completamente ionizado. Si bien la densidad electrónica en la plasmasfera es muy baja, del orden de $10^{4}$ electrones $\mathrm{cm}^{-3}$, comparada con la densidad electrónica típica de la ionosfera (del orden de $10^{6}$ electrones $\mathrm{cm}^{-3}$ en la región F2) el material completamente ionizado llena el espacio por debajo de las órbitas de los satélites de posicionamiento. Los cálculos del VTEC basados en mediciones realizadas con GPS incluyen este material, de modo que los modelos globales de TEC obtenidos con esta técnica tienden a sobre-estimar el contenido electrónico en la ionosfera.

Suponiendo que los satélites altimétricos, que orbitan la Tierra a un altura aproximada de $1300 \mathrm{~km}$ sobre su superficie, muestrean la ionosfera, mientras que las señales de los satélites de posicionamiento atraviesan tanto la ionosfera como la plasmasfera, representando la distribución espacial de los electrones libres en la plasmasfera mediante el modelo de Gallagher ha sido posible separar el contenido electrónico hasta la altura de $20.200 \mathrm{~km}$ en dos componentes, la inferior a los $1300 \mathrm{~km}$ estrictamente atribuible a la ionosfera y la superior, a la plasmasfera.

El planteo demanda la determinación de los bias instrumentales de forma simultánea con el cálculo del TEC (ionosfera) y PTEC (plasmasfera); los bias son supuestos constantes en un período de 100 días y se encuentra que:

- El cálculo de los DCBs de los satélites GPS no se ve alterado por la diferenciación de las dos regiones. 
- El cálculo de los DCBs de los receptores GPS, específicamente en la zona de influencia de la plasmasfera, es decir para las estaciones que se encuentran próximas al ecuador magnético, tampoco se ven afectados por el nuevo planteo. Numéricamente, en la zona ecuatorial los DCBs calculados separando las dos componentes difieren de los calculados suponiendo que todos los electrones por debajo de los $20.200 \mathrm{~km}$ se hallan confinados en una cáscara, en cantidades del orden de los $\pm 0,5 \mathrm{~ns}$, inferior a 1,5 TECUs para la frecuencia de las señales GPS en regiones donde el contenido electrónico plasmasférico es en promedio superior a 8 TECUs.

- El bias altimétrico pasa de $\boldsymbol{\beta}^{\mathrm{T}}=2.836 \pm 0.005 \mathrm{TECU}$ a $\boldsymbol{\beta}^{\mathrm{T}}=3.450 \pm 0.005 \mathrm{TECU}$ cuando se incorpora la plamasfera; este resultado es consistente con la hipótesis de que este bias viene a compensar la diferencia entre el sistema de posicionamiento GPS y la altimetría satelital como fuentes independientes de adquisición de datos inosféricos. El sistema GPS sistemáticamente sub-estima el TEC frente a los registros de los satélites altimétricos; esta diferencia se ve agravada cuando se atribuye, además, parte del retardo que sufre la señal GPS a la plasmasfera.

En síntesis, la discusión previa muestra que la separación del contenido electrónico en la atmósfera superior de la Tierra en dos regiones físicas, con geometrías bien diferenciadas, no se traslada numéricamente a los bias instrumentales como incógnitas que deben ser determinadas de forma simultánea con los coeficientes para calcular el VTEC y el VPTEC con el modelo ionosférico y plasmasférico LPIPM.

El modelo LPIMP ha posibilitado la cuantificación del aporte que el material completamente ionizado que llena la plasmasfera hace al contenido electrónico total vertical. En bajas latitudes esta contribución es dependiente de la hora del día y de la actividad magnética pero puede significar un aporte promedio del orden de los 8-9 TECUs al VTEC para el período analizado. En términos porcentuales, el aporte plasmasférico frente al ionosférico es significativo para bajas latitudes modip y en la zona oscura del planeta, superando el $70 \%$ en el intervalo 3-4 MLT.

Finalmente, la resolución espacio-temporal de LPIPM permitiría reconocer algunos fenómenos característicos de la envoltura externa de la Tierra:

- A partir de la introducción de un factor de escala $a_{p}$ en la representación de Gallagher, ha sido posible registrar variaciones temporales en la densidad electrónica de la plasmasfera a escala global consistentes con eventos de pérdida de masa asociados a tormentas geomagnéticas. 
- También ha sido posible distinguir anomalías en la relación entre el contenido electrónico en la ionosfera y el contenido electrónico plasmasférico espacialmente localizadas y compatibles con la presencia de plumas plasmasféricas. 


\section{Capítulo 6: Conclusiones y próximos trabajos}

Tradicionalmente, las mediciones del TEC derivadas de las estaciones terrestres del sistema de posicionamiento GNSS constituyen una fuente rica de información de la ionosfera de la Tierra. Dos grandes ventajas de esta fuente de datos son la amplia distribución de las estaciones sobre la superficie terrestre y la fácil accesibilidad a los mismos a través de internet. No menos promisorias como fuentes precisas de mediciones del TEC vertical sobre los océanos son las misiones de altimetría satelital TOPEX/Posiedón y sus sucesoras Jason, aunque más resistidas a la hora de formular representaciones globales del contenido electrónico debido a que la distribución de los datos en periodos cortos de tiempo se encuentra localmente restringida.

El objetivo de este trabajo ha sido investigar la posibilidad de asimilar, en un modelo ionosférico global y consistente, las mediciones del TEC derivadas de las misiones satelitales de posicionamiento y altimétricas. El interés estuvo puesto en el desarrollo de diferentes algoritmos capaces de sacar el mayor provecho posible a cada misión como fuente de información para monitorear el contenido electrónico ionosférico a escala global. En nuestros días, una mejor representación del TEC en la ionosfera es triplemente valorada: como una forma de cuantificar y mejorar el conocimiento de un fenómeno complejo y sumamente variable que tiene lugar en la alta atmósfera de la Tierra, como fuente de información independiente para contrastar modelos teóricos, y como insumo necesario para mejorar el posicionamiento satelital, especialmente en una época en que esta tecnología está siendo utilizada masivamente e impacta en diferentes sectores socio-económicos y productivos (transporte, agricultura, etc.), ya que la ionosfera representa la principal fuente de incerteza.

El punto de partida para llevar a cabo este trabajo fue el Modelo lonosférico La Plata LPIM, desarrollado en el Laboratorio de Geodesia Espacial y Aeronomía de la Facultad de Ciencias Astronómicas y Geofísicas de la UNLP, hasta ahora basado en mediciones GPS. 


\subsection{Conclusiones}

Se investigaron dos estrategias de asimilación de datos de las misiones de altimetría satelital fundamentadas en un modelo simple para representar la envoltura ionizada que consiste en una cáscara delgada que rodea a la Tierra a una altura aproximada de $450 \mathrm{~km}$; apoyada en la segunda, una tercera propuesta tiene en cuenta el material tenue y completamente ionizado distribuido en forma de toro en la plasmasfera. En los dos primeros casos se obtuvieron como resultado mapas ionosféricos globales con una resolución espacial de $\sim 15^{\circ}$ y temporal de 2 horas basados en mediciones GPS+altimétricas y en el tercero, además, se separó la componente plasmasférica para producir mapas plasmasféricos globales con la misma resolución.

En la primera etapa del trabajo se propuso una técnica que permite la asimilación de series de 24 horas de datos GPS + altimétricos. Se encontró que:

- las estimaciones del VTEC basadas en datos GPS + altimétricos pueden llegar a diferir de las basadas en GPS únicamente en cantidades del orden de los 20 TECUs en regiones próximas al paso del satélite altimétrico en una época de alta actividad solar;

- en una serie de 100 días analizados, la incorporación de datos altimétricos reduce la dispersión en los bias instrumentales diarios de los satélites y de los receptores GPS;

- en la serie de 100 días, en los casos que se observan variaciones en los retardos instrumentales en el tiempo, éstas pueden asociarse a la dificultad para separar el efecto que produce la ionósfera sobre la señal GPS y el originado en la parte física del instrumento de medición y la incorporación de datos altimétricos favorece el desacople;

- para obtener consistencia entre la configuración orbital de los satélites GPS y TOPEX/Poseidón y el VTEC modelado, es necesario introducir un bias o error de calibración entre las mediciones realizadas con ambos sistemas.

Con el objeto de maximizar el aprovechamiento de las observaciones altimétricas sobre los GIMs se propuso una segunda técnica de asimilación. El principal aporte en este sentido fue el desarrollo de un método que permite asimilar largas series de mediciones del TEC derivadas de las misiones satelitales de posicionamiento y altimétricas simultáneamente, por acumulación de los sistemas normales diarios sobre la suposición de estabilidad en el hardware de satélites y receptores.

El método de acumulación de sistemas normales diarios fue aplicado para asimilar un paquete de 100 días de datos combinando las dos fuentes de 
información. Se obtuvieron GIMs para cada intervalo de 2 horas y un conjunto de retardos instrumentales supuestos constantes en el período considerado; entre ellos, el bias altimétrico o de calibración entre las dos fuentes de datos resultó $\boldsymbol{\beta}^{\mathrm{T}}=2.836 \pm 0.005 \mathrm{TECu}$.

Para cuantificar la influencia de la asimilación de datos de la altimetría satelital en LPIM a través de esta técnica se recurrió a la simulación de observaciones reproduciendo la configuración real de las dos misiones satelitales. Para esto se generaron datos sintéticos, libres de errores instrumentales, con el modelo NeQuick. Se encontró que:

- la incorporación de observaciones de VTEC a través de la técnica de acumulación de sistemas normales permite una calibración de los DCBs de los receptores sensiblemente más confiable; en este contexto, más confiable implica valores más cercanos a cero como se espera por tratarse de observaciones simuladas; en promedio, para las estaciones susceptibles a la asimilación se observó una reducción del orden del $30 \%$ respecto a los valores basados en observaciones de sTEC del sistema GPS;

- el aporte de vTEC sintético reduce el error en los GIMs, que pasa (en promedio para los 120 mapas en los 10 días simulados) de 8.27 TECu cuando se usan datos GPS día por día a 7.38 TECU cuando se asimilan datos altimétricos con la técnica de acumulación, lo que representa una mejora porcentual superior al 10\%;

- estas mejoras pueden acentuarse si se asigna a cada ecuación un factor de peso que simula una redistribución homogénea en latitud de las estaciones del sistema de posicionamiento GPS y equipara la influencia de los datos altimétricos a los datos del sistema GPS;

- la utilización de un factor de peso como el descripto permitió además validar la ventaja de la asimilación de datos altimétricos en su carácter de mediciones directas del VTEC, en el sentido que no requieren la intervención de una función de mapeo, luego de haber identificado que esta aproximación limita la representación del contenido electrónico global.

La técnica de asimilación de sistemas normales implementada abrió, a su vez, la posibilidad de aprovechar la diferencia entre las alturas de las órbitas de los satélites de posicionamiento y altimétricos para reformular el modelo de capa delgada utilizado para representar la ionosfera y separar la contribución plasmasférica. Se encontró que la plasmasfera tiene un efecto global importante 
en bajas latitudes modip. En esta región, en la zona oscura del planeta, el aporte plasmasférico es del orden del $70 \%$ del ionosférico. Este resultado muestra la importancia de la contribución plasmasférica al VTEC y advierte sobre la necesidad de que esta región sea tenida en cuenta, especialmente cuando se extrapolan mediciones del contenido electrónico basadas en el sistema GPS para ser atribuidas a la ionosfera.

Finalmente, la formulación de un modelo ionosférico-plasmasférico permitió reconocer algunos fenómenos característicos de la envoltura externa de la Tierra. Por un lado, fue posible registrar variaciones temporales en la densidad electrónica de la plasmasfera a escala global, que fueron interpretados como una respuesta de esta región al viento solar. También fue posible distinguir anomalías localizadas en la relación entre el contenido electrónico plasmasférico y el ionosférico compatibles con la aparición de plumas plasmasféricas.

\subsection{Próximos trabajos}

Sobre la base de los desarrollos descriptos en esta investigación, se han propuesto cuatro nuevos trabajos:

- El primero consiste en extender el período de asimilación de datos altimétricos en LPIM para abarcar épocas de baja actividad solar y de esta forma lograr una serie que contemple el comportamiento de la ionosfera en las distintas condiciones solares.

- El segundo apunta a la generación automática de mapas globales que representen de forma independiente el contenido electrónico ionosférico y plasmasférico para ser ofrecidos a través de la web de la Red Argentina para el Estudio de la Atmósfera Superior RAPEAS; este aporte genera una interacción con la comunidad dedicada al estudio de estas regiones y especialmente hacia la formulación de reportes sobre la climatología del espacio.

- Una tercera línea de trabajo tiende a la exploración del LPIPM como detector continuo y global de plumas plasmasféricas; la capacidad de separar el contenido electrónico vertical total en dos componentes ofrece, a partir de la detección de anomalías en la relación entre ambas componentes, un indicador de estructuras a gran escala en la plasmasfera; la buena resolución espacial y temporal de los mapas permitiría no sólo la detección de estas 
estructuras sino un aporte para la comprensión del origen y la dinámica de estas estructuras que merece ser explorado.

- En LPIPM las variaciones espacio-temporales del contenido electrónico palasmasférico son fuertenente dependientes de la morfología global de la plasmasfera representada por el modelo de Gallagher; un plateo diferente es posible utilizando las mediciones del contenido electrónico provistas por los receptores GPS a bordo de los satélites altimétricos para la región comprendida entre los 1.300 y $20.000 \mathrm{~km}$.

Finalmente, en cuanto a la técnica de asimilación de datos implementada, la misma representa un aporte en el manejo de grandes volúmenes de datos para generar modelos de representación del contenido electrónico que puede ser capitalizada para el inmediato aprovechamiento de mediciones que surjan de los nuevos instrumentos instalados en el país en el Observatorio Argentino-Alemán de Geodesia (AGGO), recientemente inaugurado en las cercanías de la ciudad de La Plata. 


\section{Referencias}

Aarons J., Mendillo, M. \& Yantosca, R. (1997). GPS phase fluctuations in the equatorial region during sunspot minimum, Radio Science, 32 (4), 1535-1550.

Afraimovich, E. L., Kosogorov, E.A., Leonovich, L.A., Palamartchouk, K.S., Perevalova, N.P. \& Pirog, O.M. (2000). Determining parameters of largescale traveling ionospheric disturbances of auroral origin using GPS arrays, Journal of Atmospheric and Solar-Terrestrial Physics, 62 (7), 553-565.

Appleton, E. V. (1938). Radio transmission and solar activity, Nature, 3594, 142, 499501.

Appleton, E.V. (1946). Two anomalies in the ionosphere, Nature, 157, 691.

Azpilicueta, F. (2006). Modelo Global de TEC con observaciones GPS y de la Altimetría Satelital, Tesis Doctoral, UNLP.

Azpilicueta, F. \& Brunini, C. (2008). Analysis of the bias between TOPEX and GPS VTEC determinations, Journal of Geodesy, doi 10.1007/s00190-008-0244-7.

Azpilicueta, F. \& Brunini, C. (2009). Residual Analysis of Global Ionospheric Maps Using Modip Latitude. En: H. Drewes (ed.), Geodetic Reference Frames, International Association of Geodesy Symposia 134, DOI 10.1007/978-3-64200860-3_25, 311-316.

Azpilicueta, F. \& Brunini, C. (2011). A new concept regarding the cause of ionosphere semi-annual and annual anomalies, Journal of Geophysical Research, doi:10.1029/2010JA015977010.

Azpilicueta, F., Brunini, C. \& Radicella, S.M. (2005). Global ionospheric maps from GPS observations using modip latitude. JASR, Elsevier, (36), 552-561.

Azpilicueta, F., Brunini, C. \& Radicella, S.M. (2011). Semi-annual Anomaly and Annual Asymmetry on TOPEX TEC during a full Solar cycle, International Association of Geodesy Symposia, 135, 587-592.

Bailey, G.J., Balan, N. \& SU, Y.Z. (1997). The Sheffield University plasmasphere ionosphere model - a review, J Atmos Sol Terr Phys, 59, 1541-1552.

Balan, N., Bailey, G.J., Jenkins, B., Rao, P.B. \& Moffett, R.J. (1994). Variations of ionospheric ionization and related solar fluxes during an intense solar cycle, J. Geophys. Res., 99(A2), 2243-2253, doi:10.1029/93JA02099.

Balan, N., Otsuka, Y., Fukao, S., Abdu, M.A. \& Bailey, G.J. (2000). Annual variations of the ionosphere: A review based on MU radar observations, Advances in Space Research, 25(1), 153 - 162, doi:10.1016/S0273-1177 (99)00913-8.

Bartels, J. (1957). The geomagnetic measures for the time-variations of solar corpuscular radiation, described for use in correlation studies in other geophysical fields, Ann. Intern. Geophys (4), 227-236.

Bilitza, D. (2001). International Reference Ionosphere 2000. Radio Science 38 (6), $261-275$. 
Bilitza, D. (2002). Ionospheric Models for Radio Propagation Studies, Review of Radio Science 1999-2002, 625 - 679, Oxford University Press.

Blewitt, G. (1990). An automatic editing algorithm for GPS data, Geophysical Research Letters, 17 (3), 199-202.

Bothmer, V. (2006). Space weather: physics \& effects, Springer Verlag.

Brunini, C. (1998). Global lonospheric model from GPS measurements, Tesis Doctoral UNLP.

Brunini C., Van Zele, M.A., Meza, A. \& Gende, M. (2003). Quiet and perturbed ionospheric representation according to the electron content from GPS signals. Journal of Geophysics Research, 108(A2), 1056, DOl: 10.1029/2002JA009346.

Brunini, C., Meza, A., Bosch, W. (2005). Temporal and spatial variability of the bias between TOPEX and GPS derived TEC. Journal of Geodesy, 79:175-188. doi:10.1007/s00190-005-0448-Z

Brunini, C. \& Azpilicueta, F. (2009). Accuracy assessment of the GPS-based slant total electron content (sTEC) Journal of Geodesy, doi 10.1007/s00190-0080296-8.

Brunini, C. \& Azpilicueta, F. (2010). GPS-based slant total electron content accuracy using the single layer model under different geomagnetic regions and ionospheric conditions, Journal of Geodesy, 84, 293-304, doi 10.1007/s00190-010-0367-5.

Brunini, C., Azpilicueta, F., Gende, M., Aragón-Ángel, A., Hernández-Pajares, M, Juan \& Sanz, J. (2011). Toward a SIRGAS service for mapping the ionosphere's electron density distribution, International Association of Geodesy Symposia, 135, 575-580.

Brunini, C., Azpilicueta, F., Gende, M., Camilion, E., Aragón Á., Hernandez-Pajares, M., Juan, M., Sanz, J. \& Salazar, D. (2011). Ground- and space-based GPS data ingestion into the NeQuick model, Journal of Geodesy, doi 10.1007/s00190-011-0452-4.

Buonsanto, M.J. (1999). Ionospheric Storms - a Review, Space Science Reviews 88, 563-601.

Carpenter, D. L. (2004). Remote sensing the Earth's plasmasphere, Radio Science, $308,13-29$.

Carrano, C. S., Anghel, A., Quinn, R. A. \& Groves, K. M. (2009). Kalman Filter Estimation of Plasmaspheric TEC using GPS, Radio Science, 44, RS5014, doi:10.1029/2009RS004186.

Chapin, E., Chan, S. F., Chapman, B. D., Chen, C. W., Martin, J. M., Michel, T. R., Muellerschoen, R. J., Pi, X. \& Rosen, P. A. (2006). Impact of the Ionosphere on an L-band Space Based Radar, IEEE, doi 7803-9497-6. 
Chapman, S. (1931). The absorption and dissociatival or ionizing effect of monochromatic 16 radiation in atmosphere on a rotating earth, Proc. Phys. Soc. 43, p. 483-501.

Chappell, C. R., Fields, S. A., Baugher, C. R., Hoffman, J. H., Hanson, W. B., Wright, W. W., Hammack, H. D., Carignan, G. R. \& Nagy, A. F. (1981). The retarding ion mass spectrometer Dynamics Explorer-A, Space Science Instrumentation 5, 477.

Chelton D. B., Ries, J. C., Haines, B. J., Fu, L-L \& Callahan, P. S. (2001), 'Satellite Altimetry', Satellite altimetry and Earth sciences - A Handbook of Techniques and Applications, L-L Fu \& A. Cazenave Eds., International Geophysics Series, Vol. 69, ISBN 0-12-269545-3, pp. 1-131, Academic Press, California, USA.

Ciraolo, L., Azpilicueta, F., Brunini, C., Meza, A. \& Radicela, S. M. (2007). Calibration errors on experimental slant total electron content determined with GPS. Journal of Geodesy, Springer, (81) 2, 11 1-120, doi 10.1007/s00190-006-0093-1.

Coco, D. S., C. Coker, Dahlke. S. R. \& Clynch, J. R. (1991). Variability of GPS satellite differential group delays biases, IEEE Transactions on Aerospace and Electronic Systems, 27, 931-938.

Codrescu M. V., Beierle, K.L. \& Fuller-Rowell, T.J. (2001). More total electron content climatology from TOPEX/Poseidon measurements. Radio Science 36 (2), 325-333.

Conte, J. F., Azpilicueta, F. \& Brunini, C. (2011). Accuracy assessment of the GPSTEC calibration constants, Journal of Geodesy, Springer, (190), doi 10.1007/s00190-011-0477-8.

Coster, A., Williams, J., Weatherwax, A., Rideout, W \& Herne, D. (2013). Accuracy of GPS total electron content: GPS receiver bias temperature dependence. Radio Science, (48), 190-196, doi:10.1002/rds.20011.

Cueto, M., Coïsson, P., Radicella, S. M., Herraiz, M., Ciraolo, L. \& Brunini, C. (2007). Topside ionosphere and plasmasphere: use of NeQuick in connection with Gallagher plasmaspheric model. Advances in Space Research, Elsevier, doi 10.1016/j.asr.2007.01.073, 39, 739-743.

Darrouzet, F., De Keyser, J., D'ecreau, P. M. E., Gallagher, D. L., Pierrard, V., Lemaire, J. F., Sandel, B. R., Dandouras, I., Matsui, H., Dunlop, M., Cabrera, J., Masson, A., Canu, P., Trotignon, J. G.,. Rauch, J. L. \& Andre, M. (2006). Analysis of plasmaspheric plumes: CLUSTER and IMAGE observations, Ann. Geophys., 24, 1737-1758.

Darrouzet, F., D'ecreau, P. M. E., De Keyser, J., Masson, A., Gallagher, D. L., Santolik, O., Sandel, B. R., Trotignon, J. G., Rauch, J. L., Le Guirriec, E., Canu, P., Sedgemore, F., Andre, M. \& Lemaire, J. F. (2004). Density structures inside the plasmasphere: Cluster observations, Ann. Geophys., 22, 2577-2585.

Davies, K. (1990). Ionospheric Radio, Peter Peregrinus Ltd, ISBN 086341 186X. 
Davies, K. \& Hartmann, G.K. (1997). Studying the ionosphere with the Global Positioning System, Radio Science, 32 (4), 1695-1703.

De Jesus, R., Sahai, Y., Guarnieri, F. L., Fagundes, P. R., de Abreu, A.J., BeckerGuedes, F., Brunini, C., Gende, M., Cintra, T. M. F., de Souza, V. A., Pillat, G. \& Lima, L. C. (2010). Effects observed in the ionospheric F-region in the South American sector during the intense geomagnetic storm of 14 December 2006, Advances in Space Research, Elsevier, doi:10.1016/j.asr.2010.04.031.

Delay S., P. Doherty (2004). A Decade of Ionospheric Measurements from the TOPEX/Poseidon Mission, contribution to the International Beacon Satellite Symposium, Trieste, October 18th $-22^{\text {nd }}$.

Feynman, R. P., Leighton \& R. B., Sands, M. (1964). The Feynman lectures on Physics, Vol II. Addison - Wesley Publishing Company, Reading, Maryland.

Foster, J. C., Erickson, P. J., Coster, A. J., Goldstein, J. \& Rich, F.J. (2002). Ionospheric signatures of plasmaspheric tails, Geophys. Res. Lett., 29(13), 1623, doi:10.1029/2002GL015067.

Fu, L-L \& Cazenave, A. (2001). Satellite Altimetry and Earth Sciences. A Handbook of Techniques and Aplications, Academic Press, San Diego, California.

Galkin, I.A., Kitrosser, D.F., Kecic, Z. \& Reinisch, W. (1999). Internet access to ionosondes, Journal of Atmospheric and Solar-Terrestrial Physics, 61 (1-2), 181-186, doi 10.1016/S1364-6826(98)00126-6.

Gallagher, D. L., Craven, P. D. \& Comfort, R. H. (1988). An empirical model of earth's plasmasphere, Advances in Space Research, 8 (8), 15-24.

Garcia, L. N., Fung, S. F., Green, J. L., Boardsen, S. A., Sandel, B. R. \& Reinisch, B. W. (2003). Observations of the latitudinal structure of plasmaspheric convection plumes by IMAGE-RPI and EUV, Journal of Geophysical Research, 108 (A8), 1321,doi:10.1029/2002JA009496.

Gende, M. (2002). Modelos ionosféricos derivados de observaciones GPS, Investigaciones geofísicas y aplicaciones geodésicas, Tesis Doctoral UNLP.

Gende, M., Radicella, S., Nava \& B. Brunini, C. (2011). Ionospheric Effect in Instantaneous Positioning, ION Technical Meeting. Anaheim, EE.UU.

Gibson, E. (1973). The Quiet Sun. National Aeronautics and Space Administration, Scientific and Technical Information Office; [Sup. of Docs., U.S. Govt. Print. Off.]

Hargreaves, J. K. (1995). The solar-terrestrial environment: an introduction to geospace - the science of the terrestrial upper atmosphere, ionosphere and magnetosphere, ISBN 0-521-42737-1, Cambridge University Press, UK.

Hernandez-Pajares, M. (2003). Performance of IGS lonosphere TEC maps, presented at 22nd IGS Governing Board Meeting, Nice, $6^{\text {th }}$ April.

Hernández-Pajares, M., Juan, J.M. and Sanz, J. (1999). New approaches in global ionospheric determination using ground GPS data. Journal of Atmospheric and Solar-Terrestrial Physics, 61 (16), doi:10.1016/S1364-6826(99)00054-1. 
Hernández-Pajares, M., García-Rigo, A., Juan, J.M., Sanz, J., Monte, E. and Aragón-Àngel, A. (2012). GNSS measurement of EUV photons flux rate during strong and mid solar flares. SPACE WEATHER, VOL. 10, S12001, doi:10.1029/2012SW000826.

Ho, C. M., Wilson, B. D., Manucci, A. M., Linqwister, U. J. \& Yuan, D. N. (1997). A comparative study of ionospheric total electron content measurements using global ionospheric maps of GPS, TOPEX radar and the Bent model. Radio Science, 32 (4), 1499-1512.

Huba, J. D., Joyce, G. \& Fedder, J. A (2000). Sami2 is Another Model of the lonosphere (SAMI2): A new low-latitude ionosphere model, Journal of Geophysics Research, 105(A10), 23, 035-23,054.

ICAO (2006). Ionospheric effects on GNSS aviation operation, International Civil Aviation Organization, Navigation Systems Panel, ICAO; Montreal.

Imel, D. (1994). Evaluation of the TOPEX/POSEIDON dual-frequency ionosphere correction. Journal of Geophysics Research, 99(C 12):24895-24906.

Kelly, M. (2009). The Earth's Ionosphere. Plasma Physics and Electrodynamics. Academic Press, London, UK.

Lee, S. H., Zhang, H., Zong, Q.-G, Otto, A., Rème, H. \& Liebert, E. (2016). A statistical study of plasmaspheric plumes and ionospheric outflows observed at the dayside magnetopause, Journal of Geophysical Research: Space Physics, 121, 492-506, doi:10.1002/2015JA021540.

$L i, X_{.}$\& Yu, T. (2003). Annual and semi-annual variations of the observed $f_{0} F_{2}$ in a high solar activity year, Journal of Terrestrial, Atmospheric and Oceanic Sciences 14(1), 41-62.

Mannucci, A. J., Wilson, B. D, Yuan, .D. N, Ho, D. H., Lindqwister, U. J. \& Runge, T. F. (1998). A global mapping technique for GPS-derived ionospheric total electron content measurements. Radio Sci., 33, 565-582.

Mazzella, A.J. (2009). Plasmasphere effects for GPS TEC measurements in North America, Radio Science 44, RS5014, doi:10.1029/2009RS004186.

Mcllwain, C. E. (1961). Coordinates for mapping the distribution of magnetically trapped particles, Journal of Geophysical Research, 66 (1 1): 3681-3691

Memarzadeh, Y. (2009). Ionospheric Modeling for Precise GNSS Aplications, PhD thesis, Delft University of Technology.

Menard, Y. \& Haines, B. (2001). Jason-1 CALVAL Plan, JPL Ref: TP2-J0-PL-974-CN (PO.DAAC).

Mendillo, M., Huang, C., Pi, X., Rishbeth, H. \& Meier. R. (2005), The global ionospheric asymmetry in total electron content, Journal of Atmospheric and Solar-Terrestrial Physics 67, 1377-1387.

Mosert, M., Gende, M., Brunini, C., Ezquer, R. \& Altadill, D. (2007). Comparisons of IRI TEC prediction with GPS and digisonda measurements at Ebro. Advances in Space Research, Elsevier, doi:10.1016/j.asr.2006.10.02039, 841-847. 
Nava, B., Coïsson, P. \& Radicella, S. M. (2008). A new version of the NeQuick ionosphere electron density model. Journal of Atmospheric and SolarTerrestrial Physics 70, 1856-1862.

Park, Y. K., Kwak, Y. S., Ahn, B. H., Park, Y. D. \& Cho, Y. H. (2010). Ionospheric F2Layer Semi-Annual Variation in Middle Latitude by Solar Activity, Journal of Astronomy and Space Sciences, 319-327.

Parker, E. N. (1958). Dynamics of the interplanetary gas and magnetic fields. 128, 664, Astrophysics Journal.

Priest, E. (1982). Solar Magneto-hydrodynamics. Reidel Publishing Company, Dordrecht, Holland.

Prölss, G. (2004). Physics of the Earth's Space Environment, An Introduction. Springer-Verlag, Berlin, Heidelberg.

Reinisch, B. W., X. Huang, P. Song, J. L. Green, S. F. Fung, V. M. Vasyliunas, D. L. Gallagher \& B. R. Sandel (2004), Plasmaspheric mass loss and refilling as a result of a magnetic storm, Journal of Geophysical Research, 109, A01202, doi:10.1029/2003JA009948.

Sahai, Y., Becker-Guedes, F., Fagundes, P. R., de Jesus, R., de Abreu, A. J., Paxton, L. J., Goncharenko, L. P., Brunini, C., Gende, M., Ferreira, A. S., Lima, N. S., Guarnieri, F. L., Pillat, V. G., Bittencourt, J. A. \& Candido, C. M. N. (2008). Effects observed in the F-region in two well-separated longitudinal sectors during the intense geomagnetic disturbances in the early part of November 2004. I: Latin American sector, Journal of Geophysical Research, AGU, 113, doi:10.1029/2007JA013007.

Sahai, Y., Becker-Guedes, F., Fagundes, P. R., de Jesus, R., de Abreu, A. J., Paxton, L. J., Goncharenko, L. P., Brunini, C., Gende, M., Ferreira, A. S., Lima, N. S., Guarnieri, F. L., Pillat, V. G., Bittencourt, J. A., Candido, C. M. N. (2009-a). Effects observed in the Latin American sector ionospheric $F$ region during the intense geomagnetic disturbances in the early part of November 2004, Journal of Geophysical Research, 114, A00A19, doi:10.1029/2007JA013007.

Sahai, Y., Becker-Guedes, F., Fagundes, P. R., de Abreu, A. J., de Jesus, R., Pillat, V. G., Abalde, J. R., Martinis, C. R., Brunini, C., Gende, M., Huang, C.S, Pi, X., Lima, W. L. C., Bittencourt, J. A. \& Otsuka, Y. (2009-b). Observations of the Fregion ionospheric irregularities in the South American sector during the October 2003 "Halloween Storms", Annales Geophysicae, 27, 4463-4477.

Sandel, B. R., Goldstein, J., Gallagher, D. L., \& Spasojevic, M. (2003). Extreme ultraviolet imager observations of the structure and dynamics of the plasmasphere, Space Science Reviews, 109, 25-46.

Sardon, E. \& Zarraoa, N. (1997). Estimation of total electron-content using GPS data - Haw stable are the differential satellite and receiver instrumental biases, Radio Science, 32, 1899-1910.

Schaer, S. (1999). Mapping and Predicting the Earth's lonosphere Using the Global Positioning System, PhD Thesis of Bern University, 164 p. 
Scherliess, L, Schunk, R. W., Sojka, J. J., Thompson, D. C. \& Zhu, L. (2006). Utah State University Global Assimilation of Ionospheric Measurements Gauss-Markov Kalman filter model of the ionosphere: Model description and validation. Journal of Geophysical Research, 111, A11315, doi:10.1029/2006JA011712, 2006.

Schunk, R. \& Nagy, A. (2000). Ionosphere: Physics, Physics, and Chemistry, ISBN 0521-63237-4, Cambridge University Press, USA.

Singh, A. K., Singh, R. P. \& Siingh, D. (2011). State Studies of Earth's plasmasphere: A review. Planetary and Space Science 59, 810-834.

Thompson, D. C., Scherliess, L, Sojka, J. J., Schunk, R. W. (2009). Plasmasphere and upper ionosphere contributions and corrections during the assimilation of GPS slant TEC. Article first published online: 29 APR 2009,DOI: $10.1029 / 2008$ RS004016

Wilson, B., Hajj, G., Mandrake, L., Pi, X., Wang, C., Akopian \& Mannucci, A. (2005). Assimilation of remote ionospheric measurements: toward a global ionospheric monitor, Fall AGU, San Francisco, CA.

Wu, J., Wu, S., Hajj, G., Bertiguer, W. and Lichten, S. (1993). Effects of Antenna Orientation on GPS Carrier Phase Measurements. Manuscripta Geodaetica. 18, pp. 91-98.

Yizengaw, E., Moldwin, M. B., Galvan, D., lijima, B. A., Komjathy, A. \& Mannucci, A. J. (2008). Global plasmaspheric TEC and its relative contribution to GPS TEC Journal of Atmospheric and Solar-Terrestrial Physics Elsevier. 
Anexo 1. Estaciones GNSS de monitorio utilizadas

\begin{tabular}{|c|c|c|c|c|c|c|c|}
\hline & Estación & $\begin{array}{l}\text { Latitud } \\
\text { geográfica }\end{array}$ & $\begin{array}{l}\text { Longitud } \\
\text { geográfica }\end{array}$ & & Estación & $\begin{array}{l}\text { Latitud } \\
\text { geográfica }\end{array}$ & $\begin{array}{l}\text { Longitud } \\
\text { geográfica }\end{array}$ \\
\hline 1 & amun & -89.998 & 139.0962 & 38 & chtl & 41.6712 & 290.05 \\
\hline 2 & ankr & 39.8874 & 32.7585 & 39 & chur & 58.7591 & 265.9113 \\
\hline 3 & aqui & 42.3682 & 13.3502 & 40 & chzz & 45.4865 & 236.0219 \\
\hline 4 & arp3 & 27.8383 & 262.941 & 41 & $\mathrm{cncl}$ & -43.6662 & 169.8559 \\
\hline 5 & artu & 56.4298 & 58.5605 & 42 & cnwm & 37.5228 & 267.2965 \\
\hline 6 & aspa & -14.3262 & 189.2779 & 43 & coco & -12.1883 & 96.834 \\
\hline 7 & aus5 & 30.3117 & 262.2437 & 44 & cola & 34.081 & 278.8783 \\
\hline 8 & azcn & 36.8398 & 252.089 & 45 & cord & -31.5284 & 295.53 \\
\hline 9 & bahr & 26.2091 & 50.6081 & 46 & crao & 44.4129 & 33.9906 \\
\hline 10 & bayl & 55.1903 & 197.2929 & 47 & creu & 42.3188 & 3.3156 \\
\hline 11 & bea5 & 30.1617 & 265.8203 & 48 & $\mathrm{crol}$ & 17.7569 & 295.4157 \\
\hline 12 & bill & 45.9712 & 252.0035 & 49 & daej & 36.3994 & 127.3745 \\
\hline 13 & bili & 68.0761 & 166.438 & 50 & darw & -12.8437 & 131.1327 \\
\hline 14 & bis 1 & 56.8545 & 224.4607 & 51 & davl & -68.5773 & 77.9726 \\
\hline 15 & bjfs & 39.6086 & 115.8925 & 52 & drao & 49.3226 & 240.375 \\
\hline 16 & blkv & 37.206 & 279.5855 & 53 & dres & 51.0298 & 13.7297 \\
\hline 17 & blrw & 43.2302 & 269.4692 & 54 & dubo & 50.2588 & 264.1338 \\
\hline 18 & brig & 42.5201 & 276.2434 & 55 & dum 1 & -66.665 & 140.0019 \\
\hline 19 & brmu & 32.3704 & 295.3037 & 56 & dunt & -45.8143 & 170.6294 \\
\hline 20 & brus & 50.7978 & 4.3592 & 57 & dwhl & 47.7741 & 237.9198 \\
\hline 21 & bucu & 44.4639 & 26.1257 & 58 & dyr2 & 37.9157 & 40.2764 \\
\hline 22 & burn & 42.7795 & 242.1565 & 59 & ebre & 40.8209 & 4.92E-01 \\
\hline 23 & cags & 45.585 & 284.1927 & 60 & eisl & -27.1482 & 250.6167 \\
\hline 24 & cant & 43.472 & 356.2019 & 61 & elat & 29.5093 & 34.9207 \\
\hline 25 & cart & 10.3914 & 284.4661 & 62 & elen & 16.9161 & 270.1327 \\
\hline 26 & casl & -66.2834 & 110.5197 & 63 & eliz & 49.8731 & 232.8773 \\
\hline 27 & casa & 37.6446 & 241.1033 & 64 & elko & 40.9147 & 244.1828 \\
\hline 28 & casc & 38.6934 & 350.5815 & 65 & elp3 & 31.6915 & 253.7284 \\
\hline 29 & cast & 39.1912 & 249.3227 & 66 & engl & 29.879 & 270.0583 \\
\hline 30 & ccjm & 27.0956 & 142.1846 & 67 & eprt & 44.9086 & 293.0086 \\
\hline 31 & ccv3 & 28.4602 & 279.4548 & 68 & erla & 39.0232 & 275.3941 \\
\hline 32 & cena & 65.4982 & 215.3224 & 69 & esti & 13.0995 & 273.638 \\
\hline 33 & ceut & 35.896 & 354.6887 & 70 & fair & 64.978 & 212.5008 \\
\hline 34 & cfag & -31.6022 & 291.7674 & 71 & farb & 37.6972 & 236.9992 \\
\hline 35 & cha2 & 32.7575 & 280.1568 & 72 & fbyn & 40.0769 & 262.6872 \\
\hline 36 & chat & -43.9558 & 183.4342 & 73 & flin & 54.7256 & 258.022 \\
\hline 37 & chiz & 46.1335 & 359.5923 & 74 & fort & -3.8774 & 321.5744 \\
\hline
\end{tabular}

I. Bibbó | Anexo 1. Estaciones GNSS de monitorio utilizadas 166 


\begin{tabular}{|c|c|c|c|}
\hline & Estación & $\begin{array}{l}\text { Latitud } \\
\text { geográfica }\end{array}$ & \begin{tabular}{|l|} 
Longitud \\
geográfica
\end{tabular} \\
\hline 75 & fred & 36.9883 & 247.5007 \\
\hline 76 & freo & 40.2016 & 278.7425 \\
\hline 77 & fstl & 35.2218 & 248.1826 \\
\hline 78 & gait & 39.134 & 282.779 \\
\hline 79 & gala & $-7.43 \mathrm{E}-01$ & 269.6964 \\
\hline 80 & geno & 44.4194 & 8.9211 \\
\hline 81 & gilb & 32.4794 & 35.4165 \\
\hline 82 & glsv & 50.3642 & 30.4967 \\
\hline 83 & gnaa & 62.1124 & 214.0298 \\
\hline 84 & goug & -40.3488 & 350.1193 \\
\hline 85 & graz & 47.0671 & 15.4935 \\
\hline 86 & guam & 13.5893 & 144.8684 \\
\hline 87 & guat & 14.5904 & 269.4802 \\
\hline 88 & gus2 & 58.4178 & 224.303 \\
\hline 89 & helg & 54.1746 & 7.893 \\
\hline 90 & hers & 50.8673 & $3.36 \mathrm{E}-01$ \\
\hline 91 & hilo & 19.7192 & 204.9473 \\
\hline 92 & hklo & 35.6827 & 264.1366 \\
\hline 93 & hlid & 43.5626 & 245.5856 \\
\hline 94 & hnlc & 21.3033 & 202.1355 \\
\hline 95 & hob2 & -42.8047 & 147.4388 \\
\hline 96 & hofn & 64.2673 & 344.8021 \\
\hline 97 & holm & 70.7363 & 242.2388 \\
\hline 98 & hous & 29.7794 & 264.567 \\
\hline 99 & hrm l & 51.4537 & 358.7161 \\
\hline 100 & hrn2 & 40.8779 & 281.8188 \\
\hline 101 & htvl & 36.3577 & 273.9105 \\
\hline 102 & ineg & 21.8562 & 257.7158 \\
\hline 103 & invk & 68.3062 & 226.473 \\
\hline 104 & irkt & 52.219 & 104.3162 \\
\hline 105 & ivco & 32.8294 & 244.4932 \\
\hline 106 & jama & 17.9389 & 283.2197 \\
\hline 107 & joen & 62.3911 & 30.0962 \\
\hline 108 & joze & 52.0972 & 21.0315 \\
\hline 109 & karl & 49.0112 & 8.4113 \\
\hline 110 & kayt & 13.987 & 120.9784 \\
\hline 111 & kaza & 41.3833 & 73.9416 \\
\hline 112 & kely & 66.9874 & 309.0552 \\
\hline 113 & kerg & -49.3522 & 70.2597 \\
\hline
\end{tabular}

\begin{tabular}{|r|l|r|r|}
\hline & Estación & $\begin{array}{r}\text { Latitud } \\
\text { geográfica }\end{array}$ & $\begin{array}{l}\text { Longitud } \\
\text { geográfica }\end{array}$ \\
\hline 114 & kgni & 35.7103 & 139.4881 \\
\hline 115 & kir0 & 67.8776 & 21.0602 \\
\hline 116 & kiru & 67.8573 & 20.9684 \\
\hline 117 & kit3 & 39.1348 & 66.8854 \\
\hline 118 & kosg & 52.1784 & 5.8096 \\
\hline 119 & kouc & -20.5587 & 164.2873 \\
\hline 120 & kulu & 65.5793 & 322.8506 \\
\hline 121 & kunm & 25.029 & 102.797 \\
\hline 122 & kwj1 & 8.7222 & 167.7302 \\
\hline 123 & kyw2 & 24.5823 & 278.3472 \\
\hline 124 & lael & -6.6737 & 146.9931 \\
\hline 125 & lago & 37.0989 & 351.3316 \\
\hline 126 & lama & 53.8924 & 20.67 \\
\hline 127 & lamp & 35.4998 & 12.6057 \\
\hline 128 & laut & -17.6088 & 177.4466 \\
\hline 129 & lev1 & 56.4657 & 226.9072 \\
\hline 130 & lhas & 29.6574 & 91.1041 \\
\hline 131 & lhue & 21.9846 & 200.6608 \\
\hline 132 & lliv & 42.4781 & 1.973 \\
\hline 133 & lpgs & -34.9068 & 302.0671 \\
\hline 134 & lubb & 33.5354 & 258.1572 \\
\hline 135 & mac1 & -54.4995 & 158.9359 \\
\hline 136 & mag0 & 59.5758 & 150.77 \\
\hline 137 & mali & -2.9959 & 40.1944 \\
\hline 138 & manz & 19.0639 & 255.7019 \\
\hline 139 & mar6 & 60.5951 & 17.2585 \\
\hline 140 & mas1 & 27.7637 & 344.3667 \\
\hline 141 & mate & 40.6491 & 16.7045 \\
\hline 142 & maui & 20.7066 & 203.743 \\
\hline 143 & maw1 & -67.6048 & 62.8706 \\
\hline 144 & mawy & 44.9734 & 249.3108 \\
\hline 145 & mbww & 41.9036 & 253.8135 \\
\hline 146 & mcd1 & 27.8498 & 277.4677 \\
\hline 147 & mcn1 & 32.6953 & 276.4395 \\
\hline 148 & mcty & 36.1191 & 270.2978 \\
\hline 149 & mdol & 30.6805 & 255.985 \\
\hline 150 & medi & 44.52 & 11.6468 \\
\hline 151 & mem2 & 35.4657 & 269.794 \\
\hline 152 & mers & 36.5664 & 34.2559 \\
\hline & & & \\
\hline
\end{tabular}




\begin{tabular}{|r|l|r|r|}
\hline & Estación & $\begin{array}{r}\text { Latitud } \\
\text { geográfica }\end{array}$ & $\begin{array}{l}\text { Longitud } \\
\text { geográfica }\end{array}$ \\
\hline 153 & mets & 60.2175 & 24.3953 \\
\hline 154 & mia3 & 25.7328 & 279.8398 \\
\hline 155 & mida & 35.9219 & 239.5412 \\
\hline 156 & mlf1 & 32.0903 & 272.6082 \\
\hline 157 & morl & 40.7895 & 287.2537 \\
\hline 158 & mazg & -43.7027 & 172.6547 \\
\hline 159 & mrrn & 42.9043 & 258.3036 \\
\hline 160 & msku & -1.6312 & 13.552 \\
\hline 161 & naiu & 41.0157 & 247.7704 \\
\hline 162 & nds1 & 37.3015 & 264.3985 \\
\hline 163 & newp & 44.5851 & 235.9381 \\
\hline 164 & nico & 35.1411 & 33.3901 \\
\hline 165 & nklg & 0.3540 & 9.6721 \\
\hline 166 & nlgn & 42.2067 & 262.2047 \\
\hline 167 & nlib & 41.7716 & 268.4251 \\
\hline 168 & nomt & 45.597 & 248.3701 \\
\hline 169 & nor3 & 45.0686 & 276.4314 \\
\hline 170 & not1 & 36.8759 & 14.9898 \\
\hline 171 & noum & -22.2699 & 166.4102 \\
\hline 172 & nril & 69.3618 & 88.3598 \\
\hline 173 & ntus & 1.3458 & 103.68 \\
\hline 174 & nvsk & 54.8406 & 83.2354 \\
\hline 175 & nyal & 78.9295 & 11.8656 \\
\hline 176 & obe2 & 48.0861 & 11.2799 \\
\hline 177 & okom & 34.0903 & 271.1375 \\
\hline 178 & omh1 & 41.7783 & 264.0887 \\
\hline 179 & onsa & 57.3953 & 11.9255 \\
\hline 180 & oprd & 34.533 & 243.7077 \\
\hline 181 & orid & 41.1251 & 20.794 \\
\hline 182 & orvb & 39.5546 & 238.4997 \\
\hline 183 & pala & 7.3282 & 134.4502 \\
\hline 184 & palm & -64.7751 & 295.9489 \\
\hline 185 & para & -25.4484 & 310.7691 \\
\hline 186 & parc & -53.137 & 289.1201 \\
\hline 187 & patk & 47.208 & 11.4602 \\
\hline 188 & pdel & 37.7477 & 334.3372 \\
\hline 189 & penc & 47.7896 & 19.2815 \\
\hline 191 & petp & 53.0667 & 158.6071 \\
\hline & & & 115.8852 \\
\hline
\end{tabular}

\begin{tabular}{|c|c|c|c|}
\hline & Estación & \begin{tabular}{|l|} 
Latitud \\
geográfica
\end{tabular} & \begin{tabular}{|l|} 
Longitud \\
geográfica
\end{tabular} \\
\hline 192 & phlw & 29.8615 & 31.3434 \\
\hline 193 & piel & 34.3015 & 251.8811 \\
\hline 194 & pls 1 & 47.6638 & 245.8861 \\
\hline 195 & pltc & 40.1816 & 255.2741 \\
\hline 196 & podg & 43.3276 & 79.4847 \\
\hline 197 & polv & 49.6026 & 34.5429 \\
\hline 198 & prds & 50.8713 & 245.7065 \\
\hline 199 & prel & -25.7463 & 28.224 \\
\hline 200 & pscl & 44.4345 & 285.7504 \\
\hline 201 & ptbb & 52.2963 & 10.4596 \\
\hline 202 & publ & 38.2869 & 255.6545 \\
\hline 203 & pur3 & 18.463 & 292.933 \\
\hline 204 & rabt & 33.998 & 353.145 \\
\hline 205 & ralr & 35.7869 & 281.3613 \\
\hline 206 & redm & 44.2598 & 238.8521 \\
\hline 207 & reso & 74.6908 & 265.1063 \\
\hline 208 & reyk & 64.1389 & 338.0445 \\
\hline 209 & riga & 56.9486 & 24.0588 \\
\hline 210 & riog & -53.7855 & 292.2489 \\
\hline 211 & rwdn & 40.0867 & 259.3465 \\
\hline 212 & rwsn & 43.2989 & 294.8928 \\
\hline 213 & samp & 3.6216 & 98.7147 \\
\hline 214 & sant & -33.1503 & 289.3314 \\
\hline 215 & sc01 & 34.07 & 253.03 \\
\hline 216 & sc02 & 48.5462 & 236.9923 \\
\hline 217 & sch2 & 54.8321 & 293.1674 \\
\hline 218 & seld & 59.446 & 208.2933 \\
\hline 219 & sele & 43.1785 & 77.0167 \\
\hline 220 & seyl & -4.6737 & 55.4794 \\
\hline 221 & $\operatorname{sg} 13$ & 38.114 & 262.487 \\
\hline 222 & sg 19 & 35.354 & 261.023 \\
\hline 223 & shao & 31.0996 & 121.2004 \\
\hline 224 & simo & -34.1879 & 18.4395 \\
\hline 225 & sio3 & 32.8647 & 242.7496 \\
\hline 226 & sjdv & 45.8791 & 4.6766 \\
\hline 227 & skul & 36.7305 & 243.7896 \\
\hline 228 & slid & 39.3143 & 240.1157 \\
\hline 229 & slor & 13.4239 & 272.5635 \\
\hline 230 & soda & 67.4209 & 26.389 \\
\hline
\end{tabular}




\begin{tabular}{|r|l|r|r|}
\hline & Estación & $\begin{array}{l}\text { Latitud } \\
\text { geográfica }\end{array}$ & $\begin{array}{l}\text { Longitud } \\
\text { geográfica }\end{array}$ \\
\hline 231 & sodb & 37.1664 & 238.0745 \\
\hline 232 & sofi & 42.5561 & 23.3947 \\
\hline 233 & soll & 38.3189 & 283.5461 \\
\hline 234 & sowr & 42.2259 & 274.4664 \\
\hline 235 & spnl & 47.5183 & 242.5763 \\
\hline 236 & spt0 & 57.715 & 12.8913 \\
\hline 237 & stas & 59.0177 & 5.5986 \\
\hline 238 & stbl & 44.7955 & 272.6857 \\
\hline 239 & stjo & 47.5952 & 307.3222 \\
\hline 240 & stpo & 48.2031 & 15.6329 \\
\hline 241 & sulp & 49.8356 & 24.0145 \\
\hline 242 & sum1 & 34.8251 & 257.4882 \\
\hline 243 & sumk & 44.2083 & 73.9966 \\
\hline 244 & sup2 & 45.7495 & 272.9265 \\
\hline 245 & sup3 & 46.3027 & 274.4872 \\
\hline 246 & suth & -32.3802 & 20.8105 \\
\hline 247 & sycn & 43.1157 & 283.9066 \\
\hline 248 & syog & -69.0069 & 39.5837 \\
\hline 249 & tah1 & -17.577 & 210.3938 \\
\hline 250 & takl & -36.8436 & 174.7699 \\
\hline 251 & thul & 76.5373 & 291.212 \\
\hline 252 & tid1 & -35.3992 & 148.98 \\
\hline 253 & tlka & 62.3077 & 209.5797 \\
\hline 254 & tors & 62.0232 & 353.2354 \\
\hline 255 & tow2 & -19.2693 & 147.0557 \\
\hline 256 & trds & 63.3714 & 10.3192 \\
\hline 257 & trnd & 41.0539 & 235.8491 \\
\hline 258 & trol & 69.6627 & 18.9396 \\
\hline 259 & tsea & 61.1873 & 210.105 \\
\hline 260 & tskb & 36.1062 & 140.0873 \\
\hline 261 & tubi & 40.7867 & 29.4507 \\
\hline 262 & tucu & -26.8433 & 294.7696 \\
\hline 263 & tuva & -8.5253 & 179.1965 \\
\hline 264 & udmc & 33.5145 & 36.2851 \\
\hline & & & \\
\hline
\end{tabular}

\begin{tabular}{|r|l|r|r|}
\hline & Estación & $\begin{array}{l}\text { Latitud } \\
\text { geográfica }\end{array}$ & $\begin{array}{l}\text { Longitud } \\
\text { geográfica }\end{array}$ \\
\hline 265 & vepp & -22.1199 & 308.5915 \\
\hline 266 & urum & 43.8079 & 87.6007 \\
\hline 267 & uzhl & 48.632 & 22.2976 \\
\hline 268 & vaas & 62.9611 & 21.7706 \\
\hline 269 & vale & 39.4808 & 359.6623 \\
\hline 270 & vars & 70.3364 & 31.0312 \\
\hline 271 & vbca & -38.7008 & 297.7308 \\
\hline 272 & vcio & 36.0717 & 260.7827 \\
\hline 273 & vene & 45.437 & 12.332 \\
\hline 274 & vil0 & 64.6978 & 16.5599 \\
\hline 275 & vill & 40.4436 & 356.048 \\
\hline 276 & vis0 & 57.6539 & 18.3673 \\
\hline 277 & wasr & 35.5597 & 282.9412 \\
\hline 278 & wdlm & 44.6722 & 264.5514 \\
\hline 279 & wes2 & 42.6133 & 288.5067 \\
\hline 280 & wgtn & -41.3235 & 174.8059 \\
\hline 281 & whdl & 48.3127 & 237.3039 \\
\hline 282 & whit & 60.7505 & 224.7779 \\
\hline 283 & whn1 & 42.7393 & 256.6712 \\
\hline 284 & will & 52.2369 & 237.8322 \\
\hline 285 & winn & 49.9006 & 262.7405 \\
\hline 286 & wis1 & 46.705 & 267.9848 \\
\hline 287 & wlci & 40.8084 & 272.948 \\
\hline 288 & wnfl & 31.8972 & 267.2181 \\
\hline 289 & wroc & 51.1133 & 17.062 \\
\hline 290 & wsrt & 52.9146 & 6.6045 \\
\hline 291 & wtzr & 49.1442 & 12.8789 \\
\hline 292 & yakt & 62.031 & 129.6803 \\
\hline 293 & yarl & -29.0466 & 115.347 \\
\hline 294 & yell & 62.4809 & 245.5193 \\
\hline 295 & youl & 43.2312 & 281.0298 \\
\hline 296 & zeck & 43.7884 & 41.5651 \\
\hline 297 & zimm & 46.8771 & 7.4653 \\
\hline 298 & zwen & 55.6993 & 36.7587 \\
\hline
\end{tabular}




\section{Anexo 2. DCBs de los satélites GNSS}

DCBs de satélites GNSS calculados con LPIMG en el período [1-100] días del año 2002 (en ns).

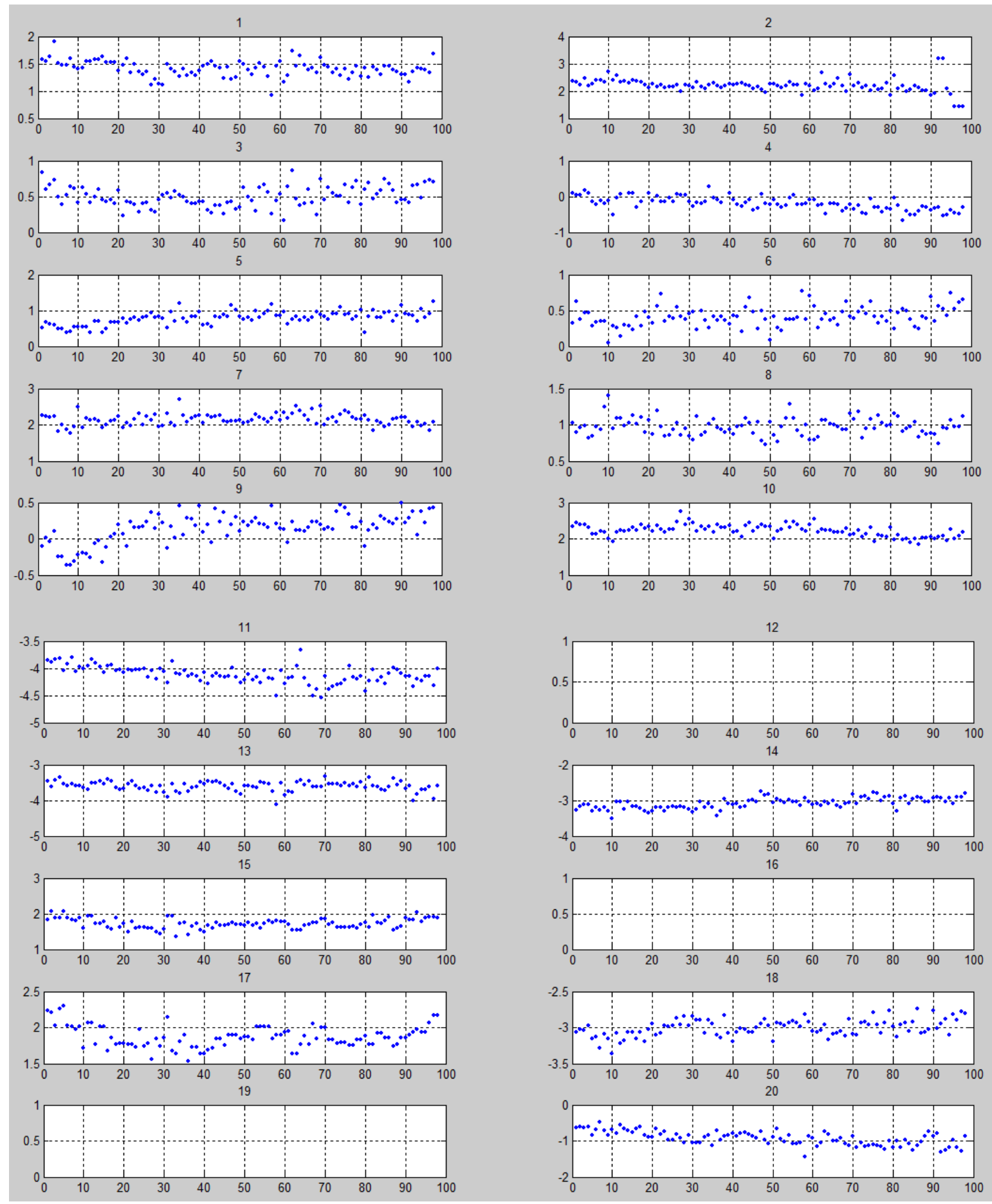


DCBs de satélites GNSS calculados con LPIMG

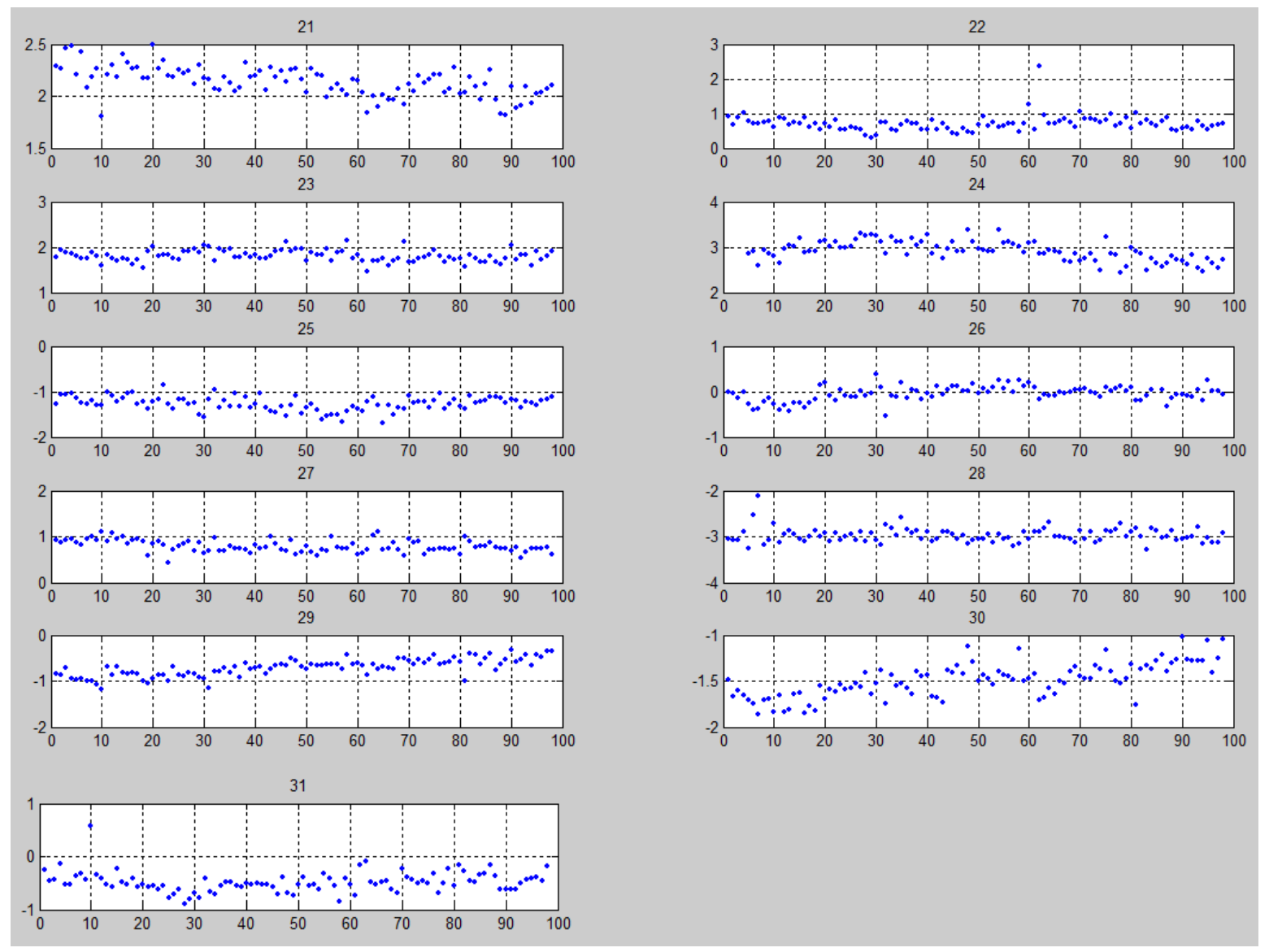




\section{Anexo 3. DCBs de receptores GNSS utilizados en el Capítulo 3}

DCBs de receptores GNSS calculados con LPIMG en el período [1-100] días del año 2002 (en ns). Se utilizaron datos de 298 estaciones.

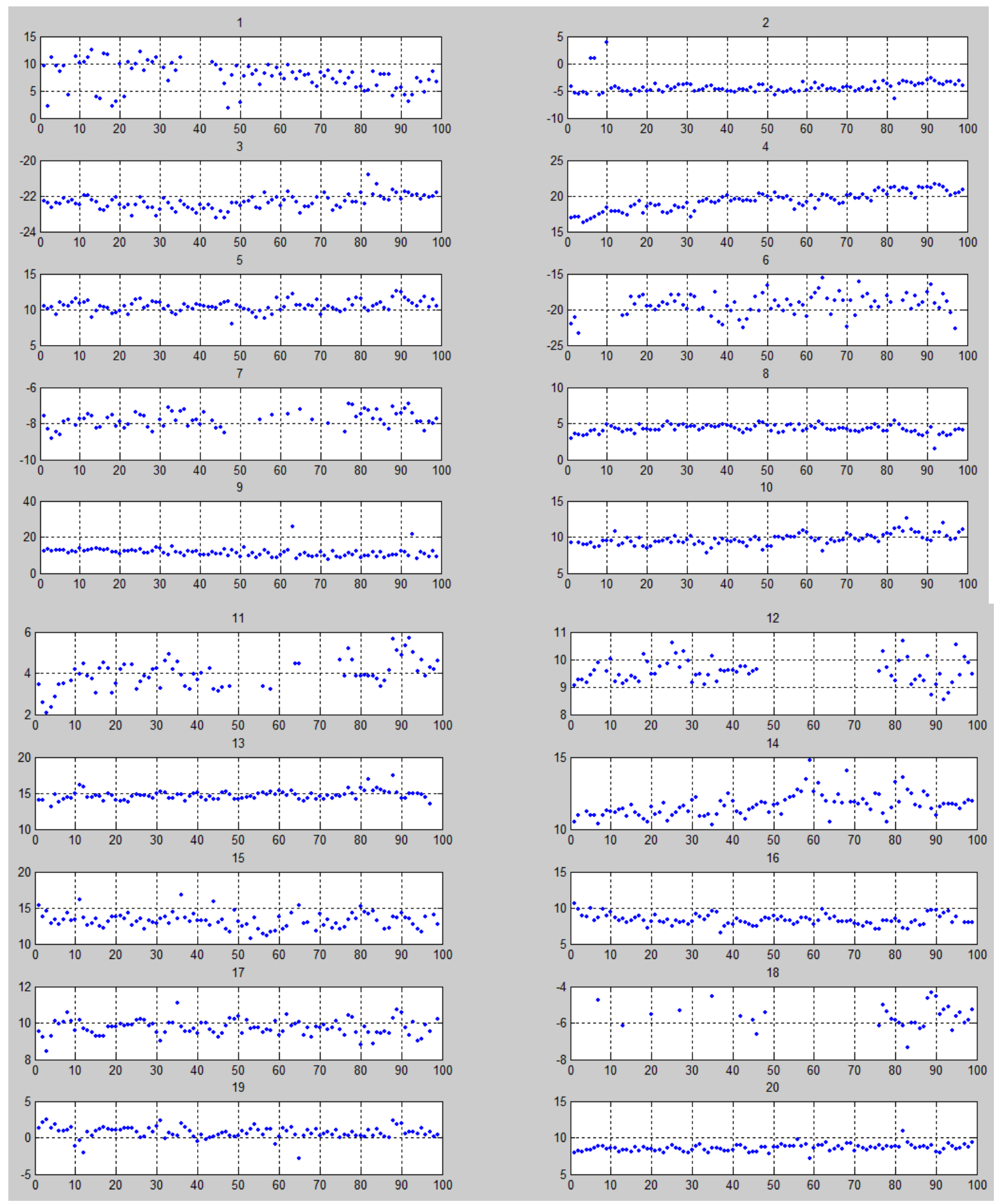


DCBs de receptores GNSS calculados con LPIMG

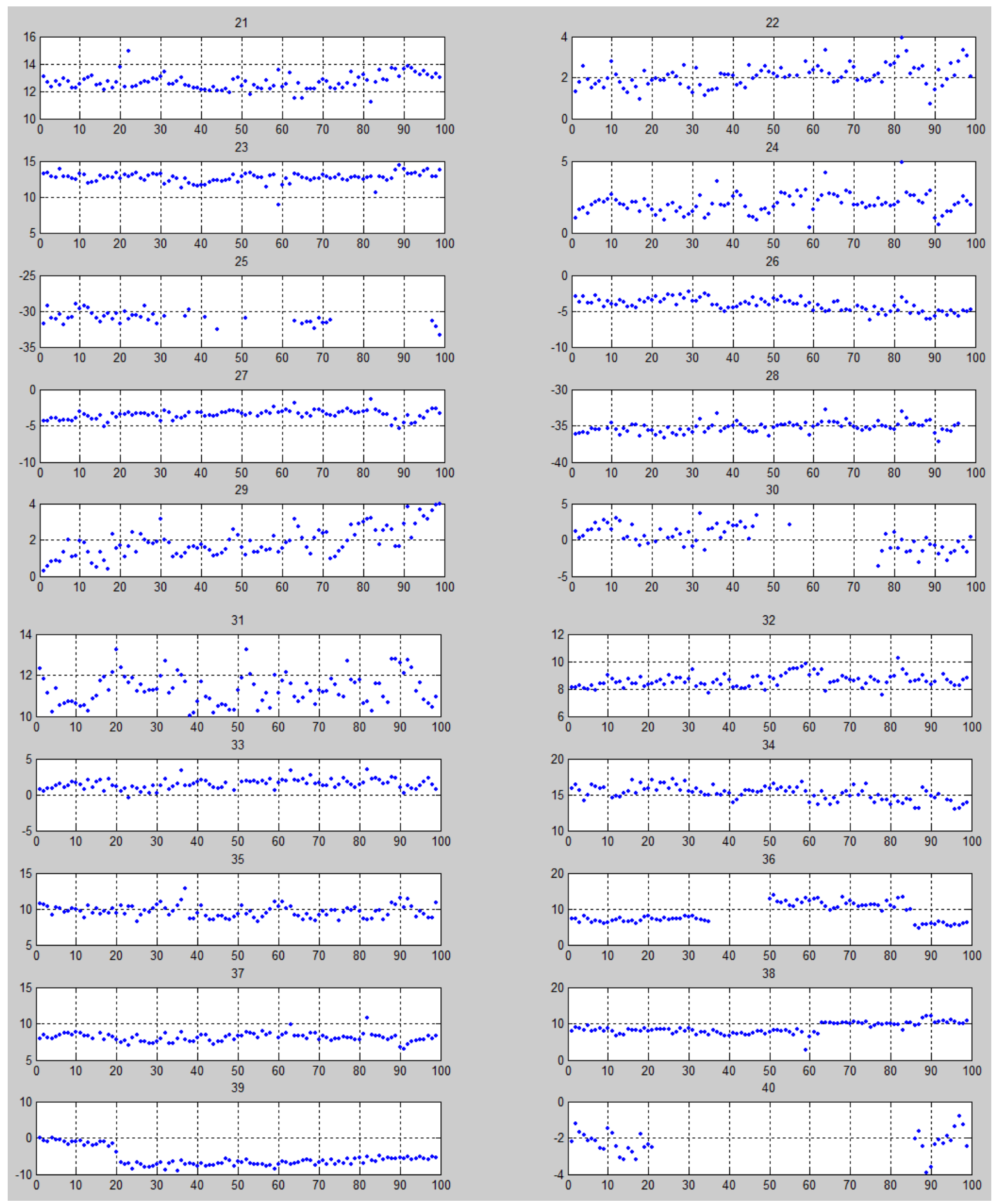


DCBs de receptores GNSS calculados con LPIMG
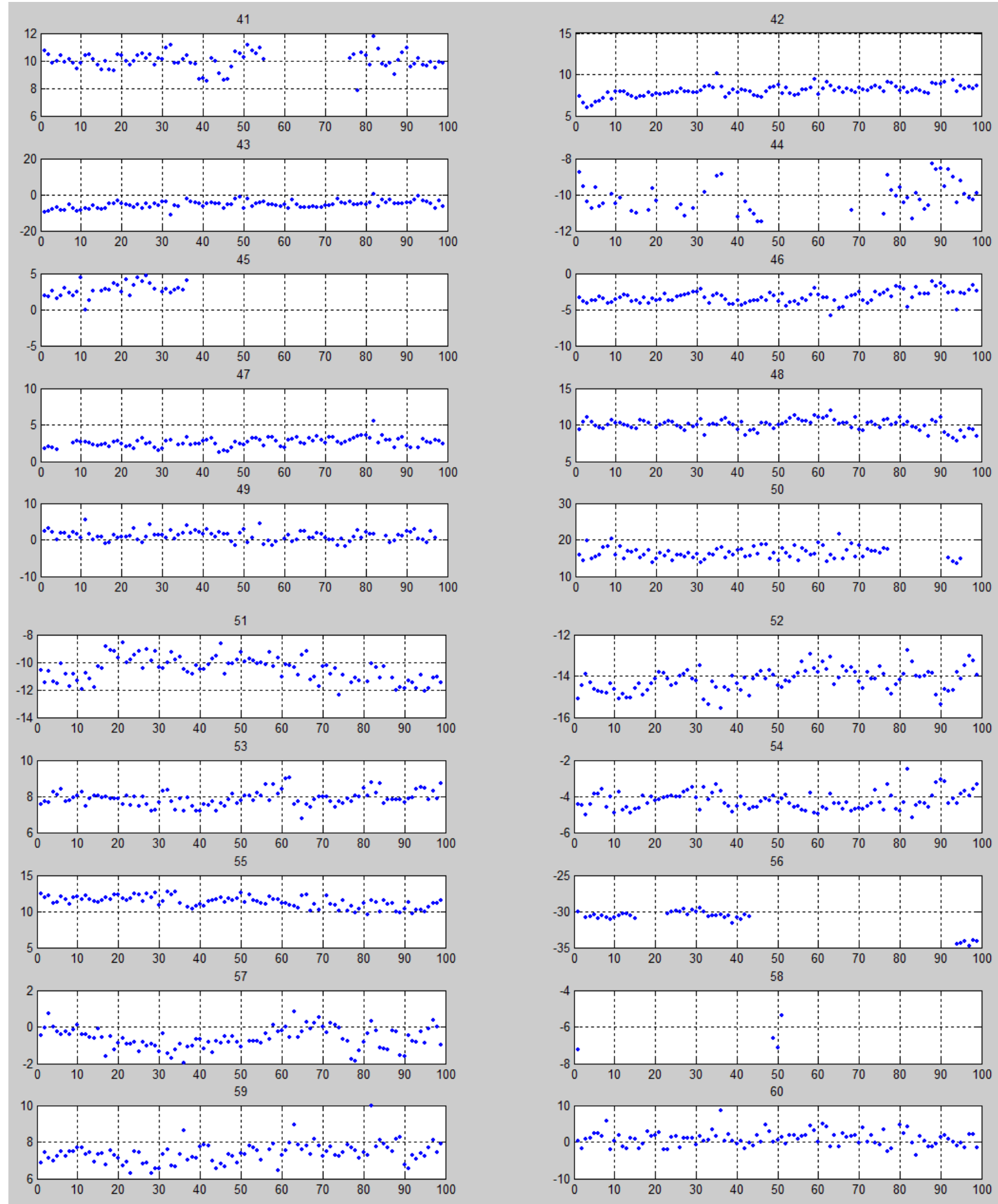
DCBs de receptores GNSS calculados con LPIMG
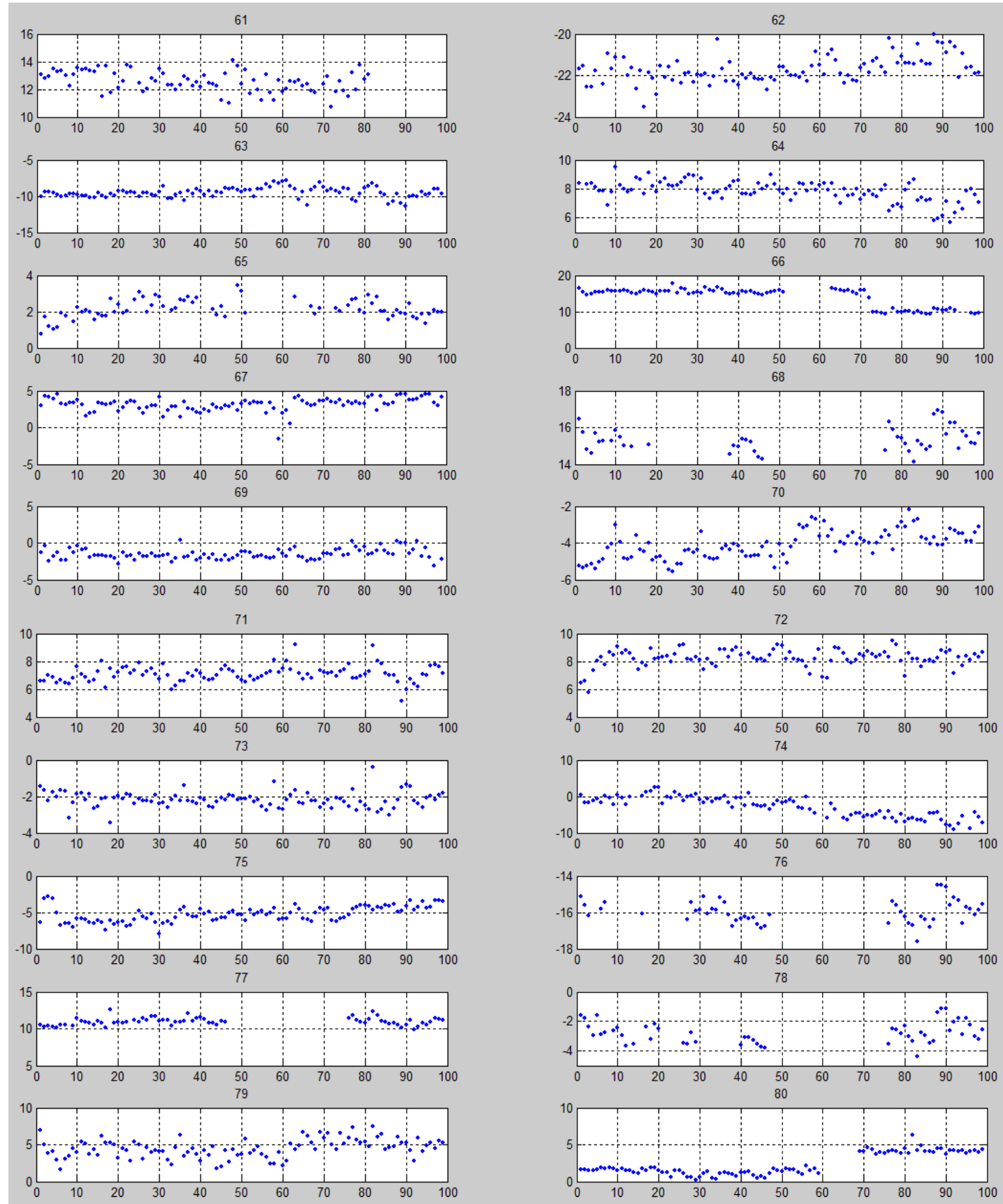

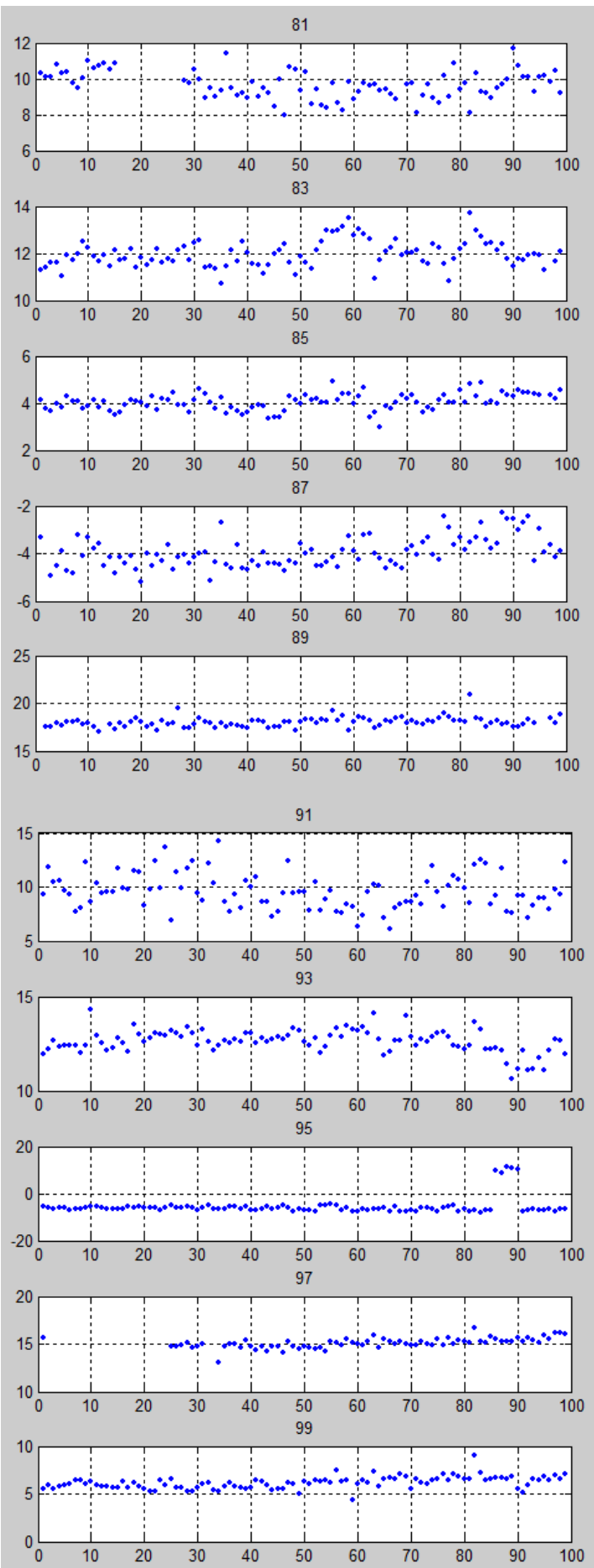
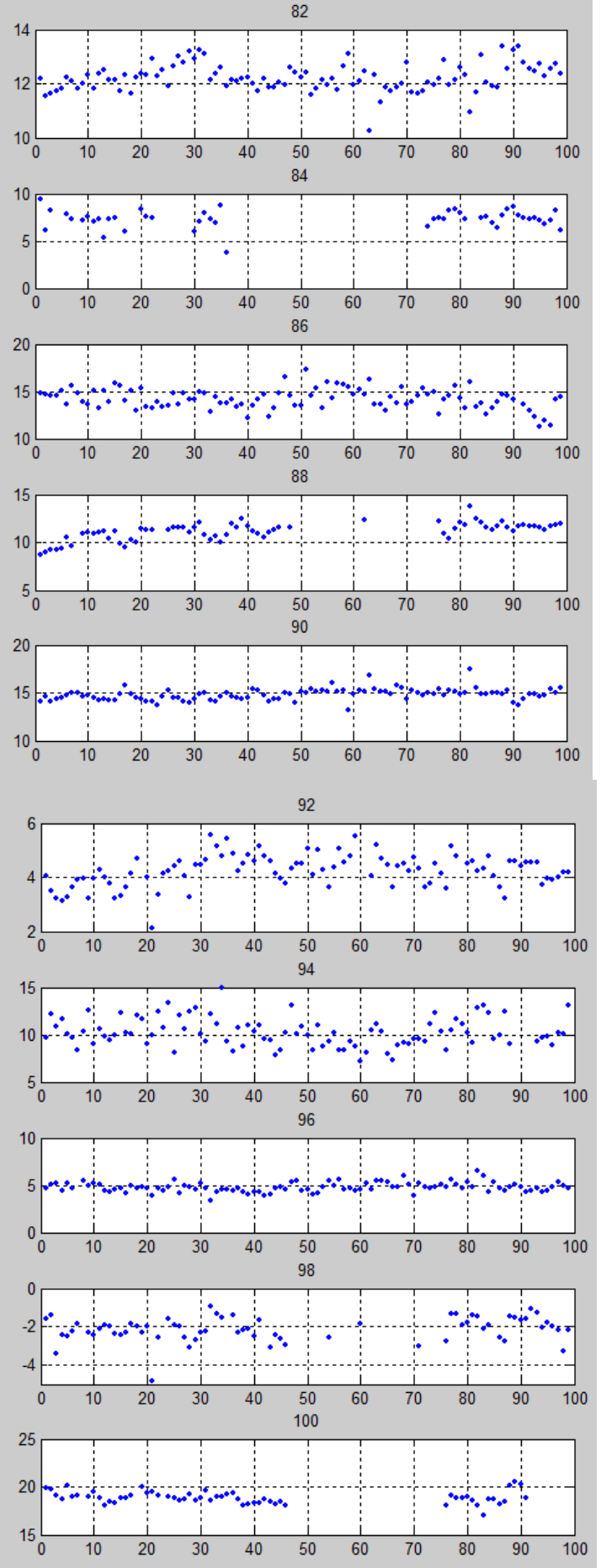


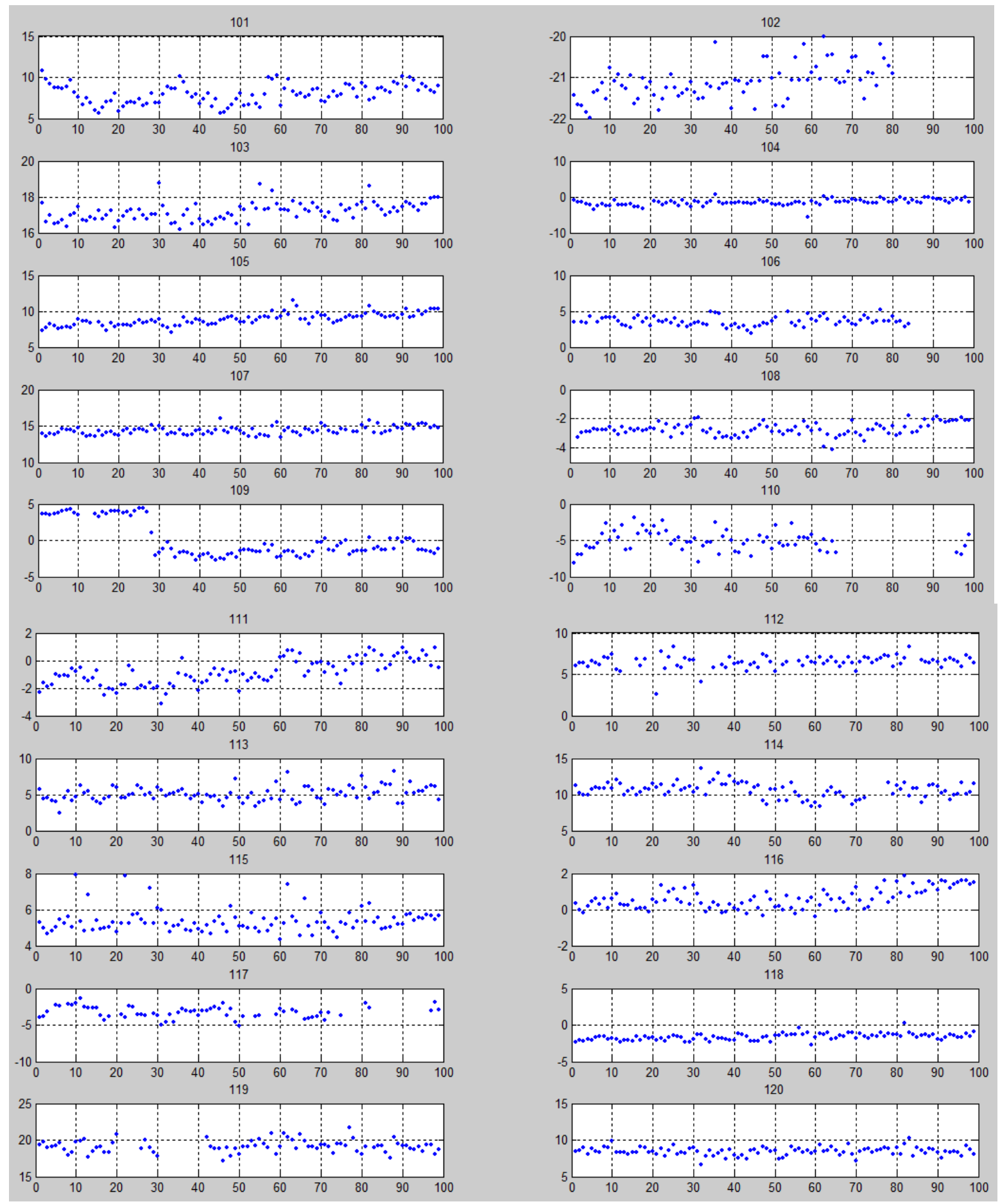


DCBs de receptores GNSS calculados con LPIMG

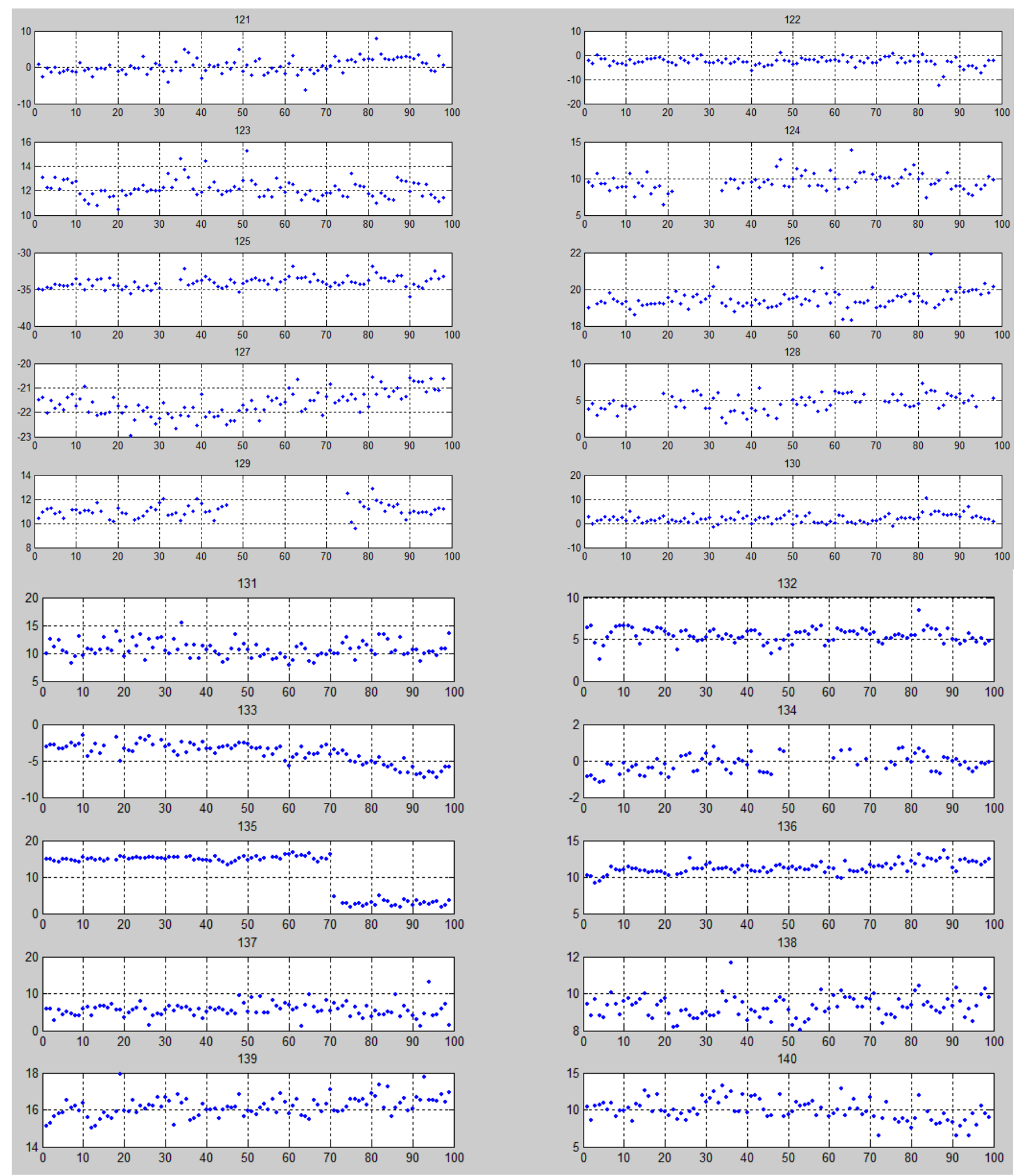


DCBs de receptores GNSS calculados con LPIMG

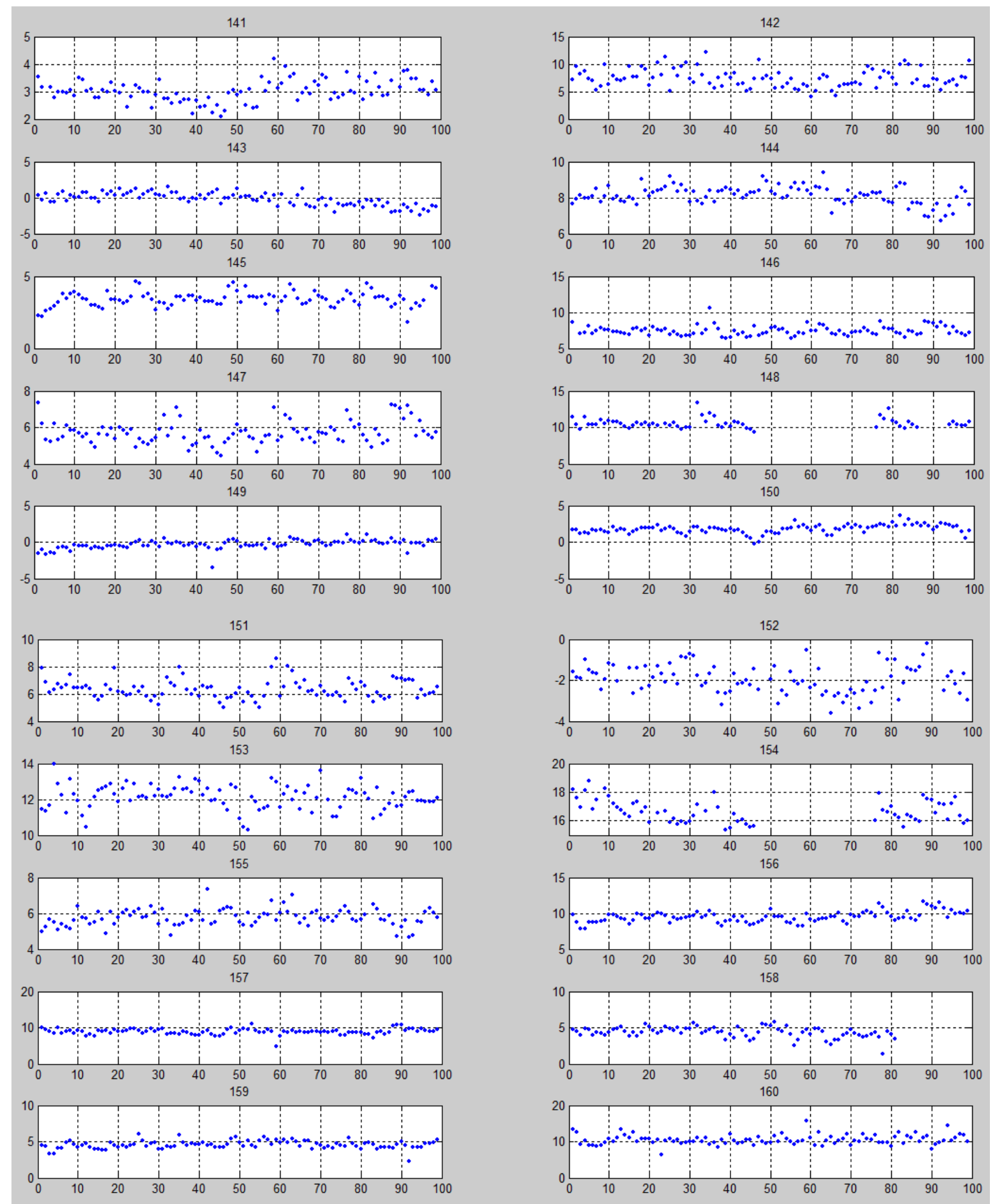


DCBs de receptores GNSS calculados con LPIMG
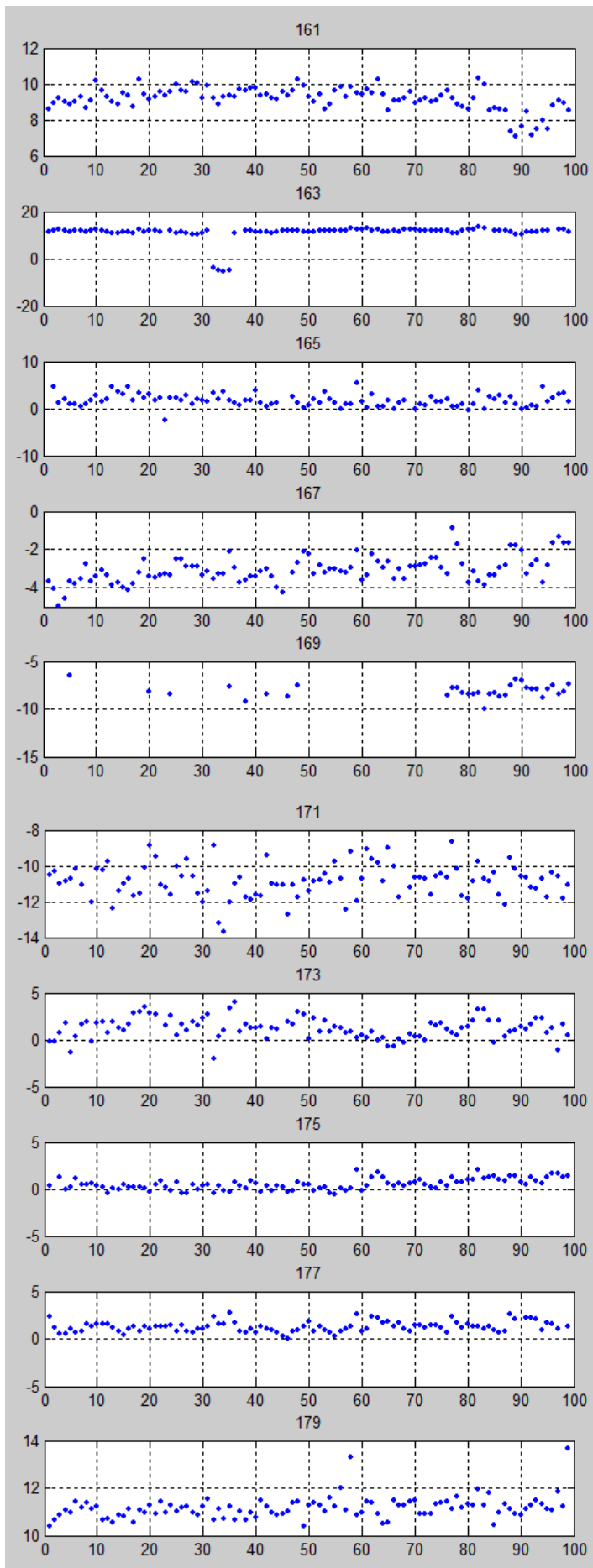
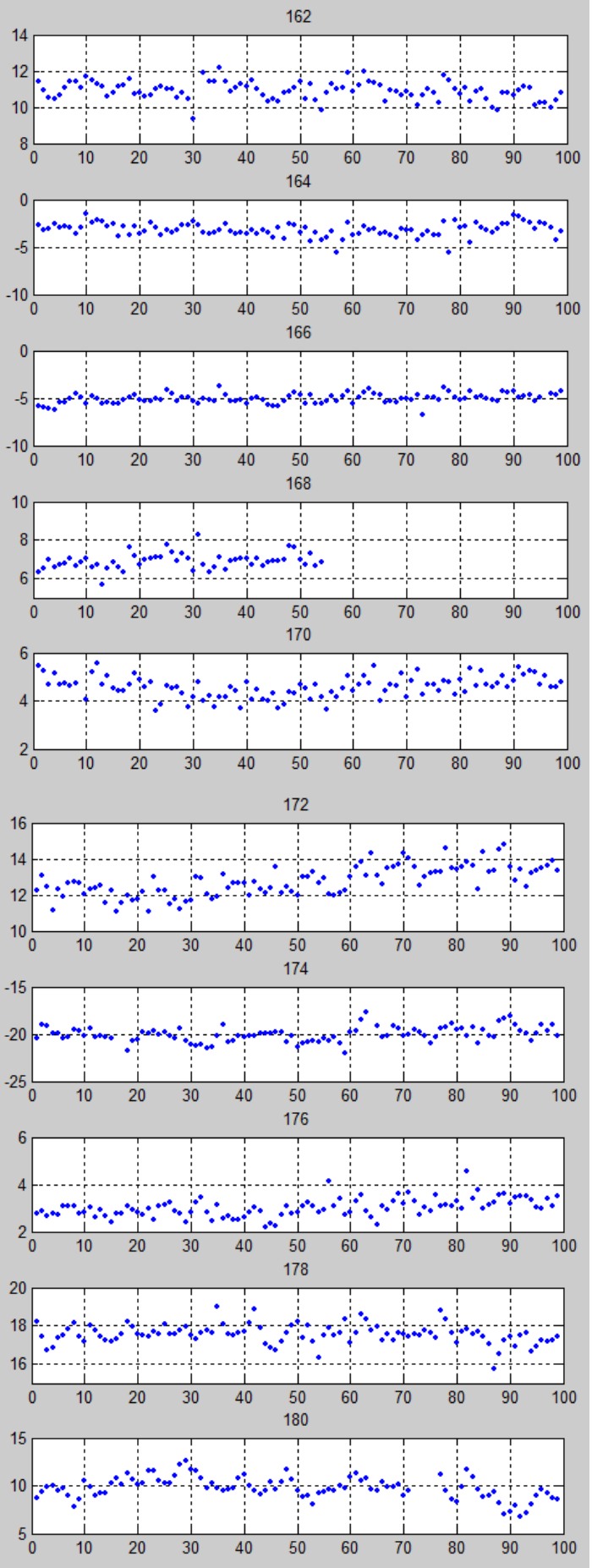
DCBs de receptores GNSS calculados con LPIMG

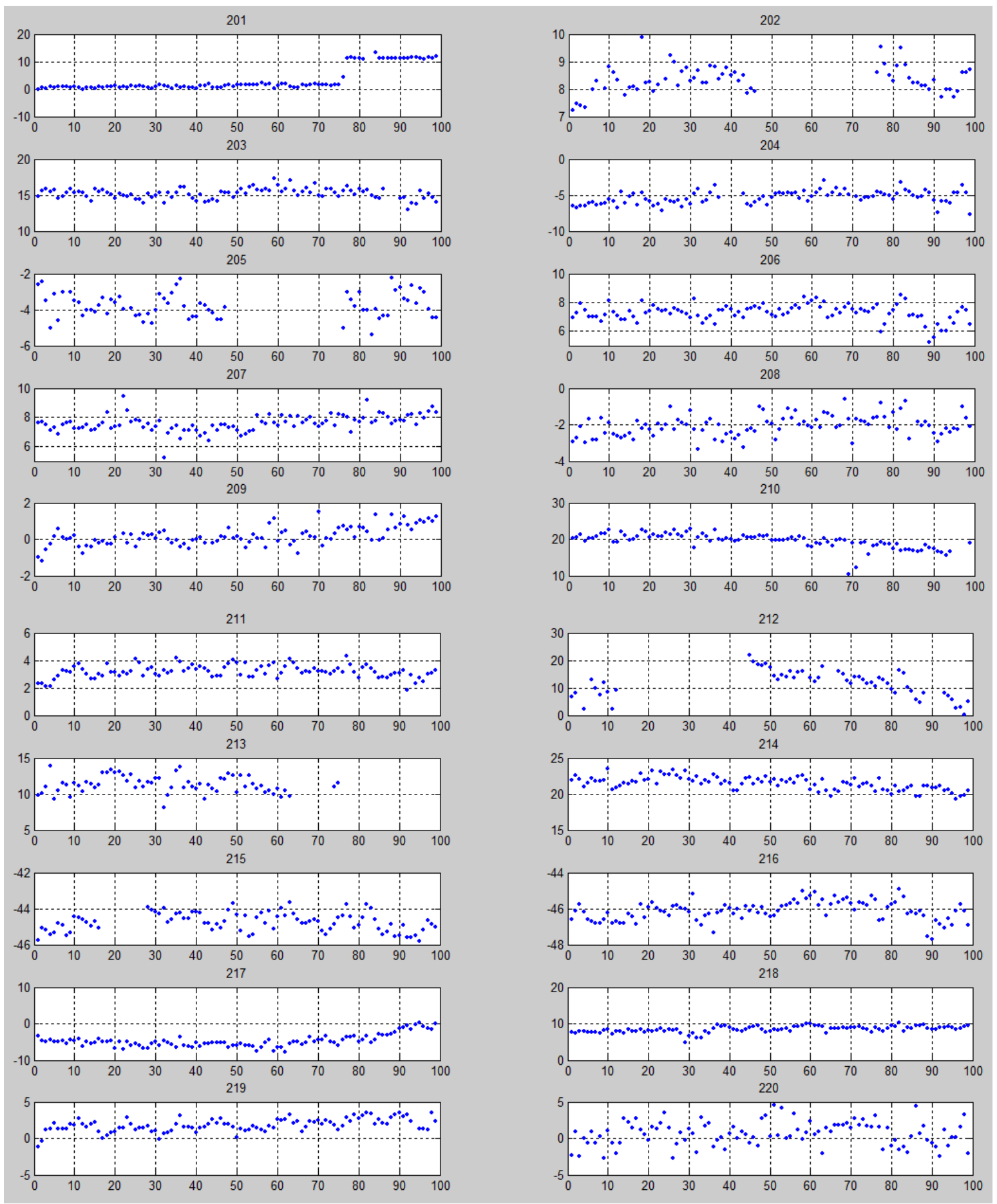


DCBs de receptores GNSS calculados con LPIMG

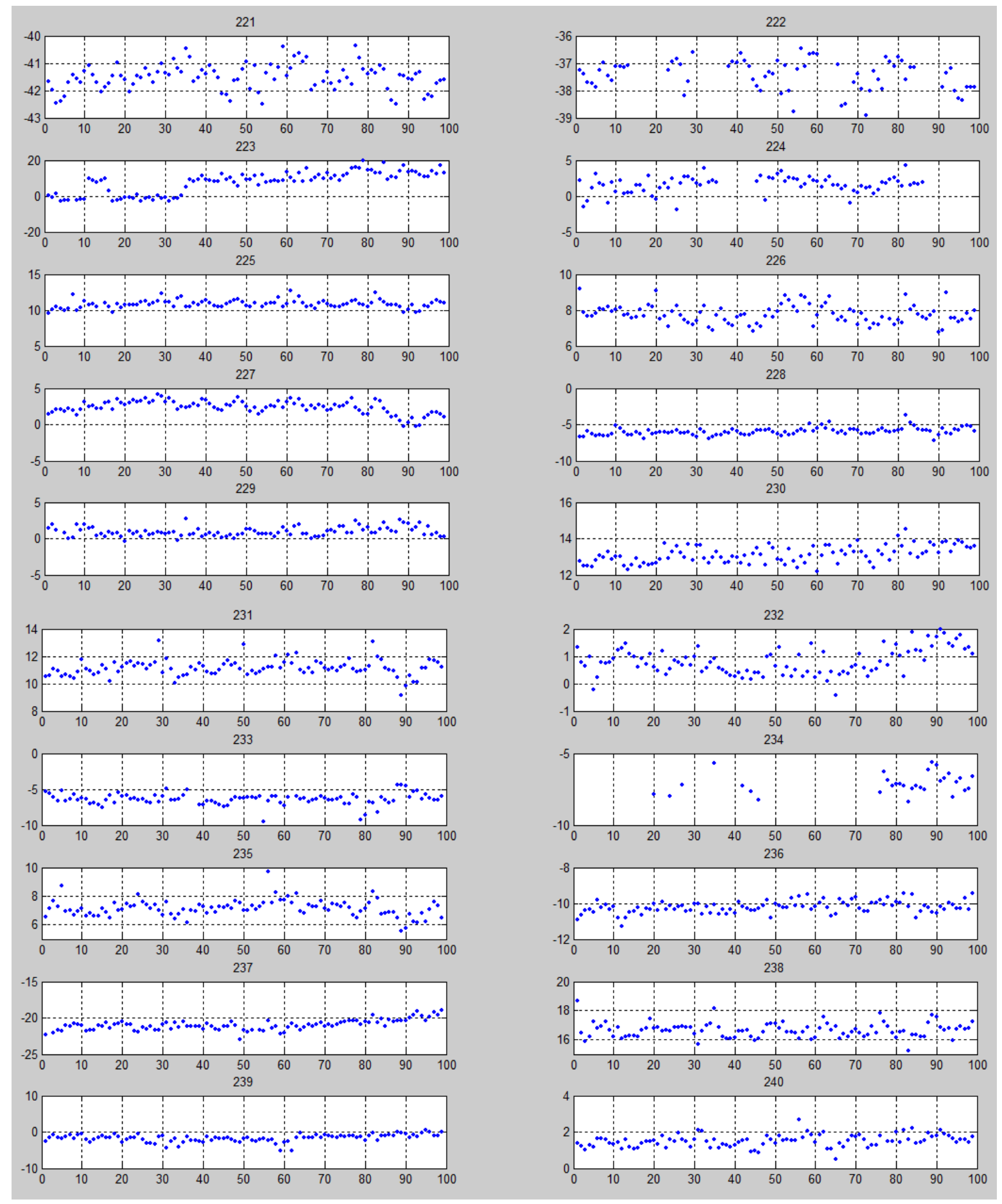



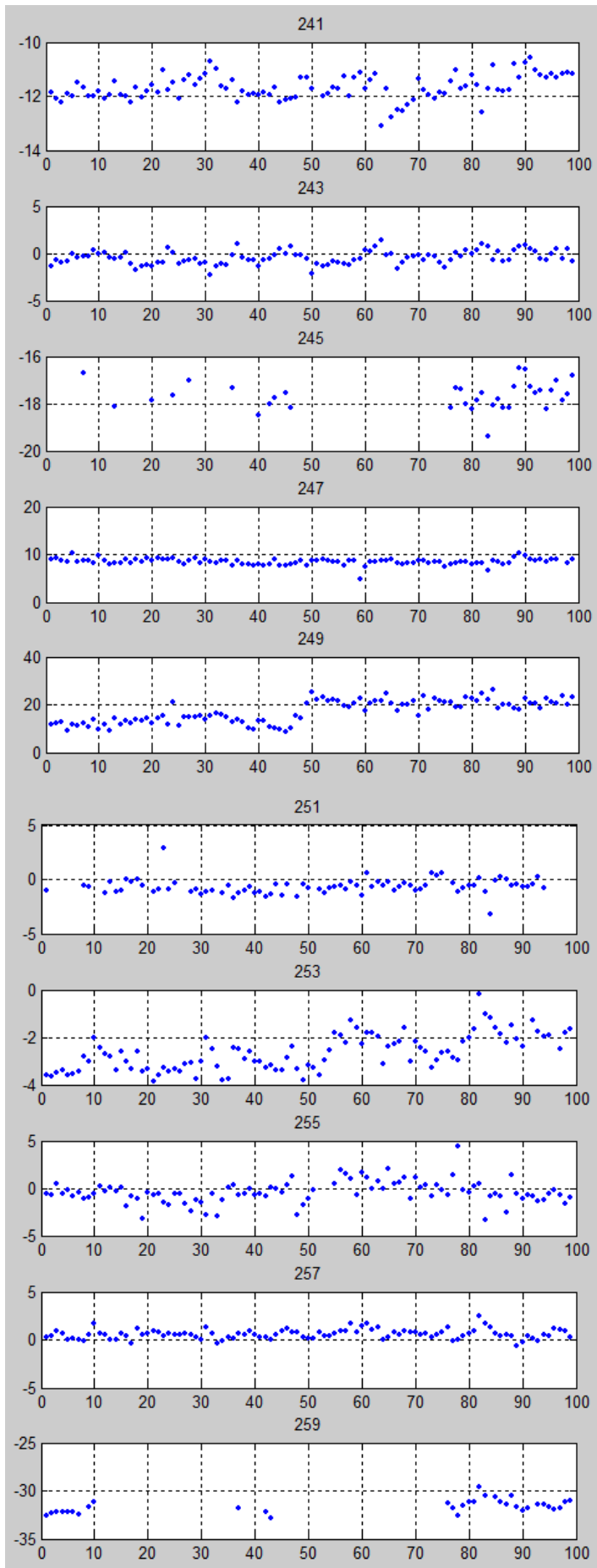
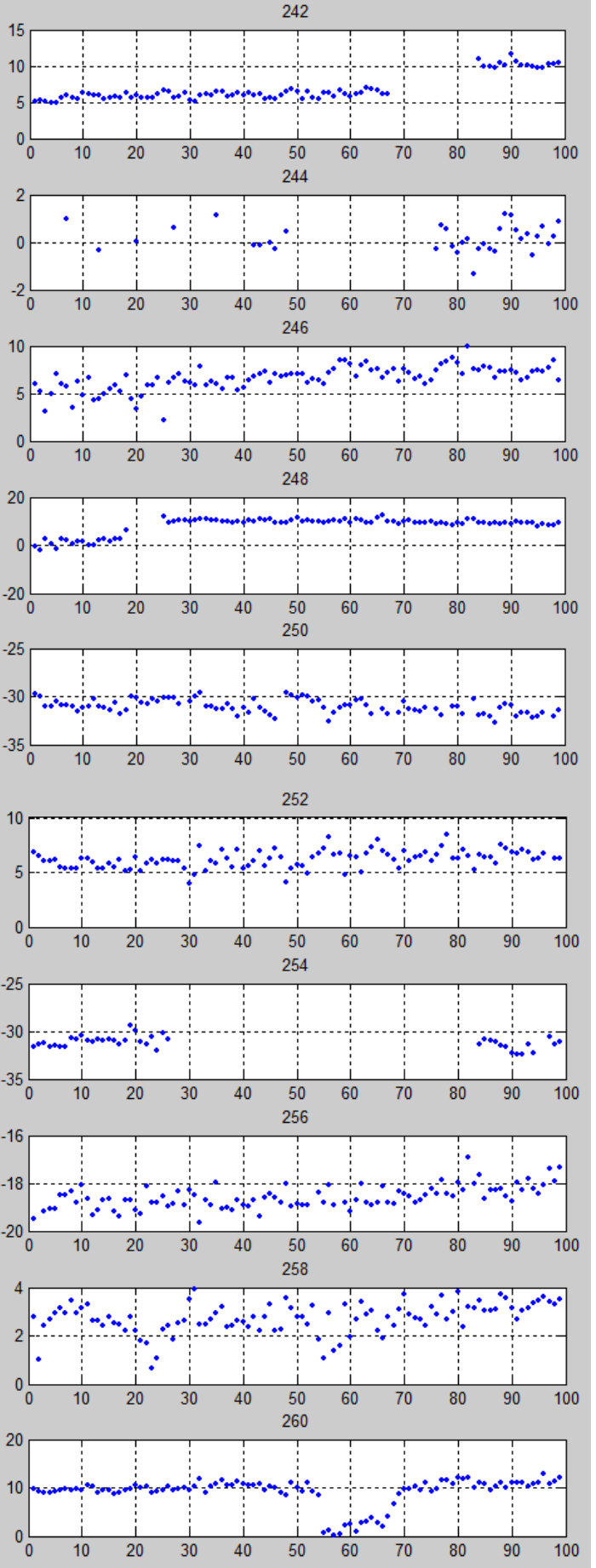
DCBs de receptores GNSS calculados con LPIMG

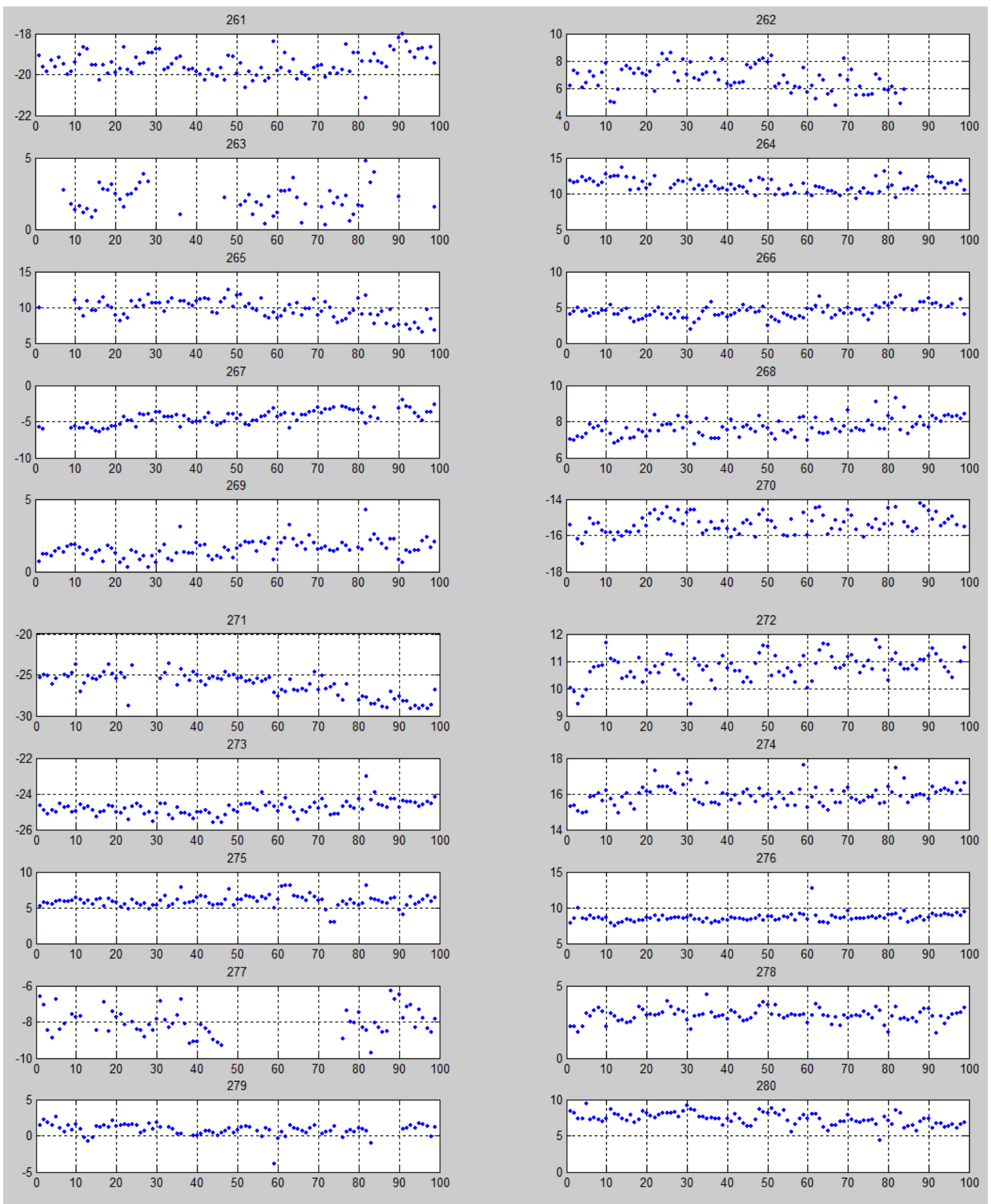


DCBs de receptores GNSS calculados con LPIMG






\section{Anexo 4. DCBs de receptores y VTEC medio medido en la estación.}
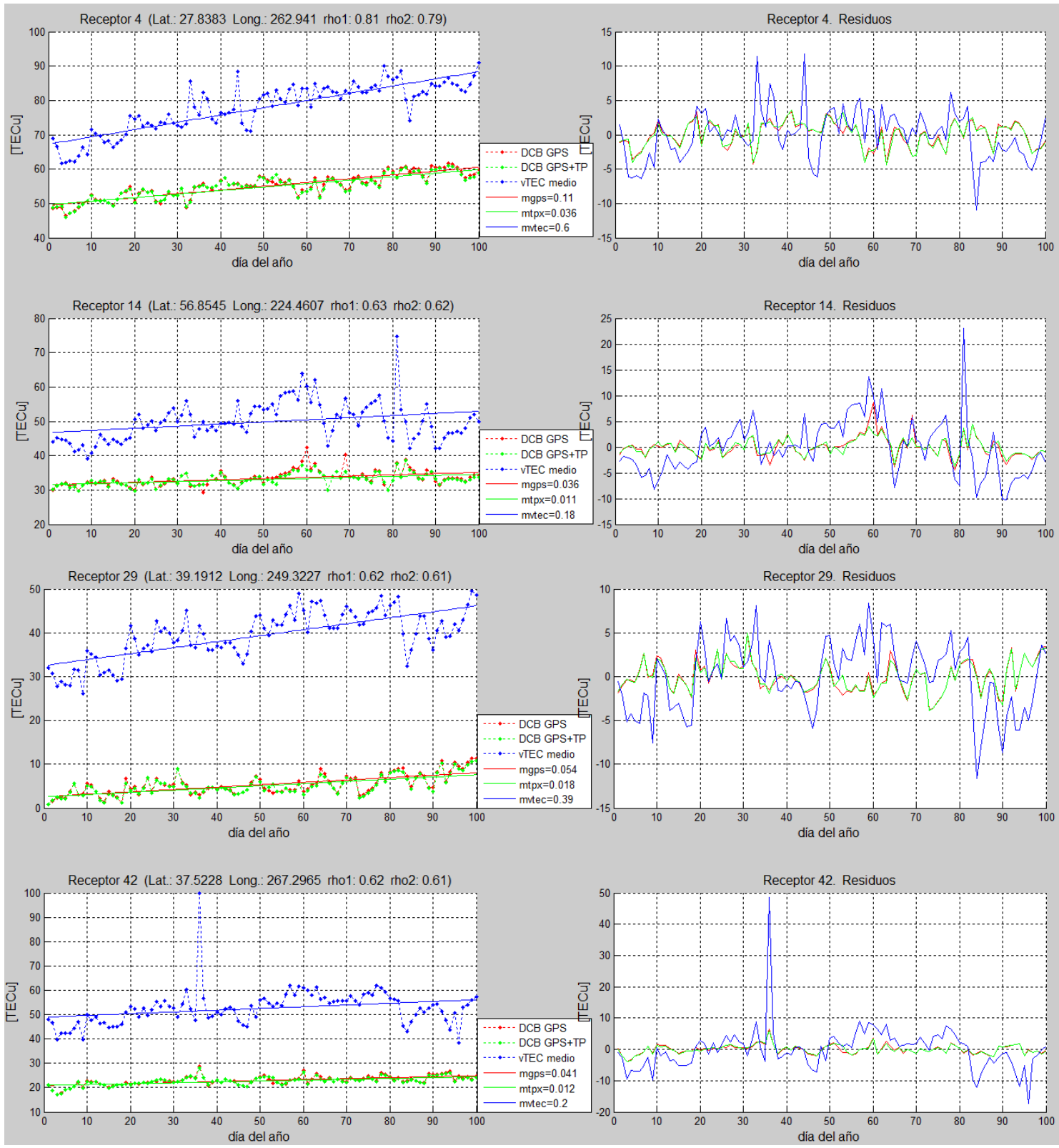

DCBs calculados con LPIMG (en rojo) y con LPIMG+T (en verde) y el VTEC medio diario observado por cada estación (en azul) 

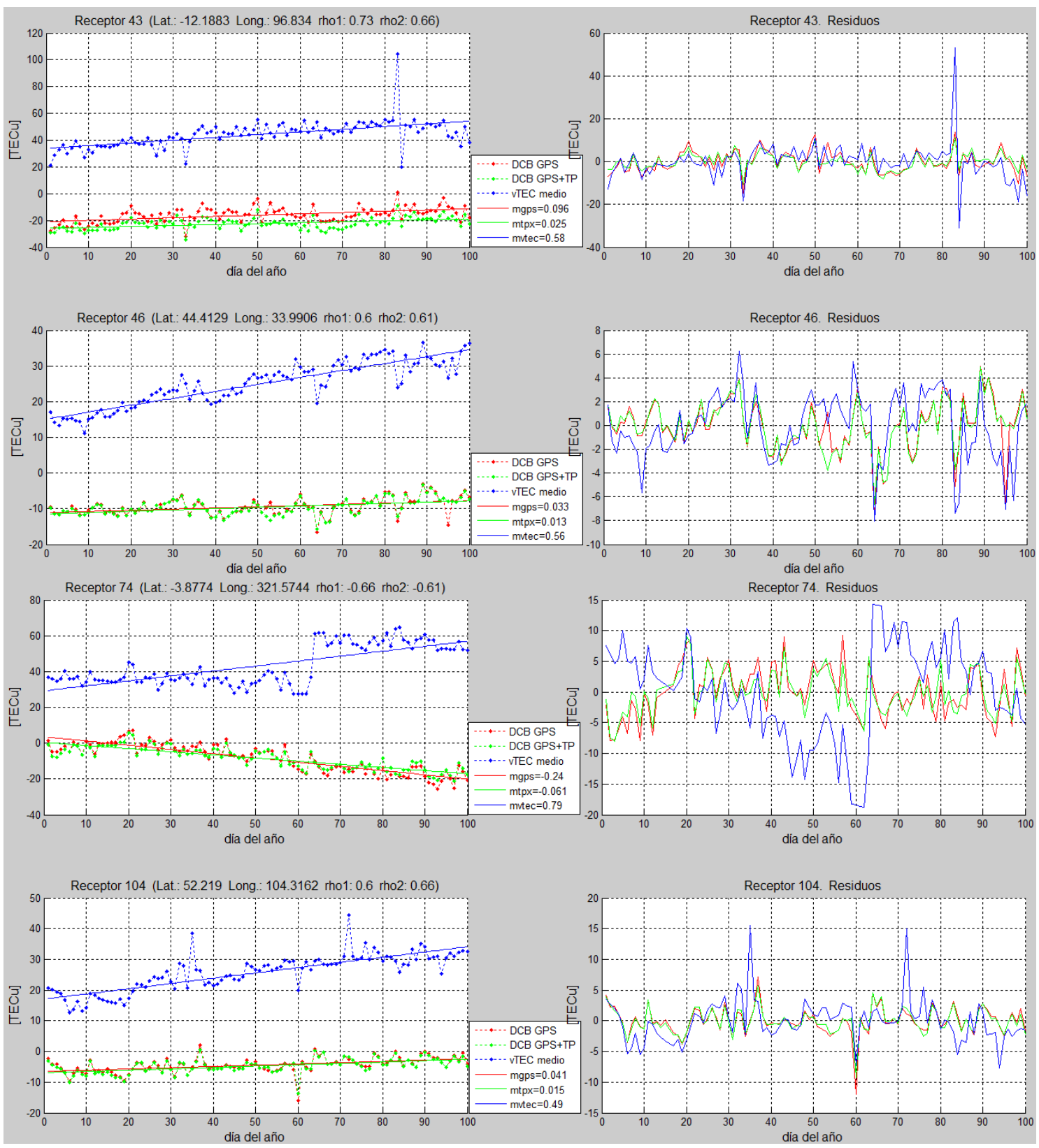

DCBs calculados con LPIMG (en rojo) y con LPIMG+T (en verde) y el VTEC medio diario observado por cada estación (en azul) 

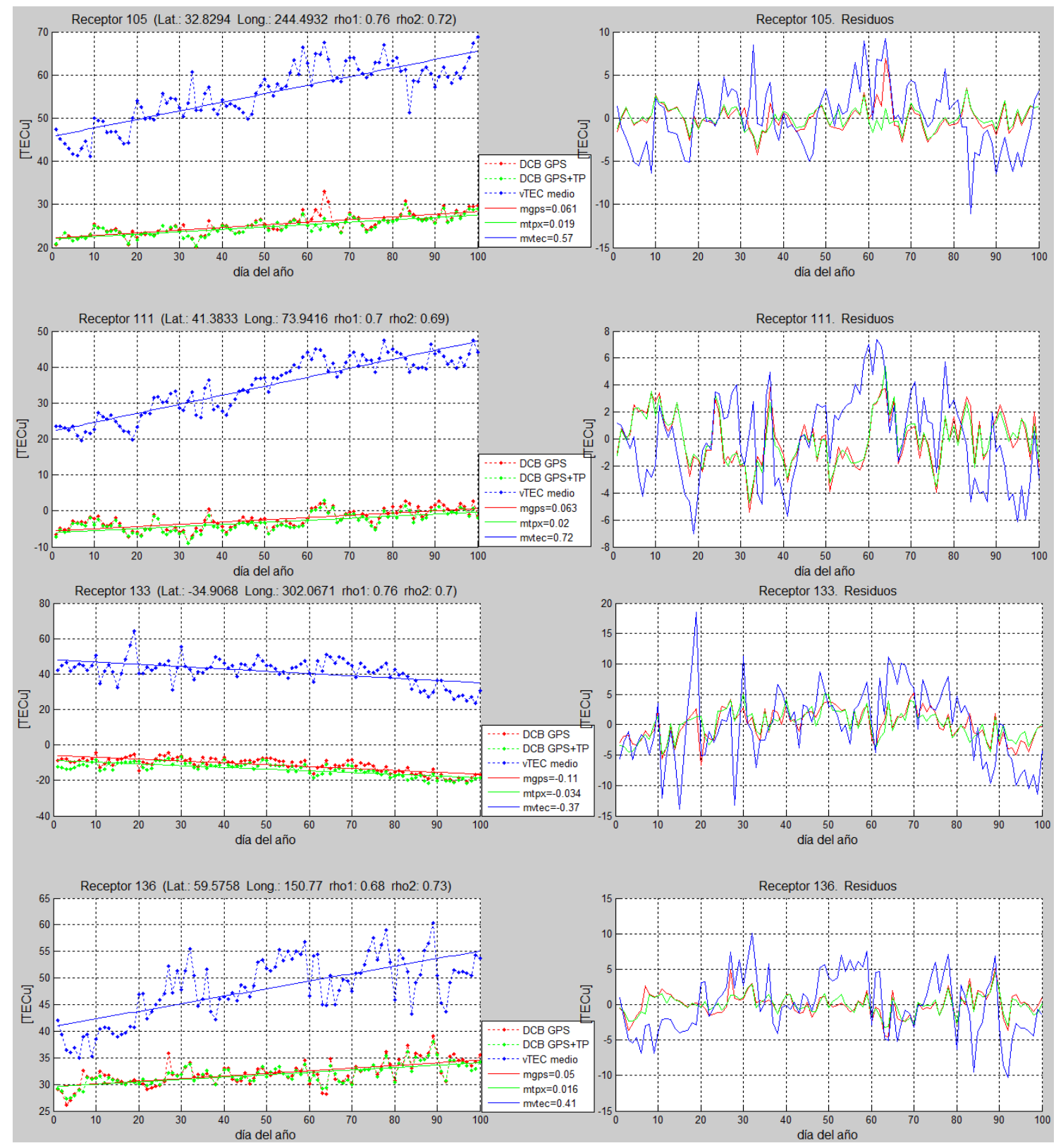

DCBs calculados con LPIMG (en rojo) y con LPIMG+T (en verde) y el VTEC medio diario observado por cada estación (en azul)

\section{Bibbó | Anexo 4. DCBs de receptores y vTEC medio medido en la



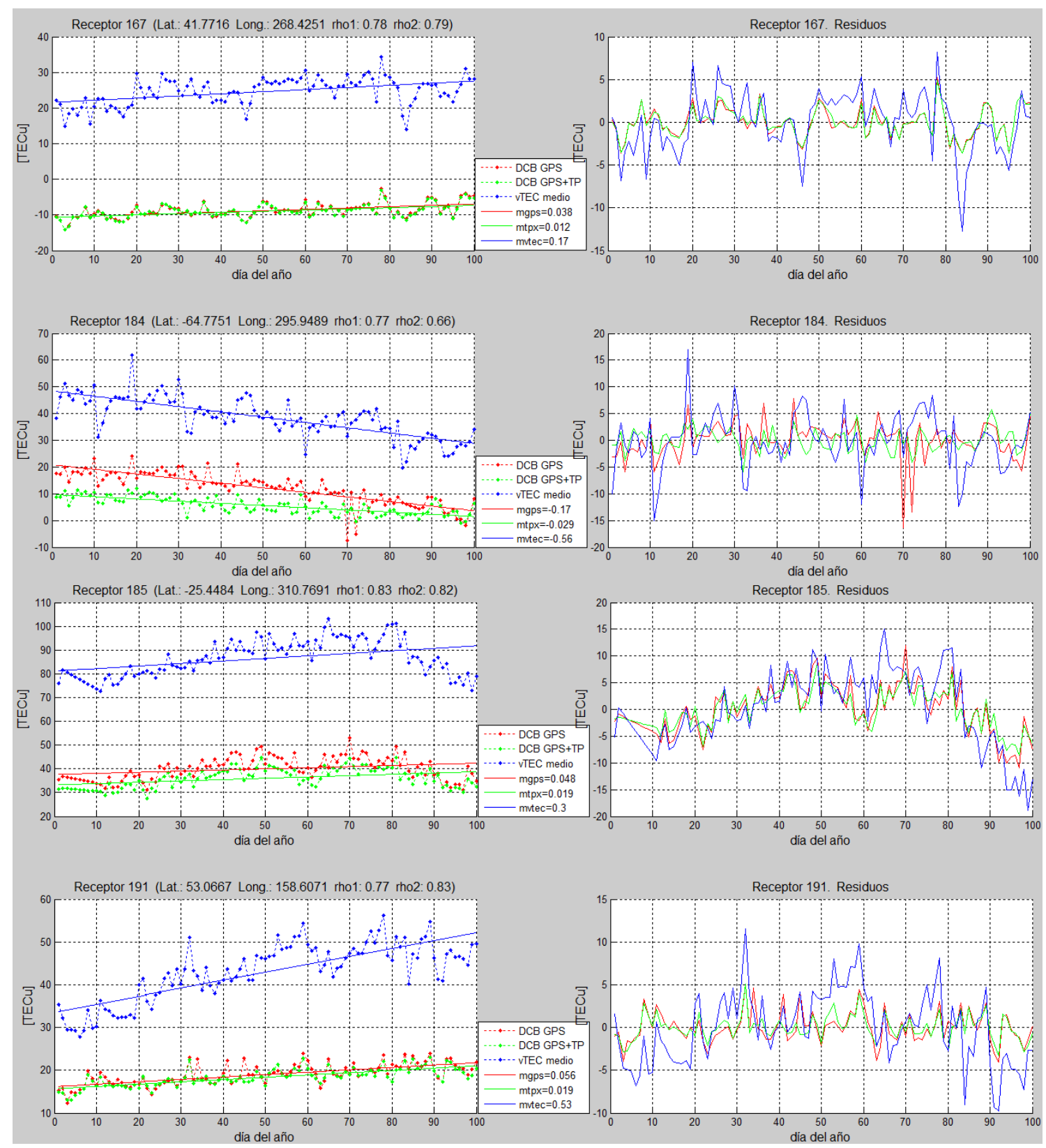

DCBs calculados con LPIMG (en rojo) y con LPIMG+T (en verde) y el VTEC medio diario observado por cada estación (en azul) 

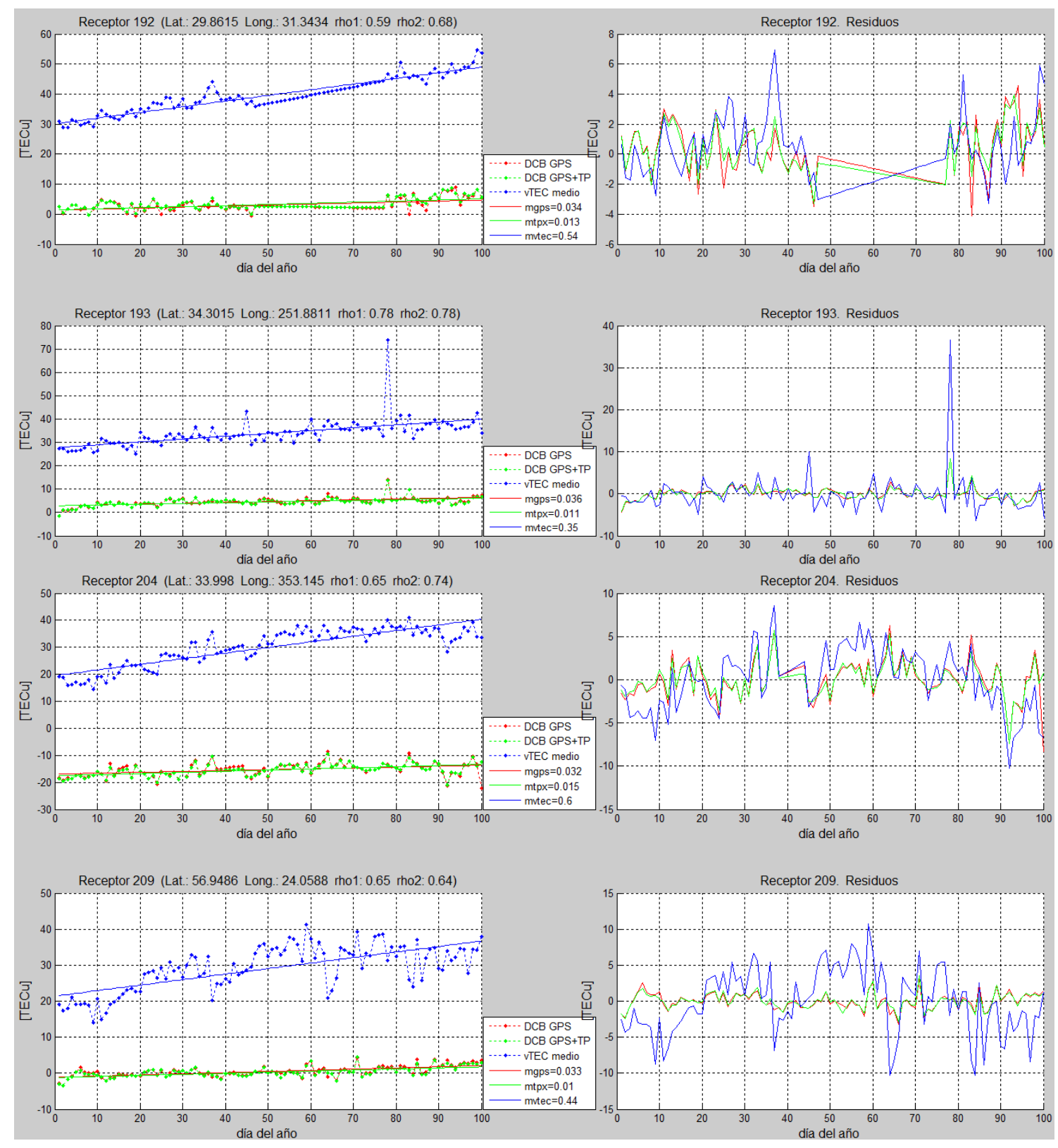

DCBs calculados con LPIMG (en rojo) y con LPIMG+T (en verde) y el VTEC medio diario observado por cada estación (en azul) 

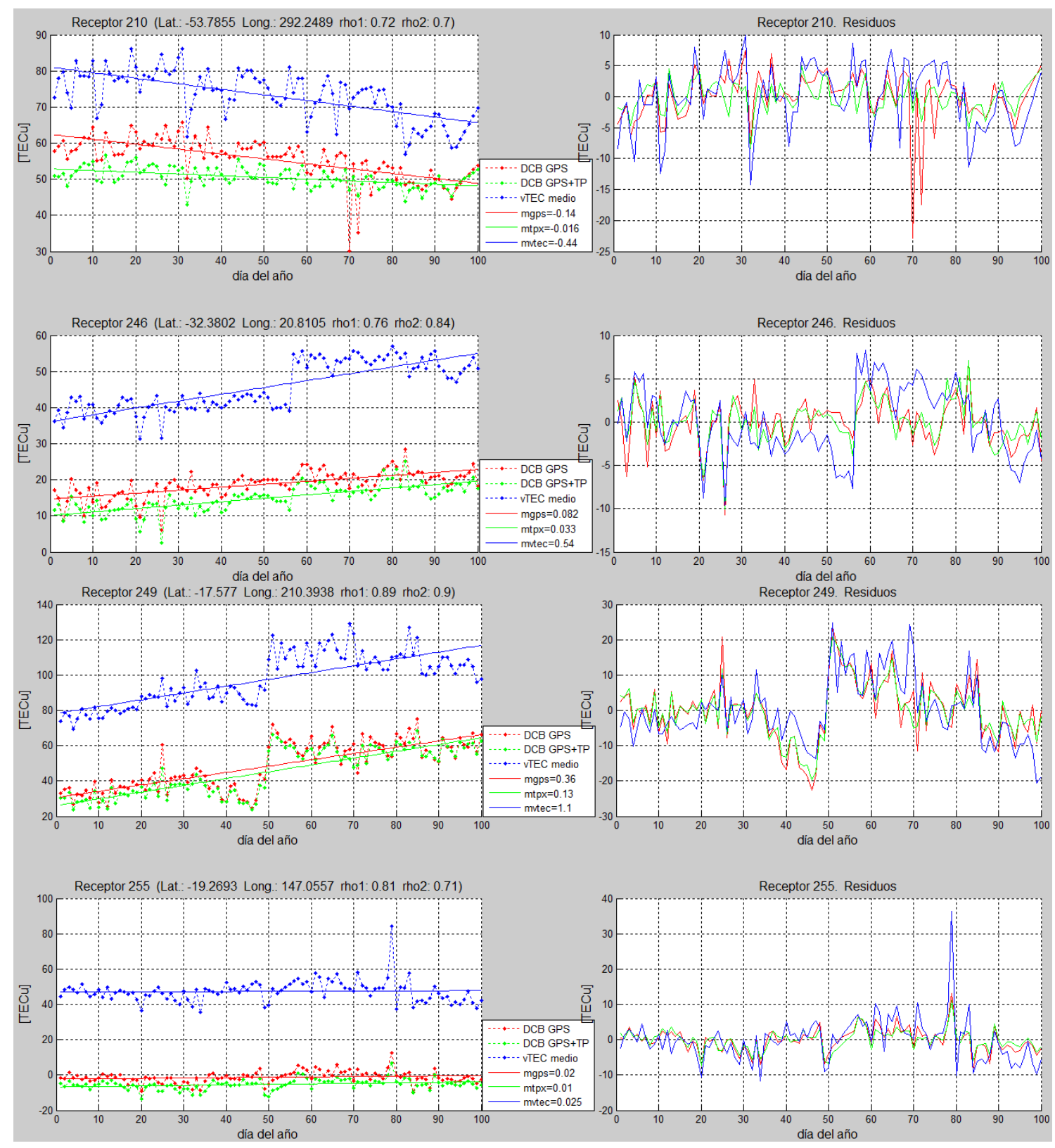

DCBs calculados con LPIMG (en rojo) y con LPIMG+T (en verde) y el VTEC medio diario observado por cada estación (en azul)

\section{Bibbó | Anexo 4. DCBs de receptores y vTEC medio medido en la



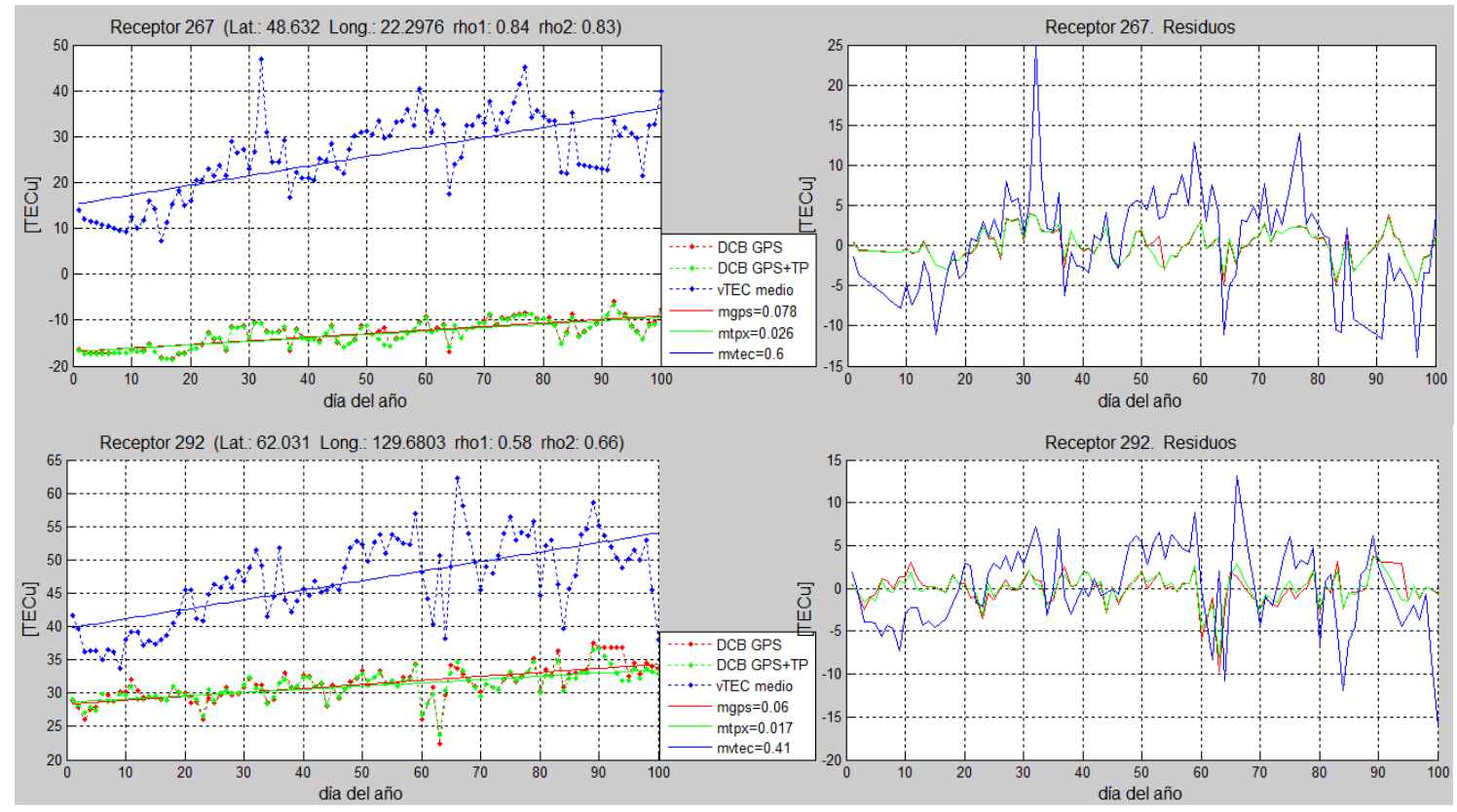

DCBs calculados con LPIMG (en rojo) y con LPIMG+T (en verde) y el VTEC medio diario observado por cada estación (en azul) 
Anexo 5. DCBs de receptores y satélites GPS calculados con datos GPS y altimétricos supuestos constantes en 100 días.

\begin{tabular}{|c|c|c|c|c|c|c|c|c|}
\hline \multirow{2}{*}{$\begin{array}{l}\text { Esta- } \\
\text { ción }\end{array}$} & \multirow{2}{*}{$\begin{array}{c}\boldsymbol{\beta}_{\mathbf{G}+\mathbf{T}}^{\mathbf{R}} \\
{[\mathrm{ns}]}\end{array}$} & \multirow[b]{2}{*}{$\sigma$ [ns] } & \multirow{2}{*}{$\begin{array}{l}\text { crol } \\
\text { daej }\end{array}$} & \multirow{2}{*}{$\begin{array}{r}10.107 \\
0.975\end{array}$} & \multirow{2}{*}{0.008} & \multirow{2}{*}{ holm } & 14.986 & \multirow{2}{*}{$\begin{array}{l}0.008 \\
0.008\end{array}$} \\
\hline & & & & & & & -2.708 & \\
\hline ankr & -4.427 & 0.006 & darw & 15.621 & 0.009 & hrml & 6.009 & 0.006 \\
\hline aquí & -22.280 & 0.006 & davl & -11.840 & 0.01 & hrn2 & 19.023 & 0.008 \\
\hline arp3 & 19.077 & 0.006 & drao & -14.137 & 0.006 & $\mathrm{htvl}$ & 7.949 & 0.006 \\
\hline artu & 10.379 & 0.007 & dres & 7.812 & 0.006 & Ineg & -20.932 & 0.007 \\
\hline aspa & -20.923 & 0.009 & dubo & -4.220 & 0.007 & Invk & 17.102 & 0.007 \\
\hline aus5 & -7.852 & 0.007 & duml & 9.403 & 0.011 & Irkt & -0.750 & 0.009 \\
\hline azcn & 4.235 & 0.006 & dunt & -31.329 & 0.011 & IVCO & 8.570 & 0.006 \\
\hline bahr & 11.102 & 0.008 & dwhl & -0.392 & 0.007 & Jama & 3.603 & 0.007 \\
\hline bayl & 9.822 & 0.007 & dyr2 & -5.635 & 0.039 & Joen & 14.202 & 0.006 \\
\hline bea5 & 3.144 & 0.007 & ebre & 7.363 & 0.006 & Joze & -2.576 & 0.006 \\
\hline bill 1 & 9.567 & 0.007 & eisl & 0.727 & 0.013 & Kayt & -5.241 & 0.015 \\
\hline bili & 14.768 & 0.008 & elat & 12.864 & 0.008 & Kaza & -0.647 & 0.008 \\
\hline bis 1 & 11.649 & 0.007 & elen & -21.911 & 0.007 & Kely & 6.219 & 0.009 \\
\hline bjfs & 13.052 & 0.009 & eliz & -9.430 & 0.007 & Kerg & 4.135 & 0.009 \\
\hline blkv & 8.131 & 0.006 & elko & 7.849 & 0.006 & Kgni & 10.836 & 0.009 \\
\hline blrw & 9.561 & 0.006 & elp3 & 2.156 & 0.008 & kirO & 5.224 & 0.006 \\
\hline brig & -5.486 & 0.011 & engl & 13.929 & 0.007 & Kiru & 0.633 & 0.006 \\
\hline brmu & 0.452 & 0.007 & eprt & 3.092 & 0.007 & kit3 & -3.207 & 0.009 \\
\hline brus & 8.326 & 0.006 & erla & 15.232 & 0.009 & Kosg & -1.725 & 0.006 \\
\hline bucu & 12.660 & 0.006 & esti & -1.494 & 0.007 & Kouc & 18.710 & 0.008 \\
\hline burn & 2.005 & 0.006 & fair & -4.016 & 0.007 & Kulu & 8.296 & 0.007 \\
\hline cags & 12.540 & 0.006 & farb & 7.122 & 0.006 & Kunm & -0.841 & 0.012 \\
\hline cant & 2.207 & 0.006 & fbyn & 8.115 & 0.006 & kwjl & -2.953 & 0.01 \\
\hline cart & -31.660 & 0.009 & flin & -2.074 & 0.006 & kyw2 & 12.024 & 0.006 \\
\hline cas 1 & -5.515 & 0.01 & fred & -4.380 & 0.006 & lael & 9.088 & 0.009 \\
\hline casa & -3.444 & 0.007 & freo & -16.186 & 0.008 & lago & -34.052 & 0.007 \\
\hline casc & -35.089 & 0.007 & fstl & 10.896 & 0.007 & lama & 19.485 & 0.006 \\
\hline cast & 1.446 & 0.006 & gait & -2.755 & 0.008 & lamp & -21.601 & 0.006 \\
\hline ccjm & -0.114 & 0.01 & gala & 4.599 & 0.009 & laut & 3.815 & 0.009 \\
\hline ccv3 & 11.151 & 0.006 & gilb & 9.483 & 0.007 & levl & 10.970 & 0.008 \\
\hline cena & 8.582 & 0.007 & glsv & 12.123 & 0.006 & Ihas & 1.424 & 0.01 \\
\hline ceut & 1.657 & 0.007 & gnaa & 11.832 & 0.007 & Ihve & 11.603 & 0.009 \\
\hline cfag & 14.396 & 0.009 & goug & 6.390 & 0.012 & Iliv & 5.201 & 0.006 \\
\hline cha2 & 9.481 & 0.006 & graz & 4.009 & 0.006 & lubb & 0.132 & 0.007 \\
\hline chat & 8.427 & 0.009 & guam & 14.780 & 0.009 & mag0 & 11.399 & 0.009 \\
\hline chiz & 8.173 & 0.006 & guat & -4.103 & 0.007 & mali & 4.725 & 0.011 \\
\hline chtl & 8.713 & 0.006 & gus2 & 11.421 & 0.008 & manz & 9.362 & 0.007 \\
\hline chur & -4.542 & 0.007 & helg & 17.930 & 0.006 & mar6 & 16.147 & 0.006 \\
\hline chzz & -1.969 & 0.011 & hers & 14.752 & 0.006 & masl & 10.192 & 0.008 \\
\hline $\mathrm{cncl}$ & 9.419 & 0.009 & hilo & 10.260 & 0.009 & mate & 3.133 & 0.007 \\
\hline cnwm & 8.001 & 0.006 & hklo & 4.532 & 0.007 & maui & 7.944 & 0.009 \\
\hline Cola & -10.250 & 0.008 & hlid & 12.596 & 0.007 & mawl & -1.350 & 0.01 \\
\hline cord & 1.784 & 0.015 & hnlc & 11.230 & 0.01 & mawy & 8.156 & 0.007 \\
\hline crao & -3.123 & 0.007 & hob2 & -6.590 & 0.008 & mbw & 3.382 & 0.006 \\
\hline creu & 2.615 & 0.007 & hofn & 4.612 & 0.007 & mcdl & 7.263 & 0.006 \\
\hline
\end{tabular}

I. Bibbó | Anexo 5. DCBs de receptores y satélites GPS calculados con 193 datos GPS y altimétricos supuestos constantes en 100 días. 


\begin{tabular}{|l|r|r|}
\hline mcnl & 5.863 & 0.006 \\
\hline mcty & 10.731 & 0.008 \\
\hline mdol & -0.200 & 0.007 \\
\hline medi & 1.550 & 0.006 \\
\hline mem2 & 6.324 & 0.006 \\
\hline Mers & -1.731 & 0.008 \\
\hline Mets & 11.834 & 0.006 \\
\hline mia3 & 16.798 & 0.008 \\
\hline mida & 5.774 & 0.006 \\
\hline mlf1 & 9.296 & 0.006 \\
\hline morl & 8.608 & 0.006 \\
\hline mazg & 3.695 & 0.009 \\
\hline mrrn & 4.483 & 0.006 \\
\hline msku & 10.910 & 0.011 \\
\hline naiu & 8.874 & 0.006 \\
\hline nds 1 & 10.367 & 0.006 \\
\hline nico & -3.448 & 0.007 \\
\hline nklg & 2.136 & 0.011 \\
\hline nlgn & -5.002 & 0.007 \\
\hline nlib & -2.782 & 0.007 \\
\hline nomt & 6.935 & 0.009 \\
\hline nor3 & -7.794 & 0.012 \\
\hline notl & 4.422 & 0.007 \\
\hline noum & -11.381 & 0.008 \\
\hline nril & 12.491 & 0.009 \\
\hline ntus & 1.199 & 0.01 \\
\hline nvsk & -20.058 & 0.008 \\
\hline nyal & 0.300 & 0.007 \\
\hline obe2 & 3.015 & 0.006 \\
\hline okom & 1.289 & 0.007 \\
\hline omh1 & 17.543 & 0.006 \\
\hline onsa & 11.096 & 0.006 \\
\hline oprd & 9.533 & 0.006 \\
\hline orid & 10.040 & 0.006 \\
\hline orvb & 6.361 & 0.006 \\
\hline pala & -8.579 & 0.009 \\
\hline palm & 2.333 & 0.01 \\
\hline para & 12.742 & 0.01 \\
\hline parc & 15.605 & 0.015 \\
\hline patk & 6.036 & 0.006 \\
\hline pdel & -31.916 & 0.008 \\
\hline penc & -1.872 & 0.006 \\
\hline pert & 8.023 & 0.01 \\
\hline petp & 6.694 & 0.008 \\
\hline phlw & 1.016 & 0.01 \\
\hline pie1 & 1.460 & 0.007 \\
\hline podc & 7.568 & 0.008 \\
\hline & -1.065 & 0.007 \\
\hline & 0.008 \\
\hline
\end{tabular}

\begin{tabular}{|l|r|r|}
\hline polv & -16.971 & 0.006 \\
\hline prds & 2.688 & 0.006 \\
\hline prel & 15.365 & 0.009 \\
\hline pscl & 17.125 & 0.01 \\
\hline publ & 8.404 & 0.008 \\
\hline pur3 & 15.428 & 0.007 \\
\hline rabt & -5.884 & 0.008 \\
\hline ralr & -4.304 & 0.008 \\
\hline redm & 6.581 & 0.006 \\
\hline reso & 7.440 & 0.008 \\
\hline reyk & -2.213 & 0.007 \\
\hline riga & 0.074 & 0.007 \\
\hline riog & 17.193 & 0.009 \\
\hline rwdn & 3.152 & 0.006 \\
\hline samp & 11.245 & 0.011 \\
\hline sant & 20.589 & 0.009 \\
\hline sc01 & -44.693 & 0.007 \\
\hline sc02 & -46.012 & 0.006 \\
\hline sch2 & -4.706 & 0.007 \\
\hline seld & 8.558 & 0.007 \\
\hline sele & 2.012 & 0.009 \\
\hline seyl & 0.337 & 0.014 \\
\hline sg13 & -41.406 & 0.006 \\
\hline sg19 & -37.415 & 0.007 \\
\hline simo & 0.947 & 0.01 \\
\hline sio3 & 10.607 & 0.007 \\
\hline sjdv & 7.829 & 0.006 \\
\hline skul & 2.561 & 0.006 \\
\hline slid & -6.110 & 0.006 \\
\hline slor & 1.040 & 0.007 \\
\hline soda & 13.244 & 0.006 \\
\hline sodb & 11.117 & 0.006 \\
\hline Sofi & 0.899 & 0.006 \\
\hline sol1 & -6.641 & 0.007 \\
\hline sowr & -6.816 & 0.012 \\
\hline spn1 & 7.007 & 0.006 \\
\hline spt0 & -9.915 & 0.006 \\
\hline stas & -21.312 & 0.006 \\
\hline stb1 & 16.803 & 0.006 \\
\hline stpo & 1.502 & 0.006 \\
\hline sulp & -11.394 & 0.006 \\
\hline sum1 & 6.340 & 0.007 \\
\hline sumk & -0.649 & 0.008 \\
\hline sup2 & 0.106 & 0.012 \\
\hline sup3 & -16.741 & 0.012 \\
\hline suth & 6.215 & 0.009 \\
\hline sycn & 8.256 & 0.007 \\
\hline takl & -31.553 & 0.008 \\
\hline thul & -0.819 & 0.01 \\
\hline
\end{tabular}

\begin{tabular}{|l|r|r|}
\hline tidl & 5.521 & 0.008 \\
\hline tlka & -2.456 & 0.008 \\
\hline tors & -32.068 & 0.011 \\
\hline tow2 & -1.001 & 0.008 \\
\hline trds & -18.670 & 0.006 \\
\hline trnd & 0.642 & 0.006 \\
\hline trol & 2.800 & 0.006 \\
\hline tsea & -31.421 & 0.011 \\
\hline tskb & 9.547 & 0.01 \\
\hline tubi & -19.325 & 0.006 \\
\hline tucu & 5.879 & 0.01 \\
\hline tuva & 1.558 & 0.01 \\
\hline udmc & 10.885 & 0.007 \\
\hline uepp & 8.894 & 0.01 \\
\hline urum & 4.255 & 0.008 \\
\hline uzhl & -4.766 & 0.007 \\
\hline vaas & 7.869 & 0.006 \\
\hline vale & 1.556 & 0.007 \\
\hline vars & -15.319 & 0.007 \\
\hline vbca & -26.800 & 0.009 \\
\hline vcio & 10.820 & 0.006 \\
\hline vene & -24.292 & 0.006 \\
\hline vil0 & 15.822 & 0.006 \\
\hline vill & 5.956 & 0.007 \\
\hline vis0 & 8.481 & 0.006 \\
\hline wasr & -9.271 & 0.008 \\
\hline wdlm & 3.109 & 0.006 \\
\hline wes2 & 0.610 & 0.007 \\
\hline wgtn & 6.817 & 0.008 \\
\hline whd1 & -1.389 & 0.006 \\
\hline whit & 11.063 & 0.007 \\
\hline whn1 & 9.537 & 0.008 \\
\hline will & -9.848 & 0.007 \\
\hline Winn & -3.679 & 0.007 \\
\hline wis1 & 17.385 & 0.006 \\
\hline wlci & 6.850 & 0.007 \\
\hline wnfl & 2.084 & 0.007 \\
\hline wroc & 6.437 & 0.007 \\
\hline wsrt & -1.042 & 0.006 \\
\hline włzr & -2.130 & 0.006 \\
\hline yakt & 10.990 & 0.009 \\
\hline yar1 & 1.725 & 0.01 \\
\hline yell & 2.943 & 0.007 \\
\hline youl & 13.021 & 0.006 \\
\hline zeck & 5.950 & 0.007 \\
\hline zimm & 4.847 & 0.006 \\
\hline & 2.034 & 0.006 \\
\hline
\end{tabular}

I. Bibbó | Anexo 5. DCBs de receptores y satélites GPS calculados con datos GPS y altimétricos supuestos constantes en 100 días. 


\begin{tabular}{|c|c|c|c|c|c|}
\hline PNR & $\boldsymbol{\beta}_{\mathbf{G}+\mathbf{T}}^{\mathbf{S}}[n s]$ & $\sigma[\mathrm{ns}]$ & PNR & $\boldsymbol{\beta}_{\mathbf{G}+\mathbf{T}}^{\mathbf{S}}[\mathrm{ns}]$ & $\sigma$ [ns] \\
\hline 1 & 1.482 & 0.002 & 17 & 1.954 & 0.002 \\
\hline 2 & 2.261 & 0.002 & 18 & -2.928 & 0.002 \\
\hline 3 & 0.546 & 0.002 & 20 & -0.867 & 0.002 \\
\hline 4 & -0.108 & 0.002 & 21 & 2.241 & 0.002 \\
\hline 5 & 0.723 & 0.002 & 22 & 0.795 & 0.002 \\
\hline 6 & 0.472 & 0.002 & 23 & 1.893 & 0.002 \\
\hline 7 & 2.207 & 0.002 & 24 & 2.903 & 0.002 \\
\hline 8 & 1.010 & 0.002 & 25 & -1.146 & 0.002 \\
\hline 9 & 0.242 & 0.002 & 26 & 0.003 & 0.002 \\
\hline 10 & 2.256 & 0.002 & 27 & 0.889 & 0.002 \\
\hline 11 & -4.076 & 0.002 & 28 & -2.971 & 0.002 \\
\hline 13 & -3.524 & 0.002 & 29 & -0.651 & 0.002 \\
\hline 14 & -3.041 & 0.002 & 30 & -1.414 & 0.002 \\
\hline 15 & 1.777 & 0.002 & 31 & -0.484 & 0.002 \\
\hline
\end{tabular}

Isabel Bibbó | Anexo 5. DCBs de receptores y satélites GPS calculados con datos GPS y altimétricos supuestos constantes en 100 días. 
Anexo 6. DCBs de receptores y satélites GPS con datos artificiales

\begin{tabular}{|c|c|c|c|}
\hline Estac. & $\begin{array}{l}\boldsymbol{\beta}_{\mathbf{G}}^{\mathbf{R}}[\mathrm{ns}] \\
\text { LPIMG }\end{array}$ & $\begin{array}{r}\boldsymbol{\beta}_{\mathrm{BC}}^{\mathbf{R}} \quad \text { [ns] } \\
\text { LPIMBC } \\
\mathrm{p}=1\end{array}$ & $\begin{array}{r}\boldsymbol{\beta}_{\mathrm{BC}}^{\mathbf{R}} \text { [ns] } \\
\text { LPIMBC } \\
\mathrm{p}=\mathrm{p} 1 . \mathrm{p} 2\end{array}$ \\
\hline ankr & $-4,681$ & $-4,203$ & $-0,212$ \\
\hline aqui & $-3,787$ & $-3,621$ & $-0,687$ \\
\hline arp3 & $-3,171$ & $-2,735$ & 0,809 \\
\hline artu & 0,504 & 0,567 & 1,564 \\
\hline aspa & $-4,106$ & $-3,463$ & $-0,755$ \\
\hline azcn & $-1,312$ & $-0,962$ & 1,518 \\
\hline bahr & $-11,616$ & $-10,780$ & $-4,703$ \\
\hline bayl & 0,774 & 1,234 & 0,648 \\
\hline bili & 2,175 & 2,523 & 1,235 \\
\hline bis 1 & 1,420 & 1,564 & 1,308 \\
\hline bjfs & $-3,675$ & $-2,880$ & 0,017 \\
\hline blkv & $-0,663$ & $-0,323$ & 2,245 \\
\hline blrw & 0,377 & 0,593 & 2,409 \\
\hline brmu & $-2,315$ & $-1,777$ & 0,919 \\
\hline brus & $-0,654$ & $-0,472$ & $-0,108$ \\
\hline bucu & $-2,787$ & $-2,416$ & $-0,362$ \\
\hline cags & 0,745 & 1,092 & 2,397 \\
\hline cant & $-3,355$ & $-3,097$ & $-0,704$ \\
\hline cas 1 & 2,934 & 1,548 & 1,245 \\
\hline casa & $-1,560$ & $-1,232$ & 0,273 \\
\hline casc & $-5,766$ & $-5,131$ & $-1,139$ \\
\hline cast & $-0,896$ & $-0,620$ & 1,304 \\
\hline ccv3 & $-2,782$ & $-2,295$ & 1,138 \\
\hline cena & 2,278 & 2,852 & 1,624 \\
\hline ceut & $-6,991$ & $-6,573$ & $-2,615$ \\
\hline cfag & $-1,655$ & $-1,855$ & $-0,867$ \\
\hline cha2 & $-1,679$ & $-1,185$ & 1,213 \\
\hline chiz & $-2,211$ & $-1,842$ & $-0,499$ \\
\hline chtl & $-0,013$ & 0,260 & 2,234 \\
\hline chur & 1,815 & 1,900 & 2,061 \\
\hline $\mathrm{cncl}$ & 2,440 & 1,584 & 0,732 \\
\hline cnwm & $-0,681$ & $-0,372$ & 2,096 \\
\hline crao & $-2,552$ & $-2,233$ & $-0,359$ \\
\hline creu & $-3,931$ & $-3,741$ & $-1,023$ \\
\hline crol & $-6,568$ & $-6,013$ & $-1,159$ \\
\hline daej & $-4,677$ & $-2,737$ & $-0,220$ \\
\hline darw & $-3,493$ & $-2,560$ & $-2,129$ \\
\hline
\end{tabular}

\begin{tabular}{|c|c|c|c|}
\hline davl & 1,883 & 0,919 & 1,488 \\
\hline drao & 0,680 & 1,020 & 1,604 \\
\hline dres & $-0,525$ & $-0,311$ & 0,216 \\
\hline dubo & 1,182 & 1,380 & 2,144 \\
\hline duml & 3,806 & 2,824 & 1,704 \\
\hline dwhl & 0,401 & 0,577 & 1,535 \\
\hline ebre & $-4,674$ & $-4,520$ & $-0,891$ \\
\hline eisl & $-1,637$ & $-1,658$ & $-1,092$ \\
\hline elat & $-10,178$ & $-10,032$ & $-2,095$ \\
\hline elen & $-6,820$ & $-6,070$ & $-0,673$ \\
\hline eliz & 0,536 & 0,795 & 1,072 \\
\hline elko & $-0,733$ & $-0,388$ & 1,114 \\
\hline eprt & 0,388 & 0,678 & 2,195 \\
\hline esti & $-8,336$ & $-7,441$ & $-2,032$ \\
\hline fair & 2,053 & 2,303 & 1,139 \\
\hline farb & $-1,715$ & $-1,284$ & 0,664 \\
\hline fbyn & $-0,243$ & 0,012 & 2,123 \\
\hline flin & 1,485 & 1,802 & 2,183 \\
\hline fred & $-1,511$ & $-1,071$ & 1,124 \\
\hline gala & $-10,694$ & $-9,200$ & $-4,031$ \\
\hline gilb & $-9,090$ & $-8,971$ & $-1,038$ \\
\hline glsv & $-0,780$ & $-0,597$ & 0,290 \\
\hline gnaa & 1,688 & 1,924 & 1,379 \\
\hline graz & $-1,791$ & $-1,545$ & $-0,415$ \\
\hline guam & $-5,387$ & $-3,773$ & $-1,142$ \\
\hline guat & $-7,911$ & $-7,128$ & $-1,761$ \\
\hline helg & 0,205 & 0,296 & 0,301 \\
\hline hers & $-0,647$ & $-0,427$ & 0,001 \\
\hline hilo & $-7,475$ & $-6,059$ & $-4,598$ \\
\hline hklo & $-1,209$ & $-0,826$ & 1,698 \\
\hline hlid & $-0,100$ & 0,179 & 1,670 \\
\hline hnlc & $-6,939$ & $-4,860$ & $-3,808$ \\
\hline hob2 & 1,817 & 1,102 & 0,118 \\
\hline hofn & 1,800 & 1,836 & 0,815 \\
\hline holm & 2,820 & 3,170 & 1,489 \\
\hline hrml & $-0,492$ & $-0,295$ & 0,030 \\
\hline htv 1 & $-0,821$ & $-0,468$ & 2,091 \\
\hline ineg & $-5,579$ & $-5,051$ & $-0,553$ \\
\hline invk & 2,682 & 2,648 & 1,602 \\
\hline irkt & 0,024 & 0,321 & 1,069 \\
\hline
\end{tabular}

I. Bibbó | Anexo 6. DCBs de receptores y satélites GPS con datos 


\begin{tabular}{|c|c|c|c|c|c|c|c|}
\hline ivco & $-2,717$ & $-2,133$ & 0,366 & mida & $-2,055$ & $-1,643$ & 0,802 \\
\hline jama & $-5,861$ & $-5,006$ & 0,067 & $\mathrm{mlfl}$ & $-1,859$ & $-1,449$ & 1,486 \\
\hline joen & 1,430 & 1,492 & 0,685 & morl & $-0,075$ & 0,314 & 2,157 \\
\hline joze & $-0,275$ & $-0,091$ & 0,425 & mqzg & 2,474 & 1,507 & 0,926 \\
\hline kaza & $-3,663$ & $-3,477$ & $-0,609$ & mrrn & 0,187 & 0,593 & 2,184 \\
\hline kely & 2,197 & 2,172 & 1,224 & msku & $-3,696$ & $-2,958$ & $-2,279$ \\
\hline kerg & 0,462 & $-0,460$ & $-0,046$ & naiu & $-0,546$ & $-0,268$ & 1,441 \\
\hline kgni & $-4,972$ & $-3,499$ & $-1,419$ & nds 1 & $-0,786$ & $-0,403$ & 2,190 \\
\hline kirO & 2,044 & 2,026 & 1,298 & nico & $-7,237$ & $-7,204$ & $-0,667$ \\
\hline kiru & 2,033 & 2,060 & 0,994 & nklg & $-3,702$ & $-2,550$ & $-2,430$ \\
\hline kosg & $-0,268$ & $-0,027$ & 0,489 & nlgn & 0,112 & 0,392 & 2,329 \\
\hline kouc & $-2,803$ & $-2,200$ & 0,687 & nlib & 0,061 & 0,354 & 1,908 \\
\hline kulu & 2,129 & 2,106 & 0,815 & notl & $-7,028$ & $-6,636$ & $-1,003$ \\
\hline kunm & $-8,647$ & $-7,464$ & $-3,187$ & noum & $-2,236$ & $-1,908$ & 1,176 \\
\hline kwjl & $-2,125$ & $-0,737$ & $-0,056$ & nril & 2,426 & 2,350 & 1,637 \\
\hline kyw2 & $-3,787$ & $-3,384$ & 0,334 & ntus & $-4,047$ & $-2,808$ & $-2,299$ \\
\hline lael & $-5,705$ & $-4,842$ & $-3,304$ & nvsk & 0,675 & 0,921 & 1,937 \\
\hline lago & $-6,818$ & $-6,148$ & $-1,598$ & nyal & 3,110 & 3,347 & 1,969 \\
\hline lama & 0,209 & 0,367 & 0,523 & obe2 & $-1,441$ & $-1,218$ & $-0,203$ \\
\hline lamp & $-8,085$ & $-7,817$ & $-1,536$ & okom & $-1,407$ & $-1,016$ & 1,051 \\
\hline laut & $-3,817$ & $-2,526$ & $-0,203$ & omhl & 0,102 & 0,376 & 2,328 \\
\hline Ihas & $-8,702$ & $-7,829$ & $-2,416$ & onsa & 0,797 & 0,938 & 0,751 \\
\hline Ihve & $-6,796$ & $-4,855$ & $-3,950$ & oprd & $-2,270$ & $-1,770$ & 1,015 \\
\hline Iliv & $-3,864$ & $-3,480$ & $-0,950$ & orid & $-4,336$ & $-3,910$ & $-0,582$ \\
\hline mago & 1,177 & 1,682 & 0,984 & orvb & $-1,219$ & $-0,883$ & 1,049 \\
\hline mali & $-3,542$ & $-2,750$ & $-1,589$ & pala & $-3,473$ & $-1,626$ & $-1,453$ \\
\hline manz & $-6,846$ & $-6,178$ & $-2,329$ & palm & 6,294 & 2,606 & 1,366 \\
\hline mar6 & 1,313 & 1,358 & 0,351 & para & $-1,246$ & $-1,473$ & 0,292 \\
\hline masl & $-11,515$ & $-10,510$ & $-4,588$ & patk & $-1,771$ & $-1,507$ & $-0,346$ \\
\hline mate & $-4,634$ & $-4,584$ & $-0,851$ & pdel & $-5,097$ & $-4,242$ & $-0,912$ \\
\hline mavi & $-7,204$ & $-5,559$ & $-4,325$ & penc & $-1,514$ & $-1,282$ & $-0,003$ \\
\hline mawl & 1,445 & 0,219 & 1,324 & pert & 0,251 & 0,090 & $-0,531$ \\
\hline mawy & 0,134 & 0,362 & 1,676 & petp & $-0,427$ & 0,327 & $-0,047$ \\
\hline mbww & $-0,138$ & 0,212 & 1,873 & phlw & $-10,239$ & $-9,790$ & $-2,720$ \\
\hline mcdl & $-2,915$ & $-2,454$ & 0,982 & piel & $-1,850$ & $-1,548$ & 0,752 \\
\hline mcnl & $-1,674$ & $-1,229$ & 1,445 & pltc & $-0,439$ & $-0,169$ & 1,805 \\
\hline mdol & $-2,613$ & $-2,073$ & 0,336 & podg & $-2,977$ & $-2,547$ & $-0,272$ \\
\hline medi & $-2,835$ & $-2,449$ & $-0,538$ & polv & $-1,079$ & $-0,885$ & 0,232 \\
\hline mem2 & $-1,105$ & $-0,731$ & 2,056 & prds & 0,955 & 1,167 & 1,799 \\
\hline mers & $-6,111$ & $-6,047$ & $-2,305$ & prel & 2,719 & 2,104 & 4,651 \\
\hline mets & 1,237 & 1,287 & 0,637 & pur3 & $-6,205$ & $-5,421$ & 0,025 \\
\hline
\end{tabular}

I. Bibbó | Anexo 6. DCBs de receptores y satélites GPS con datos 197 artificiales 


\begin{tabular}{|l|r|r|r|}
\hline rabt & $-8,121$ & $-7,761$ & $-2,435$ \\
\hline redm & $-0,194$ & 0,167 & 1,309 \\
\hline reso & 2,990 & 3,181 & 1,459 \\
\hline reyk & 1,843 & 1,726 & 0,681 \\
\hline riga & 0,738 & 0,813 & 0,724 \\
\hline riog & 4,765 & 1,852 & 0,554 \\
\hline rwdn & $-0,352$ & $-0,012$ & 2,129 \\
\hline samp & $-3,943$ & $-2,447$ & $-2,281$ \\
\hline sant & $-1,394$ & $-1,385$ & $-1,430$ \\
\hline sc01 & $-1,981$ & $-1,545$ & 1,400 \\
\hline sc02 & 0,559 & 0,882 & 1,643 \\
\hline sch2 & 1,395 & 1,581 & 2,087 \\
\hline seld & 1,421 & 1,725 & 0,467 \\
\hline sele & $-2,927$ & $-2,562$ & $-0,522$ \\
\hline sey1 & $-3,103$ & $-2,170$ & $-1,231$ \\
\hline sg13 & $-0,675$ & $-0,330$ & 2,143 \\
\hline sgl9 & $-1,338$ & $-1,002$ & 1,637 \\
\hline simo & 1,801 & 0,712 & 0,141 \\
\hline sio3 & $-2,770$ & $-2,295$ & 0,671 \\
\hline sjdv & $-2,315$ & $-2,098$ & $-0,412$ \\
\hline skul & $-1,709$ & $-1,337$ & 0,838 \\
\hline slid & $-1,302$ & $-0,899$ & 1,007 \\
\hline slor & $-8,181$ & $-7,457$ & $-1,762$ \\
\hline soda & 1,980 & 2,057 & 1,288 \\
\hline sodb & $-1,865$ & $-1,408$ & 0,621 \\
\hline sofi & $-3,826$ & $-3,745$ & $-0,997$ \\
\hline sol1 & $-0,450$ & $-0,065$ & 1,998 \\
\hline spn1 & 0,472 & 0,719 & 1,671 \\
\hline spt0 & 0,934 & 1,024 & 0,616 \\
\hline stas & 1,093 & 1,222 & 0,583 \\
\hline stb1 & 0,708 & 1,060 & 2,595 \\
\hline stpo & $-1,395$ & $-1,046$ & $-0,284$ \\
\hline sulp & $-0,891$ & $-0,730$ & 0,198 \\
\hline sum1 & $-1,589$ & $-1,166$ & 1,590 \\
\hline sumk & $-2,697$ & $-2,579$ & $-0,050$ \\
\hline suth & 2,004 & 0,843 & 0,737 \\
\hline sycn & 0,365 & 0,841 & 2,189 \\
\hline takl & 1,521 & 1,068 & 0,683 \\
\hline thul & 2,519 & 2,420 & 1,147 \\
\hline tid & 1,025 & 0,705 & $-0,019$ \\
\hline sion & 1,988 & 1,439 \\
\hline
\end{tabular}

\begin{tabular}{|l|r|r|r|}
\hline trds & 1,729 & 1,801 & 0,458 \\
\hline trnd & $-1,004$ & $-0,561$ & 0,973 \\
\hline trol & 2,306 & 2,319 & 1,202 \\
\hline tskb & $-5,022$ & $-3,652$ & $-2,645$ \\
\hline tubi & $-4,394$ & $-4,194$ & $-0,843$ \\
\hline tucu & $-2,006$ & $-2,119$ & $-0,147$ \\
\hline udmc & $-8,388$ & $-8,301$ & $-0,588$ \\
\hline vepp & $-1,442$ & $-1,561$ & 0,873 \\
\hline urum & $-2,450$ & $-1,976$ & 0,482 \\
\hline uzhl & $-1,343$ & $-1,143$ & $-0,111$ \\
\hline vaas & 1,541 & 1,631 & 0,563 \\
\hline vale & $-5,525$ & $-5,132$ & $-1,051$ \\
\hline vars & 2,189 & 2,265 & 1,209 \\
\hline vbca & 0,630 & $-0,528$ & $-0,928$ \\
\hline vcio & $-1,185$ & $-0,831$ & 1,918 \\
\hline vene & $-2,437$ & $-2,127$ & $-0,464$ \\
\hline vil0 & 1,840 & 1,966 & 0,960 \\
\hline vill & $-4,952$ & $-4,450$ & $-1,196$ \\
\hline vis0 & 0,904 & 1,055 & 0,597 \\
\hline wdlm & 0,540 & 0,886 & 2,584 \\
\hline wes2 & 0,198 & 0,446 & 2,217 \\
\hline wgtn & 2,191 & 1,619 & 0,743 \\
\hline whd1 & 0,474 & 0,707 & 1,214 \\
\hline whit & 1,836 & 2,289 & 1,548 \\
\hline will & 0,917 & 1,121 & 1,436 \\
\hline winn & 1,173 & 1,359 & 2,366 \\
\hline wis1 & 0,845 & 1,101 & 2,604 \\
\hline wlci & 0,055 & 0,406 & 2,347 \\
\hline wnfl & $-2,012$ & $-1,692$ & 0,614 \\
\hline wroc & $-0,586$ & $-0,371$ & $-0,084$ \\
\hline wsrt & $-0,073$ & 0,118 & 0,179 \\
\hline wtzr & $-1,096$ & $-0,857$ & 0,030 \\
\hline yakt & 2,081 & 2,485 & 1,354 \\
\hline yar1 & $-0,364$ & $-0,385$ & $-0,770$ \\
\hline yell & 2,104 & 2,113 & 1,892 \\
\hline you1 & 0,442 & 0,855 & 2,509 \\
\hline zeck & $-2,954$ & $-2,685$ & $-0,387$ \\
\hline zimm & $-1,938$ & $-1,678$ & $-0,238$ \\
\hline zwen & 0,491 & 0,695 & 0,969 \\
\hline
\end{tabular}

I. Bibbó | Anexo 6. DCBs de receptores y satélites GPS con datos artificiales 


\begin{tabular}{|l|r|r|r|}
\hline PNR & $\begin{array}{r}\boldsymbol{\beta}_{\mathbf{G}}^{\mathbf{S}} \text { [ns] } \\
\text { LPIMG }\end{array}$ & $\begin{array}{r}\boldsymbol{\beta}_{\mathrm{BC}}^{\boldsymbol{S}} \text { [ns] } \\
\text { LPIMC } \\
\mathrm{p}=1\end{array}$ & $\begin{array}{r}\boldsymbol{\beta}_{\mathrm{BC}}^{\boldsymbol{S}} \text { [ns] } \\
\text { LPIMBC } \\
\mathrm{p=}=\mathrm{p}_{\mathbf{B}} . \mathrm{p}_{2}\end{array}$ \\
\hline 1 & $-0,177$ & $-0,210$ & $-0,606$ \\
\hline 2 & 0,298 & 0,307 & $-0,008$ \\
\hline 3 & 0,588 & 0,635 & 0,384 \\
\hline 4 & 0,533 & 0,499 & 0,398 \\
\hline 5 & 0,451 & 0,486 & 0,593 \\
\hline 6 & 0,333 & 0,354 & 0,579 \\
\hline 7 & 0,108 & 0,142 & $-0,015$ \\
\hline 8 & 0,057 & 0,045 & $-0,323$ \\
\hline 9 & 0,281 & 0,290 & 0,937 \\
\hline 10 & $-0,195$ & $-0,237$ & 0,010 \\
\hline 11 & 0,298 & 0,285 & 0,393 \\
\hline 13 & $-0,272$ & $-0,238$ & $-0,722$ \\
\hline 14 & $-0,743$ & $-0,767$ & $-0,708$ \\
\hline
\end{tabular}

\begin{tabular}{|r|r|r|r|}
\hline 15 & 0,105 & 0,095 & 0,604 \\
\hline 17 & 0,123 & 0,121 & 0,563 \\
\hline 18 & $-0,335$ & $-0,321$ & 0,115 \\
\hline 20 & $-0,594$ & $-0,557$ & $-0,731$ \\
\hline 21 & $-0,346$ & $-0,291$ & $-0,151$ \\
\hline 22 & 0,319 & 0,369 & $-0,085$ \\
\hline 23 & $-0,087$ & $-0,041$ & 0,231 \\
\hline 24 & 0,594 & 0,601 & 0,514 \\
\hline 25 & $-0,063$ & 0,019 & $-0,069$ \\
\hline 26 & $-0,815$ & $-0,775$ & $-0,285$ \\
\hline 27 & 0,196 & 0,197 & $-0,499$ \\
\hline 28 & $-0,357$ & $-0,389$ & $-0,518$ \\
\hline 29 & $-0,832$ & $-0,788$ & $-0,510$ \\
\hline 30 & 0,373 & 0,393 & 0,343 \\
\hline 31 & 0,297 & 0,328 & $-0,049$ \\
\hline
\end{tabular}

